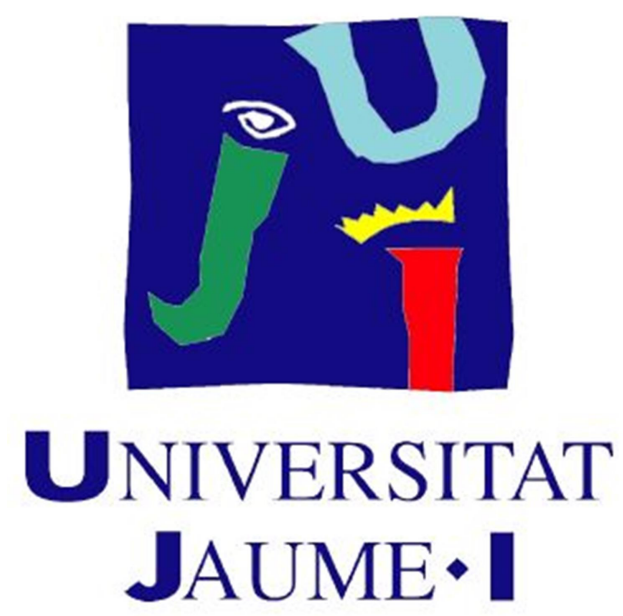

\title{
A Contrastive Study of the EFL Vowel System in Native Spanish, French, German and Russian Learners
}

Ph.D. dissertation presented by José Javier Juan Checa

\section{Supervised by}

Ignasi Navarro i Ferrando

January, 2021 


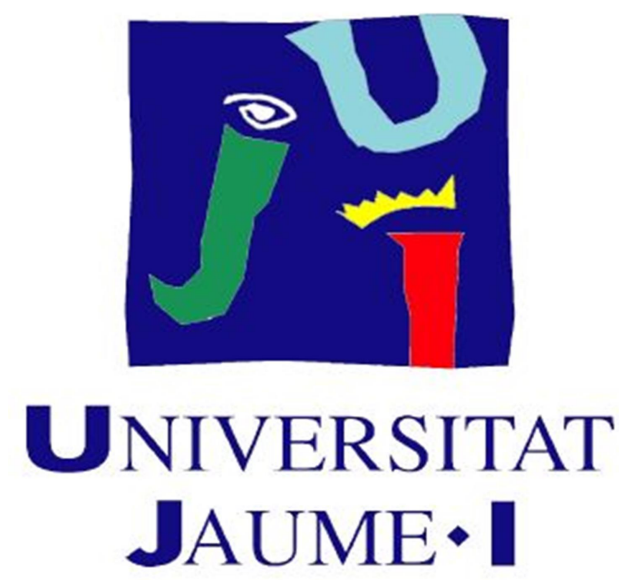

Programa de doctorado en Lenguas Aplicadas, Literatura y Traducción Escuela de doctorado de la Universidad Jaume I

\section{A Contrastive Study of the EFL Vowel System in Native Spanish, French, German and Russian Learners}

Memoria presentada por José Javier Juan Checa para optar al grado de doctor por la Universidad Jaume I

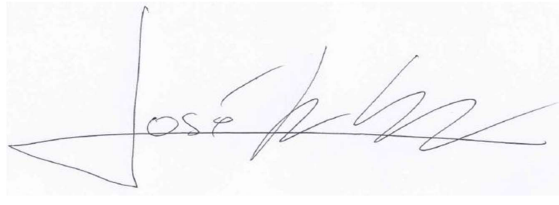

José Javier Juan Checa

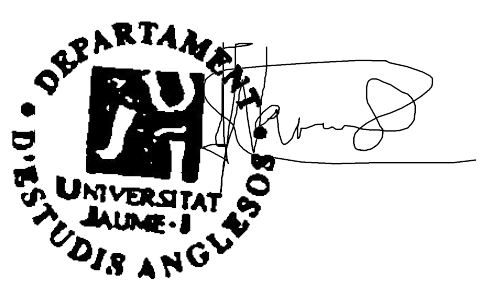

Dirigida por Ignasi Navarro i Ferrando 


\section{Acknowledgement of Funding}

My research stay at the University of Murcia has been partly supported by Universitat Jaume I (ref: 1726/CON/2018). I hereby thank the responsible personnel for this help. 


\section{Acknowledgements}

It was the best of times, it was the worst of times, it was the age of wisdom, it was the age of foolishness, it was the epoch of belief, it was the epoch of incredulity, it was the season of Light, it was the season of Darkness, it was the spring of hope, it was the winter of despair, we had everything before us, we had nothing before us, we were all going direct to Heaven, we were all going direct the other way.

Charles Dickens

These immortal words describe better than I ever could my almost 6 years of doctoral studies. Intense is an adjective that should be up there too. And emotional rollercoaster. And a few others, but Dickens did not add them, because he knew his prose better than me. He was also writing about culturally uprising London and crisis-stricken Paris, both subjects more harmless than writing about phonology.

These 6 strenuous years certainly took a toll on my health, more concretely my weight. It jumped in all directions: from my initial "I'm happy with myself" $85 \mathrm{~kg}$, I ballooned up to "maybe I should eat less" $102 \mathrm{~kg}$. Thanks to a good nutritionist, I lived for a while without carbs and regained a healthy $78 \mathrm{~kg}$. Good things do not last though, and as the stress and the workload rose, so did my weight, again. This time it even went to "we need to seriously talk about this" $110 \mathrm{~kg}$. Back to eating healthy food (aka algae and alfalfa), and leaving again the morbidly obese section...only to fall once again into the pit traps. $112 \mathrm{~kg}$ this time. I guess my health problems will not come to an end until this thesis is definitely a 
thing of the distant past. If this research kills me, I hope my epitaph reads: It was worth the weight.

Jokes aside, it was an arduous time indeed. Years of reading up, writing notes, preparing articles, rehearsing presentations, and, above all, countless sleepless nights. Nights full of doubts and writer's block. That blinking vertical line on a white page, waiting for words on my end, is scarier than that abyss staring back at you, that Nietzsche was so afraid of. It really is more terrifying, because it shows your limitations: either time or your own capabilities.

But there would be another unpleasant surprise at store, a deadly pandemic that would change everything we knew, everything we thought. Things we took for granted were taken from us, things we never thought of became talking points. We lost too many, and we had to give up a lot in order to protect the ones we love. At the moment we are still trying to hold on, despite the infinite sadness and the additional toll this crisis is taking on our physical and mental health. Time was cut short, depression was spreading like the mind-killer it is and many people aged more in a few months than they ever did before.

The common people are giving their best to survive, while hoping every night to get back to a time that seems so distant now. I am hopeful that we will prevail. I am hopeful because difficult times create strong people, and strong people create good times. Humanity faced hardships before, and thanks to the work of these strong people, these common people, we were able to turn things around and create a better world.

Therefore, I'll be eternally thankful to all these strong people that helped me on my journey. Good souls, which accompanied me on this arduous trip. Some along the whole way, others in specific moments and a few lifesavers, that bailed me out in the darkest hours. 
The following are my invaluable support; my safety scaffolding and my friends in need...friends indeed.

Ignasi Navarro Ferrando, for his never-ending patience with me, his knowledge on how to tackle things that are out of my (mental) reach and advice on every single problem I encountered on every single step of my journey. There would be no thesis without him. I repeat: his patience and grace made this possible.

José Antonio Mompeán Gonzalez, for his eye-opening knowledge, his invaluable advice on how to improve some aspects, for his help and friendliness during my research stay and for being patient enough to give me enough corrections to save myself and my work. Also, for his immeasurable gift of spending too many hours to point out every single error on my part. And God knows, the numbers were sky high.

Nieves Alberola Crespo, for advising me, whenever I encountered big problems in her typical smart, sympathetic and sincere manner.

Edgar Bernad, for listening to my rants, pushing me, and knowing the answers to all the questions in the universe.

Mercedes Sanz Gil, for finding the time to help me out, even when she is completely surrounded by an immense workload.

The friendly staff at the secretary's office at the University of Murcia and the Doctorate School at the University Jaume I, for being ever helpful and friendly with all my questions and emails and for always replying one more time.

Vicent Garcia Edo, for helping me out against the fanatics at bay, that only excel in mulish stubbornness, disgraceful shame tactics, flat-out incompetence and abuse of power. May they never triumph and everything they touch turn into ashes. 
My parents, Antonia Checa Borrego and José Juan Sanchis, for their never-ending love and patience with me, during all my life. I will make you proud and always honour you. You fought for everything and showed me the valour of bravery and doing what is right, even when it leads to difficulties and loneliness. The end result is it makes you a better and more decent human being. I learned that from you.

Francinne, my love. For being my better half. For sticking with me in good times and in bad times. For making my heart beat faster and burst with laughter, for deserving so much better. For loving me unconditionally, for letting me love you fully. You showed me how to fly together with you. Since then, our feet have not touched the ground.

Words cannot describe how helpful all of these people have been in my endeavour. My most sincere gratitude to all of you.

It is a far, far better thing that I do, than I have ever done; it is a far, far better rest that I go to than I have ever known. 


\section{Resumen}

Esta tesis se centra en las dificultades fonéticas con las que los estudiantes de inglés como lengua extranjera se toparán. A lo largo del último siglo, personas de todos los lugares del mundo han intentado aprender inglés y los resultados obtenidos no han variado en todas estas décadas. Además, la mayoría de los países han investigado ellos solos este problema durante décadas y los resultados de hace ya 100 años son asombrosamente similares a los resultados obtenidos hoy en día.

Esta investigación quiere proponer un nuevo punto de vista; un ángulo diferente y más amplio en cómo enfocar este tema. En lugar de comparar únicamente una o dos lenguas con el inglés, comparará 4 (español, francés, alemán y ruso) con características similares o diferentes basadas en el sistema vocálico y la isocronía.

Más de 30 voluntarios de diferentes países han participado en una sesión de grabación y han rellenado posteriormente un cuestionario. Tuvieron que leer en voz alta frases con varios ejemplos de todos los fonemas ingleses. A continuación, tuvieron que rellenar un cuestionario anónimo con algunas preguntas sobre ellos y bastantes más preguntas sobre el aprendizaje del inglés.

Tanto el cuestionario como las grabaciones van a ser analizados de manera tradicional (la ayuda y opinión de un nativo inglés, respectivamente). Además, los errores que se cometieron durante la grabación serán analizados a través de a espectrografía, que podría ayudarnos a comprender mejor la naturaleza del problema.

Los resultados obtenidos podrían marcar el punto de partida para promover más investigación posterior que podría ayudar a estudiantes del inglés en todo el mundo. 


\begin{abstract}
This thesis focuses on the phonetic difficulties EFL learners face. Throughout the last century, people have tried to learn English in countries around the world and the pronunciation problems have not varied in all those decades. Furthermore, the majority of countries have researched this problem for decades on their own, and results from 100 years ago are shockingly similar to results obtained nowadays.
\end{abstract}

This research wants to propose a new point of view, a different angle, much broader, on how to approach things. Instead of comparing one or two languages against English, it will compare 4 languages (Spanish, French, German and Russian) with similar or different characteristics based on vowel systems and isochrony.

Over 30 volunteers from different countries participated in a recording session and filled out a questionnaire afterward. They had to read out loud sentences with many examples of all the English phonemes. Afterward, they had to fill out an anonymous questionnaire with a few questions about themselves and many questions about English learning.

Both the questionnaire and the recordings will be analysed in the traditional way (the help and opinion of a native English speaker). Furthermore, significant mistakes made during the pronunciation will be reviewed through spectrography that could give us further insight about the nature of the problem.

By expanding the focus, the obtained data could serve as a starting point for further studies that down the way could facilitate EFL learning and more precisely, the appropriate pronunciation of English vowels all around the world. 


\section{Table of Contents}

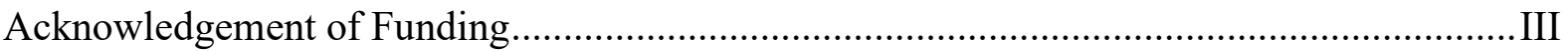

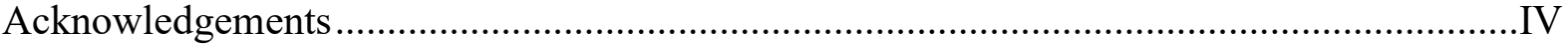

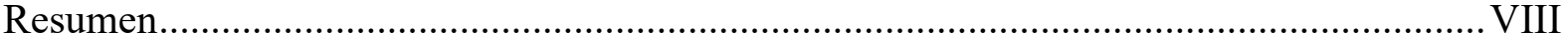

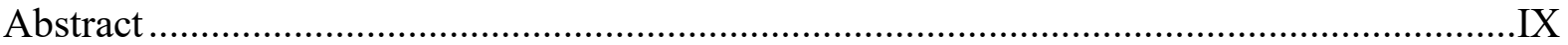

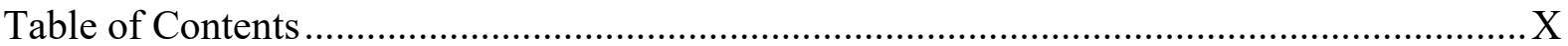

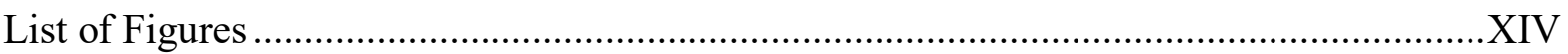

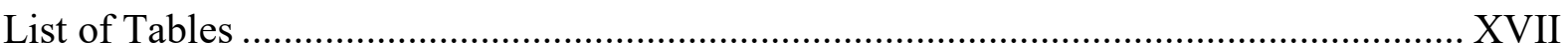

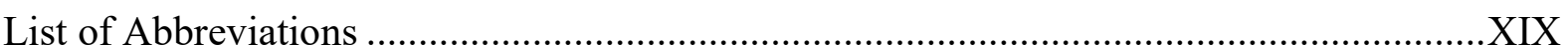

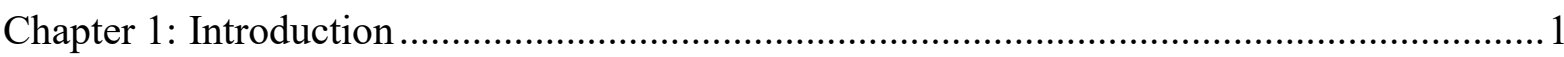

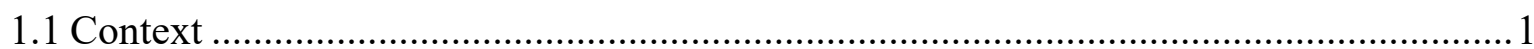

1.2 Problem statement

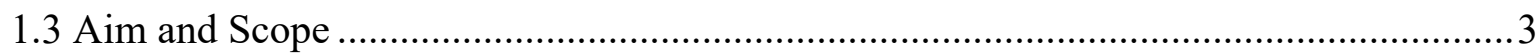

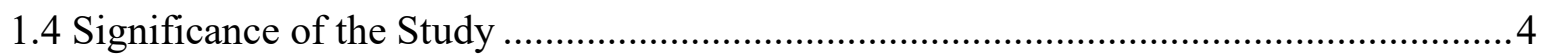

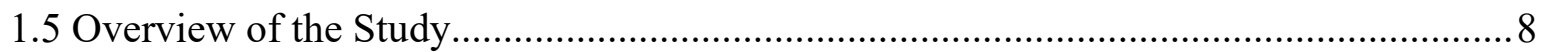

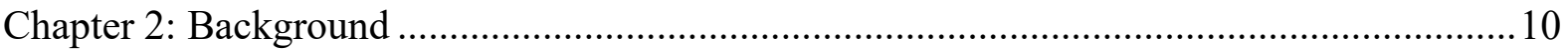

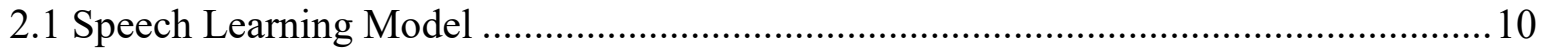

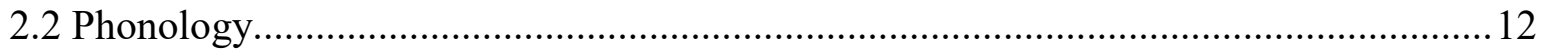

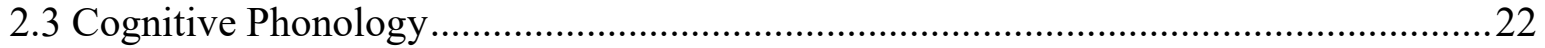

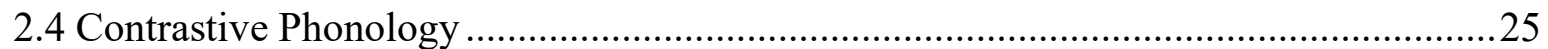

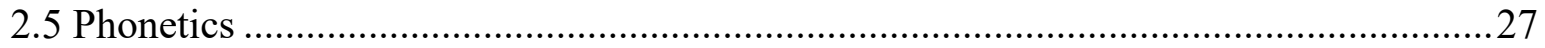


2.6 Segmental and Suprasegmental Features

2.7 Language and its origins

2.8 Background information on Languages and EFL Learning ......................................43

2.8.1 The Spanish Vowel System and EFL in Spain.......................................................43

2.8.2 The French Vowel System and EFL in France.....................................................47

2.8.3 The German Vowel System and EFL in Germany ............................................51

2.8.4 The Russian Vowel System and EFL in Russia .................................................57

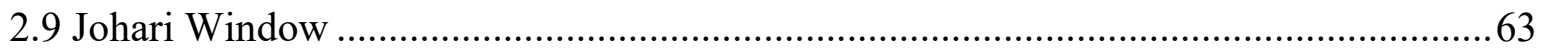

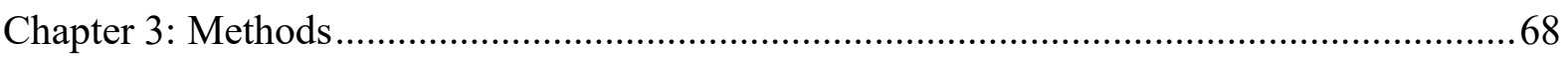

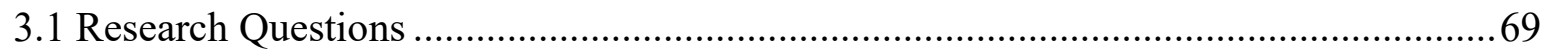

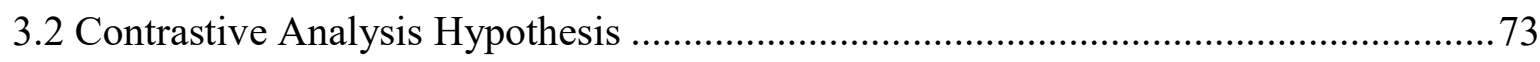

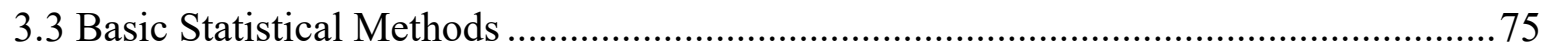

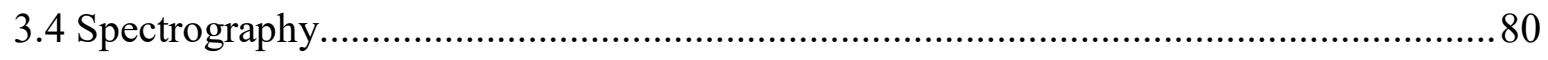

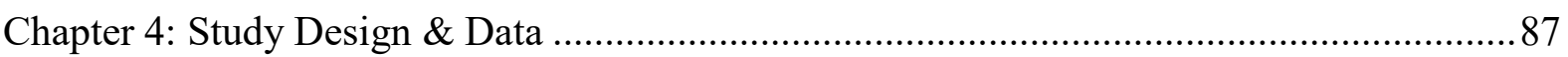

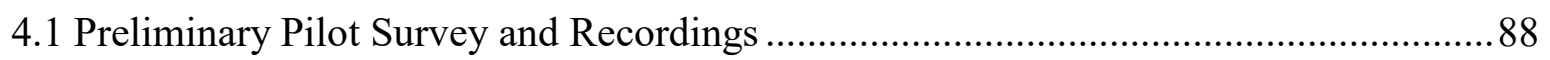

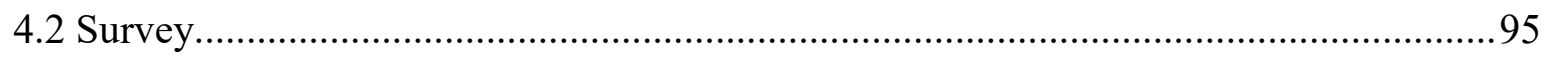

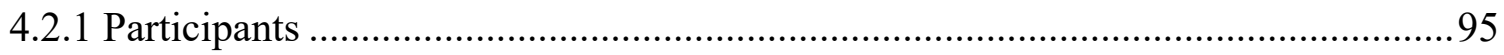

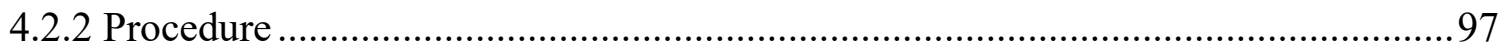

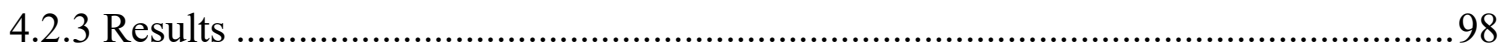

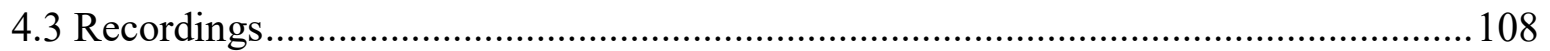

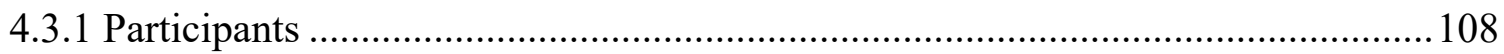


4.3.2 Procedure 108

4.3.3 Results

Chapter 5: Discussion

5.1 Human Review

5.1.1 Spectrography

5.1.2 Clipping influence

5.1.3 Simple vs. complex vowel system.

5.1.4 Stress- vs. syllable-timed languages

5.1.5 Presence vs. absence of similar phonemes in native language

5.2 Final considerations

Chapter 6: Conclusion.

6.1 Main Findings .....

6.2 Limitations 162

6.3 Directions for Future Research

6.5 Final Considerations.

Chapter 7: Resumen Final.

7.1 Introducción

7.2 Contexto

7.3 Métodos

7.4 Diseño experimental \& Datos

7.5 Discusión 
Bibliography 177

Appendix

Appendix A: Glossary

Appendix B: Preliminary Survey 200

Appendix C: Preliminary Recording Exercises 202

Appendix D: Participant's Background Information Survey 205

Appendix E: Research Reading Exercise .207

Appendix F: Scanned Questionnaires from Participants (1 Example of each Country)....209

Appendix G: Scanned unused questionnaires by other nationalities ( 2 examples) 213 


\section{List of Figures}

Figure 1: Speech Mechanism. .29

Figure 2: Speech Mechanism and Air Track .................................................................... 31

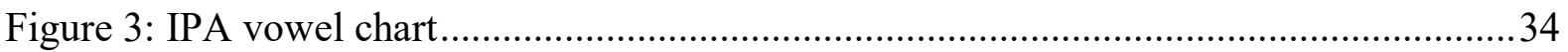

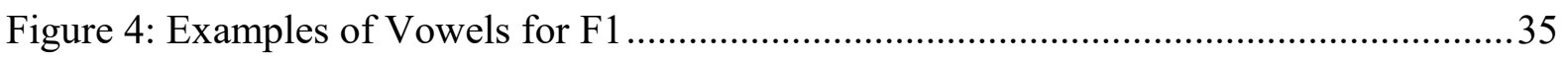

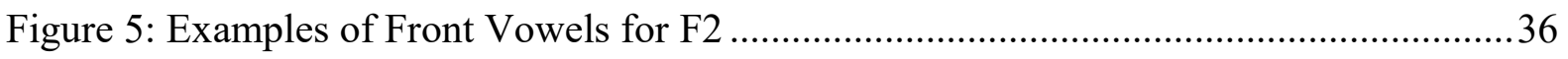

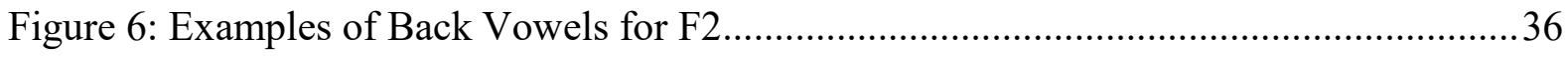

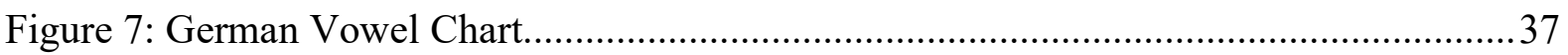

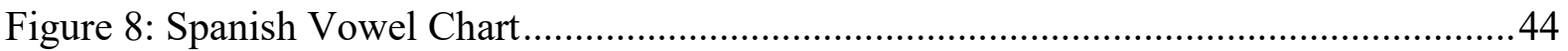

Figure 9: The English Vowel System and its Possible Misinterpretation by a Spanish EFL

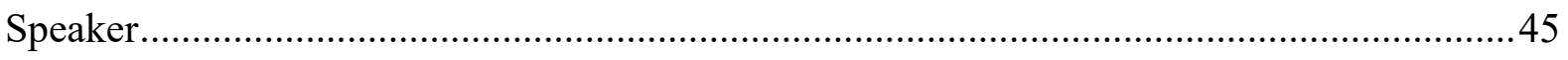

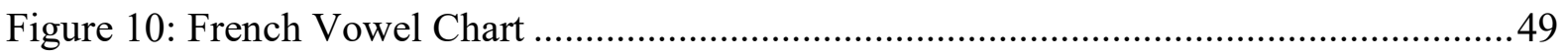

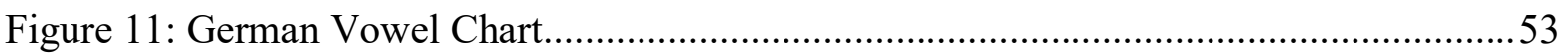

Figure 12: The English Vowel System and its Possible Misinterpretation by a German EFL

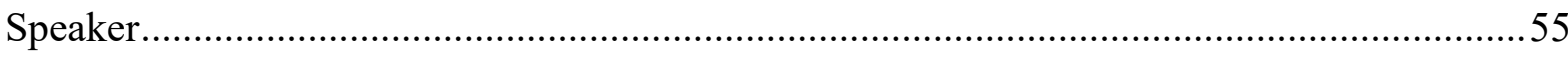

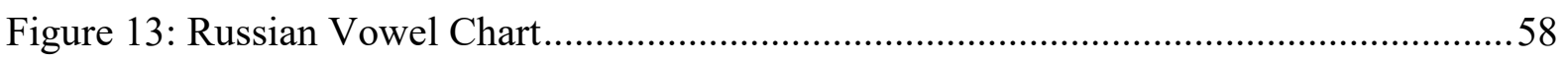

Figure 14: The English Vowel System and its Possible Misnterpretation by a Russian EFL

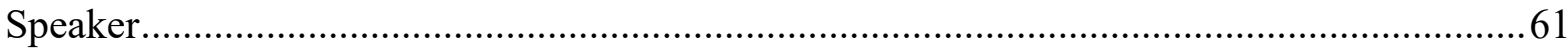

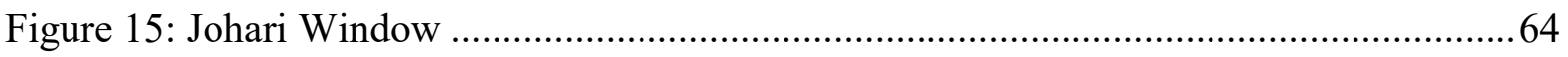

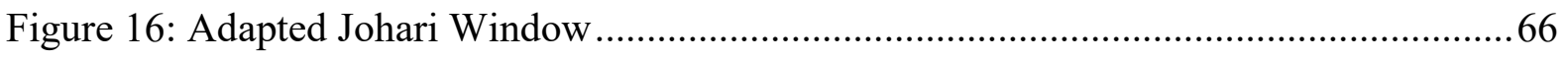

Figure 17: Example of CAH between Arabic and English............................................... 74

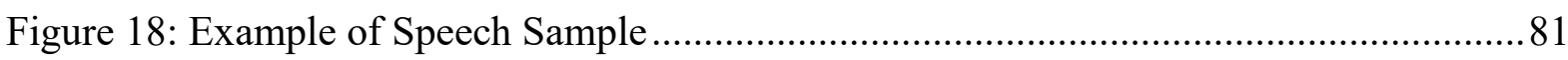

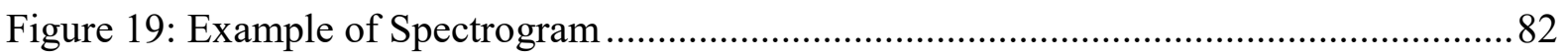

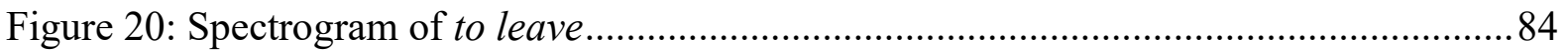

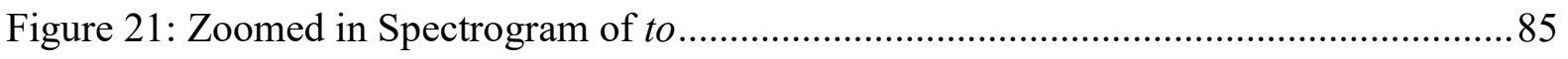


Figure 22: The 68-95-97 Rule .99

Figure 23: Participant's Background Information Analysis 102

Figure 24: Survey on Most Important Pronunciation Factors 104

Figure 25: Misrealization of /i:/ Phoneme by Sp1 115

Figure 26: Spectrogram of Leaf by $\mathrm{Sp} 1$ 116

Figure 27: Misrealization of /I/ Phoneme by Ru2.

Figure 28: Spectrogram of Recall by R2 118

Figure 29: Misrealization of /æ/ Phoneme by Fr5 119

Figure 30: Spectrogram of The Apple by Fr5 120

Figure 31: Misrealization of /a:/ Phoneme by Ge2.

Figure 32: Spectrogram of The Garage by Ge2

Figure 33: Misrealization of $/ \Lambda /$ Phoneme by Fr9

Figure 34: Spectrogram of My Other by Fr9

Figure 35: Misrealization of / $\mathrm{a}$ / Phoneme by Sp4 125

Figure 36: Spectrogram of Awful by Sp4.... 126

Figure 37: Misrealization of /p/ Phoneme by Ge1 127

Figure 38: Spectrogram of Body by Ge1 128

Figure 39: Misrealization of /u:/ Phoneme by Ru2. 129

Figure 40: Spectrogram of Noose by Ru2. 130

Figure 41: Misrealization of / $\mho /$ Phoneme by Ru6.

Figure 42: Spectrogram of Could by Ru6.

Figure 43: Misrealization of /3:/ Phoneme by Fr2

Figure 44: Spectrogram of $\mathrm{Her}$ by Fr2

Figure 45: Misrealization of /e/ Phoneme by Sp3

Figure 46: Spectrogram of Effort by Sp3. 136 


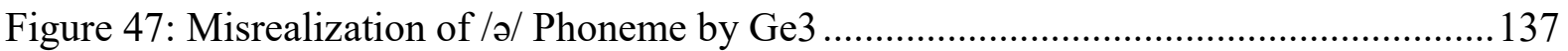

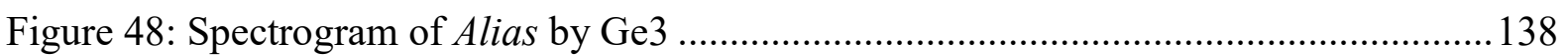




\section{List of Tables}

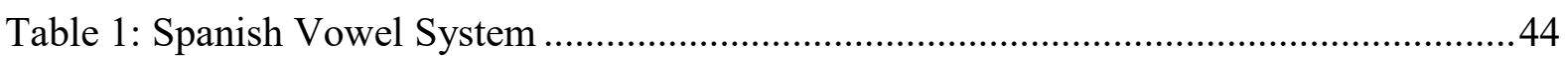

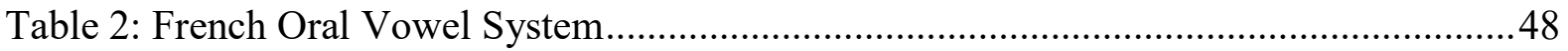

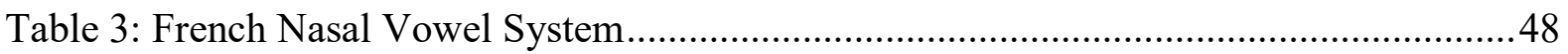

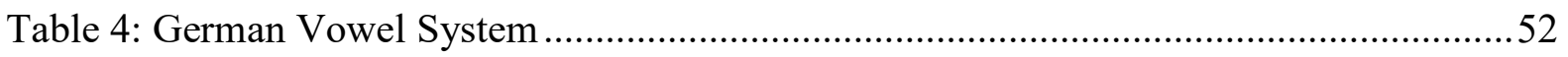

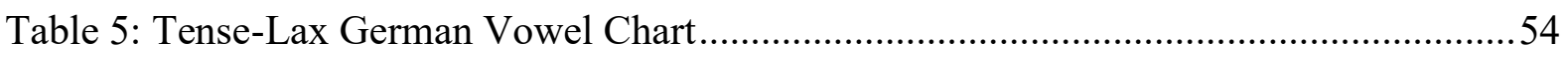

Table 6: Bavarian Schools Offering Foreign Languages.....................................................57

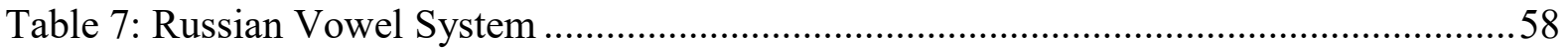

Table 8: Russian Vowels and Their Allophonic Realization................................................60

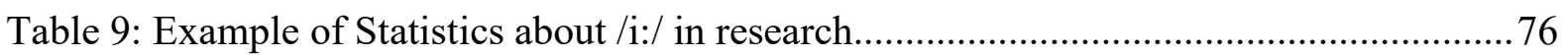

Table 10: Mean of Spanish EFL Speakers in Question 1 of Participant's Background

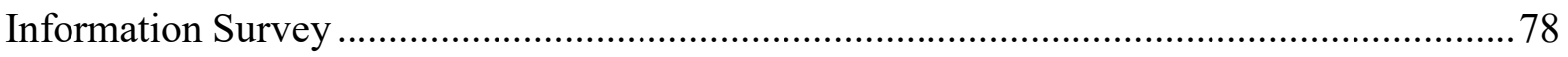

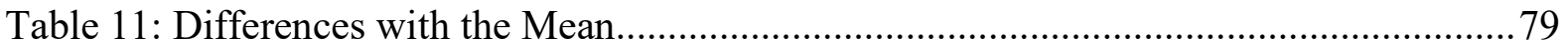

Table 12: Demographic Information and Language Background for Participants in Survey .98

Table 13: English Certificate Distribution among Participants ........................................ 101

Table 14: Most Important Pronunciation Factors in Survey............................................. 107

Table 15: Phonetic Mistakes by EFL Learners from Spain, France, Russia and Germany...111

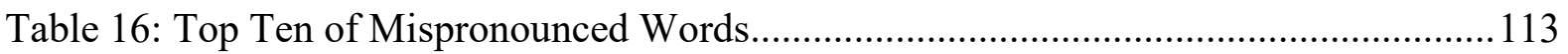

Table 17: Occurrence of English Vowel Phonemes in Other Languages............................... 143

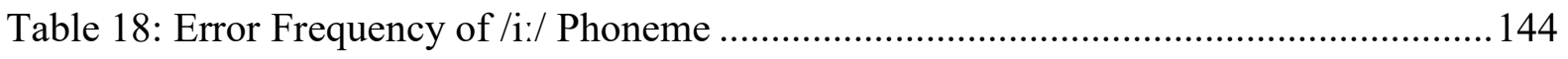

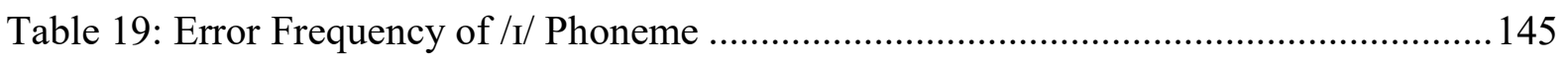

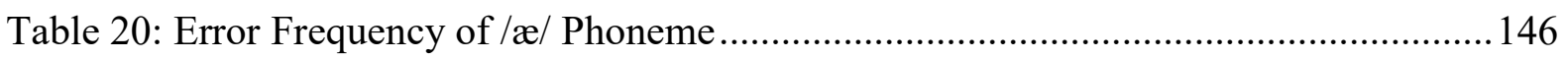

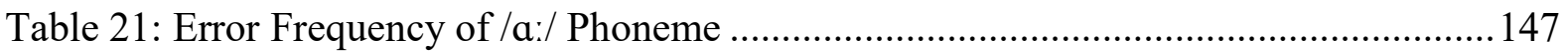

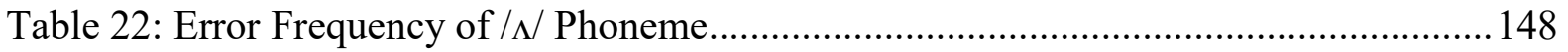

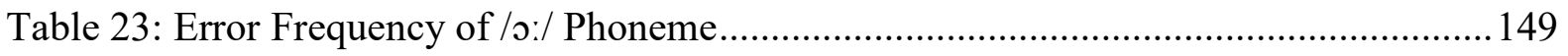




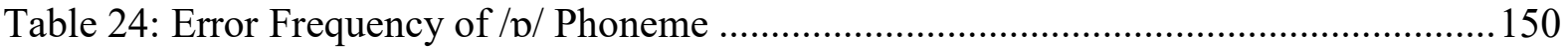

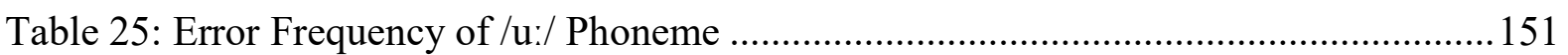

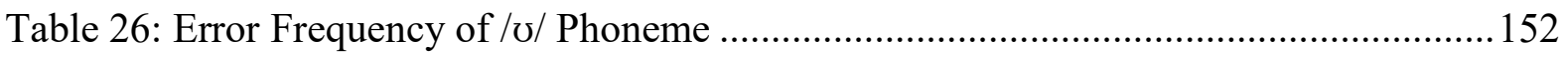

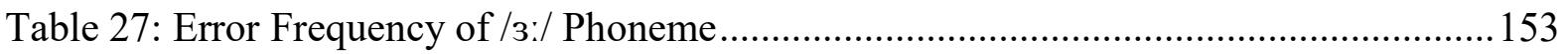

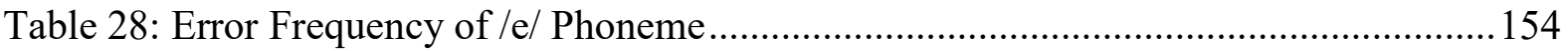

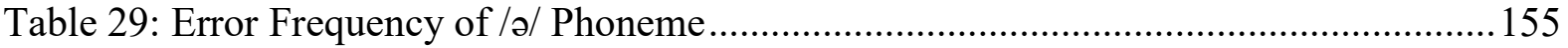




\title{
List of Abbreviations
}

\begin{abstract}
A.I.: Artificial Intelligence
\end{abstract}
Aka: Also known as

CAH: Contrastive Analysis Hypothesis

CP: Cognitive Phonology

EF: Education First

EFL: English as a Foreign Language

EPI: English Proficiency Index

F0: Fundamental Frequency

F1: Formant 1

F2: Formant 2

F3: Formant 3

IPA: International Phonetic Alphabet

L1: Mother tongue or one's first language

L2: Second language

$\mu(\mathbf{M u})$ : Mean Average

ORI: Oficina de relaciones internacionales at the Jaume I University

RP: Received Pronunciation

SD: Standard Deviation 
SLM: Speech Learning Model

SLM-r: Revised Speech Learning Model

б (Sigma): Standard Deviation

$\sigma$ (Sigma): Syllable 


\section{Chapter 1: Introduction}

After decades of improving language learning methods, EFL (English as a Foreign Language) has still not found a way to avoid the struggle that learners all around the world have with the correct pronunciation of English vowels. Each linguistic community focuses on its own share of problems concerning the target language and despite years of research, the issue is as present as ever.

\subsection{Context}

At the beginning of this research, I was reading articles from many different areas in order to identify my niche for this research: cognitive linguistics in general (Evans \& Green, 2006), but also more singular areas as Cognitive Psychology for the sake of understanding how human beings learn languages (Eysenck \& Keane, 2005), Biology for studies about the prenatal response to different languages (Sato \& al., 2012) or History of EFL learning in different countries (Kubota, 1998; Proshina, 2006). One detail that piqued my interest was the works of British linguists Ernest Mason Satow (Satow \& Ishibashi, 1976) and Edward Gauntlett (Saito \& Asby, 2013), two of the first Japanologists in the world.

Both men travelled to Japan at the turn of the $20^{\text {th }}$ century, fell in love with the country, married a local and stayed there. Being linguists they continued their work in a new and exciting environment and delivered pioneering linguistic work. Satow released in 1904 one of the first English-Japanese dictionaries, that built upon the work of James Curtis Hepburn, a physician and missionary that learned the Japanese language, used the Latin alphabet to transcribe the Japanese language (Hepburn Romanization), and then compiled this knowledge into the first dictionary. My main takeaway from both linguists was that a 
century later, Japanese EFL learners still had the same pronunciation problems, and even after the great Japanese language reforms of 1946, where kana usage aligned with the modern pronunciation (Sato, 2014), the pronunciation problems are still the same.

The Welsh linguist Edward Gauntlett succeeded both of them (Gauntlett, 1905), and focused on pronunciation, nine years before Daniel Jones established the first international standard for foreign learners (Jones, 1917). All that aroused my curiosity since I am working on EFL learning and pronunciation, but after I skimmed through this old document, it also had my full attention. Gauntlett's text explained the same pronunciation errors Japanese EFL learners face in 2019. Furthermore, Gauntlett used methods of contrastive analysis decades before Robert Lado (1957) popularized it in the 1960s and he also used illustrations and diagrams of the vocal organs before anyone else (4 years earlier than Jones, this time). The last aspect, which struck a chord with me, was his comparison with phonetic changes and phenomena from other languages both close (Korean) and distant (Latin) to Japanese.

I then started to map the community, to identify key researchers in this area and how they interrelate. I also looked for material on other languages, trying to find out if this was just a Japanese idiosyncrasy or if there was more to it, a pattern maybe, and found out that the same was true for other languages like German (Hockett, 1950) or Russian (Jopson, 1934). Pronunciation problems, that were already described decades ago, are still the same problems EFL learners have to struggle with today. Life has changed a lot in the span of a century: technological progress has not only changed life as we know it but also the perception of it. Language learning has evolved and with each passing day, we find an ever-growing wealth of sources and ways of diving into other languages. And yet, people learning English make the same mistakes. 


\subsection{Problem statement}

EFL learners always face the problem of learning the English language while lacking some of the phonemes in their respective L1 needed for English. This can lead in some cases to conspicuous accents that give native speakers a wrong impression about EFL learners. It is the same for relatively close languages to English like German or Spanish or distant languages like Korean or Japanese. The different phonetic systems of, for example, Spanish (Hammond, 2001), German (Kohler, 1999) and Russian (Timberlake, 2004) do not always share the same phonemes or sometimes even the same phonetic characteristics for a phoneme. Spanish for example does not have long vowels (Morrison, 2004), while Russian assimilates consistently the missing vowel phonemes to their Russian counterparts (Gilichinskaya \& Strange, 2010). This is a linguistic barrier that needs to be dealt with in order to acquire proper pronunciation.

This problem, despite hundreds of articles and countless research in any language (Rallo Fabra \& Jacob, 2014; Richter, 2018; Piske, MacKay \& Flege, 2001; Bergmann et al., 2016; Banzina et al., 2016; Kartushina et al., 2016; Flege \& Wayland, 2019; among others) is still there which means that the present way of doing things is still lacking in some degree and that the existing theories are not enough to find a satisfactory solution. Grounded in this context, the following research is subsequently worth tackling and justifies a further look.

\subsection{Aim and Scope}

The aim is to approach the problem from a different perspective. Until now the majority of study in this field consisted of researchers comparing their mother tongue to English. Research like Paola Escudero's The Phonological and Phonetic Development of New Vowel Contrasts in Spanish Learners of English (2006) or Zoya Proshina's Russia English: Status, Attitudes, Problems (2006) are examples of this monolinguistic approach. 
The idea for this thesis is to compare several languages with certain typological criteria against English. Furthermore, the data will be analysed first by an expert (native speaker) and then some of the appearing errors will be further investigated by spectrographic analysis. Interdisciplinarity and originality are the two key tenets in this approach, and I am trying to honour both of them to the best of my abilities.

The scope of this research acknowledges the obvious limitations: human, technical and monetary. Human limitations refer not only to the limits of my own knowledge and therefore not being able to push the boundaries of current knowledge, but also the lack of availability of test subjects. Technical limitations deal with creating similar recording conditions, analysability of the recorded material and the importance of recording it in situ, thereby restricting the availability of test subjects. Finally, monetary limitations encompass having an insufficient budget and as a consequence not being able to pay much or having access to an unlimited amount of test subjects. It also limits the researcher's ability to get test subjects from abroad, since the researcher relies on local exchange students and cannot travel to all the countries where the languages under analysis are spoken.

\subsection{Significance of the Study}

The idea is not to revolutionize language learning as we know it but that this small corpus of data, resulting from a different point of view, will be the starting point for further analysis down the road. My contribution to the field consists of using interdisciplinary methods (both old and new) and a wider variety of languages to compare with English. Uniting methods from different fields should deliver enough data, which could potentially help others and inspire future researchers to keep investigating in that direction, or realizing that it needs a few modifications. 
The addition of spectrographic analysis, as a way to look at phonetical mispronunciations, is an interesting more modern method, and as such should provide interesting data on which future research can be built upon.

This study, and academic writing in a broader sense, is not only an intellectual activity, but it also harbours an inherently social activity. This small "contribution of knowledge" opens itself up to critique, scrutiny and, ideally, use. Therefore, academic writing demands communicating results to a community of researchers that will hopefully invest time in your dissertation and it subsequently has to include certain elements (Petre \& Rugg, 2004, p. 6-7):

- a context in which your research occurs

- a justification for the content you are going to present

- the claims and data you deliver, need to be substantiated through evidence of rigour in your work

- a coherent and detailed chain of reasoning in your dissertation that shows the appropriate use of a correct structure, a clear argument and an overall coherent vision of your research

- a discussion at the end to acknowledge implications and limitations

These elements are common but additionally, each type of dissertation has a particular purpose, context and audience. Purpose and content determine what type of dissertation it is and the intended audience will influence the length, the voice and the priority of the elements.

Having said this, this following dissertation can be described as a method-mongering one. Method dissertations, in general, describe new or variants of methods, processes or techniques to a given community for a specific use. They also need to describe the method 
and explain how to use it in sufficient detail for a reader to apply. So, it comes down to this (Petre \& Rugg, 2004, p. 89-90):

- What is it?

- How does it work?

- What is it good for?

- What makes it different from other methods?

There are several subtypes of method dissertations and this one is, as mentioned, a Method-mongering one. They describe a method that may be original and even developed by the author. They could also describe an established method from a different field, which is far from getting the attention it deserves in the field you are about to use it.

This dissertation aims to look at specific aspects of phonology, namely the acquisition (or more correctly the lack thereof) of vowel phonemes by EFL learners from different linguistic communities in particular countries. This research focuses on the mistakes 4 groups of EFL learners make, namely learners from Spain, France, Germany and Russia. Various languages are spoken in these countries, and their official languages are also spoken in other countries. Thus it is important to specify that it is mistakes by L1 Spanish, L1 French, L1 German, and L1 Russian learners from Spain, France, Germany, and Russian Federation, respectively. They also share a very specific profile: all of them continue studying tertiary degrees, but none of them is doing so in an English-related degree. If the pronunciation mistakes they make are widespread amongst their peers, it will be further analysed through the use of spectrography.

The idea behind this research is not to come up with definite solutions, which other linguists and researchers could not achieve during decades. The intent is not about offering a 
different view, but to offer more views, more lenses, more options, compile more data, which could lead in the end to a better understanding.

Big data has been the buzzword for the last decade, and it refers to methods to analyse and extract information methodically from vast amounts of data sets that help to create algorithms that predict behaviour and analysis. Companies worldwide amass and analyse every single bit of user data they can get their hands on, in order to predict potential client's behaviour and thorough predictive analysis of future trends (Bachmann, 2014).

The astonishing thing about the use of big data is that, in a relatively short period of time, it went from predicting consumer trends for online retailers (Kauffmann et al., 2019) and predicting what online streaming services need to offer their viewers (Zikopoulos \& Eaton, 2011) to helping out in clinical research (Pennington et al., 2019) and even helping out in the UN, of all places, to sustain peace (Wählisch, 2019).

In any case, my research is not focused on big data, but it is focused on getting as much data as possible, by not only doing classical methods (CAH) but also adding relatively new methods (Spectrography) to get more data. That amount of data could act as a springboard for continuing down this line of research or even adding more layers and languages to the mix. It could also help others to find solutions to this phonetic problem.

In the end, it is more in line with what Nobel Prize winner for Biology, Albert Szent Gyorgyi, said:

Discovery consists of looking at the same thing as everyone else and thinking something different. Think boldly. Do not be afraid of making mistakes. Do not miss small details, keep your eyes open and be modest in everything except your aims. 


\subsection{Overview of the Study}

Working on a Ph.D. has many similarities with the classical craft of cabinet-making. In olden times, a carpenter had to make a cabinet at the end of his apprenticeship, a task that demonstrated that the apprentice had all the skills needed to become a master cabinet-maker. The resulting cabinet was known as his "masterpiece" (Petre \& Rugg, 2004). A successful $\mathrm{Ph} . \mathrm{D}$. dissertation realizes a similar role since it demonstrates that one has learned all the necessary skills to be a researcher in his own right. The dissertation and the subsequent viva voce examination have to show that one has acquired the necessary skills of academia, and that one shows its mastery throughout the thesis by, among other things, using the correct academic language, knowing the pertinent background literature, asking the appropriate research question, showing maturity as a researcher by applying the theory to your research methods and applying the correct structure.

This thesis consists of 6 chapters and it can be divided into three main parts. Following this introductory chapter, we have two chapters dedicated to background knowledge, which follow two essential functions: providing all the background material needed for this research and being the stepping-off point for my own research. This means, that Chapter 2 and Chapter 3 not only describe and define languages, concepts and research methods but also review critically its theory and existing literature. Chapter 3.1 builds up on the context, relevant knowledge, theory and practice of the previous sections and develops a few hypotheses and asks the research questions resulting from it. The aim of this is that at the end of Chapter 3, the lead-up to and reason for my research is visible and understandable.

The second part is Chapter 4 and it deals with the resulting data of my research. In the first place, it describes how a preliminary pilot survey helped me improve the actual survey and recordings. Then, it rigorously outlines the procedures in which the data was 
obtained. The resulting data related to mispronunciations gets then special attention through spectrographic analysis and similarities and differences will be detailed in the findings.

Finally, Chapter 5 discusses the findings and Chapter 6 concludes the obtained results. Here information can turn into knowledge, and shortcomings and limitations are taken into account. The results are analysed for its significance and implications. Concerning the first part of this thesis, it also checks in earnest, if it sheds some new light on some of the concepts or methodologies, or what advantages or even progress, it can offer. 


\section{Chapter 2: Background}

This chapter provides enough background knowledge to understand the context on which the research is building upon. It delineates the position of the researcher in regards to the work by defining concepts and giving a brief overview including either historical or geographical descriptions. It starts by defining the Speech Learning Model, which is the essential framework for research based on language learning mistakes. Phonology and its different methods along the years is the next thing that will be reviewed. The relatively complicated task to explain Cognitive Phonology in contrast to Phonology will be the next section. Then, this chapter will take a look at Contrastive Phonology, an important subfield of linguistics that is essential in research that wants to compare different languages. Afterwards, this chapter will review Phonetics and then examine the segmental and suprasegmental features. Both categories will be necessary for this research. Another important section covers language, both its origins, but also more specifically the languages used for this research. Subsequently, this chapter concludes with the brief explanation of the Johari Window, a concept that will be useful for this research.

\subsection{Speech Learning Model}

When trying to explain the origin of a foreign accent while producing L2 phonemes, James Flege developed the most influential and most widely applied model: the Speech Learning Model (Flege, 1995). Previous to that, it was assumed that up until 12 years of age, it was possible to learn a new language accent-free (Penfield, 1959). Neurological maturation) within the learner reduces neural plasticity, which then leads to an inability to add or produce L2 sound (Lenneberg, 1967). This theory was called Critical Period Hypothesis and was 8 years later popularized by the linguist Eric Lenneberg (1967). 
However, SPL assumes that the phonetic systems that we use in the perception and production of vowel and consonant phonemes are not limited to a critical period, but instead active during our whole life (1995, p.239):

the mechanisms and processes used in learning the L1 sound system [...] remain intact over the life span and can be applied to L2 learning

Flege conducted a study where 240 test subjects (in varying ages) learned English as an L2. The results were that if a critical period existed at all it would not result in a steep discontinuity in L2 pronunciation ability around the age of 12 (p.234).

Flege and his colleagues developed their model concerned with the attainment of L2 pronunciation. Phonetic systems reorganize themselves in response to an L2 sound by either adding a new phonetic category or modifying an old one. L1 and L2 phonetic categories coexist in the same system, and they are kept distinct from each other (Flege, 1995).

Flege developed 4 postulates and 6 hypotheses (p.239) but particularly one of these hypotheses is of major interest. According to this hypothesis, if the sounds in L2 are different from the learner's L1, they will be easier to learn (p.239).

A new phonetic category can be established for an L2 sound that differs phonetically from the closest L1 sound if bilinguals discern at least some of the phonetic differences between the L1 and L2 sounds.

The difference makes the learner form new phonetic categories, but only if it received enough input and achieved native-like proficiency. This means, experienced learners will perform better on new sounds than new learners (p.246, p.252). For L2 phonemes that are similar to L1, learners equate too often with L1 categories, thus perceiving and producing 
it always closer to L1 than to the L2 (Hao, 2014). In this situation, there is no difference between experienced and inexperienced learners.

After the publication of this article, many studies (Aoyama et al., 2004; Baker et al, 2008) have been able to corroborate this hypothesis that L2 is more easily acquired by experienced learners, thanks to their longer exposure to L2. At the same time, L2 sounds similar to L1 do not have that positive learning effect (p.265).

\subsection{Phonology}

It is important from the start to differentiate and explain the relationship between Phonology and Phonetics. Phonetics is related to all possible human sounds of any language and analyses the smallest size of a unit (Nathan, 2008). Phonology is related to the symbols and sound systems of a distinct language and their classification (p.2).

Phonetics is like the study of the nature of the materials used in building, while phonology is the study of the way in which those materials are actually used to construct buildings.

Every single spoken and written language is a system, and each system consists of various interrelated levels that focus on different units of language (Odden 2005). Using a bottom-up approach to linguistic analysis starts by recognising phonemes, then combining them into syllables, afterwards these syllables are combined into words. These words form clauses that go as high as background and contextual knowledge. These different levels can be classified by the size of the unit they are interested in analysing (Nathan, 2008).

Morphology is interested in word formation, also called grammar (this shared though with syntax). It analyses minimal forms in language, which are made of sounds that are used to build words that serve either a grammatical or lexical function (Beard 1995). 
Syntax focuses on sentence structure and the differences in meaning by changes in word order and the addition or subtraction of words (Miller, 2017). Semantics researches meaning and the relationship between words, phrases, signs and symbols (Ladefoged \& Johnson, 2011). Pragmatics studies how context contributes to meaning and the use of language in particular situations and thus relies strongly on the notion of speech act and the actual performance of language (Odden, 2005).

This study focuses on sounds and thus a background knowledge chapter should start with phonology: the study of structure and organization of language sounds. All languages spoken by humans use combinations of vowels and consonants to create words. These sounds can be grouped into syllables, which are units of pronunciation consisting of one vowel, with or without consonants.

At this point, it is important to explain segmental and suprasegmental levels because phonology is not only restricted to the segmental level. Phonology usually recognizes two branches of study (Crystal, 1981, p.23):

Segmental phonology studies the way speech can be analysed into discrete units, or segments, that constitute the basis of the sound system; [...] supra-segmental phonology studies those features which extend over more than one segment, such as intonation and rhythm.

Phonological awareness is one of the segmental phonology skills, and it refers to the awareness of separable sound units in speech and the ability to control these while suprasegmental phonology skills refer to stress placement, intonation patterns and stress patterns, also known as (henceforth aka) rhythm (Veenendaal, 2016). Chapter 2.6 will explain more. 
Different languages may use different sounds, and they may have a different syllable structure. Some languages as Hawaiian (Elbert \& Pukui, 2001) and with certain limitations Japanese (Kawahara, 2016, Labrune 2012) only permit syllables consisting of a consonant followed by a vowel. Additionally, numerous languages have greater numbers of different sounds: the Taa language, spoken by some tribe in Namibia and Botswana, has 31 vowels sounds alone, for a total inventory of 118 phonemes (Ladefoged \& Johnson, 2011). Elseways, other languages subsist on as few as 13 vowel and consonant phonemes such as Pirahã, an indigenous language of homonymous tribe residing in the Amazonas (Derbyshire \& Pullum, 1986).

Phonological theory is one of the oldest parts of linguistic theory. The Indian linguist Pānini already composed a grammar of Sanskrit, which contained the complete phonology of that language (Böhtlingk, 2018). Despite other similarly early works, linguists had to first enter our modern era of scientific understanding until they started recognizing the problems and questions related to the study of sounds. Henry Sweet, considered "the man who taught Europe phonetics", firmly installed applied linguistics in language teaching, a tradition that is still present nowadays (Howatt \&Widdowson, 2004). Furthermore, in 1890, he published the first scientific description of RP (what was then called: educated London speech), thanks to transcribing connected speech into a phonetic script (McArthur \& McArthur, 1992).

The French linguist Paul Prassy was dissatisfied with the language teaching methods of his time. He was partisan to a radical remodelling of orthography ("orthographe simplifiée"), and he founded in 1886 the International Phonetic Association where he, among others, helped create the IPA (Colombat, Fournier \& Puech. 2010).

These two but also other phoneticians like Eduard Sievers (Sievers, 1901) (responsible for the linguistic law bearing his name, that describes how preceding syllables 
affect pronunciation) or William Dwight Whitney (Alter, 2005), whose doctrines were borrowed and expanded by Ferdinand de Saussure, discovered during the $19^{\text {th }}$ century important facts about phonetic transcription. According to Nathan (2008): "sounds can be completely described with the parameters of voicing, point, and manner of articulation (for consonants) and the tongue positions and lip setting needed for vowels"(p.2).

All the linguists working for the IPA started to catalogue in terms of languages (major and minor ones). While doing so they listened with great detail to the pronunciation of languages and their respective dialects and discovered that things were not as apparent as it seemed. The Polish linguist Jan Baudouin de Courtenay found discrepancies between what the articulators do when we pronounce a word and what the speakers perceive they are doing. Phoneticians were able to hear and observe details that untrained laymen were unable to. Not to mention, that different languages ignored different details, revealing thus that these discrepancies are a language-specific fact (Koerner \& Szwedek, 2001).

Baudouin argued that there are principles, which he named "divergences". These refer to the fact that sounds are perceived and stored in one form, while automatically adjusted while we speak following a set of phonetically-defined principles. He further detailed, that when we hear others speak we undo these divergences and "hear" what the speaker intended to say. He called these sound intentions "phonemes", a unit of sound that differentiates one word from another in a language (Koerner 2001).

These principles and the rest of Baudouin's work are considered the starting point for modern phonology. In the first half of the $20^{\text {th }}$ century, the theory behind phonemes was developed in many different directions by European and American linguists. This resulted in a wealth of valuable phonological research, whose concepts and theories are essential to understanding the research that subsequently came out of it. However, a few of those theories, 
despite being recognized as valuable to phonology, are also incompatible with the cognitive aspect of grammar and phonology. The following ideas, despite their incompatibilities, are yet worth knowing.

One of these important, but conflicting ideas is the assumption, that all the variants of an intended sound can be filed into a set, while the phoneme itself gives the name to this set. These variations were called allophones, a set of related sounds classified under a single phoneme (Jones, 1917). Another definition of allophones defines them as contextuallyconditioned variants of a phoneme (Clark \& Yallop, 1995). These sets were the centre of much discussion, as linguists like Edward Sapir argued that these sets of allophones were modes of perception and that speakers heard all these allophones as the same phoneme (Nathan, 2008). He argues that people hear speech phonemically but only managed to present anecdotal evidence of this perception (Sapir, 1933, p.2-3).

Another idea clashing with the cognitive aspect came upon when one faction of linguists associated with the Prague School disputed the perception that linguists also had to give psychological explanations (Trubetzkoy, 1939). Their concept of a phoneme was based on the works of Ferdinand de Saussure (Bally \& Sechehaye, 1916), the famous Swiss linguist from the $19^{\text {th }}$ century that had a considerable impact on linguists and linguistics in the $20^{\text {th }}$ century. He developed the school of inquiry called Structuralism, which can be defined as a method that analyses and interprets elements of human culture, behaviour, cognition and experience and that these elements must be understood in relation to a broader, overarching structure.

Structuralism was further developed during the first half of the $20^{\text {th }}$ century by the Prague School. One of the tenets that germinated, as a result, was that linguistic entities are parts of a bigger system and they are only meaningful when defined by their relations to other 
parts within that system. Two linguists gave good examples explaining this precept. Henry Allan Gleason Jr. (1961) took it to an extreme and compared the system of shoe sizes and jacket sizes. In Europe, jacket sizes range from 42 to 66 . Adult shoe sizes vary from 32 to 52, including men and women. Within each system, we can compare different samples. A size 44 jacket is much smaller than a 66 jacket, while a size 50 pair of shoes is much bigger than a size 32 pair of shoes. However, it is pointless to compare a size 44 jacket with a size 44 shoe; two different systems cannot be compared. Similarly, Aronoff and Rees-Miller (2017) reminded us of the chess game analogy, where the game is not defined by the physical features of one of its chess pieces, but for the relations between every single chess piece to all the other pieces. In order two recap both examples in linguistic terms: a single distinctive unit in a language is only meaningful when it is compared to other distinctive units in the same language. Consequently, the Prague School thought it meaningless to compare the same phoneme in two different languages (Trubetzkoy, 1939).

These ideas cut off the connection of the phoneme from the speaker and hearer and turned it into a unit with a life on its own that is not reliant on the speaker's or hearer's knowledge. But since phonemes can only be defined in relation to each other, we will have cases where only a single sound is possible and the result cannot be a true phoneme. As a direct consequence, the Prague School followers introduced the concept of an archiphoneme (Trubetzkoy, 1939), a sound that does not need to fulfil all of its conditions. A sound is made up of different features, and these features are in opposition or contrast to other features. If there is no contrast, there is no possible way to distinguish one sound from another. However, the complete version of this theory did not gain too much following because native speakers can correctly identify which sound is occurring.

During the late 1950s and early 1960s, the Generative revolution pushed out the prevailing structuralism from linguistics departments in Europe and America. It was 
developed by the last living member of the original Prague School, the Russian linguist Roman Osipovich Jakobson. Together with Morris Halle and Noam Chomsky (Chomsky \& Halle, 1968), they worked on a theoretical framework that would be the dominant force behind most modern phonological theory: Generative Phonology. This generative paradigm began with the concept that all the variations in the pronunciation of a morpheme can be elucidated by setting out a single underlying form and then explaining all subsequently appearing variation through phonological rules that consistently change the phonemes' features (ibid).

One very important contribution in this framework was to ignore the concept of phoneme (p.14):

We have avoided these terms, however, because of the technical meaning they have been given in various theories of sound structure developed in modern linguistics. The term "morphophonemic representation" seems to us appropriate only if there is another linguistically significant level of representation, intermediate in "abstractness" between lexical (phonological) and phonetic and meeting the conditions placed on "phonemic representation" in modern structural linguistics. We feel, however, that the existence of such a level has not been demonstrated and that there are strong reasons to doubt its existence." We will make no further mention of "phonemic analysis" or "phonemes" in this study and will also avoid terms such as "morphophonemic" which imply the existence of a phonemic level.

According to Chapman \& Routledge (2012), Generative phonology aims "to establish a set of principles, rules and constraints efficient to produce the surface phonetic forms of a language and to model the internalized linguistic knowledge of native speakers" ( $p$. 
77). During the 60s, it was the central thought behind any linguistic research, and even though in the following decades it underwent changes and reforms, it is still the dominant framework for research in phonological theory (Al-Hindawi \& Al-Adili, 2018).

At the end of that decade, David Stampe wrote his dissertation on Natural Phonology, which he then developed during the following decade (Stampe \& Donegan, 1979). His theory defines phonology as a set of universal phonological processes which interact with one another, against the idea of a phonological system that is built on a system of rules (p.132). Phonological acquisition is instead based on suppressing habits (p.130) by for example simplifying a cluster of consonants to facilitate pronunciation. Which processes are triggered are language-dependent and they act specifically on distinctive features within prosodic groups (either a complete utterance or a part of a syllable). These processes are unordered in relation to each other and can even apply simultaneously (p. 151). Another important aspect of classical generative phonology is that it forwent with the concept of the phoneme. Phonological strings could be defined as bundles of defining features.

As previously established, Generative Phonology was the most dominant theory behind phonological research in the last decades, but Natural Phonology offers less rigid and less formalized claims, that prove useful in areas of language research with unpredictability, like resolution of conflicts (Dressler, 1989). Additionally, in the aftermath of Chomsky and Halls' approach, several new theories emerged, all of them addressing different deficiencies found in Generative Phonology: Autosegmental, Metrical and Lexical Phonology (Goldsmith \& Pierrehumbert, 1993). In the beginning, all three approaches focused on different suprasegmental aspects of speech in different language groups, which complicated the coordination to find out how much they complemented each other, and how much they conflicted with each other (p. 357). 
The main tenet behind Autosegmental Phonology is that phonemes can be divided into smaller units, which can then be individually manipulated by phonological operations (Van de Weijer, 2006). This theory is focused on "how the various components of the articulatory apparatus, i.e. the tongue, the lips, the larynx, the velum, are coordinated" (Goldsmith, 1976, p. 23). It is a non-linear approach that grants autonomy to phonological processes (e.g. tone) and also allows them to extend beyond individual vowels or consonants.

Metrical Phonology was an attempt to capture a diverse group of aspects of rhythmic patterns in speech, thus focusing on stress or linguistic prominence (Cooper \& Eady, 1986). The distinguishing feature here is the importance of a unit is in relation to the other units in the same phrase. Metrical Phonology organizes segments into groups. These groups are then organized into syllables, the syllables are organized into metrical feet, the feet are organized into phonological words and finally, the resulting words are organized into larger units. These relationships between units are symbolized by metrical trees. "The new system allowed linguists to explain how two words echo one another by means of rhyme, assonance, consonance, and alliteration" (St. Clair, 2006, p.128).

Lexical Phonology is the last theory that emerged in the $80 \mathrm{~s}$ in the direct aftermath of Chomsky and Hall's phonological framework that tried to address some of its deficiencies. This theory focuses on organizing the interactions of morphological and phonological modules of grammar into the word building process (Booij, 2006). The Lexicon plays a vital part in this theory, as morphological and phonological rules are a part of it. Mohanan (1987, p.8) said:

At the heart of Lexical Phonology [...] is the idea that a subset of phonological rule application takes place in the lexicon, in tandem with the morphological operations, and another subset takes place postlexically. The output of phonological operations 
may undergo morphological operations, and may then undergo further phonological operations. Phonology and morphology, in other words, are inputs to each other.

In the 80s, Autosegmental Phonology inspired the rise of Government Phonology. It separated itself from the classical generative approaches by replacing the rule component with the definition of universal principles that are common to all linguistic systems. Additionally, it also added a series of parameters that delimit the nature of linguistic variation from one linguistic system to another (Cyran, 1997). In other words, Government Phonology wanted to provide an account for phonological phenomena through the replacement of the rule component of phonology. In its stead, it used a defined and limited set of universal principles and parameters, which was a split from the classical generative approaches (Honeybone, 1999, p. 179).

Government Phonology is an 'abstract' theory of phonology [...] in that it takes the object of the study to be abstract [...] there is no linguistically relevant level of phonetic representation.

Contrary to rule-based approaches, it is more of a theory of representations where phonological phenomena are regarded as arising directly from a series of principles and parameters and it is also highly confined in its view on phonological structure. Phonological oppositions are defined by univalent elements, each one of them with an independent phonetic interpretation (Cyran, 1995).

Optimality Theory, developed by Prince \& Smolensky (1993), is another refinement of Generative Grammar, perhaps the most important in the 90s. It changed morphophonological inquiry and gave an important push to the study of language learning (Boerma et al., 2000). However, it differentiates itself from other generative models in several ways, e.g. that universal constraints are changeable, while previous models assumed 
the inviolability of principles (Kager, 2011). The main shift it brought about in phonology was the change to an output-based model instead of a rule-based model. This model focused on the phenomenon called phonological conspiracies that refer to the various phonological rules that work together for the same phonological goal. Optimality theory was able to express the conspiracies (Boerma et al., 2000).

\subsection{Cognitive Phonology}

The problem with Cognitive Phonology (and the cognitive label in general) consists that it has been used with different underlying frameworks and assumptions. This can lead to a misnomer, where specific researchers (e.g. Paul Kaye) were labelled as cognitive scientists, despite using an approach to phonology that subscribes for example to the Universal Grammar approach. It is thus, non-cognitive in the cognitive linguistic sense.

One of the principles of Cognitive Grammar is the declaration that a unit of language is made of three structures: the semantic pole with its conceptual material, the phonological pole with its articulatory material and the symbolic structure as the relationship between the previous structures (Langacker, 2008). Cognitive linguists have centred their research on the semantic half of this structure, and phonology has been largely ignored.

One of the first to introduce research based on the study of sound through a cognitive lens was Paul Kaye. In his book, Phonology: A Cognitive View (1989), Kaye realized the importance of incorporating emerging technical advances into phonology in order to improve research. Especially in the last decades, but also in the late 1980s, linguistics has been influenced by research in diverse fields as Computer Science or Cognitive Psychology. One specific area that needs to be mentioned is the exponential increase in Artificial Intelligence (henceforth A.I.). These current technological advances are not included in Kaye's book, but he smartly included the increasing advances in A.I. in this 
textbook that served as an introduction to the issue of phonology paired with past concerns of this field and challenging the generative approach, that according to him was just not enough. Chomsky and Hall (1968) already discarded the phoneme concept and Kaye even proclaims the death of the phoneme, because "the idea of a phoneme as a segment, while intuitively satisfying, was getting questioned by its cognitive reality (p.148). While not going deeper into detail, Kaye was an early attempt at challenging traditional paradigms in phonology, although in the end, he did not become a major influence in mainstream phonological theory in regards to the question of the phoneme.

One of the fathers of A.I. is John McCarthy that coined the term in 1955 and organized one year later the now renowned Dartmouth Conference, which started A.I. as a field (Roberts, 2016). McCarthy defined the aim of A.I. as to develop machines that behave as if they were intelligent.

During decades, this definition proved not enough, because intellectual processes (Lakoff, 1989; Goldsmith, 1993) like memorizing and reciting on the spot very long texts or fast multiplication of long complicated numbers are most certainly signs of intelligence, but simple computers or calculators can do so and we do not associate A.I. with these devices. Some of the aims of human intelligence, in general, are to solve many difficult problems, adapt to complex situations and learn new strategies in the face of adversity (Ertel, 2016). So, how can these notions be reflected in an appropriate definition? It was not until Elaine Rich (1983), a (now retired) distinguished Senior Lecturer at the University of Texas, found an elegant definition that would concisely and tightly describe it: "Artificial Intelligence is the study of how to make computers do things which, at the moment, people do better" (p.3).

A subfield of A.I. is computational learning theory that devotes itself to the study of the design and the analysis of machine learning algorithms (Anthony \& Biggs, 1992). 
Advances in this field influenced how linguistic results can be obtained. Once it was limited to internal data that could be obtained by linguistic analyses of any given system. Now, thanks to the commonly increasing interdisciplinarity results can also be obtained by using specific computer programmes (Clark \& Lappin, 2012).

In 1993, Lakoff wrote Cognitive Phonology. He found out that while neural processes occur in real-time, it would be completely impossible that phonological derivations and all the steps in-between occur in real-time too. Lakoff defends the notion that phonology should be treated the same way as Cognitivism treats grammar: linguists can use construction-based analyses and use general cognitive mechanisms to get a cognitively realistic model that represents the links between phonetic and morphological sequences. Lakoff also supports that cognitive phonology has to be an integral part of Cognitive Grammar. However, Lakoff's work (and Cognitive Linguistics in general during that time) focused more on semantics and grammar. His output contains references to phonology, but these aspects had very little influence and were just an early attempt within cognitive linguistics (Mompeán González, 2006).

Another cognitive approach to phonology came in 2006, in the form of the article Towards a Usage-based Cognitive Phonology by Gitte Kristiansen (2006). She is a cognitive dialectologist interested in the depiction of social variation within the organization of a phoneme. According to her, sociolinguistic stereotypes have to be represented in an exemplar model and "a cognitive dialectology - including a cognitive phonology - may well serve not only to mediate between language and society but also to spell out in full the consequences of a truly multi-faceted approach to phonetic variation" (p.125). Following this thought, phonemes can carry content information related both to the speaker and to inferences made by the listener concerning the social status of the speaker. 
Unfortunately, Phonology is still mainly ignored by Cognitive Linguistics, but researchers like Mompeán (2014) are working hard to change that. He argues that one of the remaining challenges of Cognitive Linguistics is to expand some of the already sketched out ideas about how Phonology is as amenable to a cognitive treatment as any other linguistic area.

He asserts that Phonology operates on the same cognitive mechanisms (e.g. perception, categorization or conceptual combination) as other areas of study (p.382):

[...] language is the outcome of general properties of cognition, and that language is the outcome of the bodies humans have and how they interact with the sociophysical world [...] Cognitive Linguistics should take into account the general cognitive processes that shape and give rise to phonological units as well as the various factors - linguistic and language-independent- which motivate those units.

\subsection{Contrastive Phonology}

Contrastive Phonology is a subfield of Contrastive Linguistics, which itself is a part of Linguistics that compares two or more speech systems, in order to describe differences and similarities. Contrastive studies can work on those differences and similarities by focusing on some of the different levels of speech: Syntax, Phonology, Pragmatics, Morphology, etc. (Kruppa, 1985).

Contrastive studies have been used in linguistic analysis since the end of the $19^{\text {th }}$ century and can be divided into three clear phases. The first one is the American Structuralism phase that went from the 1920s and 1930s. The second one was during the 1960s and belongs to Chomsky and Halle's (1968) contribution to Linguistics: Generative 
Grammar. The latest phase starts in the 1970s and is characterized by the shift from an emphasis of grammatical competence to sociocultural competence that includes communicative competence (Sajavaara, 1981).

Learning a second language is arguably more arduous than the acquisition of L1 because any new language is learned under the shadow of L1 (Bylund, 2009). Contrastive Linguistics emerged over the past decades fully aimed at minimising the negative effects of L1 onto a second language. To achieve this, one has to point out the difficulties that speakers will encounter when trying to learn a specific language (Escudero \& Wanrooij, 2010).

The two most important concepts in contrastive linguistics are transfer and interference. Transfer is the term for the fact that L1 speakers are likely to transfer structures to L2. A priori, this is neither positive nor negative (Kubota, 1998). Languages with similar structure benefit from this transfer, e.g. German and English sharing the same isochrony or the phonemic distinction of vowel lengths. In cases like this, it is called positive transfer.

Negative transfer, which is also called interference, is a hindrance for language learning (Selinker, 1972) as it transfers some L1 structure that is not present in L2 and thus we produce ungrammatical speech. However, negative transfer is not the sole responsible for all types of error that occur while learning a new language, mainly because the risk of interference is greater when L1 and L2 are mostly or more similar in structure. Then, transfer is easier, because the one-to-one correspondence can be faster established between source and target (p.229).

Interference can be classified into several main types (Ioup, 1984):

a) Substitution: At any point during language acquisition, learners may use an L1 element for one which they do not possess, e.g. English L1 speakers will have trouble with 
L2 German, because of missing phonemes. The German word Buch [bu:x] would instead be pronounced [bu:k], substituting the unknown L2 phoneme [x] with the English [k].

b) Over- and under-differentiation: When a word is over-differentiated in one language, it is then subsequently under-differentiated in the other. When L1 has more than one verb, whereas L2 only uses one for the same reasons, then L1 is over-differentiated, while L2 is under-differentiated.

c) Over-indulgence and under-representation: This is a so-called scalar phenomena, where the structure used in L2 is not wrong, but not commonly used among L2 native speakers. Like the previous two types, these concepts are mirror-images of each other. Overindulgence on the part of one language leads to under-representation on the other. EFL learners, for example, may have a restricted range of words and synonyms and thus use way too many times the word think instead of using synonyms such as reflect on, consider, etc.

d) Overgeneralization: the misapplication of a productive process in L2 means that while learning English you see for example the morpheme -er and realize it is used for jobs, and you add it to the word cook, creating the wrong word cooker for cook.

\subsection{Phonetics}

The difference between Phonology and Phonetics lies in that Phonology focuses on what languages do with sounds while Phonetics is interested in human speech sounds themselves. Phonology researches how languages select one sound over another, how sounds can form larger units, and how the sounds fit into the environments. Phonetics on the other hand is considered an inventory of possibilities defined by the human perceptual system or the human vocal apparatus (Meyer and Schiller, 2003). Nathan (2008) encapsulates it 
accurately: "Phonetics and phonology interact, with phonetics being the study of the raw materials used to create language, and phonology being the design principles that languages use to take those raw materials and build words out of them". (p. 2)

Describing speech is the main concern of phonetics. The reasons behind it are varied: some are interested in pathological speech; some are interested in improving computers in order to facilitate speech recognition. Others want to classify the different sounds that occur in languages. The reasons are various, but for all intents, phoneticians need to describe the sounds of speech and they also require finding out what people are exactly doing when they are talking (Ladefoged \& Johnson, 2011).

Sound can be defined as pressure oscillation occurring very rapidly one after another (Filippi, 1998). These fluctuations move through a medium (e.g. gas, water or air) that is elastic enough to allow molecules to crowd together and move apart. In human physiology, some of the sounds are called speech. The fluctuations here are caused by the actions (e.g. vibrations) of the vocal organs against the outgoing amount of lung air. Figure 1 is a visual representation of the mouth and the mentioned structures involved in sound production. 


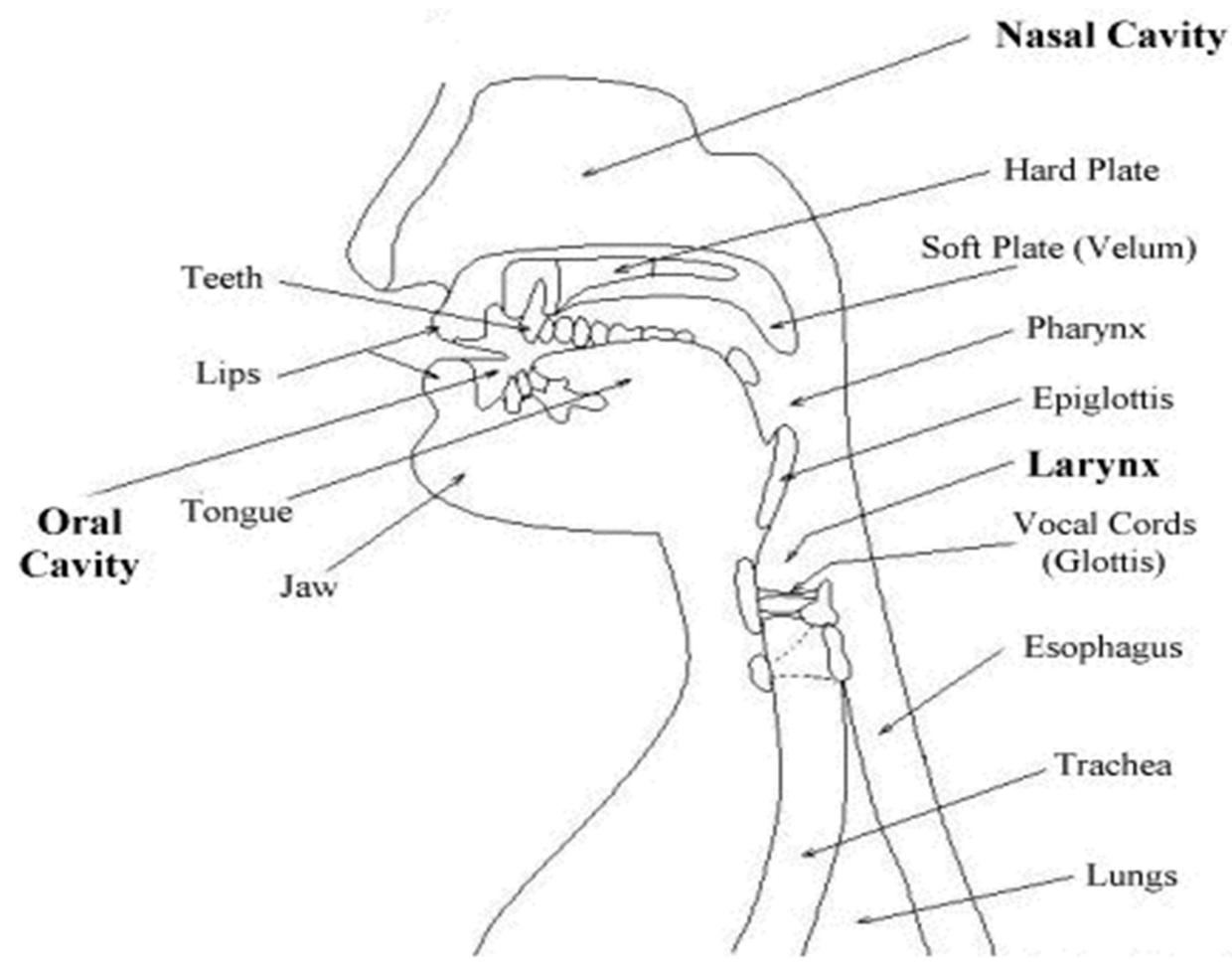

Figure 1: Speech Mechanism. (http://www.personal.rdg.ac.uk/)

\subsection{Segmental and Suprasegmental Features}

Since this research is centred on vowels, this section will skip here features not relevant to the work and concentrate mainly on characteristics needed for a better understanding of the variables that were used on this research, namely isochrony and vowel phonemes. Every phonological system is divided into two components: segmental and suprasegmental (Anderson et al., 1985).

The Segmental component deals with phonemes, a perceptually distinct unit of sound in any language that distinguishes one word from another (Ladefoged \& Johnson, 2011). All the phonemes of any language can be divided into two basic types: consonants and vowels. Speech is mostly a result of tongue, jaw and lips movement, and these gestures are 
responsible for producing particular sounds with which we convey information from one person to another. Vowels and consonants are segments because they are the result of a segmentation process that slices speech into discrete phonetic units (p. 23-24).

Audible speech gestures involve pushing air out of the lungs whilst we produce noise in the mouth or throat (Odden, 2005). Sound production requires energy and in most sounds that basic energy derives from air getting pushed out of the lungs. While talking, air leaves the lungs, rises up the trachea towards the larynx. At that moment it must cross two muscular folds, which are called the vocal cords and they are situated within the larynx. If the vocal cords form a narrow passage, the airstream passing them will make them vibrate. Howbeit, if the vocal cords are apart, the airstream will pass smoothly towards the pharynx and the mouth (McKinney, 2005).

A theory that describes this process is the myoelastic-aerodynamic theory of phonation (Van den Berg, 1958). Vocal Cords come together and breath pressure is applied upon them. They remain closed until the subglottic pressure is high enough to push them open again, thus allowing air to escape and to reduce the pressure just enough so that the muscle tension recoil can reunite the folds. Once apart, the pressure starts building again and the whole cycle repeats itself. The amount of times at which the cords repeat the process of opening and closing (number of cycles per second) decides the pitch (McKinney, 2005).

Every sound that is produced with vibrating vocal cords is called voiced, contrasted with sounds that pass effortlessly through vocal cords that are apart, which are called voiceless. This distinction is very important to distinguish sounds since the voiced/voiceless pair $k / g$ helps us separate words like kill or gill. Voiceless sounds can also be produced with complete abduction of the vocal folds (as in glottal stops) (Ladefoged \& Johnson, 2011, p. $61)$. 
The sound $[p, t, k]$ are not the only voiceless stops that occur in English. Many people also pronounce a glottal stop in some words. A glottal stop is the sound (or, to be more exact, the lack of sound) that occurs when the vocal folds are held tightly together.

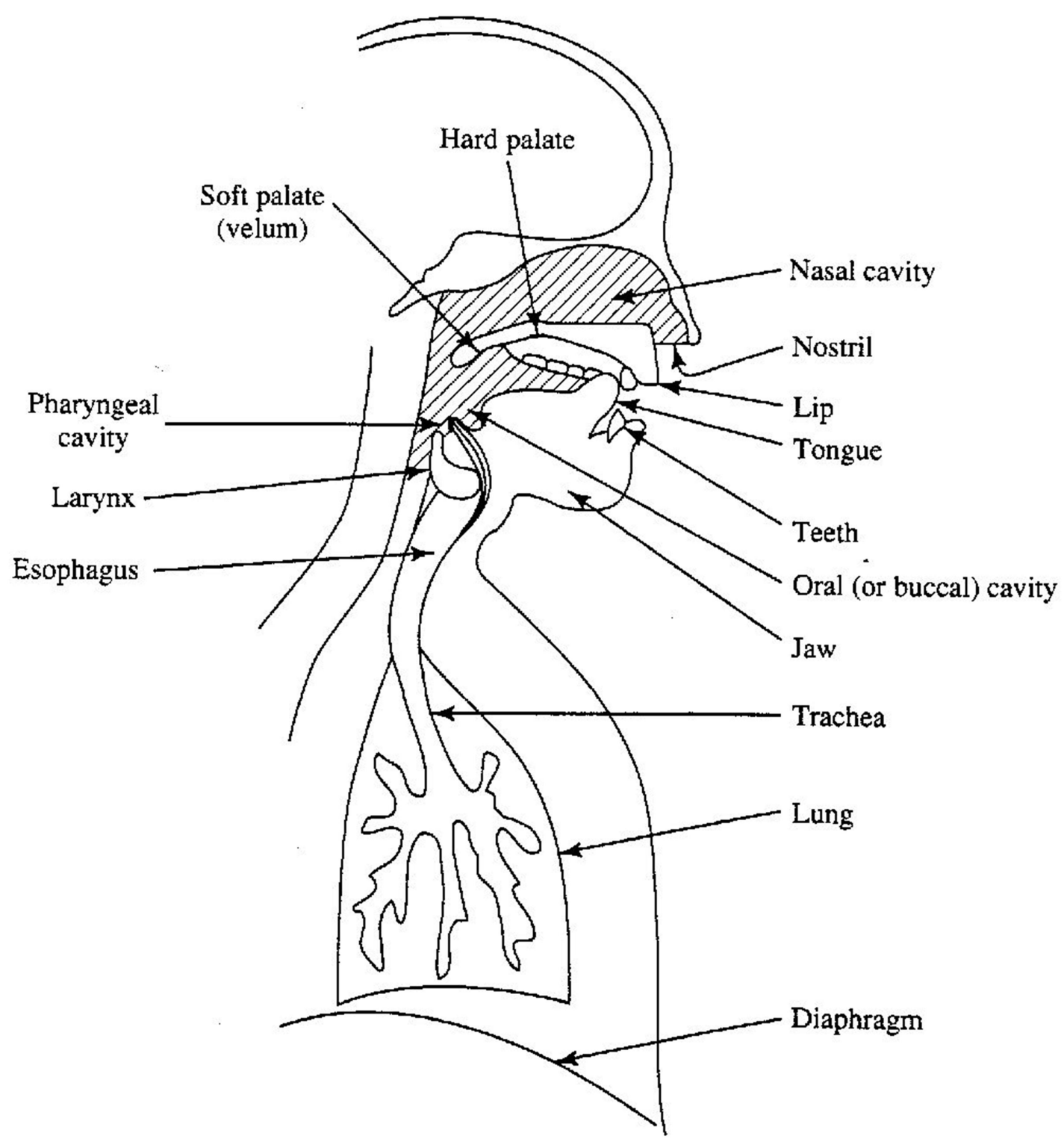

Figure 2: Speech Mechanism and Air Track. (http://www.personal.rdg.ac.uk/) 
In figure 2, we can see that the larynx in the vocal tract, which consists of the oral tract that includes the mouth and pharynx and the nasal tract within the nose. The velum at the back of the oral tract controls the airflow through the nose. Soft palate (velum) contacts posterior pharyngeal wall to transmit air pressure and sound energy into the oral cavity for oral consonant and vowel productions. If the velumpharyngeal port is open (the area bounded by the soft palate, the posterior pharyngeal wall and the lateral pharyngeal walls), air enters and leaves through the nose and speech sounds like [m] or [n] can be produced (Andreassen et al., 1991). It is worth adding that the vocal cords are vibrating too at the same time, but some languages like Burmese also have voiceless nasal sounds (Bhaskararao \& Ladefoged, 1991). Every part of the vocal tract that participates in the formation of sounds is an articulator. However, for vowel research, it is easier to describe sounds through acoustic structures than through articulatory movement.

As vowels do not have a significant obstruction in the oral tract, they have less of a point of articulation as consonants do, but some approximation of articulators can be identified and thus it is possible to classify them (Catford, 1988). The classification of vowels is generally troublesome since the unending and critical amount of variation in natural speech is hard to generalize across multiple speakers, accents and dialects (Virginia Reid, 2016). One of the most common frameworks used (even by the IPA) to describe vowels is the cross-cutting dimension of using several variables referring to height, frontness and roundedness. It is possible to describe vowel sounds with the position of the highest tongue point and the position of the lips. Unfortunately, this framework is inaccurate: early phoneticians mistakenly described what they believed was the highest point of the tongue... whereas they were describing formant frequencies (Ladefoged \& Disner, 2012), a concept that is analysed in Chapter 3. Yet, despite being accepted by the IPA that "the vowel quadrilateral must be regarded as an abstraction and not a direct mapping of tongue position" 
(IPA, 1999), this erroneous concept is still used (especially for pedagogic purposes) since it describes intuitively how vowels can be distinguished.

It is important to explain cardinal vowels at this point. They are a group of reference vowels that are used by phoneticians concerning the description of sounds in languages (Ashby, 2011). They are not meant to represent any specific vowel in a specific language; they are but a measuring system (p.85). Instead, the vowel sound produced in any language is described in concordance with the closest cardinal vowel, despite the fact, that some languages have indeed vowels that are very close to the cardinal vowels (Ladefoged, 1971)

Vowel height defines the vertical position of the tongue in relation to the palate. In reality, it refers to the first formant (henceforth F1), the lowest resonance of the voice, which is linked to tongue height (Figure 2). IPA recognizes seven degrees of vowel height (Pulleyblank, 2011):

- Close/high

- Near-close/near-high

- Close-mid/high-mid

- $\quad \mathrm{Mid} /$ true-mid

- Open-mid/low-mid

- Near-open/near-low

- Open/low 


\section{VOWELS}

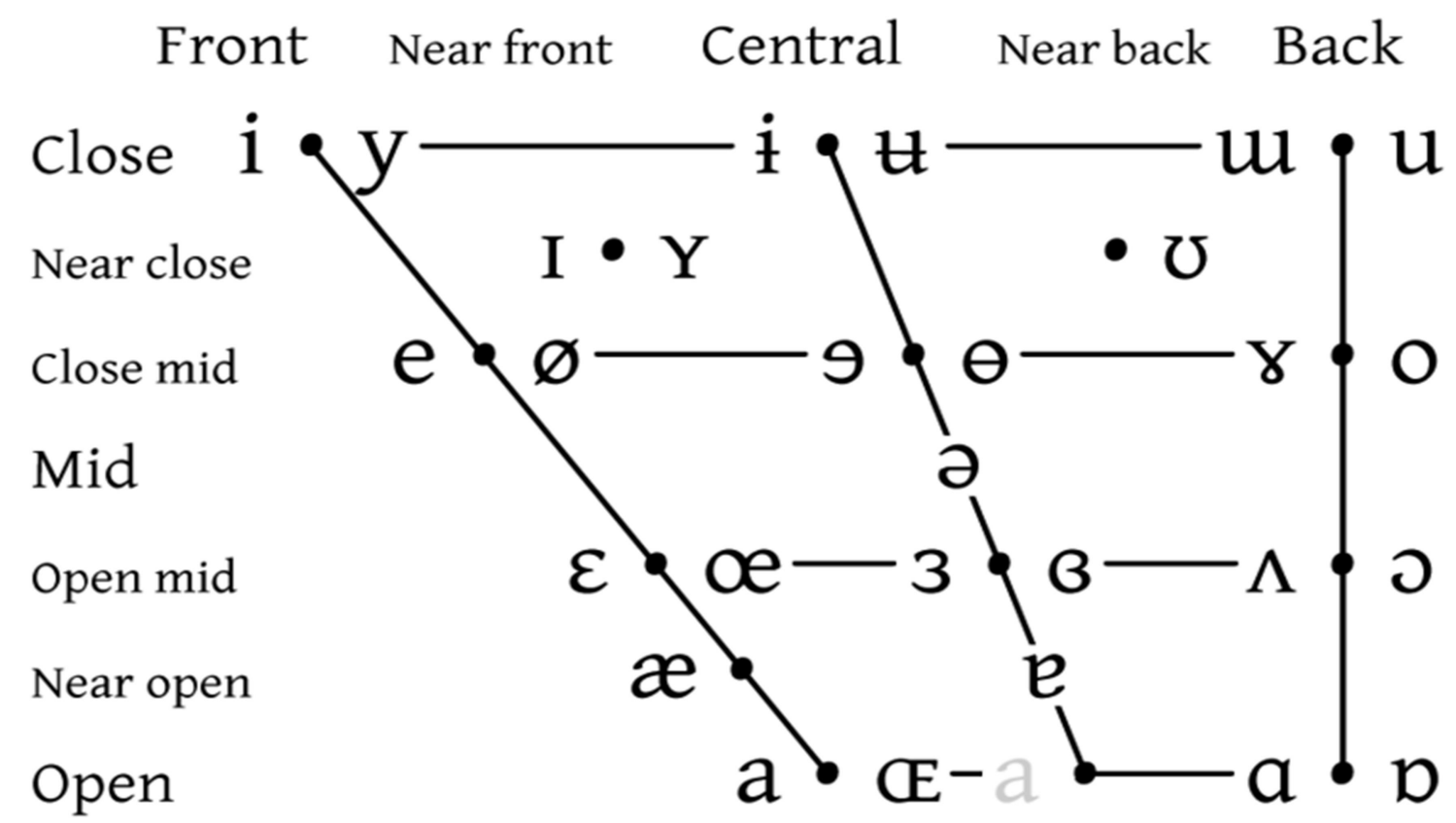

Vowels at right \& left of bullets are rounded \& unrounded.

Figure 3: IPA vowel chart. Reprinted from https://www.internationalphoneticassociation.org/

Close vowels have the tongue high in the oral tract, which means that F1 has the tongue close to the palate. On the other hand, open vowels find the tongue in the lower parts of the mouth and F1 is coherent with an open jaw. Every single spoken language that has been researched up until now uses height as a contrastive feature, although not a single language uses more than four of the seven degrees of tongue height (ibid).

Vowel frontness refers to the position of the tongue in relation to the back of the mouth. Similar to vowel height, it refers to the second formant (henceforth F2), which is linked to the position of the tongue. The IPA recognizes five degrees of vowel frontness (ibid):

- Front

- Near-front

- Central 
- Near-back

- Back

Front vowels find the tongue forward in the mouth and accordingly, have a higher frequency F2. Opposite to that, back vowels are closer to the back of the mouth and have a lower frequency F2 as a consequence. Phonemes that have a small difference between F1 and F2 are closer to the lower back of the mouth, while a big difference between F1 and F2 a high front vowel defines (ibid).

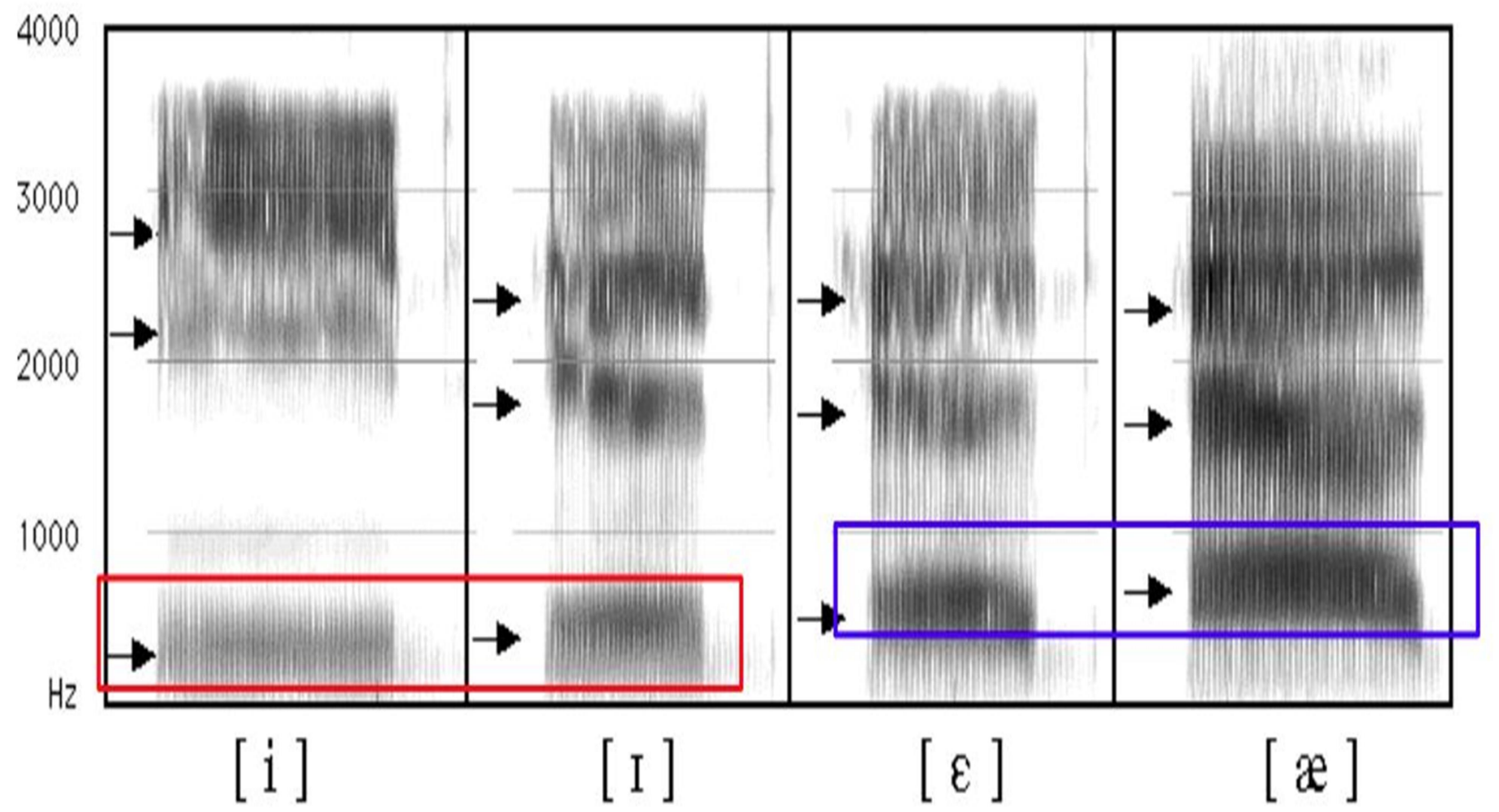

Figure 4: Examples of Vowels for F1. Reprinted from u.arizona.edu

In figure 3 is an example of front vowels. Highlighted in red and blue is the first formant. Vowel height is inversely related to the first formant. The lower the vowel, the higher the first formant. [i] is produced higher than [æ] and thus the former first formant is lower than the latter first formant. 


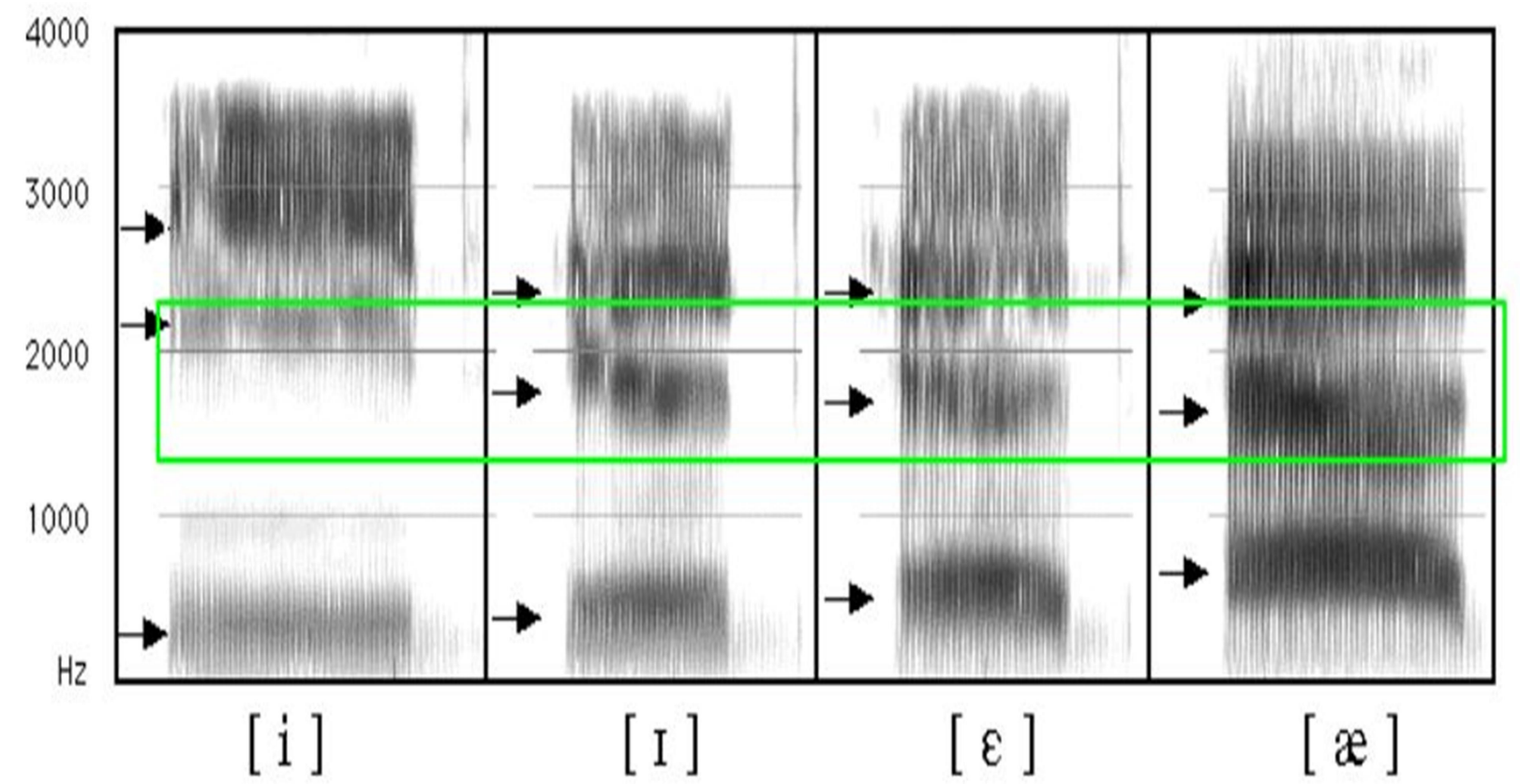

Figure 5: Examples of Front Vowels for F2. Reprinted from u.arizona.edu

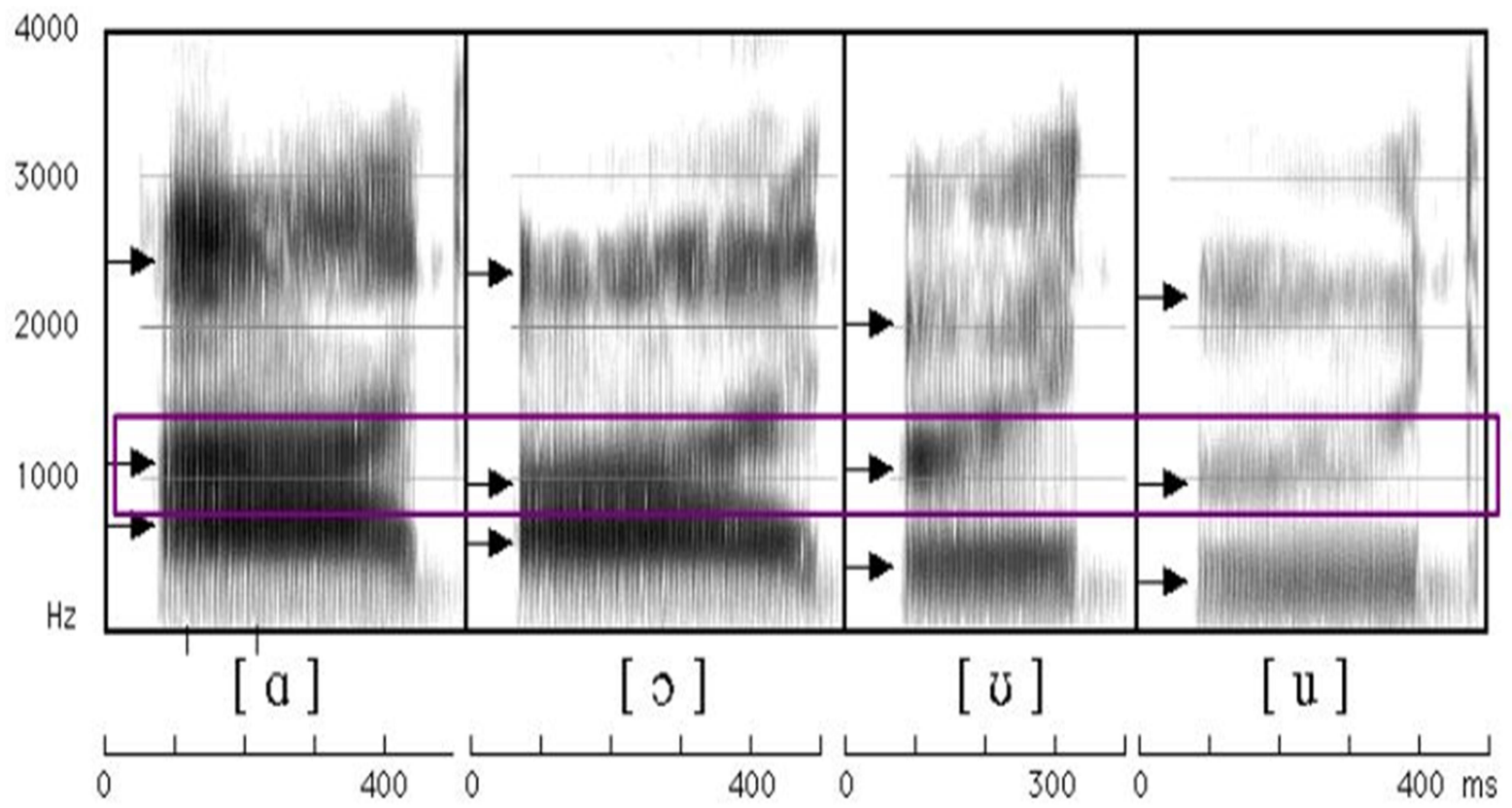

Figure 6: Examples of Back Vowels for F2. Reprinted from u.arizona.edu

In figure 4 we see F2 highlighted in green, while in figure 5 F2 is highlighted with purple. $\mathrm{F} 2$ is to some extent related to the frontness. A higher second formant means a more fronted vowel. However, a better way to predict the frontness of vowels is the distance between F1 and F2. The farther away both formants are, the more fronted the vowel is. 
Roundedness refers to how much rounding of the lips is involved while articulating a vowel. Lips form a circular position when you pronounce a rounded vowel, whilst unrounded vowels are pronounced with relaxed lips. This roundedness is often related to the third formant, F3. For the most part, the lower the frequency of F3, the more round the vowel is. The majority of languages have rounded back and unrounded front vowels. Nonetheless, languages like German or French have rounded and unrounded front vowels of the same height (Robins, 2014). Figure 6 is the IPA vowel chart for German. In every pairing, the right one is rounded, while the one on the left is unrounded. One of those German vowel pairings would be /ع/ and /œ/ (Glück, 2005). Both sounds appear in German words like kennen ['k عnən] (to know) and können ['kœnən] (can do).

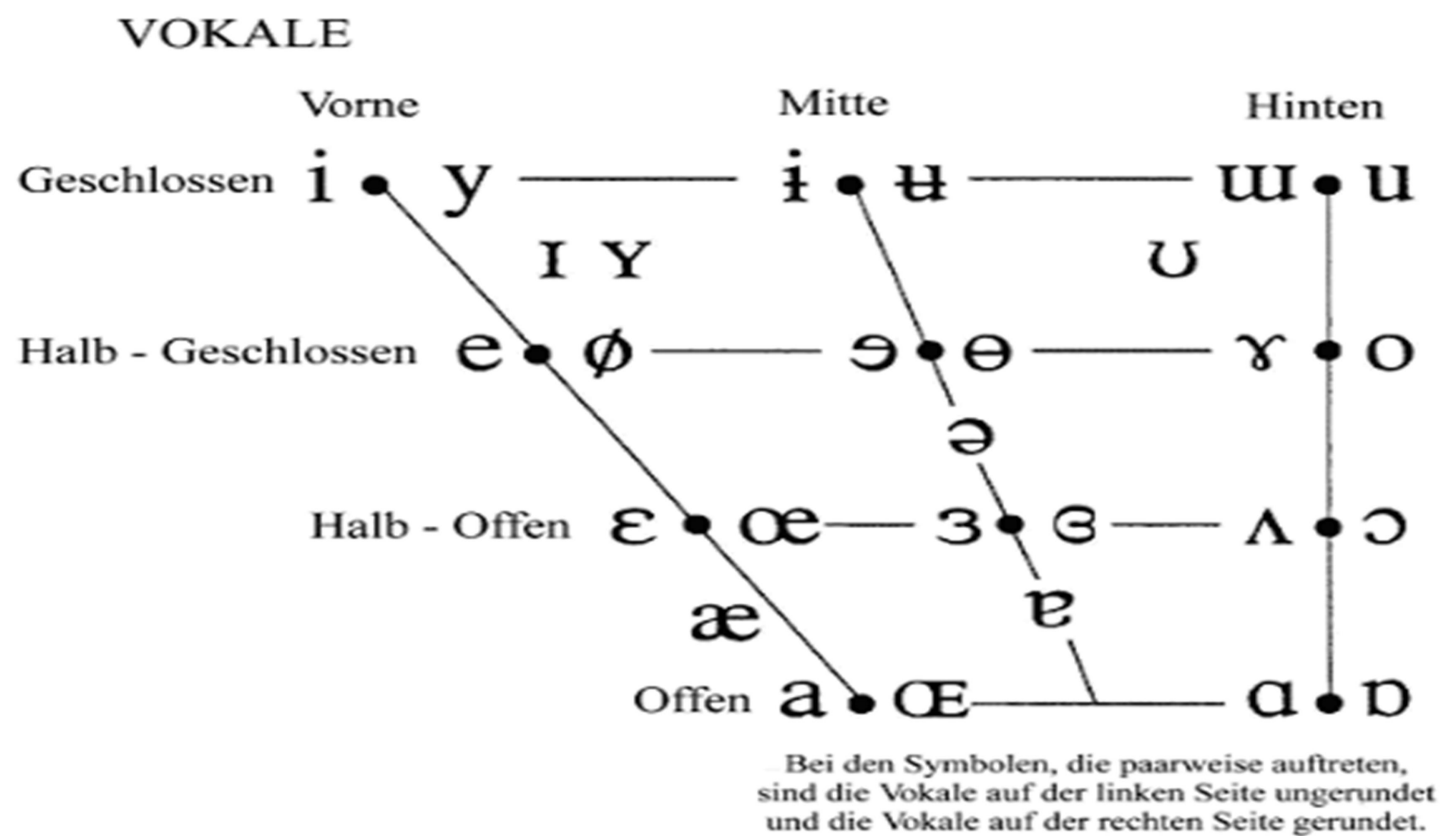

Figure 7: German Vowel Chart. Reprinted from ling.upenn.edu/courses/german428/

A nasalized vowel refers to the sound that is produced when the velum is lowered and air escapes through the nose and mouth at the same time, whereas oral vowels are realized without nasalization. Due to the process of assimilation, vowels near nasal consonants tend to be produced with either a partially or fully lowered velum, and are thus 
technically nasal (Ohala, 1990). This happens in English but there is no phonemic distinction between nasal and oral vowels in this language (Beddor, 1983). In French, however, nasalization in vowels is contrastive. Let us take a look at the minimal pair bon and bonne.

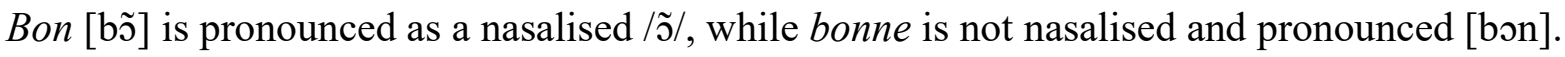

Tenseness is another distinction, typically used in phonology. It refers to the pronunciation of a sound with higher muscular effort or constriction. The key differentiation is the duration between tense and lax vowels. Tense vowels are produced with a greater muscular effort, with a slightly higher tongue position and with longer duration than lax vowels. According to Jakobson, Fant and Halle (1952, p. 38):

In contradistinction to the lax phonemes, the corresponding tense phonemes display a longer sound interval and a larger energy [...] In a tense vowel the sum of the deviation of its formants from the neutral position is greater than that of the corresponding lax vowel (p.36). Tense phonemes are articulated with greater distinctiveness and pressure than the corresponding lax phonemes. The muscular strain affects the tongue, the walls of the vocal tract and the glottis. The higher tension is associated with greater deformation of the entire vocal tract from its neutral position. This is in agreement with the fact that tense phonemes have a longer duration than their lax counterparts.

So far this chapter has focused on the segmental component that deals with phonemes (vowels and consonants). As previously mentioned, phonemes are some sort of abstraction and the specific realizations of these phonemes are allophones: contextually-conditioned variants of a phoneme (Ladefoged \& Johnson, 2011, p.46). An example of this would be the length in vowels. Long vowels are relatively short 
when they are followed by a voiceless obstruent (e.g. seat [si:t]), but they are longer when they are followed by sonorants (e.g. seed [si:d]) or a pause (e.g. see [si:]).

These phonemes form the segments of which speech is composed. Subsequently, uniting these phonemes form a new unit: syllables. These syllables have different features that are known as suprasegmentals. Stress, intonation, and rhythm are the most important suprasegmental linguistic features. Vocal cords vibrating faster or slower change the pitch of a sound (p.21-24). Vocal cords vibrating with higher amplitude of sound pressure wave increases loudness (p.7).

Stress is the emphasis speakers give to certain syllables in a word or longer stretches of speech. English and Spanish are variable stress languages, while French is a fixed stress language (p.23).

However, stress is not relevant to the variables in this research, but rhythm is (p.116118). It is also called isochrony and defined as the sense of movement in speech, and it is marked by stress, timing and the number of syllables. It is language dividing time into rhythmically equal portions. There are three types of language rhythms in the world (Abercrombie, 1966).

1. Stress-timed, where the interval between two stressed syllables is equal

2. Syllable-timed, where the duration of every syllable is equal

3. Mora ${ }^{1}$-timed, where the duration of every mora is equal

Up until recently, linguists assumed there were three ways in which language can divide time, however, current research argues that the difference between syllable-timed and mora-timed is neglectable, and subsequently, there are only two rhythms, namely stress-timed

\footnotetext{
${ }^{1}$ a unit in phonology that determines syllable weight, which in some languages determines stress or timing
} 
and syllable-timed (Nespor, Shukla \& Mehler, 2010). For this research, it is ultimately irrelevant since no mora-timed languages are used for this research. Only stress-timed and syllable-timed languages are distinguished for the purposes of this research.

The first rhythm is stress-timed (languages like English, German, Portuguese, Arabic or Russian) where some syllables (henceforth written as $\sigma s$ ) are longer and louder than others. Stressed $\sigma$ s tend to occur at regular intervals which give stress-timed rhythm a galloping effect, where speech sounds jerky and uneven (Odden, 2005, p.23).

Syllable-timed languages (like Spanish, French or Cantonese) have rhythms, where os last about the same and are relatively loud. These os occur normally at regular intervals. This rhythm produces a staccato, a typewriter machine effect (p.33).

There are also mora-timed languages (like Korean or Japanese). They have regular rhythms but are nevertheless its own categories. Mora is a phonological unit that defines syllable weight, which then determines in some languages stress or timing. Although some definitions vary, it is mainly defined as "something of which a long syllable consists of two and a short syllable consists of one" (McCawley, 1968). Languages as Japanese have regular pacing but are mora-timed instead of syllable-timed. A vowel syllable or a consonant and vowel syllable takes up one unit of time. Since Japanese does not have vowel length or diphthongs, but instead uses double vowels, a consonant and double vowel syllable take twice as much time as a consonant and vowel syllable (Labrune, 2012).

The variation in pitch pattern is the intonation. It is a universal feature since all languages use it. In English, the same sentence and the same pattern of stress can be repeated with several different melodies, and those melodies give it different expressive forms, indicating a range of attitudes and emotions (Pierrehumbert, 1980). 
Clipping is a phonetic process that shortens the utterance of a phoneme. In most cases, clipping shortens the length of a vowel phoneme. A vowel that has been affected by this process is called a clipped vowel and their pronunciation is faster and reduced compared to an unclipped vowel (Wells, 1990).

This process can occur in many languages but English has two types of clipping: pre-fortis and rhythmic clipping. Clipping is a synonym for shortening. Thus it means that when a stressed syllable is followed by a voiceless consonant within the same syllable, prefortis clipping considerably reduces the length of that stressed syllable. An example would be the word pair leave and leaf. The former has a long vowel followed by a voiced consonant /li:v/, while the latter is followed by a voiceless consonant and as a consequence, the vowel preceding it gets reduced /li:f/ (Brunori, 2016).

\subsection{Language and its origins}

About eight million years ago, ape-like creatures had a limited vocal communication system that consisted of twenty or thirty calls, similar to the chimpanzees. They were a very early hominin genus and they are the last common ancestor that humans and chimpanzees share. This early ancestor (the technical name is Ardipithecus) had the precondition that is necessary for vocalized human speech: a larynx that relocates to the place between lungs and pharynx in the first two years of life (White et al., 2009).

The origin of language was first described through theology. Adam's first task given by God was to name all the animals. Even the language variety was explained as punishment for human arrogance through the tale of the Tower of Babel (Oaks, 2015). Sooner or later, a 
religious explanation would not suffice and secular explanation was sought. This need for a laic interpretation would not arise until the eighteenth-century, but it was analysed through a Romantic prism that led philosophers like Jean-Jacques Rousseau to the feeble conclusion that language did not emerge as an evolutionary need in order to communicate thoughts for various purposes. He relegated language to mere passionate reasons: it emerged to woo and conquer females with passionate rhetoric (Rousseau, 1781).

Nowadays, we know that language and its functions (e.g. vocabulary, grammar, syntax, etc.) are lateralized in the left hemisphere of the brain for right-handed persons (and right hemisphere for left-handers), while feelings like passion are lateralized in the right hemisphere (vice versa for left-handers) (Ocklenburg et al., 2018), contradicting thus Rousseau's contribution. In fact, his and other contributions never reached a consensus and their data was rejected by the then linguistic society. In 1866, the Linguistic Society of Paris therefore included in its statutes the total ban of papers and research concerning the origin of language (Mohammad \& Mohammad, 2012).

A full century later, the majority of linguists still believed that inquiring about the origin of language is indubitably futile, because of its high speculative nature. American linguist Noam Chomsky became the dominant force behind the theory of grammar in the 1960s (Chomsky \& Halle, 1968). While he and his followers in the following decades researched individual languages by referencing a Universal Grammar, the majority of them neglected the study of language evolution. Chomsky himself actively discouraged researching further into our innate biological endowment that allows humans to acquire efficiently and rapidly a language in our first year of life. Chomsky $(1988$, p.12) insisted that it is a matter of interest for evolutionary biologists: 
I doubt very much that it makes any sense to speak of a person as learning a language. Rather, a language grows in the mind/brain. Acquiring a language is less something that a child does than something that happens to the child, like growing arms rather than wings, or undergoing puberty at a certain stage of maturation.

\subsection{Background information on Languages and EFL Learning}

Following the example of Kenworthy (1987) and his review of possible problems following a contrastive analysis of the systems in various languages, this thesis deals with EFL learners from Spain, France, Germany and Russia, with a focus on vowel phonemes, it is necessary to lay out the vowel systems of the respective languages and the attitude or history towards EFL in those countries.

\subsubsection{The Spanish Vowel System and EFL in Spain}

Spanish belongs to the Romance Languages, the subgroup of Italic languages from the Indo-European language family. Spanish is the official language in 20 countries including Spain and the Americas (Peru, Bolivia, Colombia, etc.) It is one of the big global languages in the world (only second to Mandarin), with roughly 480 million native speakers and 75 million L2 speakers. It is one of the six official languages of the United Nations and the official language in many international organizations (e.g. the Union of South American Nations). It is the third most used language on the Internet after English and Mandarin; however it is not very relevant in scientific writing, the exception being articles on humanities studies (Guisán, 2014). Castilian Spanish (Martínez-Celdrán et al., 2003) is the 
language variety used for this research. Henceforth it will just be called Spanish, for the sake of convenience.

As opposed to English, the orthography in Spanish is quite similar to the sounds it represents. The 5 Spanish vowels have 5 phonemes /a, i, e, o, u/. Table 1 and figure 8 show us this vowel system and the distribution of the phonemes within the mouth.

Table 1: Spanish Vowel System

\begin{tabular}{|c|c|c|c|}
\hline & Front & Central & Back \\
\hline Close & i & & $\mathrm{u}$ \\
\hline Mid & e & & o \\
\hline Open & & a & \\
\hline
\end{tabular}

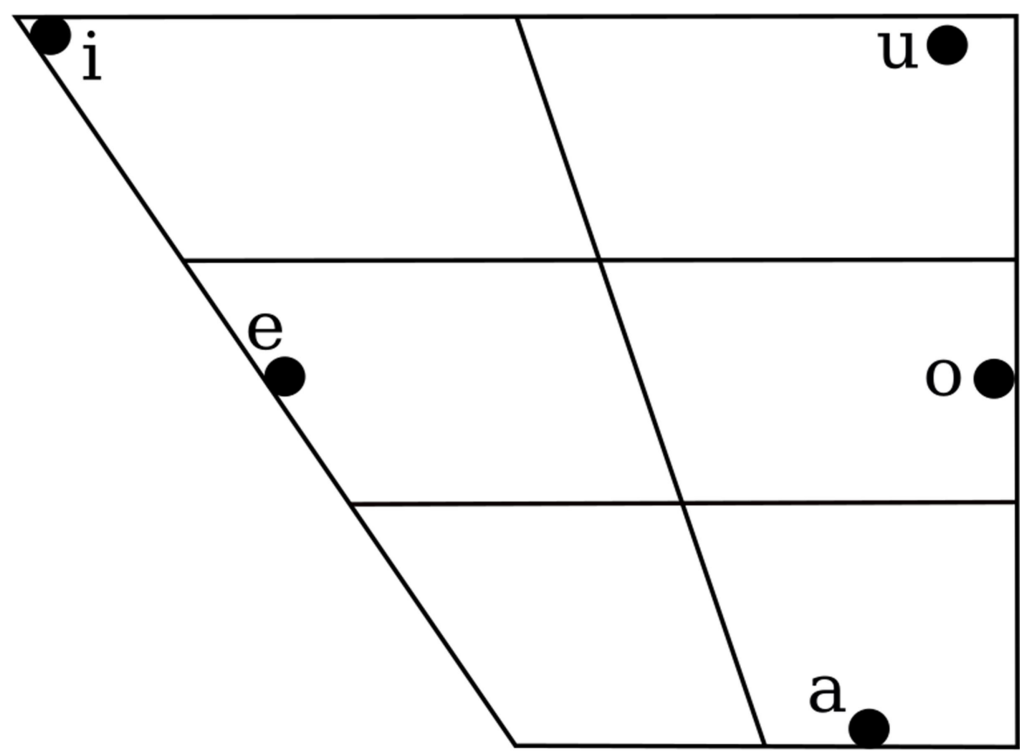

Figure 8: Spanish Vowel Chart (Source: Ladefoged \& Johnson, 2010)

Comparing both vowel systems, one can predict a few differences and problems. The first apparent difference is the scarcity in pure vowels in the Spanish language when 
compared to English. Moreover the 5 Spanish vowels do not coincide exactly with any of the English ones (admittedly the differences in some case are minuscule), which means that Spanish speakers do not make the right shape with the mouth. Having 5 Spanish vowels for 12 English vowels means that there is assimilation (e.g. the word heat [hi:t] becomes [hit]), Another example is the Spanish /u/ that is produced with the tongue at the back, while English / / / is more open and central (e.g. the word good [god] becomes [gud]. Figure 9 shows the assimilation process of Spanish EFL speakers. And finally we can observe that Spanish does not have central vowels.

English Phoneme Spanish Mispronunciation

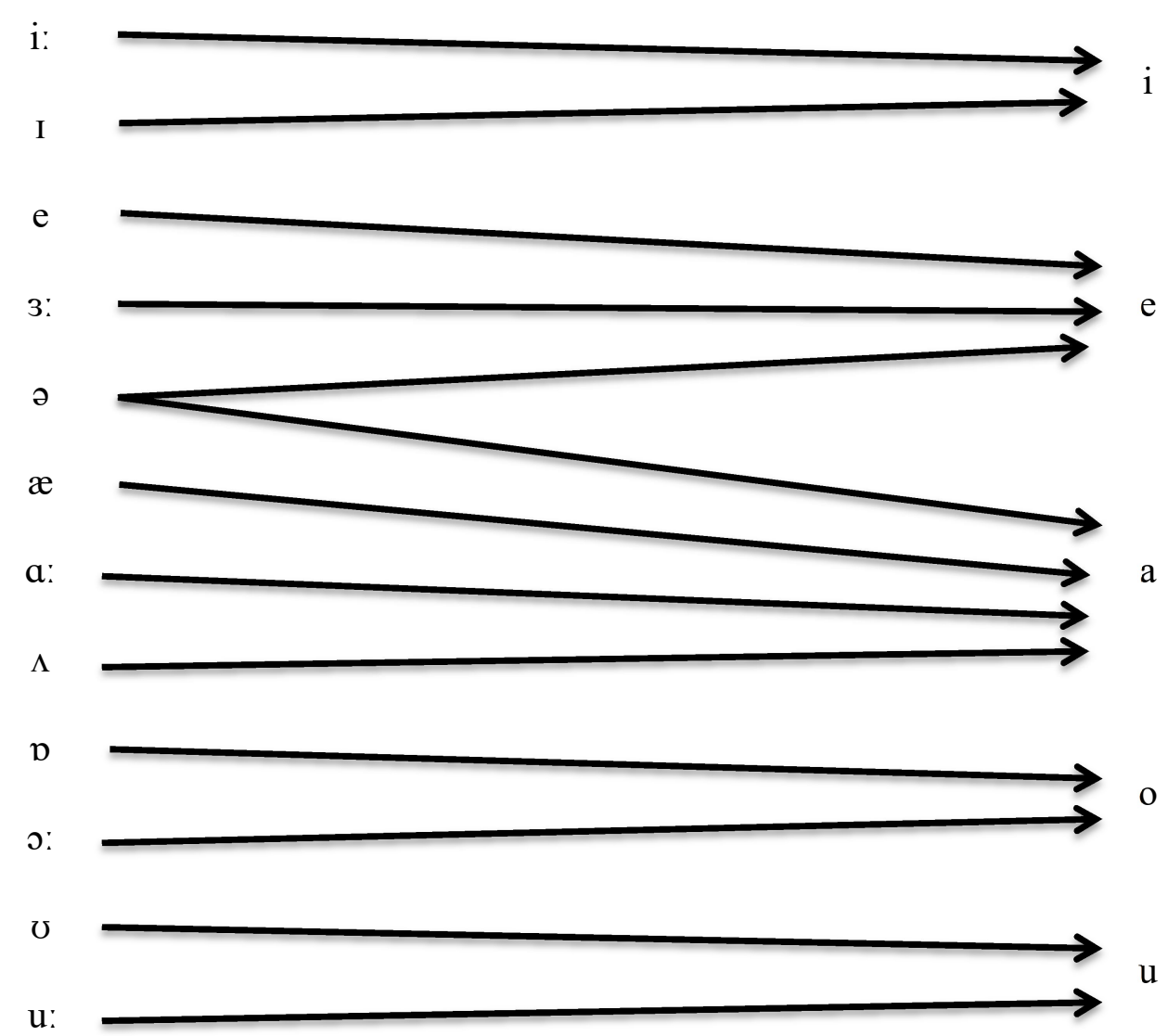

Figure 9: The English Vowel System and its Possible Misinterpretation by a Spanish EFL Speaker (Source: Ortiz \& Lira, 1982) 
Spain and EFL's first contact harkens back to the Middle Ages (a few contacts between scholars but mainly traders), but it was not until the $18^{\text {th }}$ century, when Charles III of Spain started his Europe-friendly policies which included English for the first time in school curriculum (Martín-Gamero, 1961). The Spanish War of Independence and especially its aftermath caused many Spaniards to migrate to England until the amnesty treaty in 1823 and their return marked an increase in the use of English in Spain (Fernández-García, 1972).

During that century, the first English academies started to sprout throughout Madrid, and books on grammar and English teaching were readily available. However, one has to bear in mind that illiteracy was rampant (up until far into the $20^{\text {th }}$ century) and that only the socialite's children were able to learn English. The rest of the population even struggled to properly learn how to write and read Spanish (Gómez-Capuz, 1993).

This status quo did not change until the end of the Second World War, where the rise of English worldwide also manifested itself in Spain. In 1953, the Francoist regime started to open up Spain to the rest of the world again and started signing treaties with other countries and in 1955, Spain became a full-fledged member of the United Nations (De la Cierva, 1978). Some Spanish linguists were fuming with the rise of English, and warned vehemently against its use to the detriment of the Spanish language (England \& Caramés, 1978).

Despite some educational reforms in 1970, at the end of the decade French was still the most studied language at school, although English was slowly gaining traction (PalaciosMartinez, 1994). In the 1990s, another educational reform, had students start to learn English in primary schools at the age of 8 (Rodríguez Medina, 2003). 
However, Spain is not considered to be one of the most proficient EFL countries. In fact, in the EF EPI of 2018, it just managed an unsatisfactory position at 32, just between Lebanon and South Korea, in the average proficiency tier (EF, 2019).

\subsubsection{The French Vowel System and EFL in France}

French too belongs to the Romance Languages, a subgroup of Italic languages from the Indo-European language family. French is the official language in 29 countries from different continents (e.g. France, Seychelles, Haiti, Monaco, Togo etc.) It is one of the major languages in the world, with roughly 300 million people worldwide using it. Thereof 76 million are native speakers and around 235 million fluent speakers. It is the fourth most widely used mother tongue in the European Union. French is also usually the primary or secondary language of international organizations (e.g. International Committee of the Red Cross) and after English and Mandarin it is the third most useful language for business (Lauerman, 2011).

The French vowel system (Standard Parisian French) has up to 13 oral vowels and up to 4 nasal vowels. Some particularities include that Parisian French has less oral and nasal vowels and that some French dialects do not contrast all of these vowels. For the purposes of this research we acknowledge these particularities but they are in no way a deal breaker (Lodge, 2004). Table 2 and 3 and figure 10 show us this vowel system and the distribution of the phonemes within the mouth. 
Table 2: French Oral Vowel System

\begin{tabular}{|c|c|c|c|c|}
\hline \multirow{2}{*}{} & \multicolumn{2}{|c|}{ Front } & \multirow{2}{*}{ Central } & Back \\
\cline { 2 - 3 } & unrounded & Rounded & & \\
\hline Close & $\mathrm{i}$ & $\mathrm{y}$ & & $\mathrm{u}$ \\
\hline Close-mid & $\mathrm{e}$ & $\varnothing$ & $($ ) & $\mathrm{o}$ \\
\hline Open-mid & $\varepsilon /(\varepsilon:)$ & $\propto$ & & 0 \\
\hline Open & $\mathrm{a}$ & & & $(\mathrm{a})^{2}$ \\
\hline
\end{tabular}

Table 3: French Nasal Vowel System

\begin{tabular}{|c|c|c|c|}
\hline \multirow{2}{*}{} & \multicolumn{2}{|c|}{ Front } & \multirow{2}{*}{ Back } \\
\cline { 2 - 4 } & unrounded & rounded & \\
\hline Mid & $\tilde{\varepsilon}$ & $(\tilde{\propto})$ & $\tilde{\jmath}$ \\
\hline Open & & & $\tilde{a}$ \\
\hline
\end{tabular}

\footnotetext{
${ }^{2}$ Parisian French does not have the vowels in parenthesis
} 


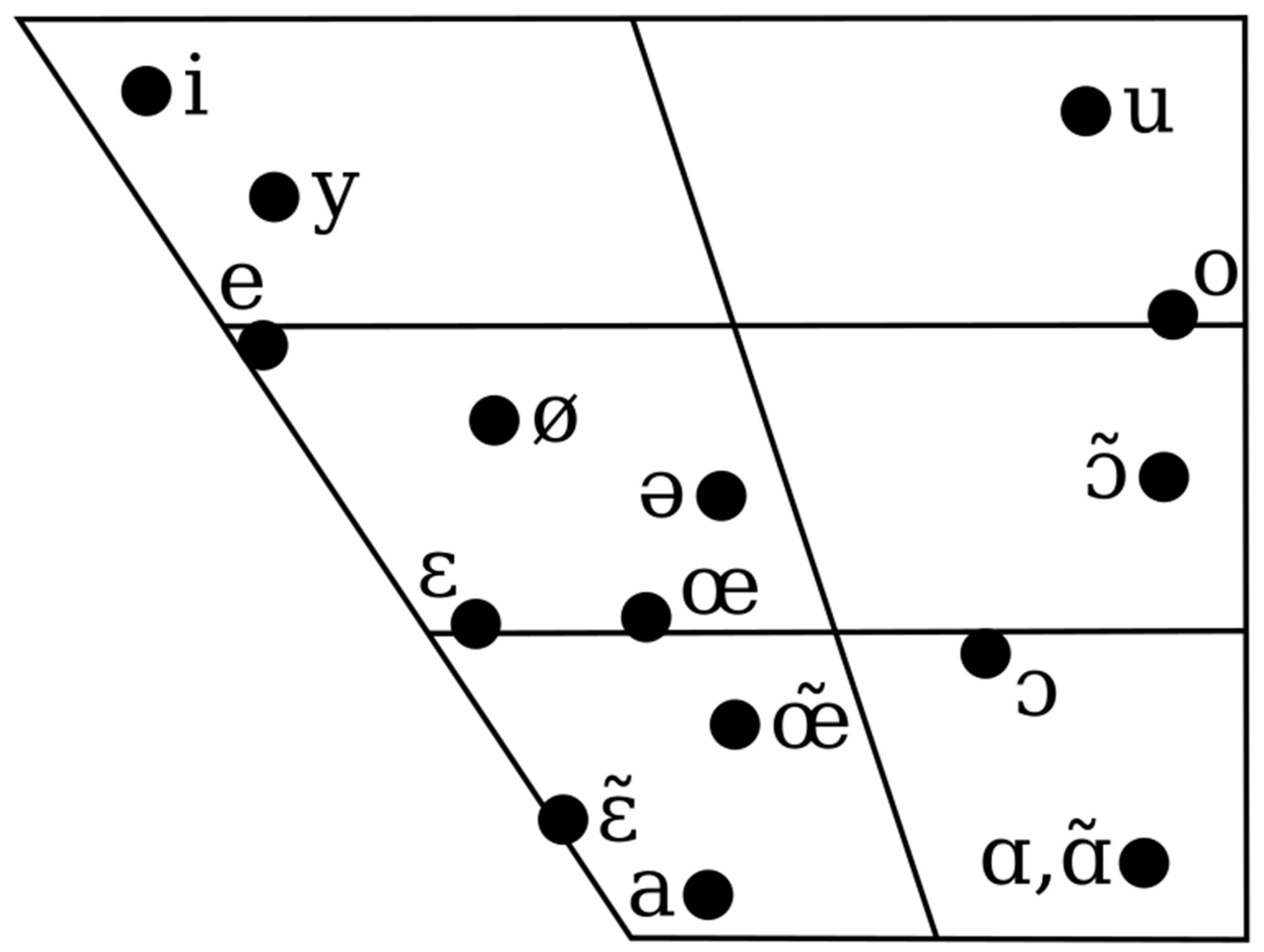

Figure 10: French Vowel Chart (Source: Collins \& Mees, 2003)

One particularity of French is the nasalized vowels. However, the phonetic qualities of the nasal vowels from the back are not similar at all to their counterparts in oral vowels

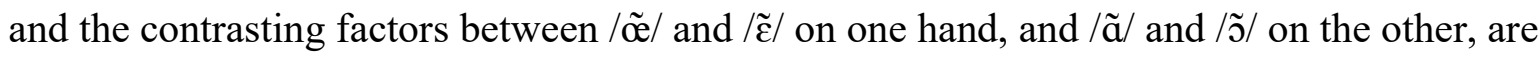
extra lip rounding and tongue height in the latter. Nevertheless, nasal oral vowels are not going to be a relevant aspect to this research (Hansen, 1998).

Comparing both vowel systems there are a few differences that complicate phoneme acquisition for French learners of L2 English. One of the problems is the English open vowels /a:/ and /æ/ which are not present in French, and thus a French speaker tends to use /a/ (e.g. instead of cat [kæt] they pronounce it [kat]). Another example is the two English close front vowels /i:/ and /I/. French only has one close front vowel, and it is /i/ (e. g. the word sheep [Ji:p] becomes [Jip]). Also, French tends to pronounce centre and front vowels, which 
produces a different sound because they are rounded versions, whereas in English those vowels need to be made with neutral lips.

EFL in France has a very interesting history. France was once the ruler of the (known) world. In fact, the last time England was conquered was in 1066, by the Norman William the Conqueror. His language was not the French we know today, but it influenced England to a large extent. Even today we find examples of the French language in purely British institutions (e.g. the extremely British chivalric Order of the Garter uses the French motto "Honi soit qui mal y pense" (May he be shamed who thinks badly of it) on their official shield). In the $18^{\text {th }}$ century France started to push away Latin for international treaties and became the "langue diplomatique".

From that moment on, French was used in the majority of European court rooms, and gained international cultural prestige thanks to philosophers and thinkers (Diderot's Encyclopédie, Voltaire's passionate writings for freedom of speech, Condorcet's philosophy on how to improve the human spirit, etc.). To sum it up, French influenced international thinkers like the German Kant, the English Burke and the military spread the influence of France across several countries by conquering territories like Louisiana, Canada or French Indochina.

At the same time, during the $18^{\text {th }}$ and $19^{\text {th }}$ century England as well started to gain influence. The British Empire was even bigger than France's and the industrial revolution in England forced other countries to learn English if they wanted to keep up with all the achievements and modern comforts. English was becoming the lingua franca and France did not know how to react and for a long time were too proud to start teaching English methodically at their schools. 
The $20^{\text {th }}$ century with both of its World Wars would worsen its global position. After the Second World War, France and Germany would sign the Élysée Treaty in 1963. That treaty called for constant deliberations between the two nations on topics like commerce, defence and education. This treaty was considered of the utmost necessity because the rivalry between both countries had led to bad blood for decades, and some historians claim that the Versailles Treaty at the end of the First World War is in part responsible for the Second World War twenty years later. Direct results of this treaty were the creation of FrancoGerman high schools, a Franco-German Youth Office and a higher emphasis on German as a foreign language in schools (Riegert, 2013).

The following decades saw the rise of English, thanks to the US winning the Cold War against the Soviet Union, and in the last decades, the use of the Internet accentuated even more the importance of English. Despite the increasing demand of English, Germany still insisted on the treaty for a long time and every academic decrease of German saw protests and protesting letters aimed at the French Ministry of education (Simons, 2015).

It is this mix between history and national pride that made it very difficult to find articles at all on this subject. Unfortunately, this means France holds just position number 35 at EF EPI, making it subsequently the worst country in Europe to speak English (EF, 2019).

\subsubsection{The German Vowel System and EFL in Germany}

Standard German belongs to the West Germanic Languages, the largest of the three branches of Germanic languages, which is now used in Central European and the official language in 7 countries (e.g. Germany, Liechtenstein, Luxembourg, Austria, etc.) It is one of the major languages in the world, with almost 100 million people worldwide using it as their 
native language and in the European Union it is the most widely spoken native language. It is the third most commonly spoken language in the EU after English and French and it is the second most commonly used scientific language (Ammon, 2015).

The German vowel system contains 8 vowels with (/a, e, i, o, u, ä, ö, ü/) 14 vowel phonemes and 3 diphthongs (which are not considered in this research). Some scholars consider even 17 different phonemes, but for the sake of this research, we acknowledge the fact that there is a strong debate among scholars of German, but according to Richard Wiese in The Phonology of German, (1996) the debate is so far settled on 14. German is much more phonetically consistent than English. This means that once you know the pronunciation rules, the exceptions to these rules are few and far between. The basic 14 vowel system can be seen in table 4 and figure 11.

Table 4: German Vowel System

\begin{tabular}{|c|c|c|c|c|c|c|c|c|}
\hline & \multicolumn{4}{|c|}{ Front } & \multicolumn{2}{c|}{ Central } & \multicolumn{2}{c|}{ Back } \\
\cline { 2 - 9 } & \multicolumn{2}{|c|}{ unrounded } & \multicolumn{2}{c|}{ Rounded } & \multicolumn{2}{c|}{} \\
\cline { 2 - 9 } & short & long & short & long & short & long & short & long \\
\hline Close & I & i: & Y & y: & & v & u: \\
\hline Close-mid & & e: & & $\varnothing:$ & & & & o: \\
\hline Open-mid & $\varepsilon$ & & œ & & & & 0 & \\
\hline Open & & & & & a & a: & & \\
\hline
\end{tabular}




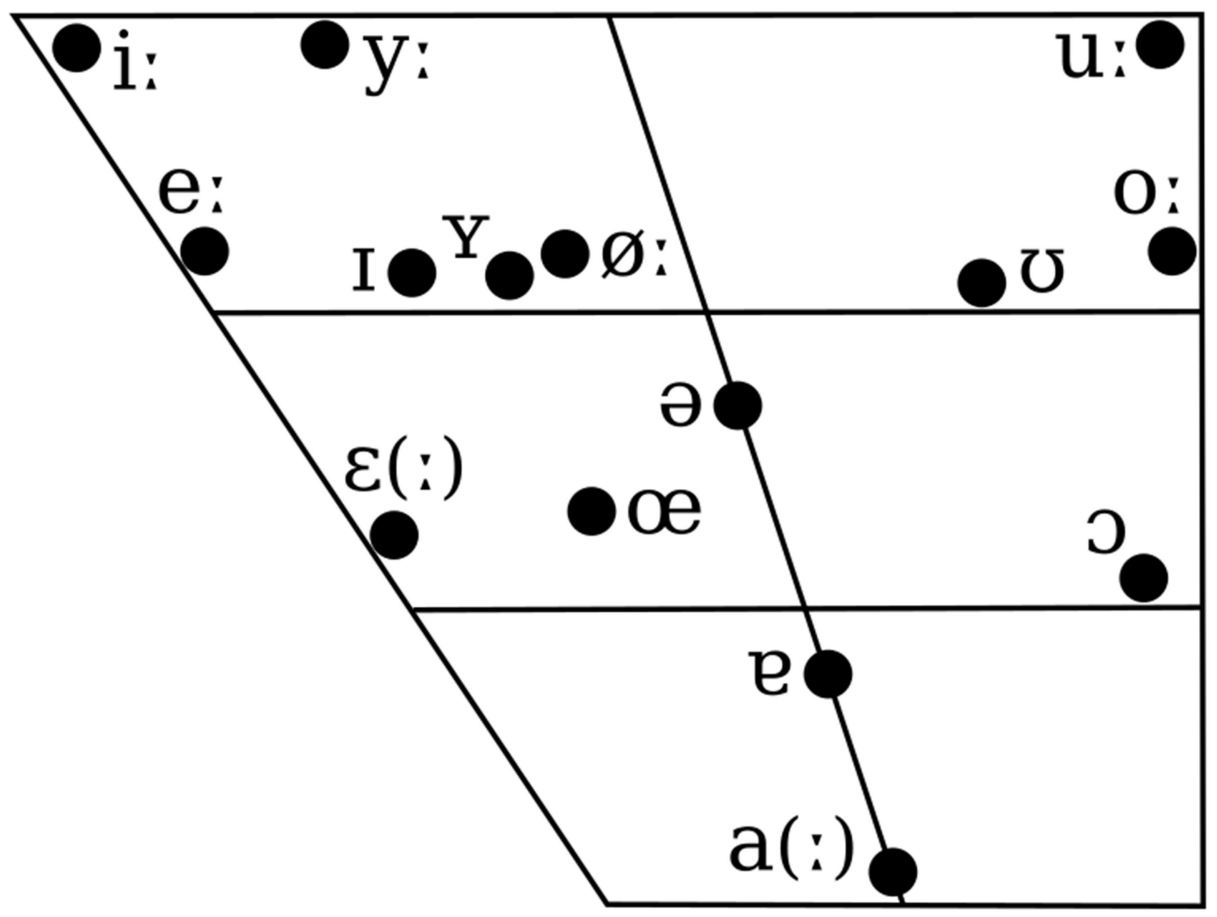

Figure 11: German Vowel Chart (Source: Kleine \& Knöbl, 2015) ${ }^{3}$

One major characteristic of German vowels is the distinction between tense and lax vowels. The distinction between both groups is more or less connected to the distinction between short and long vowels. With the exception of /a/ and / a:/, all vowels have a tense/lax counterpart. Table 5 shows the distribution among them.

\footnotetext{
${ }^{3}$ This chart includes the three phonemes $(/ \varepsilon: /, / \mathfrak{e} /, / \mathrm{a} /)$ that some scholars still debate
} 
Table 5: Tense-Lax German Vowel Chart (Source: Tomaschek, 2011)

\begin{tabular}{|c|c|c|}
\hline $\begin{array}{c}\text { Lax } \\
\text { Short }\end{array}$ & $\begin{array}{c}\text { Tense } \\
\text { long }\end{array}$ \\
\hline$[\mathrm{I}]$ & {$[\mathrm{i}:]$} & in - ihn \\
\hline$[\varepsilon]$ & {$[\mathrm{e}:]$} & Herr - Heer \\
\hline$[\mho]$ & {$[\mathrm{u}:]$} & muss - Mus \\
\hline$[0]$ & {$[\mathrm{o}:]$} & Wonne - wohne \\
\hline$[\mathrm{y}]$ & {$[\mathrm{y}]$} & Hütte - Hüte \\
\hline$[œ]$ & {$[\varnothing:]$} & Hölle - Höhle \\
\hline
\end{tabular}

Comparing German with English there are a few differences in their vowel systems. English has two low back vowels that German does not share: rounded /p/and unrounded /a:/. Quite a few times, the unrounded /a:/ coincides with the orthographic $a$ (e.g. plant [pla:nt]), whereas the rounded / $\mathrm{p} /$ corresponds to the orthographic $o$. Also, German speakers may mix up the English sounds /æ/ and /e/ which makes words like pet [pet] and pat [pæt] sound almost identically. This happens because German EFL speakers do not open their jaw wide enough and also because they do not lower the tongue while moving it slightly forward. Another example is the open-back vowel / $\mathfrak{p}$ / is not present in German, and many Germans use thus the mid-open /s/ (e.g. not gets confused with nought). The final example is that German EFL speakers do not relax the lips when making English /3:/and instead round their lips, which leads to mispronunciation of words like first [fз:st]. Figure 7 shows the assimilation process of German EFL speakers. 


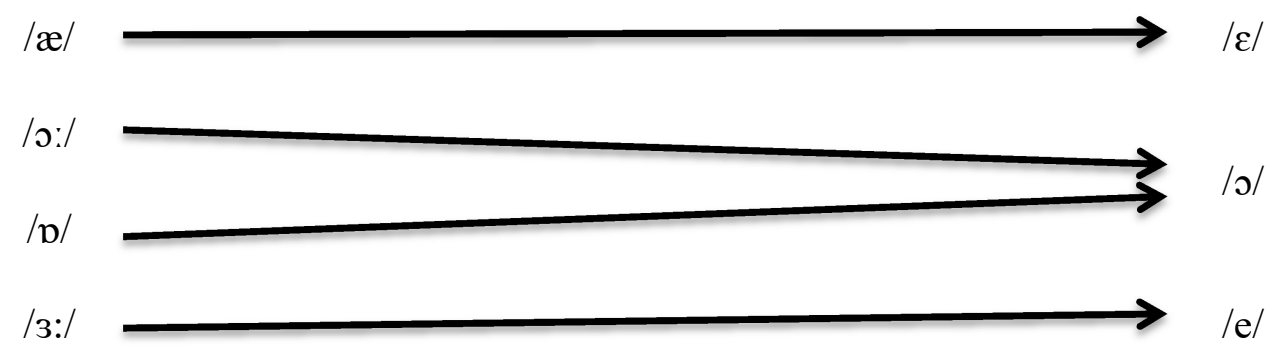

Figure 12: The English Vowel System and its Possible Misinterpretation by a German EFL Speaker

Language Learning in Germany can be divided into 4 stages (Christ \& Rang, 1985):

1. $19^{\text {th }}$ century with dominance of classical languages

2. The first third of the $20^{\text {th }}$ century with the upswing of modern languages

3. The linguistic hostage situation due to the National Socialists

4. The period after 1945

The first German areas to start EFL learning were the trading towns near the Northern coast, while the rest of the Prussian interior started a bit later. However, during the $19^{\text {th }}$ century, language learning was mainly limited to the classical languages Latin, Greek and French in a distant third position. Towards the end of that century, other languages like English or Italian started to appear as minor courses (Klippel, 1994).

At the beginning of the $20^{\text {th }}$ century, the new languages started slowly to gain the upper hand in schools, when in 1914 it was possible to finish secondary school without Latin and Greek. In 1923, English became the number one foreign language taught in German schools, a position that has not changed since then. Curricular and text books focused more on more on pragmatic language abilities, whilst ignoring translation. Typical text books 
included slice of life texts for beginners and literary writings that wanted to convey social and cultural aspects of the English country (Christ \& Rang, 1985).

During the Nazi regime, English shared the number one spot of foreign languages with Latin, but the curricular focus shifted towards the education policy of the regime and texts and writings became politicised whilst ignoring pragma-linguistic necessities (Lehberger, 1986).

After the war, the occupying forces (British, Americans, French and Russians) divided Germany into 4 territories and with the exception of the Communist zone, the other forces decided not to interfere too much with the curricular previous to the Nazi regime. In 1964, upon insistence of the US, English became an option on all 3 types of German secondary schools. The final reform in 2004, made English a mandatory subject in primary schools. The chart below shows the evolution of Bavarian Schools of secondary higher education across the different years that teach different languages. German secondary schools teach at least 2 languages and therefore the sum of the percentages cannot be $100 \%$. Nevertheless, table 6 shows a clear rise of secondary schools that teach English (Ruisz, 2014). Unfortunately, information like this was not readily available for the other languages, and even for other federal states. 
Table 6: Bavarian Schools Offering Foreign Languages (Source: www.historisches-lexikon-bayerns.de)

\begin{tabular}{|c|c|c|c|c|c|c|c|c|c|}
\hline Year & $\begin{array}{c}\text { Total } \\
\text { amount } \\
\text { of } \\
\text { students }\end{array}$ & Latin & Greek & English & French & Italian & Spanish & Russian & $\begin{array}{c}\text { Other } \\
\text { Languages }\end{array}$ \\
\hline $1963 / 64$ & 141,125 & $59.4 \%$ & $10.6 \%$ & $79.7 \%$ & $31.3 \%$ & $0.6 \%$ & $0.5 \%$ & $0.6 \%$ & $0.1 \%$ \\
\hline $1971 / 1972$ & 283,426 & $54.8 \%$ & $3.5 \%$ & $86.6 \%$ & $29.8 \%$ & $0.5 \%$ & $0.4 \%$ & $0.5 \%$ & $0 \%$ \\
\hline $1979 / 80$ & 311,785 & $50.3 \%$ & $2.3 \%$ & $87.3 \%$ & $33.7 \%$ & $1.0 \%$ & $0.5 \%$ & $0.4 \%$ & $0.4 \%$ \\
\hline $1997 / 98$ & 532,141 & $41.3 \%$ & $1.3 \%$ & $91.6 \%$ & $34.4 \%$ & $2.0 \%$ & $1.7 \%$ & $0.4 \%$ & $1.4 \%$ \\
\hline $2005 / 06$ & 641,912 & $46.4 \%$ & $1.0 \%$ & $94.4 \%$ & $36.7 \%$ & $1.6 \%$ & $3.6 \%$ & $0.1 \%$ & $0.1 \%$ \\
\hline
\end{tabular}

After losing two World Wars, language learning was used both for improving the language level of the students and for peacekeeping, by bringing new generations of German in touch with other cultures. This decades-long investment in language learning, especially English, paid off and for decades Germany has been in the top tier of EF EPI, ranking number 10 worldwide among English proficiency (EF, 2019).

\subsubsection{The Russian Vowel System and EFL in Russia}

Russian belongs to the group of East Slavic Languages, a branch of the IndoEuropean languages that are extensively used throughout Eastern Europe, Central Asia, Caucasus and the Baltic States, making it thus the most widely spoken of the Slavic languages with over 153 million speakers as of 2012 and another 110 million speakers as L2 (Simmons \& Fennig, 2018). An interesting titbit is the fact, that Russian is the second most used language on the Internet behind English.

The Standard Russian vowel system contains 5 vowels (/a, e, i, o, u/) and 5 possible diphthongs (/aj, ej, ij, oj, uj/), although diphthongs are not relevant to this research. Russian is 
mostly a phonetic language, where all the letters in a word are pronounced. The basic vowel 5-system can be seen in table 7 and figure 13.

Table 7: Russian Vowel System

\begin{tabular}{|c|c|c|c|}
\hline & Front & Central & Back \\
\hline High & $\mathrm{I}[\mathrm{i}]$ & & $\mathrm{u}[\mathrm{u}]$ \\
\hline Mid & $\mathrm{e}[\varepsilon]$ & & $\mathrm{o}[\mathrm{o}]$ \\
\hline Low & & $\mathrm{a}[\mathrm{e}]$ & \\
\hline
\end{tabular}

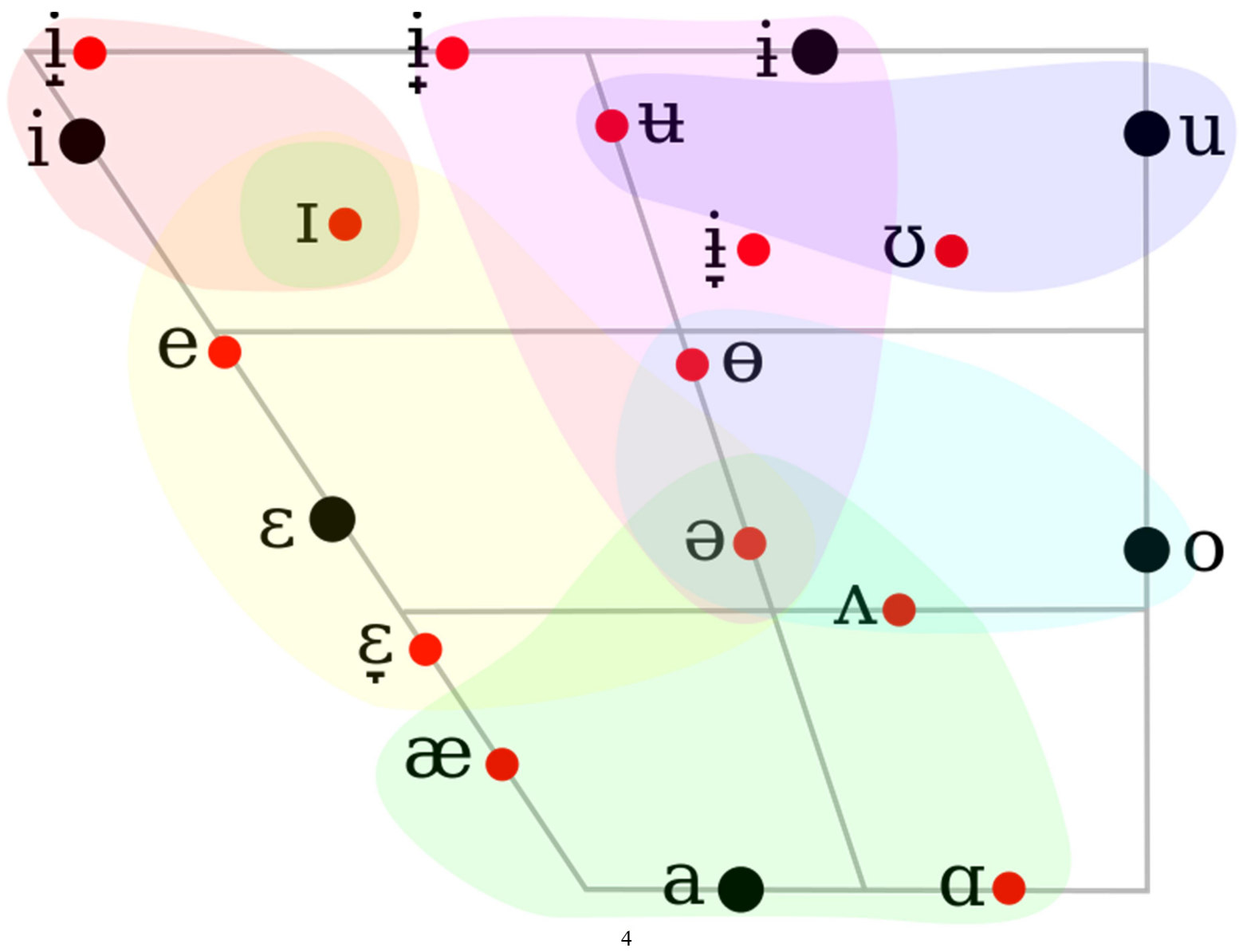

Figure 13: Russian Vowel Chart (Source: Jones \& Trofimov, 1923)

\footnotetext{
4 This chart is from 1923 and still considered the current allophone [i] as a phoneme
} 
This vowel system has one very particular characteristic: it is very susceptible to allophony. The realization of the vowels is affected by two conditions: stress and neighbouring consonants. Stress, or in this case the lack thereof, merges the unstressed vowel /o/ with /a/ and the unstressed vowel /e/ merges with /i/, reducing thus everything to a threevowel system /a, i, u/. In figure 13, the black dots refer to the vowels, the red ones to their allophonic realization.

Russian classifies consonants into two groups: palatalized (soft) consonants vs. unpalatalized (hard) consonants. These two consonant groups affect the vowels mainly like this (Barnes, 2004):

- Following a hard consonant, the high front vowel [i] is realized as the allophone [i]

- Following a soft consonant, the mid front vowel $[\varepsilon]$ is raised and fronted a bit to become the allophone [e]

- Being between two soft consonants fronts the vowels and realizes them as the allophones [æ] and $[\uplus]$.

It is very important to mention that there is a very old discussion among Russian linguists about the phonological status of the vowel $[y] /$ that is the reason why figure 13 lists 6 vowels, instead of 5). The origin of this debate goes back to the proto-language of all Slavic languages, the Proto-Slavic. Exact dates are contradictory, but this language represented the Slavic community from approximately the $5^{\text {th }}$ to the $9^{\text {th }}$ century (Comrie \& Corbett, 1993). At that time $y$ was considered as the sixth vowel (the term phoneme has not been used by the 
different Russian linguistic schools). The Saint-Petersburg Phonology School still holds on to this six-vowel view, which was also taught at schools until a few decades ago (Zemsky et al., 1971). The current state of the debate agrees with the Moscow school and the sixth vowel is considered an allophone of /i/ (Chew, 2003; Byun, 2018). Table 8 shows the allophone realizations.

Table 8: Russian Vowels and Their Allophonic Realization

\begin{tabular}{|c|c|c|c|c|}
\hline Phoneme & $\begin{array}{l}\text { Typical Russian } \\
\text { Alphabet letter }\end{array}$ & Position & Stressed & Reduced \\
\hline \multirow{3}{*}{ /a/ } & $\mathrm{a}$ & (C) $\mathrm{V}$ & [ä] & [ə], [e] \\
\hline & \multirow{2}{*}{ Я } & $\mathrm{CjVC}$ & [a] & \multirow{4}{*}{ [I] } \\
\hline & & $\mathrm{C}^{\mathrm{j} \mathrm{VC}^{\mathrm{j}}}$ & [æ] & \\
\hline \multirow{4}{*}{ /e/ } & Э & $\mathrm{VC}$ & {$[\varepsilon]$} & \\
\hline & $\mathrm{e}$ & $\mathrm{CjVC}$ & {$[\varepsilon]$} & \\
\hline & \multirow{2}{*}{$\ni, \mathrm{e}$} & $\mathrm{CVC}$ & {$[\varepsilon]$} & \multirow{2}{*}[\dot{\mathrm{t}}]{} \\
\hline & & $\mathrm{CVC}^{\mathrm{j}}$ & [e] & \\
\hline \multirow{2}{*}{ /i/ } & и & $\left(\mathrm{C}^{\mathrm{j}}\right) \mathrm{V}$ & [i] & {$[\mathrm{I}]$} \\
\hline & Ы, и & (C) V & {$[\dot{\mathrm{i}}]$} & {$[\dot{\mathrm{i}}]$} \\
\hline \multirow{2}{*}{ /o/ } & $\mathrm{o}$ & $(\mathrm{C}) \mathrm{V}$ & 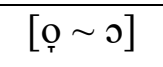 & [ə], [e] \\
\hline & $\ddot{\mathrm{e}}$ & $\mathrm{CjV}$ & {$[\Theta]$} & {$[\mathrm{I}]$} \\
\hline \multirow{3}{*}{$/ \mathrm{u} /$} & $\mathrm{y}$ & (C) $\mathrm{V}$ & \multirow{2}{*}[\mathrm{u}]{} & \multirow{2}{*}[\mho]{} \\
\hline & \multirow{2}{*}{ Ю } & $\mathrm{CjV}(\mathrm{C})$ & & \\
\hline & & $\mathrm{C}^{\mathrm{j} V \mathrm{C}^{\mathrm{j}}}$ & {$[\mathrm{H}]$} & [ư] \\
\hline
\end{tabular}

Comparing both the Russian and the English vowel system, it is obvious that Russian has half the vowels as compared to the English system. The acquisition task for 
Russian EFL learners will consist of subdividing their phonetic and phonological vowel space in order to include the vowels not present in their native language. Some of the expected mistakes can be seen in figure 14 .

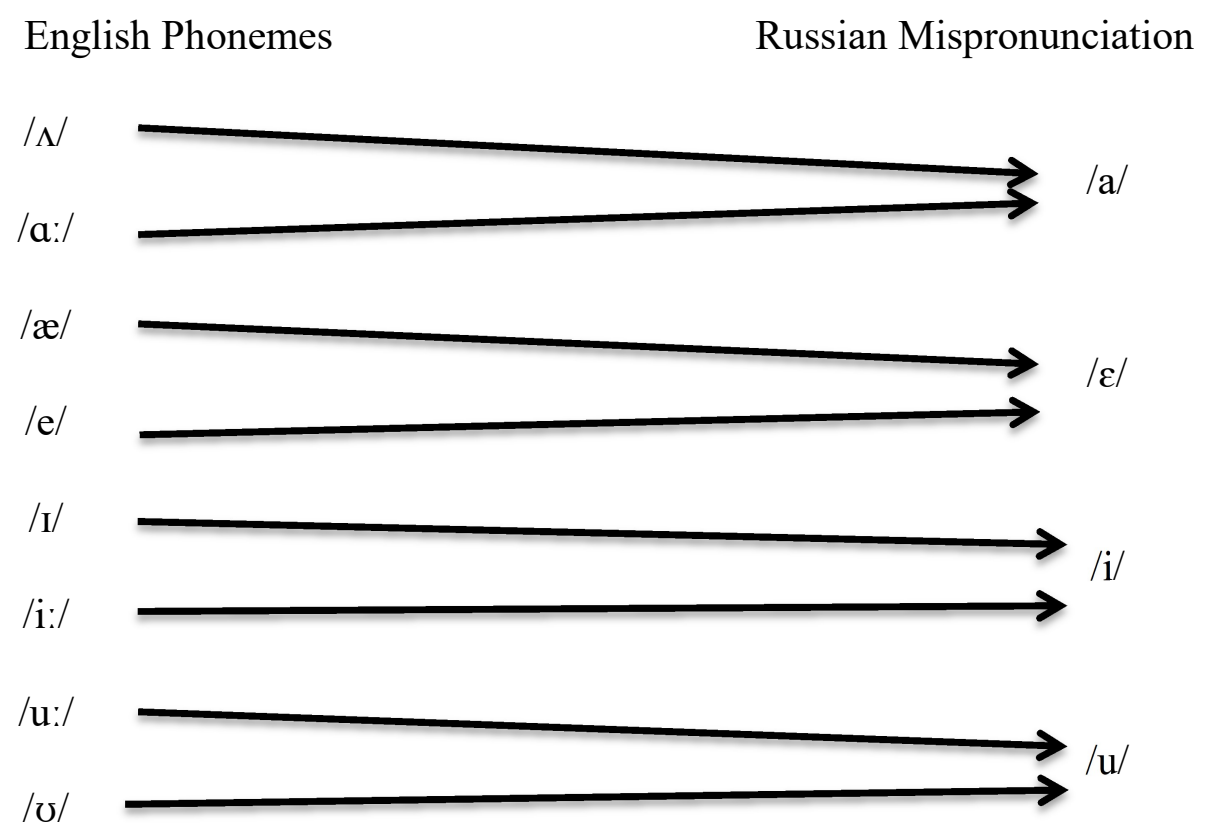

Figure 14: The English Vowel System and its Possible Misnterpretation by a Russian EFL Speaker

As one can see in figure 14, one typical mistake consists in replacing English /a:/ and $/ \Lambda /$ with Russian /a/ (e.g. hut [h/t] gets pronounced [hat] or barn [ba:n] get pronounced [ban]. Another mistake is the English /æ/ and /e/ that get pronounced as /E/ (e.g. the singular man [mæn] gets turned into its plural men [men]). The final mistake that should be mentioned is that Russian speakers tend to combine English /i:/ and /I/ into their/i/ (e.g. the word feet [fi:t] into [fit].

Russian and EFL have the youngest shared history among the countries related to this research. Until the end of days of the Iron Curtain, EFL was not as widespread in Russian education as in other countries. But the last 15-20 years have seen an increase in EFL demand, 
since the market is appreciating the value of speaking English in these times of globalization. Young Russians see English as the key factor in getting a better job or even a life abroad (Leitch, 2018).

However, Russia usually scores badly in the EF EPI and it was not until 2018 that they managed to get a narrow average rating, whereas in the previous years they always scored lower. All in all, they managed to get rank 42 (out of 88 countries) which positions them in the lower middle field of English proficiency (EF, 2019).

The reasons for this are two-fold: the lack of professional training on EFL instructors hinders the proper learning (Rasskazova, 2017). Qualified personnel is overworked since they are in high demand and Russian government is of no help, since, instead of facilitating entry, Russian lawmakers not only raise the qualification level for work visas but they also added an additional need for work permits for native English teachers. The reason behind this blocking tactics is to avoid foreign political "mischief-makers" that could slowly incite political and religious strife (Elsami-Rasekh, 2005; Morello \& Englund, 2019).

The other reason that holds back EFL in Russia is the insufficient pragmalinguistic awareness. Many contemporary English textbooks for Russian EFL learners do not provide opportunities to students to consider the linguistic and non-linguistic factors that shape real social conversations in English (Clenell, 1999). This leads to obvious moments, where Russian EFL learners encounter difficulties engaging in authentic and meaningful interactions and miscommunications with native speakers (Elsami-Rasekh, 2005; Clenell, 1999). 


\subsection{Johari Window}

The Johari window is a heuristic method developed, back in 1955, by psychologists Joseph Luft and Harrington Ingham (Ingham \& Luft, 1955). Heuristics are techniques that solve problems, learn or discover new information through practical methods though in some cases, due to cognitive biases, can lead to systematic errors. These biases are defined as systematic patterns of deviation from rationality in judgement, and thus some consider them irrational and useless if the bias is not confirmed by reproducible research (Haselton, Nettle \& Andrews, 2005). With proper care though, Heuristics results in easily accessible information in order to solve problems or even abstract issues (Michaelewicz \& Fogel, 2000).

A Johari window, as originally used in psychological contexts, aims to improve interpersonal relationships and communications (Luft \& Ingham, 1955). It is represented by a window divided into 4 quadrants - the top left window is called arena/open, the top right window is referred to as blind (spot). On the bottom left we have the façade/hidden window and the final window on the bottom right is the unknown quadrant (Verklan, 2007). Figure 15 shows a blank Johari Windows and its 4 windows. 


\section{Johari Window}

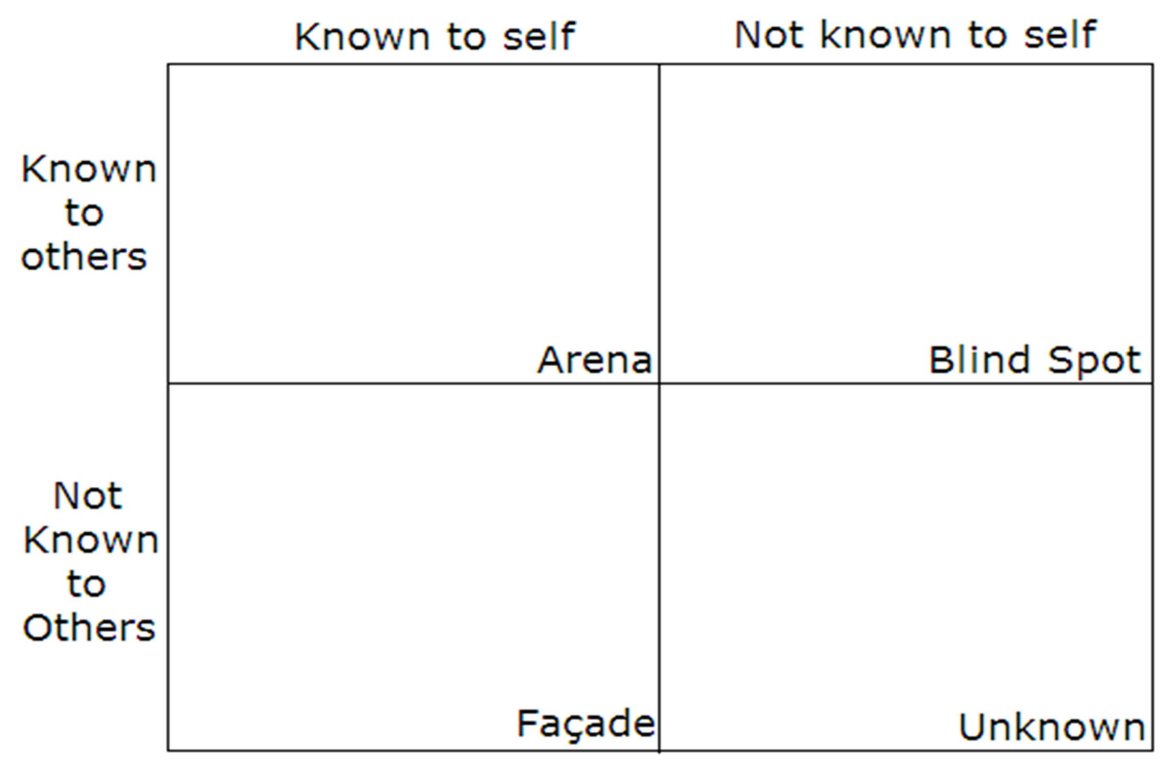

Figure 15: Johari Window

The arena quadrant represents characteristics that everyone, including the subject in question, knows. The façade quadrant consists of characteristics the subject knows about himself but keeps from others. The blind spot reveals characteristics that are unknown to the subject, but known to everyone else. Finally, the unknown contains characteristics that no one knows about the subject. The four windows can be seen in figure 14 .

This model for interpersonal awareness has come a long way since the 50s and has since been applied to a vast array of learning situations and educational tools (Halpern, 2009). My proposal is to adapt it for linguistic means. The original consists of two variables, number of persons and knowledge. Thus my adapted model consists of two variables too. In this case, the variables will represent different language features that will be further explained in Chapter 4.

The reason it was included in this methodology is because it helps us to layout the language comparisons differently from what researchers usually do when they conduct 
phonological studies. Johari Window is a personality technique from the field of Psychology. It manages to juxtapose different categories with each other and in the end it reveals more information about the person than it would have done in four independent tasks.

To the best of my knowledge, Johari Window has not been applied to any sort of linguistic research, be it phonology, syntax or whatever. Using this method is not about being an innovator, since this method was already developed years ago in the first place. Using a Johari Window could be an interesting new lens to look through at old problems.

The original definition and the Johari window itself have been slightly modified for the purposes of this study, in order to adapt it to the needs of the present research. It is a psychological tool for interpersonal analysis, in order to discover all sides of one's personality, even the ones not known to the participant. As of now, this adapted Johari window is a technique that helps linguists better understand the relationship between speech characteristics.

For this $\mathrm{PhD}$ research on difficulties with English vowels, the focus was on rhythm and vowel systems in order to produce innovative or revealing results. Using these two aspects of pronunciation as variables in comparing different languages against English helps us add a different point of view to the standard CAH method used in linguistics.

English, as we know, is a stress-timed language with 5 vowel letters and 13 vowel phonemes in the RP variety and has traditionally been considered to be a stress-timed language.

The second aspect analysed in this work, vowel system, is a very common way to differentiate languages, but this research is going to separate the vowel systems of languages into two camps. On the one hand we have languages that have 5 vowel letters and precisely 5 
vowel phonemes. These languages were defined as having simple vowel systems. On the other hand, we have languages that also have 5 vowel letters, but more than 5 vowel phonemes, which means that every vowel letter has several different vowel phonemes. These languages have complex vowel systems.

With these distinctions clearly explained, the resulting adapted Johari window would look like this (figure 11):

\section{Adapted Johari Window}

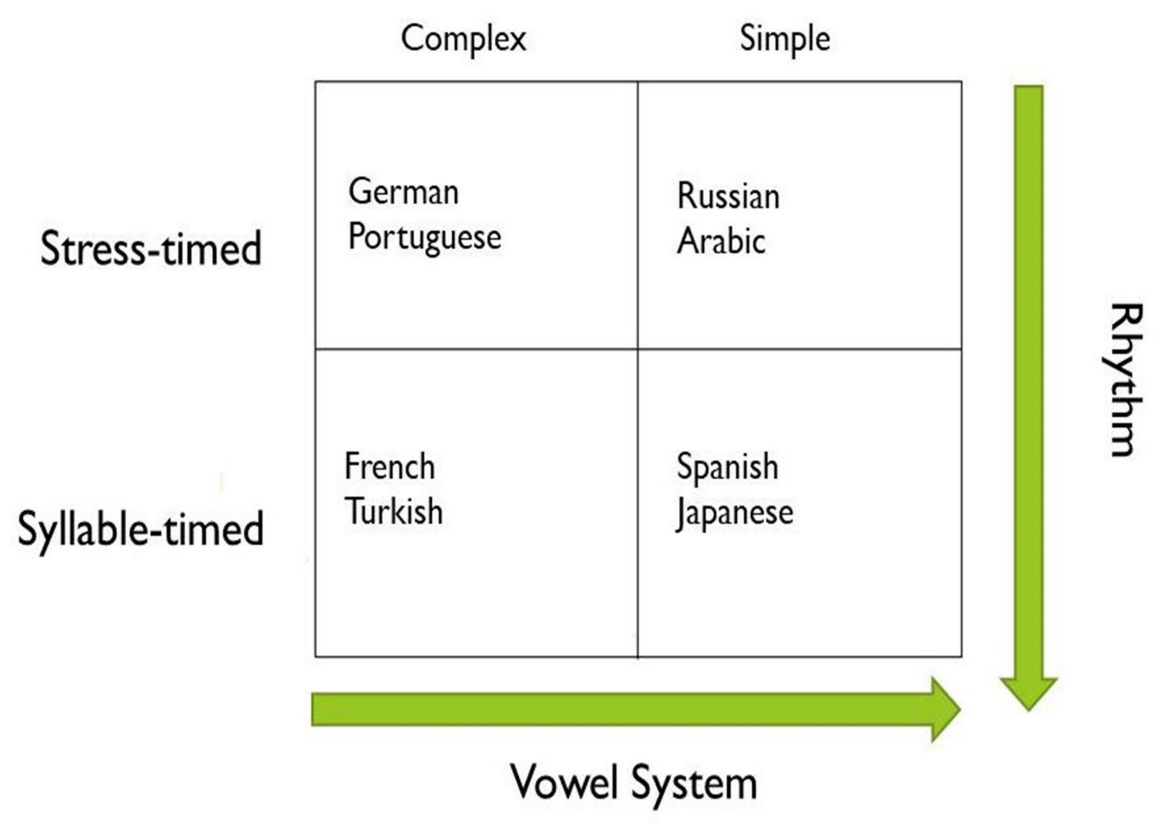

Figure 16: Adapted Johari Window

The Adapted Johari Window serves as a visual layout to contrast 4 languages based on their isochrony and vowel system. During the elaboration phase of the final research project it was of utmost importance to research languages that could be part of one of the quadrants in Figure 15. However, the difficulty lies in finding native speakers of those 
languages that fulfilled the rest of the criteria for the research project. After looking at different languages that fulfilled both conditions (isochrony and vowel system), 8 languages fulfilled both conditions but could also be realistically available in either at two universities based in Spain.

In the end, 37 participants from 7 different countries took the survey and let themselves get recorded. But, since it was essential to have at least 5 participants per language, 5 samples (1 Portuguese, 2 Japanese and 1 Turkish) had to be removed. With 32 participants from 4 different languages that covered the 4 different windows of the adapted Johari Window, the research could start.

In the top left window, we have languages like German or Portuguese that share both the rhythm (stress-timed) and the complex vowel system with English. The top right window includes languages like Russian or Arabic, that share the rhythm (stress-timed) but not vowel system with English (both languages have a simple vowel system). Continuing with the bottom left window, we have languages like French or Turkish, that share the complex vowel system, but not the rhythm (both are syllable-timed) with English. Finally, the bottom right window includes languages like Spanish or Japanese that share neither rhythm, nor vowel system with English. 


\section{Chapter 3: Methods}

After providing a context and essential background knowledge, Chapter 3 states the research questions, discusses and justifies the research methods used in the following chapters to test hypotheses, answer questions or evaluate innovations.

This chapter starts with the statement of the research questions, before reviewing the methods that were used, discussing their limitations and justifying their use. Then, the sum of these parts should position this research and finish this chapter.

There is also a need to differentiate between the title of this chapter, methods, and methodology, because those terms are often mixed up by researchers. Methodology refers to the branch of knowledge that works with method and its applications in a particular field of study or research. Hence the reason why social scientists use it to describe the general stance that a researcher is assuming (whether the researcher designs empirical experiments or acts as an objective observer, etc.).

Methodology can become a type of lens through which researchers view not only their research but also the world....and obviously some things will be out of focus. That is another good reason to add more methods to the research methodology, in order to reduce the blind spot as much as possible. It is also important to remember that the availability of an established methodology does not absolve the researcher from justifying his method choices in regards to his methodology, his research question and the desired evidence (Petre \& Rugg, 2004). 


\subsection{Research Questions}

This background chapter has so far given information that dealt directly or indirectly with the problem this thesis is concerned about: the accuracy in the acquisition of the EFL vowel system. It is a common problem, because even countries such as Germany, which score higher on proficiency tests like EF EPI, are not considered to have EFL speakers with a flawless pronunciation. Far from it, media from countries with good proficiency still focus on those conspicuous details that out immediately non-native speaker (Trentmann, 2013; Spiewak, 2016) and leer at other countries with envious eyes (Huber, 2017).

There are obviously many biological factors involved in this process, but nevertheless as we have seen throughout this chapter, countries have tried to improve their English pronunciation and have studied the phonemes in particular (Richter, 2018; Piske; Kartushina et al., 2016; Flege \& Wayland, 2019). This research is thorough, detailed and, in general, remarkable and well done, but in the end it is not quite there yet. But then again, can this problem ever be solved?

The proposal of this dissertation is simple: let us add more perspectives and see what results they produce. This refers specifically to get more data. Besides Statistics and CAH, both classic methods in linguistic analysis, this research also includes the modern method spectrography with the visual layout of the Johari Window. Johari Window per se, is not going to add a whole new set of data, but it will be used as a means of organization in order to compare different languages against each other.

The right research question and design depends on identifying what is important, and to arrange this impulse with something that could prove useful for everyone. As the old Latin aphorism by Horatio goes: "dulce et utile". Things have to be sweet and useful at the same time in order to have some value (Burguera, 2005). The motivation for this research 
was the fact that linguists a century ago already faced the same phonetic problems and 100 years later there is still a lack of phoneme acquisition.

However, a research question has to be reasonable enough, because the pursuit of it needs to be feasible within the resources available: time, materials, participants, instruments, money, etc. Then the obtained results should satisfy the research question. With that in mind it is important to ask: what kind of evidence would make one think the question was worth asking? A helpful approach is to bear in mind possible counter-evidence. Researchers have a tendency to seek evidence that confirms their ideas, and build their whole methodology on that principle. But it can be more useful if you take into account that the results may be unexpected, contradictory or even-counterexamples.

This research does not expect to find the key that opens the lock to perfect language acquisition, but the aim of it is to offer a bit more than the traditional experimental approach of collecting and analysing data. The addition of Spectrographic Analysis and the shuffle in combination outlook that the Johari Window offers, should at the very least result in interesting data. That data could serve many purposes: it could be a starting point for future research, if the results so far seem satisfactory and the methodology seems adequate. It could also serve others, by inspiring them what to do, or, in a worst case scenario, what not to do.

This research is about the comparison and contrast of these vowel acquisition processes, taking as a comparative term the respective mother tongues. The objective of the thesis is the detailed and contrastive description of the difficulties that English phonology presents for speakers of different languages. For this, a data collection will be carried out through experimental methodology in groups of learners from different linguistic communities. 
If this objective is carried out successfully, patterns of learning of phonology in the foreign language will be elucidated. A starting hypothesis can be established about the phonological configurations that could result from the data analysis. This hypothesis leads us to establish as a starting point the premise that native phonological systems provide a cognitive template on which learning is configured. It is expected to prove that the phonological configurations of the learners of each linguistic community will mark different learning paths for each community. Based on this hypothesis, a data analysis based on the experimental method is proposed.

More specifically, the important question here is, if any pattern in the vowel acquisition process could be deduced by comparing 4 languages against each other in a specific layout? Do certain language features facilitate language acquisition?

Preliminary research indicates that this is a longstanding problem without solutions, which definitely is a clear indicator that a solution to this problem could be at best extremely complex with too many different variables and at worst out of reach.

The preliminary hypothesis of this research goes that comparing many languages in a certain layout with several variables could point out some of the problems in vowel acquisition. The use of the Johari Window layout to contrast the languages, the use of spectrography to analyse the mistakes and the use of isochrony and vowel systems as relevant variables in the group of selected languages are the gears in this hypothesis.

This hypothesis can be also stated in several ways: if the contrast of these previously mentioned variables is correct, it will reveal further insight into the problems of phoneme acquisition. Another way to formulate it would be that the more languages are compared against these variables, the easier it is to recognize the problems in language acquisition. 
Additionally, the null hypothesis would be that both the layout and the selected variables will not reveal further insight into the process of language acquisition. Eventually, these hypotheses lead us to the research question: is the combination of different languages compared against each other under two variables enough to bring enough to reveal specific vowel phoneme acquisition problems?

This research handles two variables: the first one is stress-timed languages versus syllable-timed languages and the second one is complex vowel systems versus simple vowel systems.

The train of thought is the following: since English is a stress-timed language with a complex vowel system, the null hypothesis suggests that German, being also stress-timed and with a complex vowel system, should have fewer difficulties, and consequently fewer errors. Following this hypothesis, Spanish, being a syllable-timed language with a simple vowel system, should be the one with the most difficulties and therefore the most errors. Additionally, Russian and French each share a variable with English. Russian is stress-timed and French is complex. This thought process follows the proposed layout structure in the Johari window.

The second variable deals with the complexity of the vowel system, which has traditionally been considered as the determining factor of error. For this reason, the null hypothesis indicates that Russian (simple vowel system) will present more difficulties and more errors than French (complex vowel system).

Thus the research questions would be: 
1. Are the variables stress-timed and vocalic system complexity determining the difficulty and the error? Are these factors cumulative, so if they come together in one language, the speakers of that language will make it worse?

2. Which variable is more determining V1 or V2?

\subsection{Contrastive Analysis Hypothesis}

First is the contrastive analysis hypothesis (henceforth $\mathrm{CAH}$ ), that can be defined as the systematic study of two (or more) languages in order to identify both their structural similarities and differences.

CAH has been for decades one of the best methods when it comes to language acquisition. It is an effective procedure when you want to compare the speaker's native language (L1) against another language (L2) and how the L1 itself could predictably affect the learning of L2. Hence CAH concentrates at the differences and similarities between at least two languages (Gast, 2012).

This contrastive approach emerged after the end of the Second World War when the US gave importance to foreign language learning. Furthermore, more and more research based on bilingualism from immigrants started to get published (ibid).

Professor Robert Lado defined, in 1957, the so-called strong version of CAH, (Lado, 1957) which states that all errors made in L2 were due to interference by L1 and subsequently all errors could be predicted. No empirical evidence has sustained this claim (Banathy et al., 1966) and it neglected essential criteria such as age. It also focused too much on the inference aspect of the L1 language and offered little use to language teachers (Newmark \& Reibel, 1968). 
After this strong version, researchers defined an alternative though, the so called ' weak' version; this one commences with the errors already made by the learner which then gets explained as much as possible by designating the differences and similarities between both languages (Stockwell, 1967). This is viewed as a complementary research to error analysis and intrinsically shares a few of the typical mistakes (e.g. error analysis is not enough when you want to identify learning complications).

Finally, a third (and last) iteration of $\mathrm{CAH}$, a moderate version, came around and became an essential research method for second language acquisition: "the categorization of abstract and concrete patterns according to their perceived similarities and differences is the basis for learning; therefore, wherever patterns are minimally distinct in form or meaning in one or more systems, confusion may result" (Oller \& Ziahosseiny, 1970, p.5). It clearly contradicts Lado's original variant, since the hypothesis here goes the other way round: the more different the L2 is from your own L1, the easier it will be to learn the targeted new language.

Minimal pair test between the phonemes $/ \mathbf{k} /$ and $/ \mathbf{g} /$ in English and Arabic:

English: came /Keim/ vs. game /geim/ Arabic: /kelb/ 'dog' vs. /gelb/ 'heart'

In Algerian Arabic /q/ and /g/ are phonemes and allophones: /gern/ 'horn' vs. /gern/ 'century' ât' phonemes /gma::r/ 'moon' vs. /gma:r/ 'moon' ât' allophones 
Figure 16 shows an illustrative example of Contrastive Analysis. Both languages (Arabic and English) have two phonemes compared against each other and one can quickly see the differences and similarities and use that information beforehand to anticipate problems (King, 2018).

Contrastive analysis, as a tool of contrastive linguistics, is something that was included as a method, because despite its shortcomings, it is still a valuable tool when dealing with different languages. It can be used to anticipate negative transfer of languages. This means, when L1 affects the learning of L2. In this case how L1 could affect the acquisition of the necessary new vowel phonemes in L2. Its descriptive focus serves as a link between theory and application. The theoretical findings and description of language models are useful and at the same applicable (Gast, 2012).

\subsection{Basic Statistical Methods}

Statistical methods deal with data collection, organization, analysis, interpretation and presentation. It is also known to be a quantitative approach to research when linguistics and languages usually use qualitative methods. These use data exclusively for identifying language feature usage and then afterwards describing them, while giving real-life examples of specific phenomena (Cantos Gómez, 2013).

Supplementing these qualitative analyses of language with the quantitative research method of statistics can contribute fruitfully to linguistic analysis and research. In the latter, linguistics features are classified and counted to create even more complex statistical models, that explain in more details the observed facts (Cantos Gómez, 2013). 
Table 9: Example of Statistics about/i:/ in research

\begin{tabular}{|c|c|c|c|c|c|}
\hline & Total & Spanish & French & German & Russian \\
\hline $\begin{array}{l}\text { Number of } \\
\text { participants }\end{array}$ & 32 & 10 & 11 & 5 & 6 \\
\hline $\begin{array}{c}\text { Average Age } \\
\text { (in years) }\end{array}$ & 24.97 & 23.5 & 22.27 & 24.2 & 33 \\
\hline $\begin{array}{c}\text { Mistakes } \\
\text { with /i:/ }\end{array}$ & $8.13 \%$ & $10 \%$ & $5.5 \%$ & $0 \%$ & $16.66 \%$ \\
\hline
\end{tabular}

Table 9 is an example of statistics. In my research the English phoneme /i:/ was at no moment a significant source of mistakes. It also shows that the Russian group was significantly older than the rest of the groups.

Despite some linguists dismissing quantitative methods, due to lack of training, or even disliking them due to belonging to the realms of mathematical sciences, the most popular statistical techniques are also the most accessible ones. In regards to linguistic purposes (Cantos Gómez, 2013), they have been used:

1. to observe and describe certain aspects of language phenomena

2. to apply quantitative techniques or model to problems related to describing natural language or language teaching

3. to solve methodological problems of linguistic measurement or sampling 
This research includes basic statistics because it has been a mainstream tool in linguistic research and a formidable ally to human sciences for a very long time and putting the obtained data into numbers gives a clear perspective on what the results actually are. Standard statistical methods can be applied to a huge assortment of social situations and allow the researchers to identify correlations between sets of data, which mark a possible causal link between them. Statistics, with the proper method and correct analysis, helps us to learn from data and make discoveries in science. It allows us to understand a subject more deeply and thus make decisions and predictions based on data. Furthermore, it also strengthens the interpretation of the data.

But Statistics is more than just numbers and facts. It is a collection of knowledge and procedures that gives us the chance to produce reliable data, which then can be used to draw reasonable conclusions. But one has to be careful while using statistics in order to avoid traps that a lack of knowledge can bring with it. Mistakes like biased samples, overgeneralization or even an incorrect analysis are common, but one is aware of the ways that can produce misleading results (Hartgerink et al., 2019). To the best of the researcher's abilities, those pitfalls will be avoided by acknowledging the limitations of this research.

The following basic statistical methods are going to be part of this research (Cantos Gómez, 2013, p.3-10):

Mean: It is the sum of all the scores in a set, divided by the total number of scores. In Table 10 is an example using the data obtained from the group of Spanish EFL learners. 
Table 10: Mean of Spanish EFL Speakers in Question 1 of Participant's Background Information Survey

\begin{tabular}{|c|c|c|}
\hline Spanish & Answer & Calculations \\
\hline Sp1 & 5 & 1. Sum of Scores $\sum X$ \\
\hline Sp2 & 5 & $=5+5+5+4+4+4+3+3+5+4$ \\
\hline Sp3 & 5 & \\
\hline Sp4 & 4 & $=12$ \\
\hline Sp5 & 4 & \\
\hline Sp6 & 4 & 2. Number of scores N \\
\hline Sp7 & 3 & 3. Mean: $\bar{X}$ \\
\hline Sp8 & 3 & $=\frac{42}{10}$ \\
\hline Sp9 & 5 & $=4.2$ \\
\hline Sp10 & 4 & \\
\hline
\end{tabular}

Variance: It is the average of the squared differences from the mean. This research is going to use the Standard Deviation and in order to calculate that, the variance is needed. We are going to use the same data from table 10 and are going to calculate the difference. The formula for the difference is: difference ${ }_{1}=\mathrm{X}_{1}-\bar{X}$ 
Table 11: Differences with the Mean

\begin{tabular}{|c|c|c|c|}
\hline Spanish & Answers & Difference with & Differences \\
EFL Speaker & & Mean $\bar{X} .2$ & \\
\hline Sp1 & 5 & 0.8 & 0.64 \\
\hline Sp2 & 5 & 0.8 & 0.64 \\
\hline Sp3 & 5 & 0.8 & 0.64 \\
\hline Sp4 & 4 & -0.2 & 0.04 \\
\hline Sp5 & 4 & -0.2 & 0.04 \\
\hline Sp6 & 4 & -0.2 & 0.04 \\
\hline Sp7 & 3 & -1.2 & 1.44 \\
\hline Sp8 & 3 & -1.2 & 1.44 \\
\hline Sp9 & 5 & 0.8 & 0.64 \\
\hline Sp10 & 4 & -0.2 & 0.04 \\
\hline $\mathrm{N}=10$ & & 0 & 5.6 \\
\hline
\end{tabular}

A way to check if the calculations are performed correctly is to add all the differences and the result must be zero (example in table 11). For the variance we need the sum of the differences though: $\mathrm{V}=\frac{\sum \operatorname{diff} 2}{N}=$

$$
\mathrm{V}=\frac{5.6}{10}=0.56
$$

This formula works for large sets. In this example, and in the case of this research project, the sample sizes are small and the formula must be varied a bit.

$$
\mathrm{V}=\frac{\sum \operatorname{diff} 2}{N-1}=
$$


$\mathrm{V}=\frac{5.6}{9}=0.6 \overline{2}$

Standard Deviation: It is the measure of how spread out the numbers are. The symbol used for $\mathrm{SD}$ is $\sigma$. In order to get $\mathrm{SD}$, one only needs to take the square root of the variance.

$\sigma=\sqrt{0.6 \overline{2}}=0.79$

SD measures how far values tend are from the mean.

- $68 \%$ of the values in the data lie between $\mu-1 \sigma$ and $\mu+1 \sigma$

- $95 \%$ of the values in the data lie between $\mu-2 \sigma$ and $\mu-2 \sigma$

- $99.7 \%$ of the values in the data lie between $\mu-3 \sigma$ and $\mu+3 \sigma$

When the $\sigma$ is small, the dispersion of values is lower.

\subsection{Spectrography}

Spectrography is a modern approach to linguistics and since it originated in a different field it needs to be explained.

The vibrations made in the vocal tract can be visually represented by speech waveforms. Figure 14 visually represents how pressure variation changes with time. 


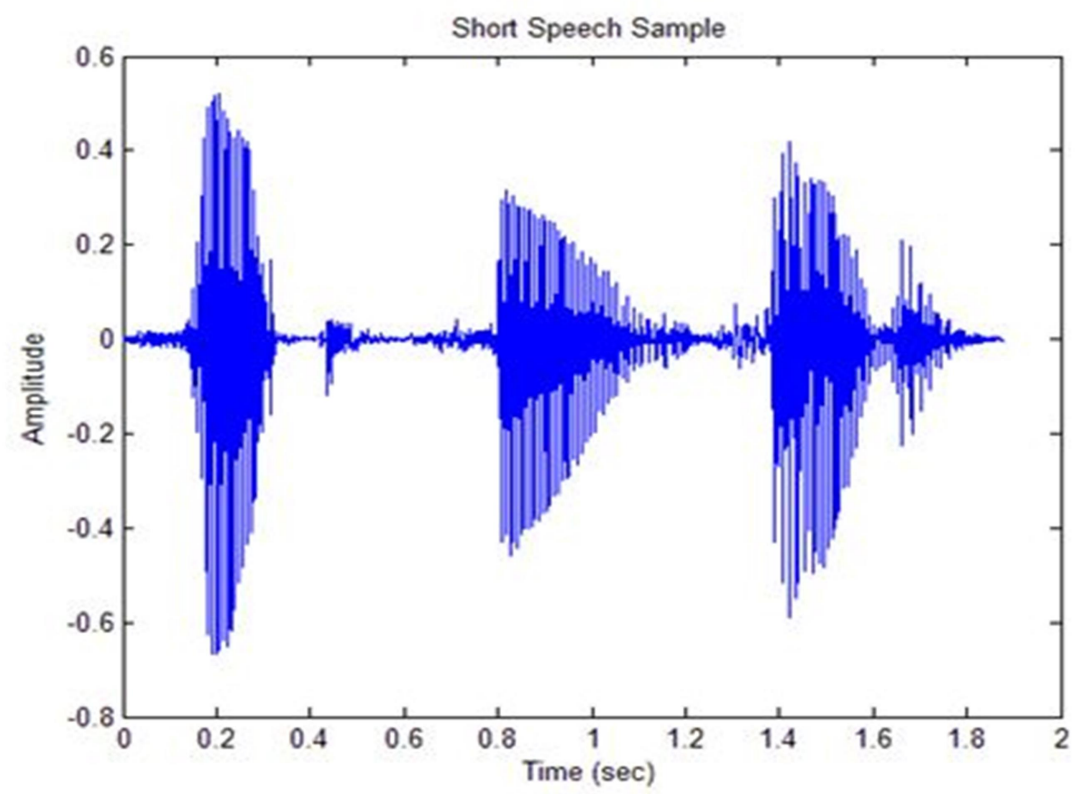

Figure 18: Example of Speech Sample (Source: www.cs.tut.fi)

The y-axis measures the pressure variation (measured as amplitude) while the $\mathrm{x}$-axis reflects the time needed for the changes of pressure. The amplitude can be defined as a measure of the average pressure variation from normal atmospheric pressure. Some graphs can show a straight line in the centre of the waveform ( 0 amplitude) which represents normal atmospheric pressure. If the wave is above 0 it means that the pressure is greater than the atmospheric pressure while being below 0 means that pressure is lower than the atmospheric one.

Waveforms have one problem though: it is near impossible to read them as words. Through the use of Fourier analysis we can find out what frequencies are present at any given moment in the speech signal. The result of this analysis can be graphically represented as a spectrum: the amplitude of the sinewave components that are present in the signal within a given time window. 
Several spectra though still do not let us identify the sounds in words. But if we compute the spectrum for one short section of speech and keep computing the spectrum for the adjoining short section of speech until the end of the waveform we will be able to display all the computed spectra in a 3D graph. This graph is called a spectrogram, a visual representation of the frequency and intensity of speech sounds against time.

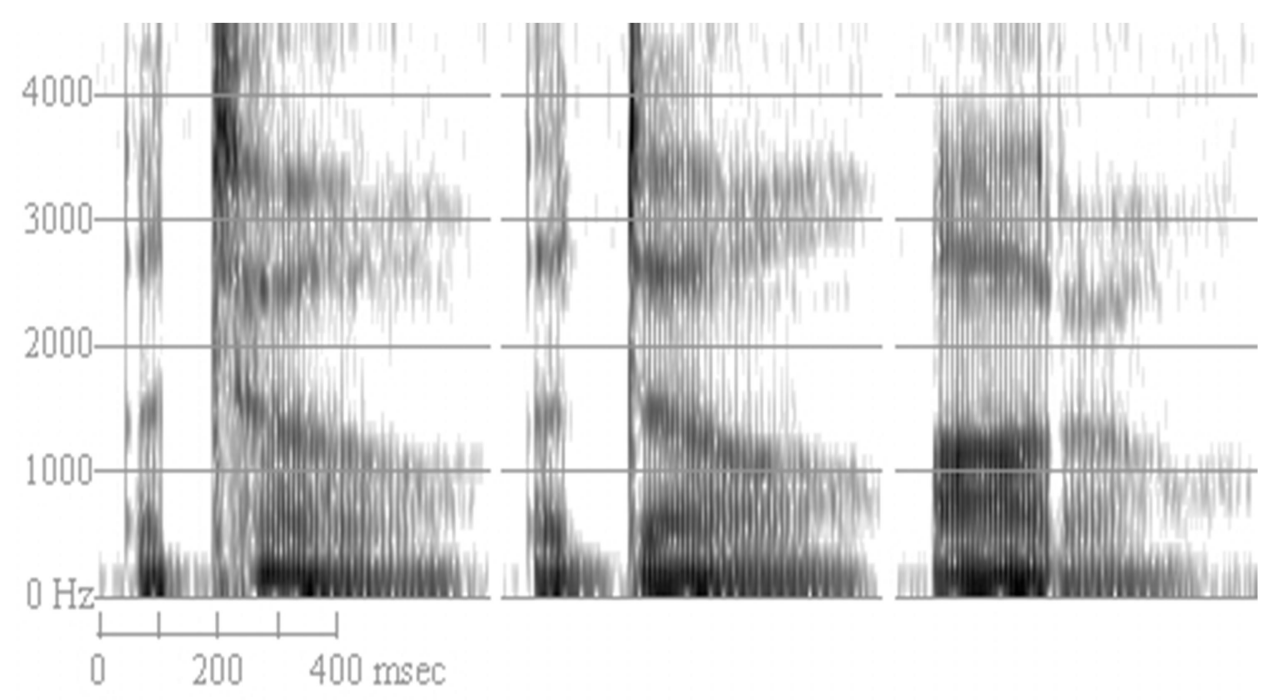

Figure 19: Example of Spectrogram (Source: www.home.cc.umanitoba.ca)

Spectrograms like the one showed in Figure 19, can be read due to the idiosyncratic phonetic features of phonemes and thus spectrographic analysis can be used to improve language learning (Ladefoged \& Johnson, 2011).

The reason spectrography was used for this research is that it gives us the chance to make sound visible. Spectrographic analysis makes speech visible. Analysis of speech has relied on human review, which is inherently flawed. Having two different people analyse recorded speech will lead in some cases to different opinions on what is valid and not. Perceptual assessment is idiosyncratic and two people will not experience sound the exact same way. Therefore, spectrography helps us to move the subjective into something more 
objective. It also sheds a bit more light into the pronunciation mistakes, than a simple wrong or inadequate. Spectrography allows us to analyse its formants and see exactly what the speaker's intention were while pronouncing the phoneme? Was he trying to pronounce the English phoneme or was he just transferring the L2 phoneme to some L1 phoneme familiar with him?

When you record EFL learners from different languages, you analyse their speech afterwards with a native speaker of the language you are interested in. At best, it is possible to find a helpful native English teacher with a background in linguistics that spares hours and hours to analyse several dozens of recorded data.

Even native speakers can sometimes have problems correctly reviewing English pronunciation. This could lead in some cases to skewed results.

With the use of spectrographic analysis, every phoneme occurs at certain frequencies, which means that modern software analyses objectively if the spoken phoneme occurs at the frequency most usual in the chosen variety. Figure 20 is a demonstration of this with a spectrogram of the word to. 


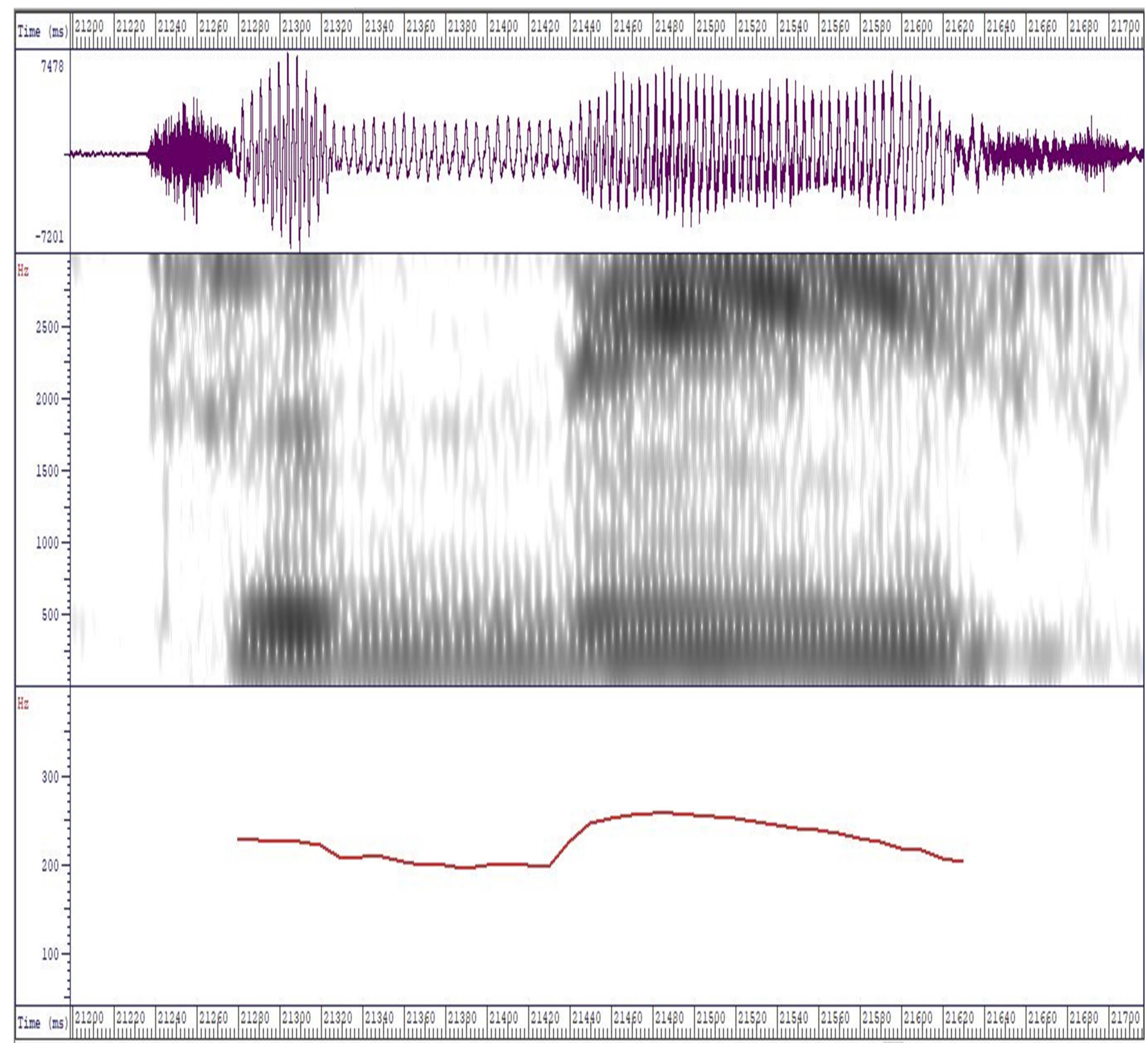

Figure 20: Spectrogram of to leave (Source by Theresa May speech held on July $11^{\text {th }}, 2016$ )

Consonants have recognizable patterns but we skip explanations on them. Vowels are easily recognizable on a spectrogram because of formants. They are peaks of amplitude around a given frequency in the speech wave due to a resonance of the vocal tract. There are usually many formants for a periodic sound and each formant depends on the position of the tongue and lips. Graphically they are represented by clear bands of energy and their location 
and the distance between each of the formants tells us roughly the identity of the vowel.

Since these formants occur at relatively lower frequencies (F1 occur from $250-900 \mathrm{~Hz}$, while F2 occur from 2700-800Hz) (Ball \& Rahilly, 1999) we will zoom in on the spectrogram in figure 21.

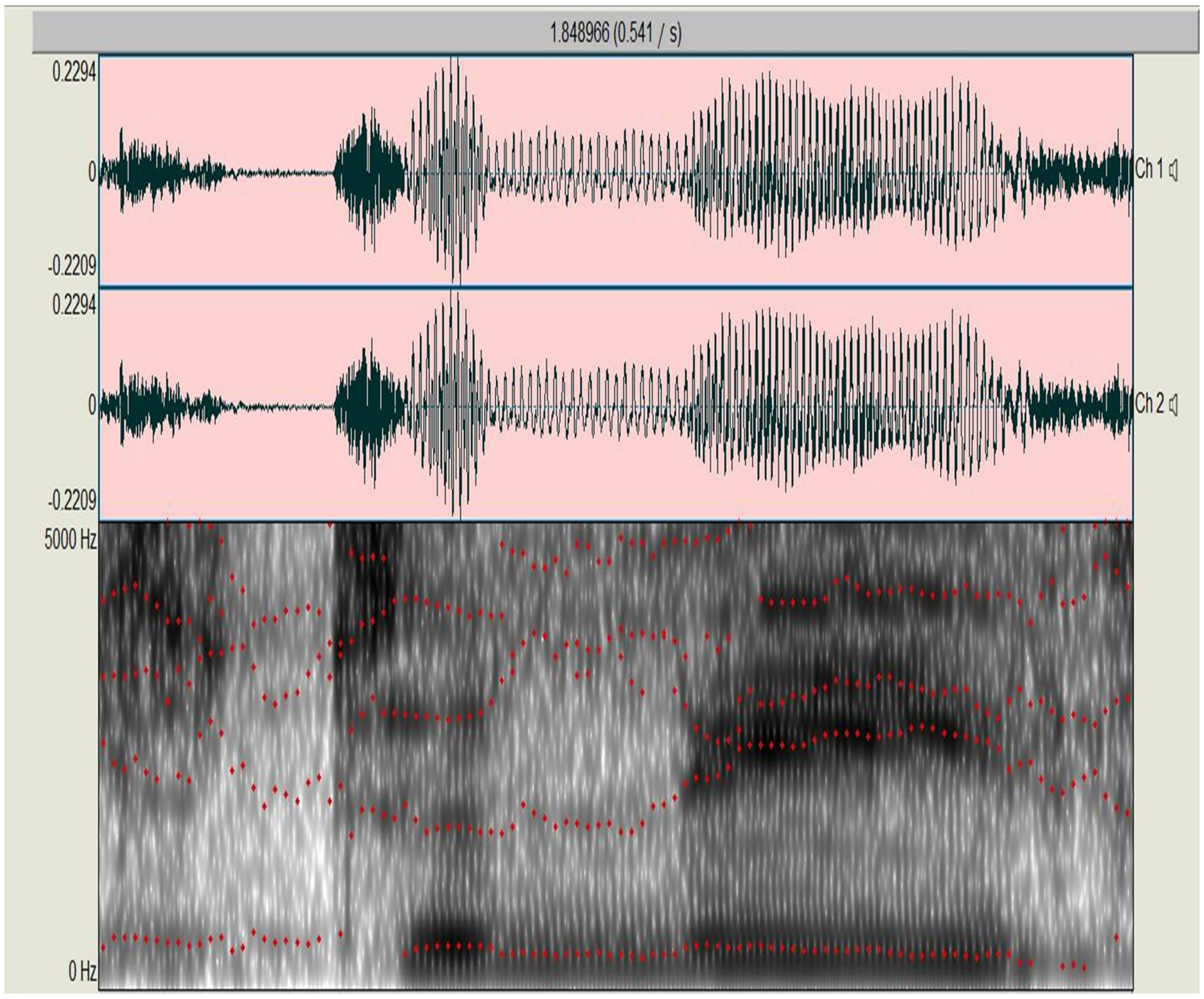

Figure 21: Zoomed in Spectrogram of $t o$

These peaks of amplitude occur on lower frequencies due to the fact that the first formant (henceforth F1) relates to the tongue height while the tongue location relates to the second formant (F2). You can clearly see the darker sections. These are the formants for /3:/. 
Finally, the amount of energy used for a prolonged period of time shows that it is the long vowel /3:/.

Every vowel phoneme has clearly defined formants, and thanks to modern software we can actually analyse to what degree a given phoneme is pronounced in accordance to the current standard for a given country or community, thus adding an additional second opinion, besides the native speaker's analysis. Having two sets of results is extremely useful, not because of the comparable results, but especially when the software and the native's ear classify a phoneme differently. 


\section{Chapter 4: Study Design \& Data}

This chapter explains the design of the experiment and the research procedure. With the help of the information in Chapters 2 and Chapters 3, the research hypothesis and research questions can be clearly identified. Thus the position of this work will be clearly outlined (to compare several languages and study the mispronunciation) and the dimension that is appropriate (first an analysis by a native English professor, then error analysis by spectrography) to successfully achieve this goal. This chapter also combines both the process followed and the procedure in order to explain the whole process at the same time.

There are "Three Ignoble Truths" that are essential in research planning. Knowing them and interiorizing them will avoid producing no findings at all. Every truth bears wisdom that should not be ignored by researchers, since they refer to things that are out of our hands.

The Three Ignoble Truths are (Petre \& Rugg, 2004, p. 111):

- $\quad \mathbf{1}^{\text {st }}$ Ignoble Truth: hardware will break and software will crash

- $\mathbf{2}^{\text {nd }}$ Ignoble Truth: resources will not be there when you need them

- $3^{\text {rd }}$ Ignoble Truth: people will get sick, die and fail to deliver

The first truth deals with technology, and how easily it can malfunction. In the same way, when you prepare a speech or presentation, you prepare a plan B and C in case your microphone is not going to work, there is an electrical shortage, the computer breaks down precisely the day of your speech, the computer is unable to read your presentation, etc. During this course of this research, two computers broke down and one even got infected with Ransomware which promptly destroyed everything that was written up until that point and was not saved on an external hard drive or saved on some cloud. 
The second truth considers resources, both external and personal. If you rely on equipment that does not belong to you, you may run into the unfortunate situation that someone will need the same equipment the same day at the same time and he will borrow it first, or will pull rank and get it anyway. Again, it is important to plan in advance for situations where you are left without equipment. It could also refer to quiet recording rooms that due to their soundproof nature are popular even among non-researchers and subsequently need to be set aside as soon as possible.

The third truth refers to people and how they strangely enough seem to have a life and will of their own. Participants telling you that they will help you out and be on time for your research is not necessarily a gentleman's agreement. Consequently, preparations should be made to not lose resources and time when the majority of them do not show up. This is one truth that proofed fatal during the pilot survey test and it is probably the one problem during this research that needed to be palliated the most.

\subsection{Preliminary Pilot Survey and Recordings}

A pilot study is usually a small-scale research project that guides the development of the research plan. It is conducted before the final full-scale study (Ismail, 2018) in order to identify strengths and weaknesses of the research process. This feedback helps the researcher to adjust and refine the methodology used in the final research project by:

1. Testing with a small group the time and resources (human, economic and technical) needed to complete the final research on a larger scale

2. If the methods used in the pilot survey are the most adequate ones for completing your aims

3. It helps to single out methodological issues and filter research questions 
Important proclaimer: Personally, this preliminary pilot survey cannot be considered a full-fledged intentional Pilot Survey in its academic definition. It was more a first trial run in which some honest mistakes were made that were then remedied with the invaluable help of experts in the field. Despite advice from experts and attempts to control for as many factors as possible in the research, any remaining mistakes are my own.

Obviously the first thing to do was to decide which ethical principles to apply, when you have human participants responding to questionnaires and letting them get recorded by a researcher. The approach to research ethics, based on principles, is the following (Petre \& Rugg, 2004, p. 107):

- Principle 1, compliance with protocol: research with humans follows a strict protocol, wherein informed consent to participate is sought, gained and accepted by sitting down for the recording. Additionally, participants are informed how data is collected, stored and later accessed and finally, participants are also informed about their rights.

- Principle 2, informed consent: participants are always informed in advance and in clear terms of potential benefits, risks, inconveniences and obligations related to the research that might affect their willingness to take part in it.

- Principle 3, openness and integrity: researchers must be open and frank about the purpose and the subject matter of their research. Researchers must also behave professionally at all times.

- Principle 4, protection from harm: researchers must assure, to the best of their abilities, to minimize the risks or harms, be it physical or psychologically, that could arise, not only for any participant, but also to the institution. 
- Principle 5, confidentiality: with the exception of written consent, researchers must respect and preserve the confidentiality of the participants' identities and data at all times.

- Principle 6, professional codes of practice and ethics: when the subject of research belongs to the domain of a professional body with an already established code of practice and ethical guidelines, researchers must comply with the codes and guidelines.

The second thing to define was the research question. Finding questions that can be answered does not automatically make them worth asking (e.g. do xenophobes have a harder time learning new languages, or any language at all). The best strategy is usually, to ask a question in such a way that, whatever the results are, the outcome will prove interesting and useful.

In this case it involves a problem that has not been resolved by researchers for many decades, which means that the solution is probably somewhere unlikely and that the aim should be less the true answer, but instead to reduce the problem space. A wonderful metaphor for this is the meticulous sea captain that maps unknown seas and territories, instead of the intrepid captain risking the life of his crew finding El Dorado.

In this research, and despite having a very specific group of participants, opening paths to a solution of a century-long problem does not seem like a shoo-in, that is the reason why instead of finding the definitive solution to the perfect acquisition of vowel phonemes by EFL learners, the main interest lies in proposing new angles at which to look at problems and obtaining more data as a result of using more perspectives on old problems.

The research questions of this thesis involve comparing phonetic difficulties by EFL learners from native speakers of different languages by obtaining recorded evidence of 
phonetic mispronunciations of English vowel phonemes. Subjects coming from different countries were needed and travelling to several countries and recording local students was out of my financial reach.

In order to circumvent the problem of not being able to access native speakers in their home countries, the ORI (oficina de relaciones internacionales) at the Jaume I University was contacted. They were kind enough to send an email to all the exchange students ${ }^{5}$, advertising the probability to participate in a language experiment that would help them improve their English pronunciation. This email, sent in November 2017, did not go into details, describing the nature of the experiment, since that could bias the results. However, it did explain, that after the experiment there would be a small explanation on how to self-improve pronunciation through the means of recording your own speech.

The participants had to fulfil several criteria: being born and having grown up in their respective country (at this point of the research the potential countries that were considered were Spain, Germany and Japan), being at least 18 years old, preferably monolingual, having studied English at school and now studying or having a college degree not related to anything English (English, Translation, Literature and the sorts).

At that point the criterion for comparing different languages was distance, the (literally geographically) distance between them and UK. Accordingly the countries chosen were picked along these lines. The subjects should be as homogenous as possible and thus it was decided to look for a monolingual profile for all EFL participants in this research.

Picking adults attending college is making a virtue of necessity. Ideally, the recordings would take place in the other countries needed for this research, but as previously explained, it was not possible. One of the easiest ways to access foreign speakers is through

\footnotetext{
${ }^{5}$ Thanks a lot to Professor Mercedes Sanz Gil.
} 
several student exchange programs at college. In this case thanks to the help of the ORI the researcher was able to get in contact with potential subjects.

Avoiding students working on a degree in any field related to English seemed essential. Supposedly, students in those fields would be better trained in pronunciation, while it would be better for the research to find a profile of participants that would be as near as possible to the average adult monolingual speakers in every country. EFL is mandatory in many countries around the world, but it was important to profile differently in this research and thus look for possible subjects interested in tertiary education in non-English degrees.

There is no mention of gender, as no differences were expected in this respect in the current study. However, it was fully expected to find a slightly higher percentage of females among the possible subjects. This is due to the higher enrolment percentage of females in tertiary education. In Japan, a traditionally male dominated college world, in 2018 females made up, for the first time, 50.1\% of all college students (Mishima et al, 2018), German females made up constantly at least $53 \%$ of all students in German colleges in the last decade (Hobler et al., 2016) and in Spain that percentage rises up to 55\% (Molina, 2018).

Only 7 people replied, and some bailed even after confirming participation. Tied to this, some of the responses said that they wanted to participate, but were unable to be recorded on the set date, Friday December $1^{\text {st }}$. This is another serious problem that had to be dealt with for the definitive recording session.

On the day of the recording session several logistical problems were encountered: recording several students at the same time is not an ideal solution. Despite explaining the exact procedure before the recording, questions were asked while others were already recording their lines, which is far from ideal. However, the recording room and the professional equipment mitigated the unnecessary noises. 
From the technical point of view, using Audacity (https://www.audacityteam.org) as recording program proved to be a good idea, since its intuitive interface turns recording and exporting those recordings into different formats an easy task. WASP (https://www.phon.ucl.ac.uk/resource/sfs/wasp) was also an easy to use program to turn the recorded audios into something visible: spectrographs. At that point of the research, the program seemed useful but it would later be exchanged for an even better program available to the research community, PRAAT (https://www.fon.hum.uva.nl/praat).

On the content and methodological part, there were also some details that needed fine-tuning. One thing that was not evident during the elaboration of the prep questionnaire was that there were still some important questions missing in relation to background information about the participants. Additionally, the text the participants had to read had not enough items of every English phoneme needed for analysis. Both of these mistakes were immediately pointed out by an expert professor when he looked at the preliminary research.

All in all, this test run already showed a handful of the things that can go wrong, that would have never passed a first time researcher's mind during prep time for the definite research investigation. Accordingly, this facilitated the possibility to come up with several solutions.

People not wanting to participate or even bailing after having agreed to participate can be traced back to lack of interest. Which is understandable, therefore something was needed to motivate students in order to come willingly and help me get data. Economic rewards seemed suitable in order to recruit students and prevent drop-outs during the study.

Money alone was not enough to motivate them though. During the recruitment phase for the definitive research some interested speakers asked about the monetary reward that entailed their participation. For better or worse, I have been working the majority of the time 
doing my Ph.D., in order to support me of course, and to do a research stay and pay for other doctorate-related things. This facilitated the possibility to spend some money on students, but overpay them was out of reach nevertheless. Additionally, recording the pronunciation and filling out the questionnaires takes a maximum of 10 minutes, which means that overpaying speakers for their participation was unethical. So, when some replies showed a slight discontent about the low rate for 10 minutes of work, free beverages were added to the equation. Money and free beverages solved the low commitment to the research project and it also solved the low number of responses.

The problem of participants not being able to show up, because they had something else to do, was easily solved by just adding more dates. The preliminary experiment was at a fixed date, at one fixed hour. For the definitive session, a plethora of available dates were organized. This way gave the possible participants more time to come by, and it also solved another problem: by having more time, it facilitated to record them one at a time, which means that a possible source of distraction and background noise was eliminated.

Regarding the mistakes in the questionnaire and the text: thanks to an expert professor, two more relevant questions were added, one asking the participants if they have an English certificate and the other one asking if they ever stayed in an English-speaking country (Appendix B). Professor Mompeán also recommended adding more items of each phoneme to the text (Appendix C), in order to have more examples of potential pronunciation mistakes. He also advised to take the clipping process into consideration and so it was included. For each English phoneme that had to be recorded, 5 examples were needed, two of them with clipping.

Since this was just a preliminary test run answers and recordings were not analysed. The small numbers would additionally lead to unfruitful results. But anyways, this 
preliminary pilot survey and recording served its purpose (making mistakes and fixing them for the definitive research).

\subsection{Survey}

The purpose of the questionnaire (Appendix D) was to gather information about the participant's language background. It started with a few general questions about age, gender, country of residence and length of stay in an English-speaking country and proficiency. Despite the questions being as less personal as possible (Appendix D), the researcher fully committed to the duty of care to these respondents and assured them that their names would remain out of the public by assigning them the name of their mother tongue and a number (e.g. the first Spanish participant would be called Spanish 1 or even Sp1).

Using a five-point Likert evaluation, the questionnaire could also ask questions about language learning and what factors they consider important in order to learn the proper pronunciation of a language.

\subsubsection{Participants}

Participants were recruited in four ways. They were contacted per email thanks to invaluable help of the International Offices from both Jaume I University and Murcia University. Emails were also sent to tutors of foreign exchange student and asked, if they were able to redirect this email to them. In total, 69 different emails were sent different professors, secretaries and associations. The vast majority of them replied immediately, and someone was even polite enough to reply months later. 
Popular gathering points for Erasmus students were also visited in order to recruit students or to convince them after reading the email, that their help would really be appreciated. The last recruitment option was by asking participants if they knew anyone that met the conditions and if so, redirect them the email.

The goal was to recruit at least 5 participants in any language, in order to even qualify for a very small sample size. Ideally, in a research like this the ideal minimum number was 10 upwards. After sending out the email, native speakers of all these 8 languages were asked to participate because it was important to keep all language options open and have as many subjects as possible in order to get more reliable size samples. Arabic proved very difficult from the beginning: not a single person replied, and when the Arabic Culture centre in Murcia was contacted, the person that answered the call made it very clear, that it would be difficult to find any help or volunteers.

In total, 37 students were interested and these participants were paid $5 €$ for their time and they also got a voucher for a free drink at the bar nearest to the college campus.

The participants had to fulfil certain criteria: having been born and raised in their respective country of origin, be of adult age (18+), being monolingual and having studied English at school but studying then a degree in a non-English field. Their gender is irrelevant. Subjects were recruited, as previously explained, at the university of Murcia and Jaume I.

The students were put into different groups according to their native language and 4 groups could be filled with the desired criteria:

1) a group of 10 Spanish EFL learners

2) a group of 11 French EFL learners

3) a group of 6 Russian EFL learners 
4) a group of 5 German EFL learners

These 4 languages fulfilled the criteria for this research: each language would be one of the windows in the Johari Window, and these languages would be distributed according to their isochrony (stress- or syllable-timed) and vowel system (simple with 5 vowel phonemes or complex with more than 5 vowel phonemes).

\subsubsection{Procedure}

The whole session was held in English. The level of English used for the description was as basic as possible. The participants were informed about their rights and the session was explained in detail. These instructions were delivered in basic English and if there were still communication problems, the researcher would be able to deliver them again in Spanish, German and French. For other languages (Italian, Russian, etc.) basic keyword instructions were prepared beforehand with the help of Google Translate (e.g. "Please read your rights", "please answer questions", etc.). Should this fail too, the researcher would have to cancel the appointment. Fortunately, this did not happen.

They were first recorded reading a text, and afterwards they had to fill out a questionnaire (Appendix D) after a short explanation on what they had to do. The part with the Likert-scale was explained conscientiously on how the scale reflects their opinion and also what every statement exactly meant. The majority of them only needed 2-3 minutes to fill it out. One of the question (“Are you monolingual?") served as a test question, in case anyone lied when asked about fulfilling one of the conditions. Participants that answered no, which means they're at least bilingual (any form of bilingualism), were eliminated from the sample. Afterwards, they got a thorough explanation of the meaning behind everything they did. 


\subsubsection{Results}

37 people from different countries participated, but since a bare minimum of 5 subjects was needed in order to represent each language, 5 subjects from 3 different countries (Portugal, Italy and Japan) had to be discarded. The final sample is thus reduced to $n=32$.

Table 12 summarizes general characteristics.

Table 12: Demographic Information and Language Background for Participants in Survey

\begin{tabular}{|c|c|c|c|c|c|}
\hline & TOTAL & Spanish & French & Russian & German \\
\hline$n$ & 32 & 10 & 11 & 6 & 5 \\
\hline Mean age & 24.97 & 23.5 & 22.27 & 33 & 24.2 \\
\hline Age range & $19-42$ & $19-40$ & $19-29$ & $22-42$ & $21-28$ \\
\hline Females & $65.63 \%$ & $60 \%$ & $81.81 \%$ & $50 \%$ & $60 \%$ \\
\hline $\begin{array}{c}\text { Monolingual } \\
\text { English }\end{array}$ & $100 \%$ & $100 \%$ & $100 \%$ & $100 \%$ & $100 \%$ \\
\hline $\begin{array}{c}\text { Certificate } \\
\text { Stay abroad }\end{array}$ & $50 \%$ & $70 \%$ & $45.45 \%$ & $33.33 \%$ & $40 \%$ \\
(x<1 month) & $81.25 \%$ & $80 \%$ & $81.81 \%$ & $83.83 \%$ & $80 \%$ \\
\hline
\end{tabular}

32 participants were studied. French had the most representatives, while German fulfilled the bare minimum of subjects needed. The mean $(\mu)$ age of all participants was 24.97 years. With the Standard Deviation being 6.5, the data shows us that the mean age of Russian participants stands out between $1 \sigma$ and $2 \sigma$, which situates it in the $95 \%$ area. $\sigma$ stands here for Standard Deviation. SD measures how far typical values tend to be from the mean.

If $\mu=24.97$ and $\sigma=6.5$ then: 
- $68 \%$ of the values in the data lie between $\mu-1 \sigma(24.97-6.5=18.47)$ and $\mu+$ $1 \sigma(24.97+6.5=31.47)$.

- $95 \%$ of the values in the data lie between $\mu-2 \sigma(24.97-13=11.97)$ and $\mu-$ $2 \sigma(24.97+13=37.97)$.

- $99.7 \%$ of the values in the data lie between $\mu-3 \sigma(24.97-19.5=5.47)$ and $\mu$ $+3 \sigma(24.97+19.5=44.47)$.

The smaller the SD, the lower the dispersion of values. Here our SD is not as low, which reflects the wide age range of participants that were recorded for this project.

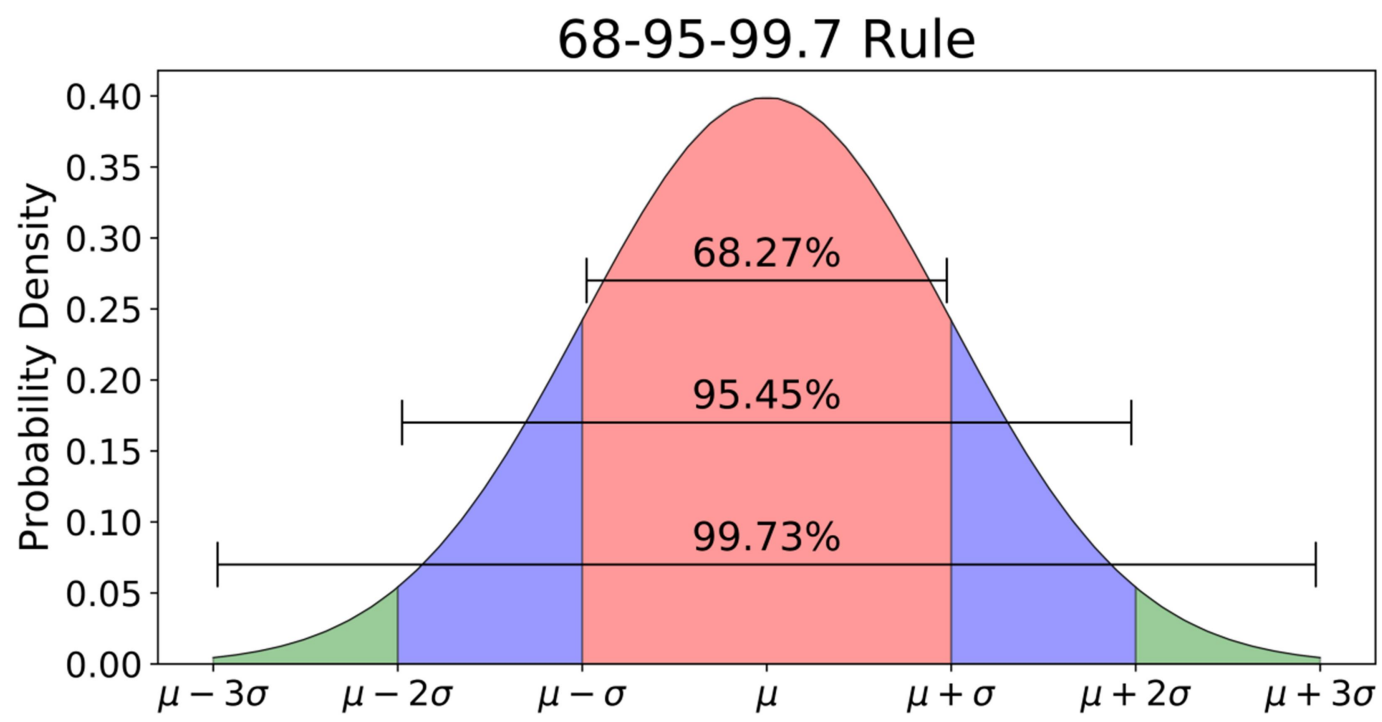

Figure 22: The 68-95-97 Rule (Source: www.towardsdarascience.com)

The $68-95-97 \%$ rule (figure 18 ) refers to the fact that $68 \%$ of the data falls within $1 \sigma$ of the mean. $95 \%$ of the data falls within $2 \sigma$ of the mean. $99.7 \%$ of the data falls within $3 \sigma$ of the mean. And only $0.3 \%$ deviates more than $3 \sigma$ from the mean. For our participants it means that the Russian ones are not as homogeneous as the rest of the languages in regards to age, but since the size sample is quite small $(n=6)$ and it only falls in the $2 \sigma$ range, it is neglectable. 
The age range is $19-42$ and females make up $65.63 \%$ of all participants. We previously established that nowadays females make up more than $50 \%$ of students at universities, so having a mean average of $65.63 \%$ is a bit higher than expected, especially French females that make up $81.81 \%$ of the French language participants. Since we had limited access to possible participants and the gender was of no importance for the analysis and results in this work, we can accept the fact that the females that were contacted for this study were more interested in research project and move on. The test question about the participants being monolingual was answered satisfactorily by all of them.

English certificates were obtained by $50 \%$ of the participants. Only one third of Russians participants had any sort of English certificate, whereas $70 \%$ of Spanish participants had an English certificate. This coincides more or less with the background on EFL in each language. Spain has put an emphasis on English learning for a long time, and made it abundantly clear that you need a degree in English, where Russia, due to historical and current political situation is still a bit behind the (English learning-) curve compared to the rest. See Table 13 for a detailed overview of the English certificates obtained by the participants. 
Table 13: English Certificate Distribution among Participants

\begin{tabular}{|c|c|c|c|c|c|c|}
\hline \multicolumn{2}{|c|}{} & Total & Spanish & French & Russian & German \\
\hline \multicolumn{2}{|c|}{ n } & 32 & 10 & 11 & 6 & 5 \\
\hline \multicolumn{2}{|c|}{ None } & $50 \%$ & $30 \%$ & $54.55 \%$ & $66.67 \%$ & $60 \%$ \\
\hline \multirow{3}{*}{ Cambridge } & A2 & $6.25 \%$ & $20 \%$ & $0 \%$ & $0 \%$ & $0 \%$ \\
\cline { 2 - 7 } & B1 & $9.38 \%$ & $30 \%$ & $0 \%$ & $0 \%$ & $0 \%$ \\
\cline { 2 - 7 } & B2 & $18.75 \%$ & $20 \%$ & $27.27 \%$ & $0 \%$ & $20 \%$ \\
\hline \multicolumn{2}{|c|}{ IELTS C1 } & $3.13 \%$ & $0 \%$ & $9.09 \%$ & $0 \%$ & $0 \%$ \\
\hline \multicolumn{2}{|c|}{ Other non-specified } & $9.38 \%$ & $0 \%$ & $9.09 \%$ & $16.67 \%$ & $20 \%$ \\
\hline
\end{tabular}

The question about the length of stay in an English-speaking country was the one with the biggest homogeneity amongst all participants. The average time spent in an Englishspeaking country was less than one month for $81.25 \%$ of all participants, with only the smallest variations in percentages amongst the languages. This can be once again explained, thanks to the particularities of the selected participants, since the research focused on students with non-English degrees.

After the general background information, it is time for the participant's opinions about English learning and pronunciation. This information was asked using a Likert-scale type of questionnaire, where 5 means "Absolute Agreement", and 0 means "Total Disagreement". Figure 23 is a visual and statistical summary of the first four questions in the Participants’ Background Information survey. 


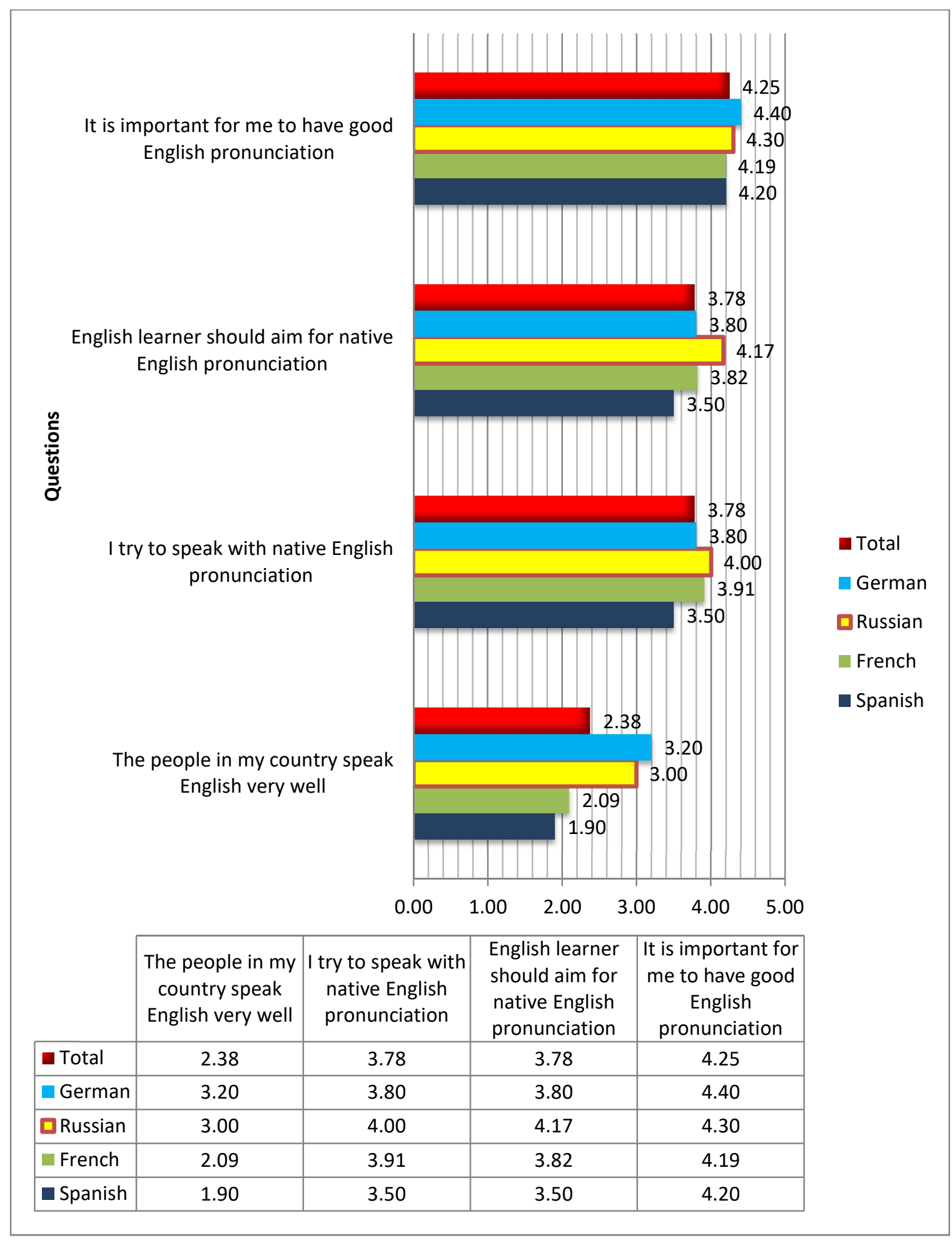

Figure 23: Participant's Background Information Analysis

As we can see, the first question "It is important for me to have good English pronunciation?" was answered with very strong agreement. The $\mu$ is 4.25 and all groups of 
participants have more or less the same sentiment towards the importance of having a proper English pronunciation.

"English learner should aim for native English pronunciation" is the second statement and the consensus here is that, yes, it is important but with the exception of Russian participants $(\mu=4.17)$ that feel very strongly towards it, the rest of the groups simply agree with the statement with a so-so $\mu=3.78$.

"I try to speak with native English pronunciation" is the third statement and the consensus among the participants was that it was important $(\mu=3.78)$ with little variations between the countries. Spain agreeing here a bit less than the rest with $\mu=3.5$ but it is still a strong positive sentiment.

The fourth statement "The people in my country speak English very well" is the most disperse so far. The general consensus is slightly negative with $\mu=2.375$, and on the one hand we have two countries that think their countries speak well enough (Russia and Germany with $\mu=3$ and $\mu=3.2$ respectively) and on the other Spain and France that have somewhat strong negative feelings towards that statement (Spain with a quite low $\mu=1.9$ strongly disagrees and thinks that English is not spoken very well here).

The following part consists of factors related to English pronunciation. The participants were asked to use the Likert-scale to evaluate these factors according to their personal opinion on what is most important for language learning. The results can be seen in figure 20 . 


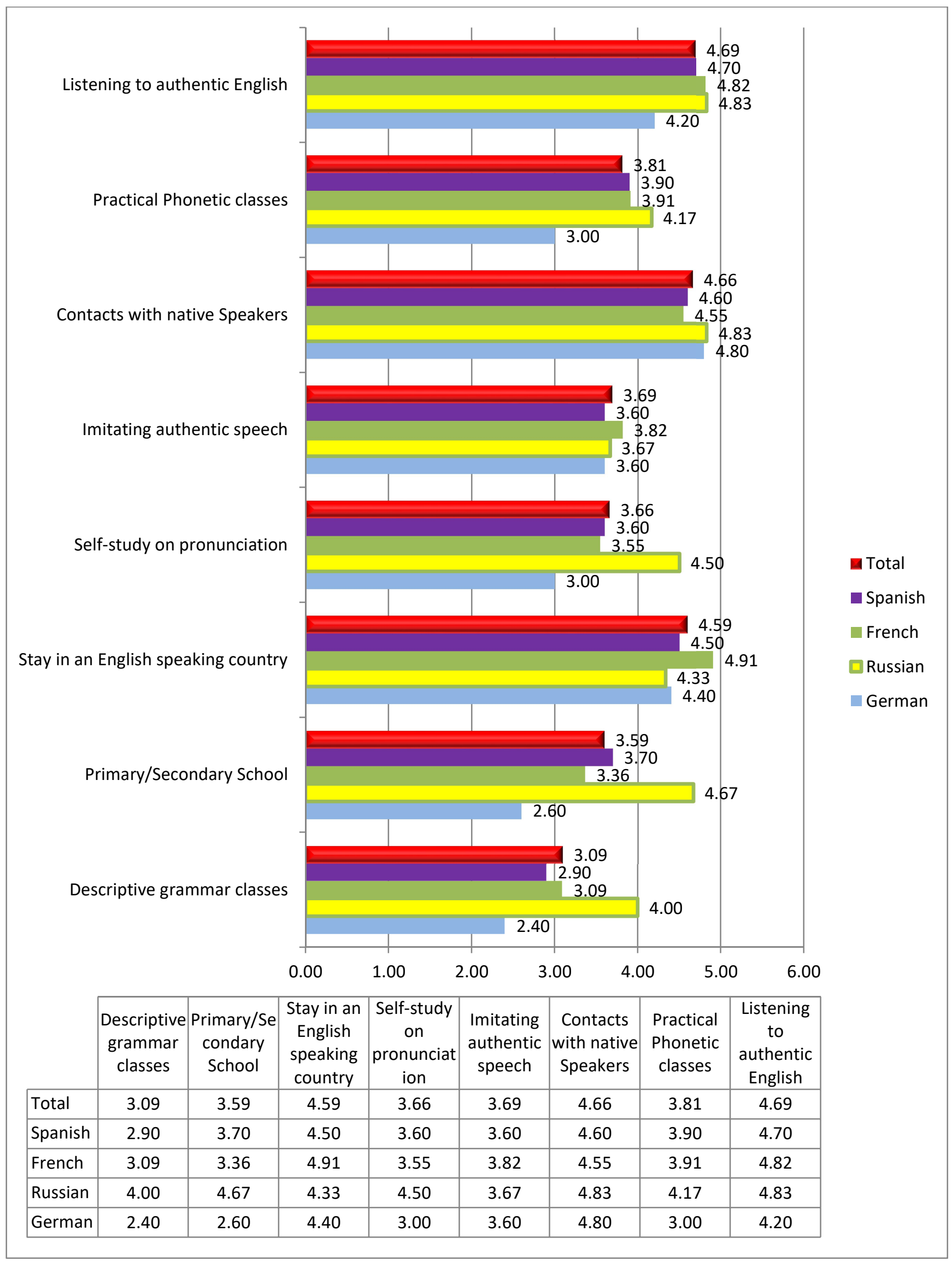

Figure 24: Survey on Most Important Pronunciation Factors 
The factor "Listening to authentic English" refers to the exposure to real English speakers instead of the artificial recordings during classes. The consensus here among the 4 countries is very strong $(\mu=4.69)$, which means that people consider it one of the most important things to do, when you aim for proper pronunciation. In fact, this factor is in the top three lists of factors in all 4 countries (Russia gave it an almost perfect note, the $\mu=4.83$ ).

"Practical Phonetic classes" refers to classes focused on teaching students the notions of Phonetics. While the general consensus is quite positive $(\mu=3.81)$, there are some slight disagreements. Germans only consider somewhat important, with an above average $\mu=$ 3, while Russian consider it one of the most important factors by giving it $\mu=4.16$.

"Contacts with native speakers" refers to actually meeting native speakers (on a stay abroad or them being exchange students here). It is another factor that is considered extremely important all across the board, one of the most quintessential factors in order to have good pronunciation $(\mu=4.66)$. Russian and German participants gave it a near perfect score $(\mu=4.83$ and $\mu=4.8$ respectively).

"Imitating authentic speech" refers to the technique that by listening and copying or even exaggerating phonetic features of the target language one can improve the pronunciation. The consensus here is that it is a solid factor $(\mu=3.69)$ with no major variations among the languages.

The factor "self-study on pronunciation" referring to people recording themselves and listening back to what they have said in order to improve their pronunciation is another factor that is considered solid $(\mu=3.66)$, but German think less of it $(\mu=3)$ whereas Russians have it among the top factors needed to improve English pronunciation $(\mu=4.5)$. 
"Staying in an English speaking country" is the last part of the holy trifecta of factors considered essential for language learning $(\mu=4.59)$. The unanimity is strong again, but France gave it the highest score in the whole questionnaire $(\mu=4.9)$ and since they also had the largest amount of participants in this project $(n=11)$, it can be considered, one of the most statistically significant findings in this survey.

"Primary/Secondary school" is a somewhat more general question related to the usefulness of learning English at a very young level. Participants considered it important $(\mu=$ 3.59) although Germans thought that it had no real influence $(\mu=2.6)$ and Russians scored it very high $(\mu=4.6)$.

The last factor "Descriptive grammar classes" is without an ounce of a doubt, the worst considered factor $(\mu=3.09)$. It gets a general slight approval, but there are discrepancies. Germans fail it, by giving it the worst score in the factor section $(\mu=2.4)$ while Russians consider it important $(\mu=4)$.

All in all, table 14 shows what all the participants considered the best factors in order to acquire a proper pronunciation and the mean score. 
Table 14: Most Important Pronunciation Factors in Survey

\begin{tabular}{|c|c|c|}
\hline Position & Factor & $\boldsymbol{\mu}$ \\
\hline $\mathbf{1 .}$ & Listening to Authentic English & 4.69 \\
\hline $\mathbf{2 .}$ & Contacts with Native Speakers & 4.66 \\
\hline $\mathbf{3 .}$ & Stay in an English-speaking Country & 4.59 \\
\hline $\mathbf{4 .}$ & Practical Phonetic classes & 3.81 \\
\hline $\mathbf{5 .}$ & Imitating Authentic Speech & 3.69 \\
\hline $\mathbf{6 .}$ & Self-study on Pronunciation & 3.66 \\
\hline $\mathbf{7 .}$ & Primary/Secondary School & 3.59 \\
\hline $\boldsymbol{8 .}$ & Descriptive Grammar Classes & 3.09 \\
\hline
\end{tabular}

The rankings for the individual languages can be found in the Appendix section, but there are two things noteworthy about this data:

The top three factors are almost the same across all 4 languages (Russians also consider "Primary/Secondary School" a very important reason behind proper pronunciation)

The three least liked factors are also generally the same, as the ones in the table above, with "Descriptive Grammar Classes" being the least positive aspect of English pronunciation.

This questionnaire serves two purposes:

- To acquire some statistical data about the groups and their participants (but also acknowledging the limitation for generalization due to the limited numbers) 
- To gather personal data about how they think proper English pronunciation is acquired

The results show that all groups value more social ways of acquiring a proper English pronunciation than Phonetic classes. Despite Phonetic classes ranking 4th, $\mu$ is one tier below the first three factors. It also shows that all groups value less starting to learn as early as possible English (except Russian), and descriptive grammar clauses are considered the least helpful for English pronunciation.

\subsection{Recordings}

The purpose for these recordings were to analyse the English pronunciation of the EFL learners from different countries, more specifically the mispronunciation of 12 English vowel phonemes / I, v, e, ə, p, æ, $\Lambda$, i:, u:, o:, 3:, a:/.

\subsubsection{Participants}

The participants were the same as in the previous Survey participants' description, since the questionnaire and the recording were held in the same session.

\subsubsection{Procedure}

There were several recording sessions held throughout the months of February $\left(15^{\text {th }}\right.$, $16^{\text {th }}, 21^{\text {st }}, 22 \mathrm{nd}$ and $23 \mathrm{rd}$ ) and the $15^{\text {th }}$ of May 2018 . At the Jaume I University, they were recorded in a separated sound-proof room in the basement of the Faculty of Human Sciences ${ }^{6}$. At the University of Murcia, they were recorded in a separated quiet study room in the office

\footnotetext{
${ }^{6}$ Thanks to my tutor professor Navarro Ferrando for giving me access to the keys
} 
building near the faculty of languages that usually has students silently learning during the afternoons, but during the recording sessions no one was there ${ }^{7}$.

The recording was made in both locations with a laptop and the Audacity recording software. The microphone used for all the recording sessions was a Samson microphone (model C01U Pro), which is considered a professional device to record music, broadcasts, podcasts and linguistic recordings. The setup itself consisted of a table with a laptop, the microphone on a professional tripod stand and a paper (Appendix E: Research Reading Exercise) the participants need to read.

Once the participants accommodated themselves, I started to give precise instructions, in English, explaining what was expected of them. If they understood these instructions and had no doubts or questions, I proceeded to move the paper with the text in reading distance, afterwards I moved the microphone to an ideal distance from their mouth and as soon as the person signals me that we can begin I start the recording and remain quiet and calm until the participant stops reading.

The text consists of 28 sentences. Some linguists use nonce-words for their research (Mahood Macey, 2019; Hohenhaus, 2007), but this research preferred to use nonsensical sentences in order to not give any indication at all about the purpose of my research. Using nonsensical sentences does not mean nonsensical words, it just means that the sentences do not make sense (e.g. "The child opened the door and was pulled up the sky"). But I was aware that nonsensical sentences can flabbergast or even stupefy the participants, thus I decided to give some breathing room and a small window for accommodation. The first 5 sentences in the text are of no research value and only serve to put the participant at ease or even relax them, if the thought of getting recorded may worry them. The remaining 23

\footnotetext{
${ }^{7}$ Thanks to professor Mompeán González and the people at the office building for their help and collaboration
} 
sentences contain at least one example of the vowel phonemes I was interested in. As indicated earlier, each vowel phoneme gets 5 items in my text. Thus, the remaining 23 sentences contain a total of 60 items for later analysis. The complete recording process usually lasted between 1:40 and 2:30 minutes.

Once they finished reading, I waited a few seconds and then stopped the recording. I asked them to please change the seat and sit at the opposite end of the table where another paper was waiting for them, the Participant's Background Information Survey (Appendix D). In English again, I explained to them thoroughly what they had to do and also what each factor referred too. Once they understood everything and had no doubts and questions, I gave them a pen and they could start the survey.

Meanwhile, the instructor checked per Audacity if the recording went well and if it is possible to do some spectrographic analysis later on. The participants usually took 2 to 5 minutes to finish the questionnaire. Afterwards, it was explained to them the motivation behind the research project. If they were interested, they were able to listen to their own recording and observe the specific vowels of interests.

The obtained data were analysed on May 23th 2018 with the assistance of Professor Richard Mark Nightingale, an England-born researcher interested in Multilingualism, sociolinguistics, pragmatics, contextual linguistic factors and language learning. Over the course of several hours all the valid recordings (at least 5 participants per language) were analysed. A simple tick marked if the phoneme was pronounced appropriately, and an $\mathrm{x}$ marked a mispronunciation. In total, 1920 items were analysed. 


\subsubsection{Results}

Table 15 shows the amount of phonetic mispronunciations of English that every language, represented by its research participants, has produced. The table also shows the total amount of mistakes (mispronunciation) committed by all of the languages together.

Table 15: Phonetic Mistakes by EFL Learners from Spain, France, Russia and Germany

\begin{tabular}{|c||c|c|c|c|}
\hline & $\boldsymbol{n}$ & items & Phonetic mistakes & $\boldsymbol{\mu}$ \\
\hline Spanish & 10 & 600 & 131 & $21.83 \%$ \\
\hline French & 11 & 660 & 129 & $19.54 \%$ \\
\hline Russian & 6 & 360 & 93 & $25.83 \%$ \\
\hline German & 5 & 300 & 36 & $12 \%$ \\
\hline \hline Total & 32 & 1920 & 389 & $20.26 \%$ \\
\hline
\end{tabular}

As we can see from the table above, the total $\mu$ for all languages is $20.26 \%$. The Spanish and Russian group mispronounce above the average $(21.83 \%$ and $25.83 \%$ respectively), while the French and especially the German group make fewer pronunciation mistakes (19.54\% and 12\% respectively). In broad terms, this reflects with the EF EPI chart from Chapter 2. Spain, France and even Russia are in the same tier, the average tier. Russia was barely included in the average tier of English proficiency in the 2018 index (EF, 2019), while Spain and France had average positions in the average tier.

However, France was the lowest ranked European country in the EF EPI 2018 and in the research project it scored higher than Spain. This could be explained by the fact, that the research participants from France were Erasmus students, while the Spanish participants were locals. Students that participate in the Erasmus program are expected to pass a language 
examination test (B1 or B2); this could explain the slight difference with the Spanish speakers: they were not Erasmus, but local students.

Germany, despite the very small sample, ranked highest amongst the four countries that participated in this project, which again confirmed the expected ranking.

A general overview of the 12 analysed English phonemes and which phoneme caused the biggest problems to which EFL learners would make a chart too big and unwieldy to add something of value. Therefore, in the next chapter, each phoneme gets its own section and problematic phonemes get looked at through spectrography. 


\section{Chapter 5: Discussion}

The idea behind this chapter is to offer information that we did not know before we started the project and subsequently help us to reach some conclusions. Theoretical results though need further validation before their suitability in real life is accepted.

\subsection{Human Review}

The obtained data needs to be systemised into different parameters in order to compare the 4 EFL groups and to get meaningful results. But first there is also some general data about the obtained results. Table 16 shows the ten most mispronounced words by EFL learners from the countries that participated in this research.

Table 16: Top Ten of Mispronounced Words

\begin{tabular}{|c|c|c|c|c|c|c|c|c|}
\hline & & & & & $\%$ of $\mathrm{S}$ & eakers th & at mispror & ounced \\
\hline & Phoneme & Word & № of mistakes & Clipping & Spanish & French & Russian & German \\
\hline 1. & & relative & 23 & Yes & $60 \%$ & $90.90 \%$ & $66.66 \%$ & $20 \%$ \\
\hline & $\partial$ & banana & 23 & No & $80 \%$ & $72.72 \%$ & $83.33 \%$ & $40 \%$ \\
\hline 3. & & alias & 21 & Yes & $80 \%$ & $72.72 \%$ & $50 \%$ & $40 \%$ \\
\hline & $æ$ & compact & 21 & Yes & $100 \%$ & $54.54 \%$ & $83.33 \%$ & $0 \%$ \\
\hline 5. & $a:$ & garage & 20 & No & $70 \%$ & $45.45 \%$ & $50 \%$ & $100 \%$ \\
\hline 6. & $æ$ & apple & 16 & Yes & $50 \%$ & $63.63 \%$ & $66.66 \%$ & $0 \%$ \\
\hline 7. & o: & awful & 14 & Yes & $50 \%$ & $27.27 \%$ & $83.33 \%$ & $20 \%$ \\
\hline 8. & $æ$ & fan & 13 & No & $90 \%$ & $54.54 \%$ & $66.66 \%$ & $0 \%$ \\
\hline & $\Lambda$ & other & 13 & No & $40 \%$ & $63.63 \%$ & $33.33 \%$ & $0 \%$ \\
\hline & $\Lambda$ & couple & 13 & Yes & $0 \%$ & $63.33 \%$ & $83.33 \%$ & $20 \%$ \\
\hline
\end{tabular}


From table 16, one can see that both /ə/ and /æ/ were the most difficult phonemes to pronounce. Especially /a/ completely occupies the top three positions with over 20 mistakes (bear in mind that over two out of three participants (71.88\%) mispronounced it). It was definitely the most difficult phoneme for Spanish EFL learners $(\mu=73.33 \%)$. The same phoneme was also troublesome for French EFL learners $(\mu=78.78 \%)$ and for Russians EFL learners it was also very high $(\mu=66.66 \%)$ but they had even more problems with $/ æ /(\mu=$ $72.22 \%$ ). Finally, all German EFL learners completely failed to pronounce the /a:/ in garage correctly.

\subsubsection{Spectrography}

Spectrography allows for a visual analysis of sounds. Vowels, as opposed to consonants, do not have a fixed place of articulation but each phoneme does have a realization and occurs at certain positions in the mouth. In a formant plot you can actually draw the spot at which the sound occurs and then compare it against the frequencies at which the sound should occur.

The following pages will cover the vowels used in this research:
a) /i:/

Figure 25 is a spectrogram of Sp1 pronunciation's mistake of leaf: As shown in the picture the vowel he pronounced has an F1 of approx. $480 \mathrm{~Hz}$ and an F2 of 1352Hz. Sp1 wanted to pronounce /i:/, which is a front unrounded (upper-high) vowel, whose frequencies are very different (both around F1: 294 and F2: 2343). Sp1 frequencies' would situate it in the upper-mid back unrounded section. It seems a plausible explanation that this is an error due to interference, since he is a Spanish EFL learner, and he possibly read the ea in leaf as 
an $e$. Further proof for this is that his tongue changed its position in the mouth $(\mathrm{F} 1: 510 \mathrm{~Hz}$ and F2: 1840), as if Sp1 was trying to pronounce a diphthong (Figure 21).

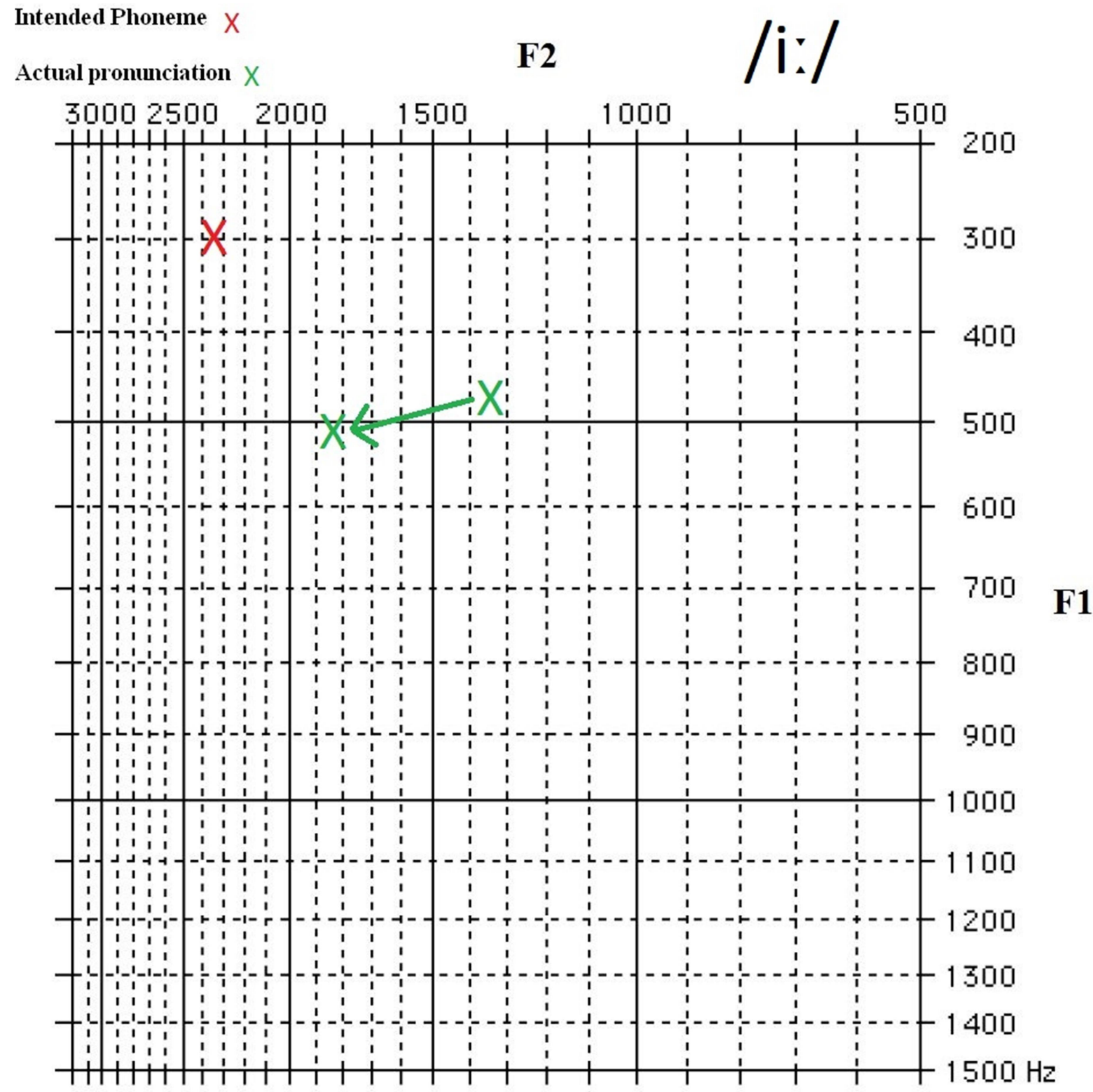

Figure 25: Misrealization of /i:/ Phoneme by Sp1 


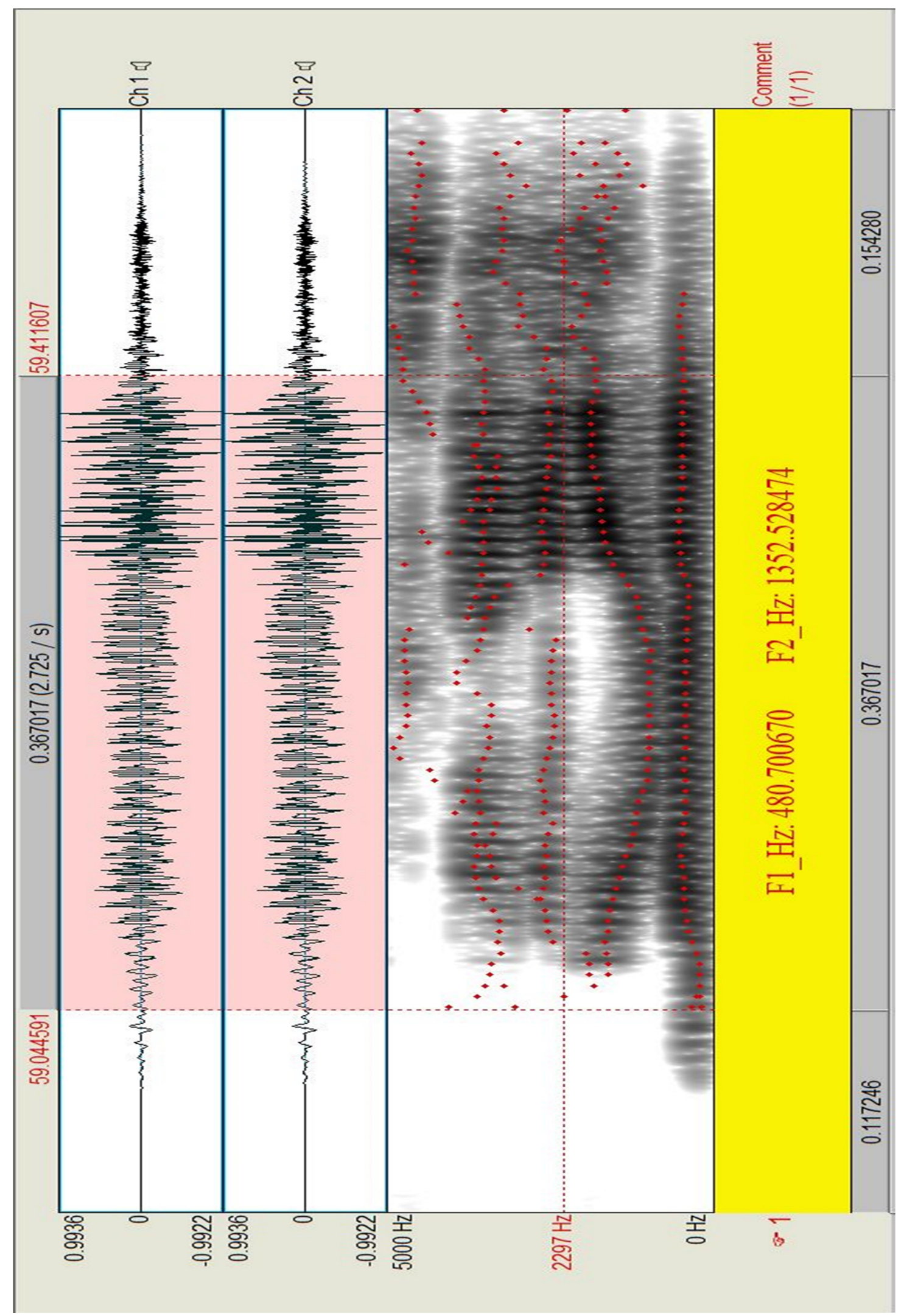

Figure 26: Spectrogram of Leaf by Sp1 
b) $/ \mathrm{I} /$

In Figure 26, we see the spectrogram of the mispronounced word recall by Ru2. The frequencies the participant used were lower-high front rounded (F1: 367 and F2:1864), while the phoneme /I/ has a similar height but it is more fronted (approx. F1: 360 and F2: 2187). This speaker was quite close to the target pronunciation (Figure 23)

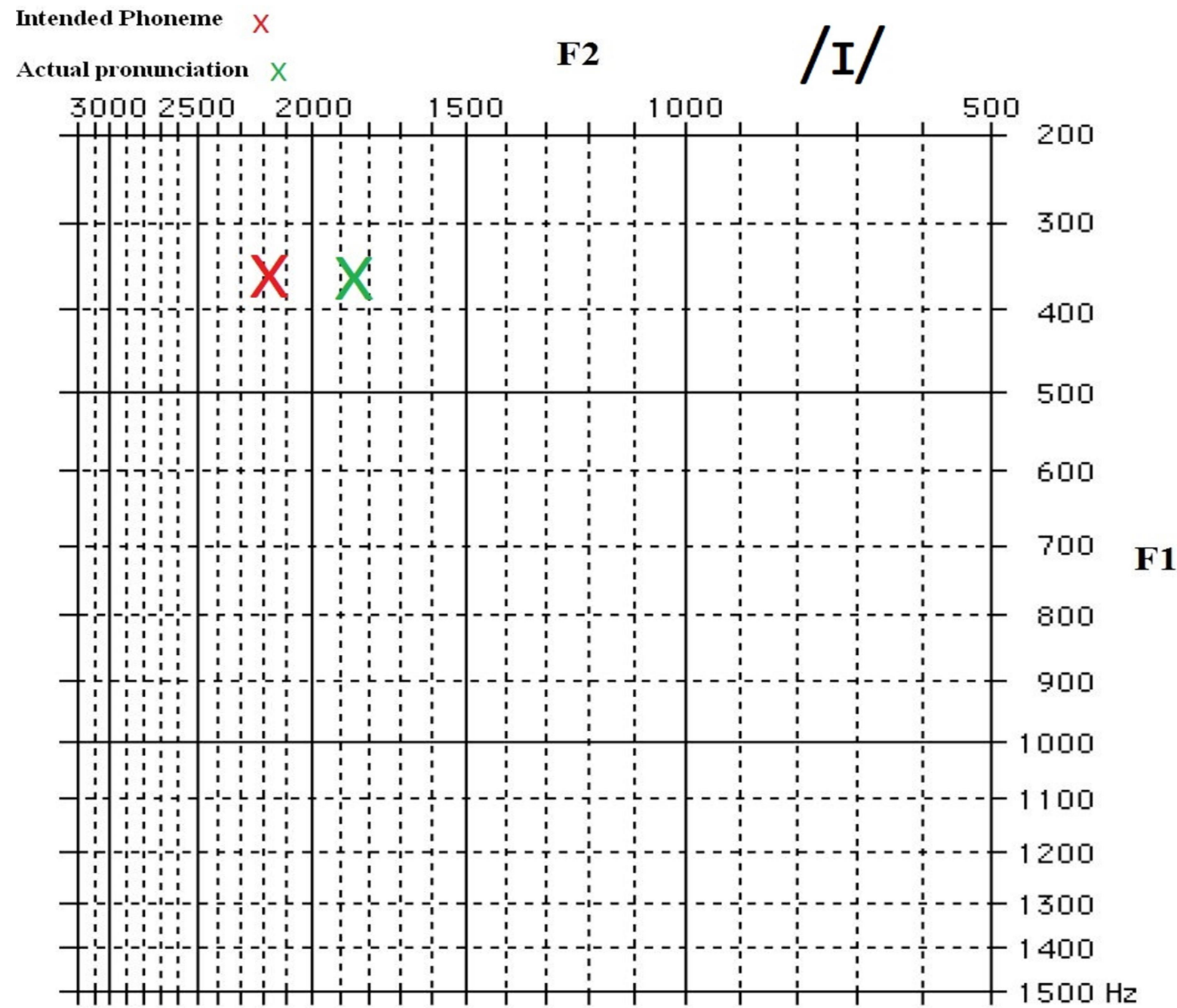

Figure 27: Misrealization of /I/ Phoneme by Ru2 


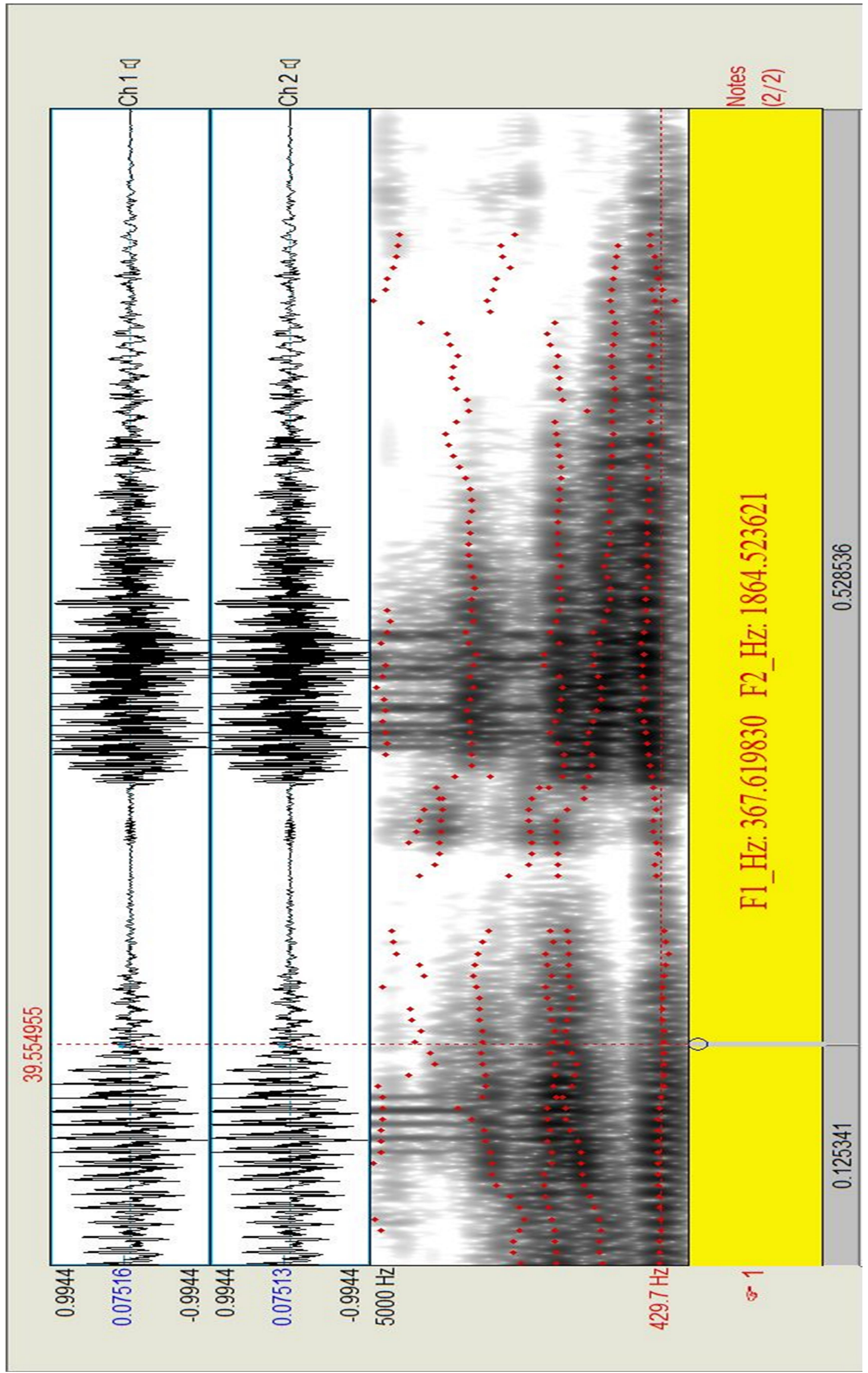

Figure 28: Spectrogram of Recall by R2 
c) $/ æ /$

In Figure 26, we take a look at how Fr5 mispronounced the word apple. The participant produced a lower-mid central vowel (F1: $611 \mathrm{~Hz}$ and F2: 1505Hz), while /æ/ (approx. F1: 766 Hz and F2: 1782Hz) is much more fronted and open. The speaker not only mispronounced the desired vowel, but also glided the vowel from the article the into the /æ/ phoneme, creating thus on the spectrography a formant that moves position as if it were a diphthong (Figure 26).

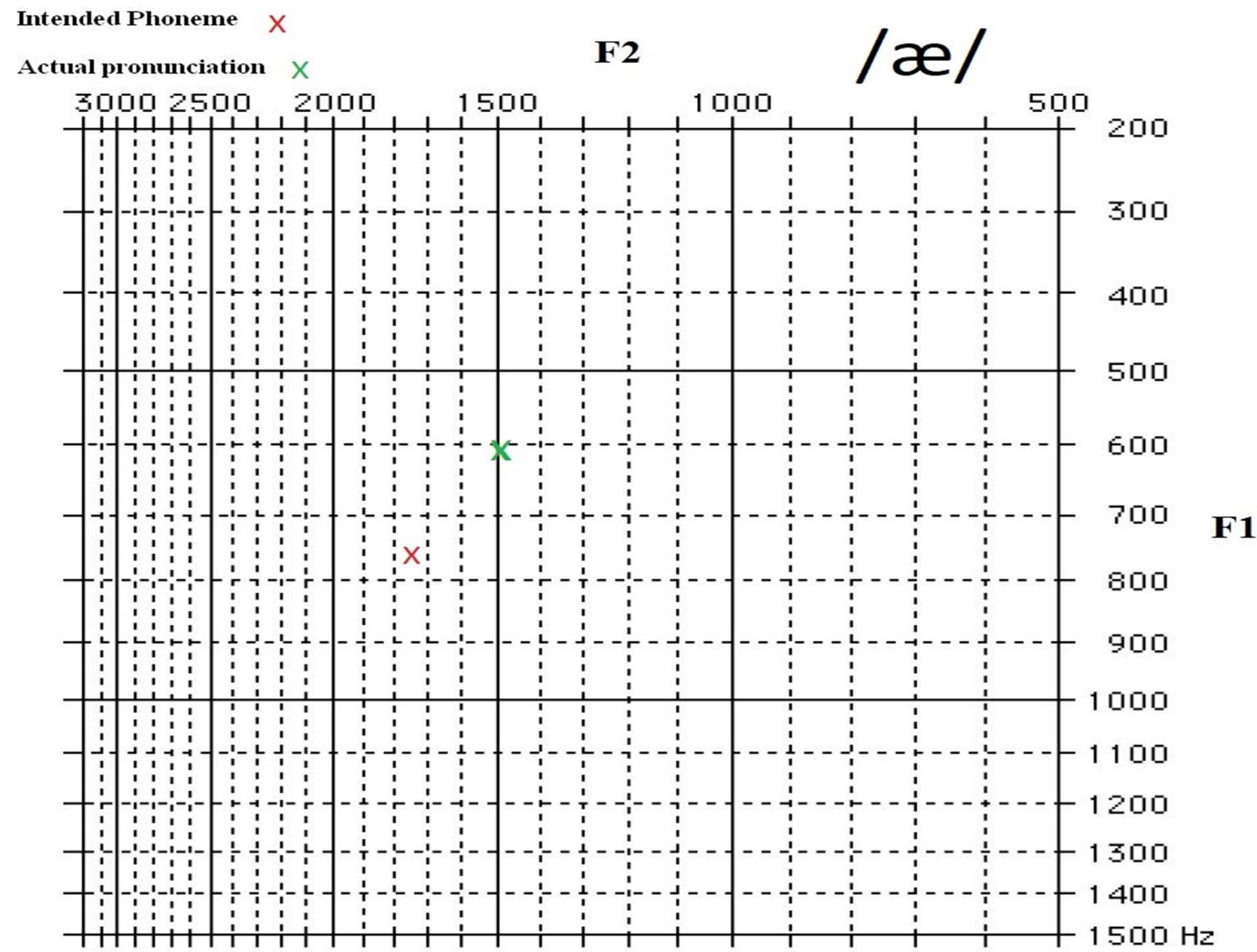

Figure 29: Misrealization of /a/ Phoneme by Fr5 


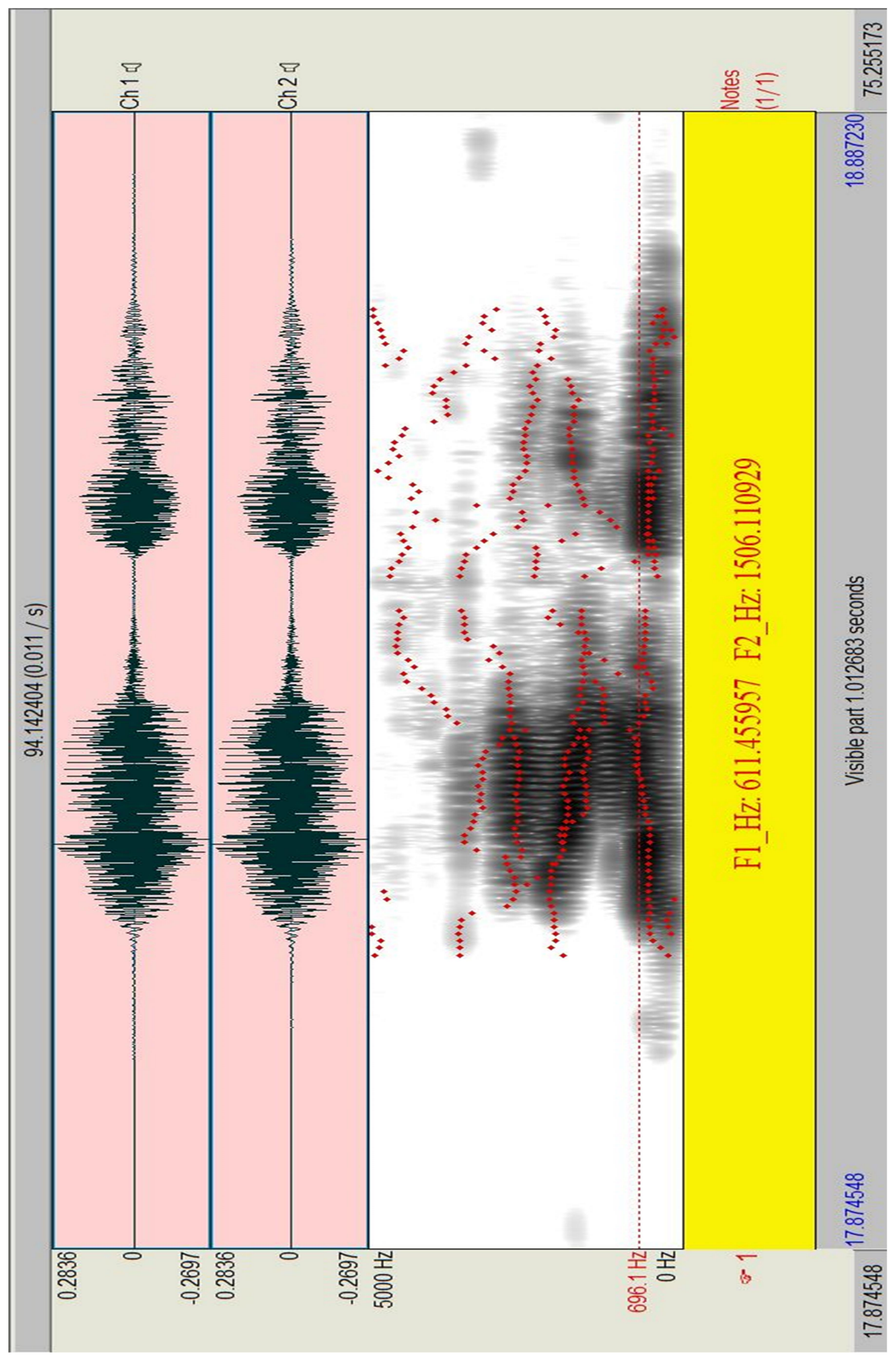

Figure 30: Spectrogram of The Apple by Fr5 
d) /a:/

In Figure 28, we have the spectrogram of the garage and how it was mispronounced by Ge2. The speaker used a lower-mid back unrounded vowel position (F1: $582 \mathrm{~Hz}$ and F2: 1200), while the phoneme /a:/ has a lower tongue position (F1: approx. 781HZ and F2: 1065). Ge2 maintained the longer duration of a long vowel though (Figure 27).

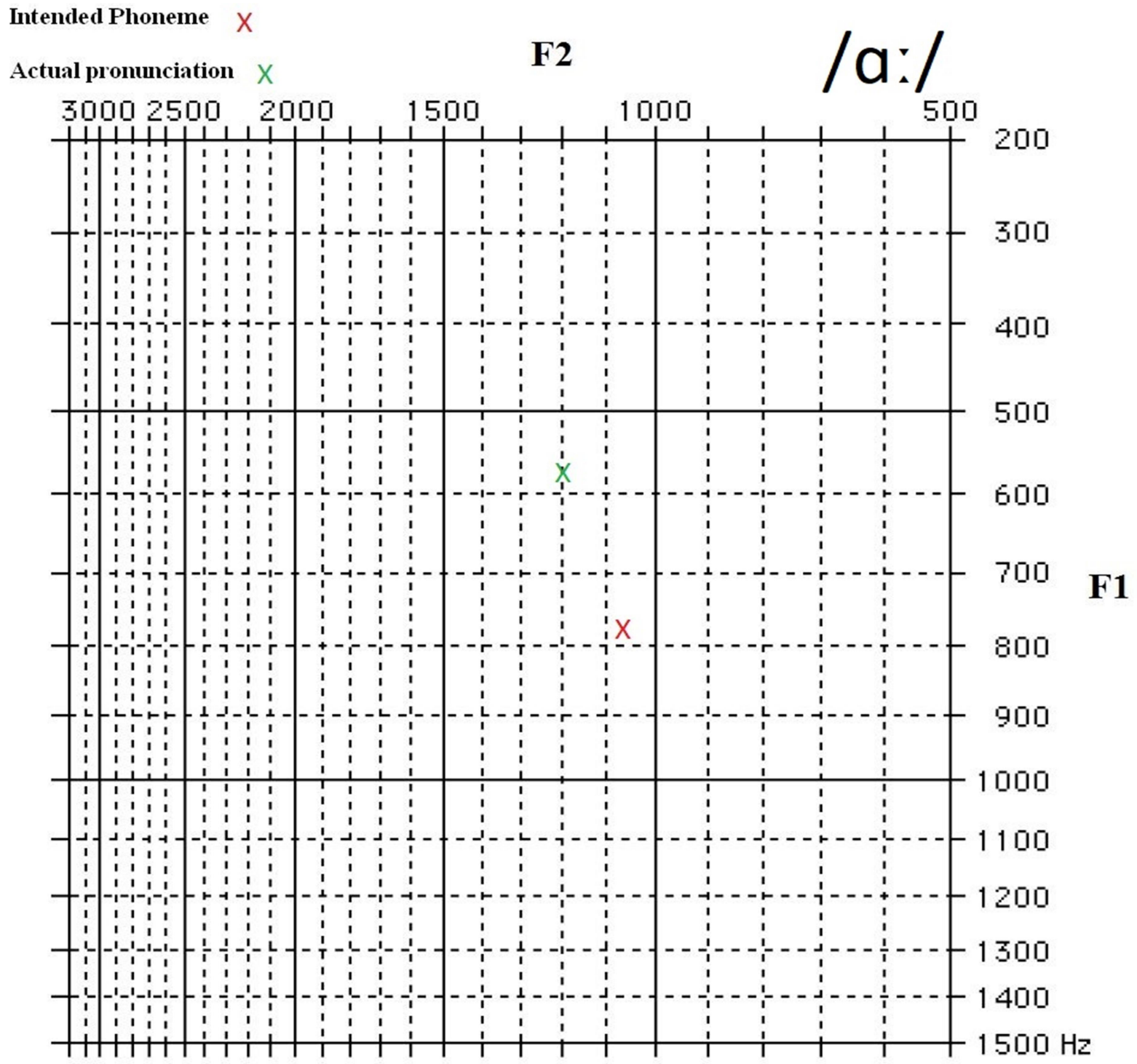

Figure 31: Misrealization of /a:/ Phoneme by Ge2 


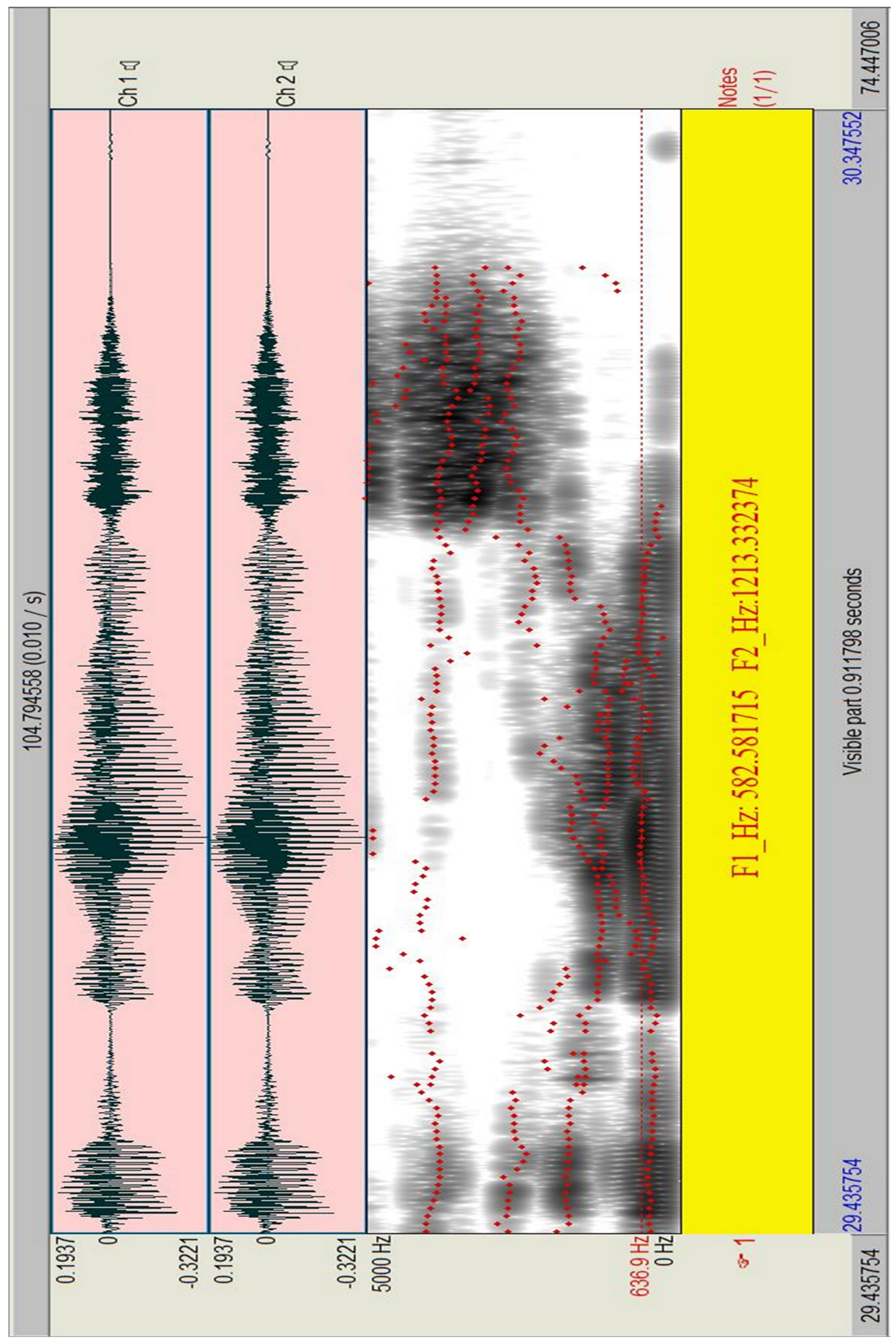

Figure 32: Spectrogram of The Garage by Ge2 
e) $/ \Lambda /$

Figure 30 shows the spectrography of other mispronounced by Fr9. The French EFL learner produced a mid central vowel (F1: $463 \mathrm{~Hz}$ and F2: 1182Hz), while the actual English phoneme $/ \Lambda /$ needs to lower the lower the tongue more $(\mathrm{F} 1=707 \mathrm{~Hz}$ and $\mathrm{F} 2=1350)$.

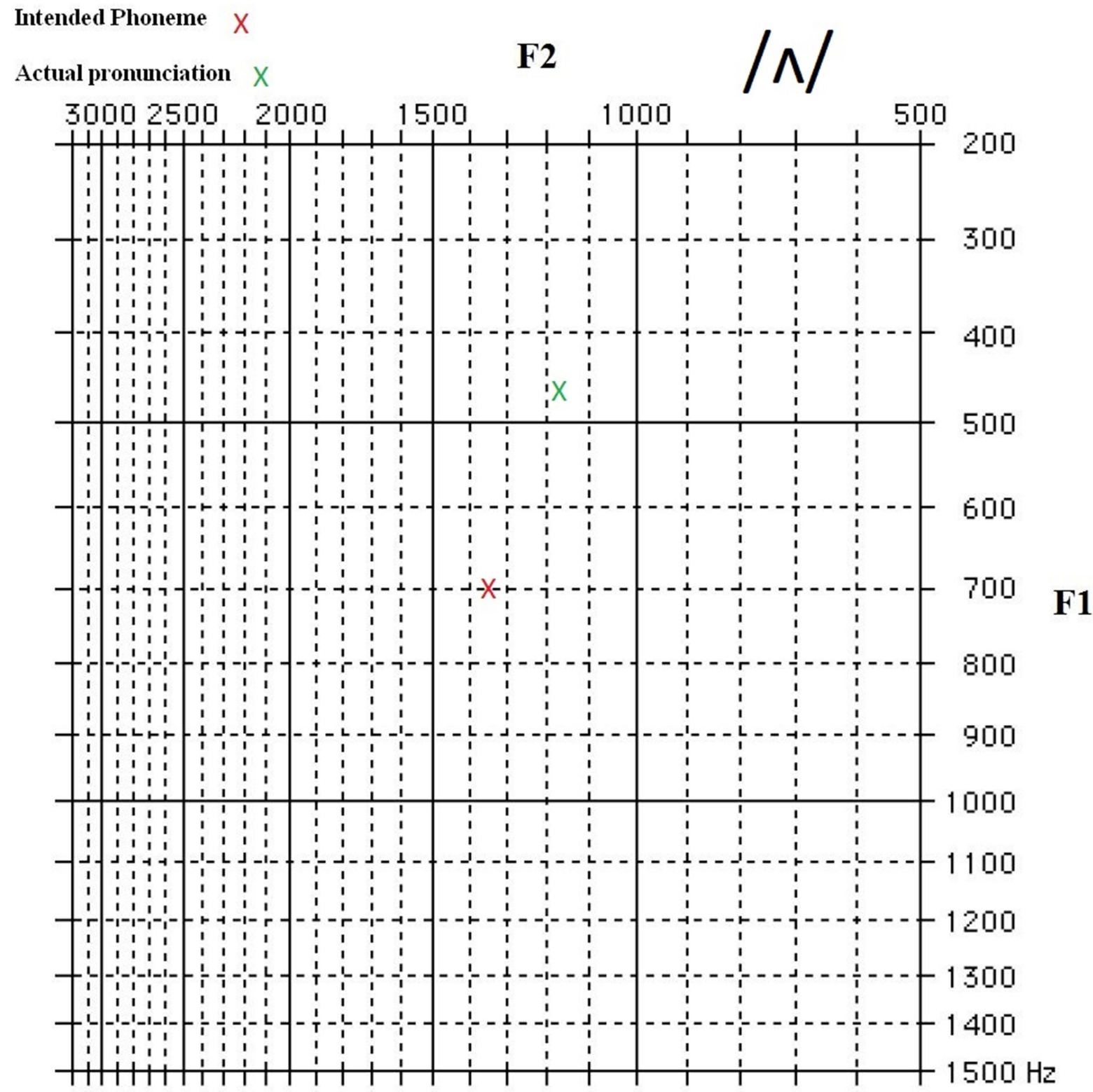

Figure 33: Misrealization of / $/$ / Phoneme by Fr9 


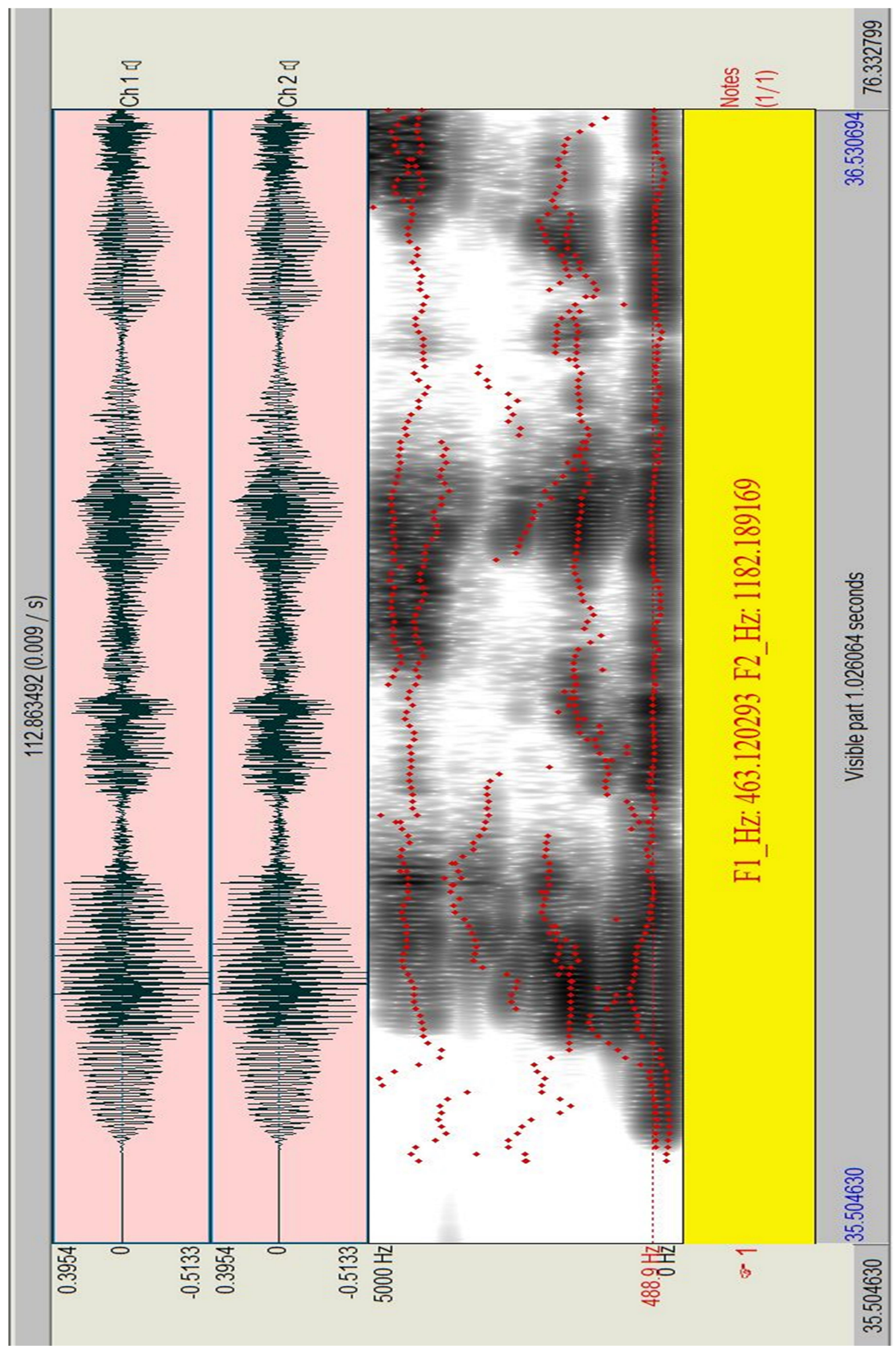


f) $/ 0: /$

The Spanish EFL Speaker mispronounced the word awful (Figure 32) by producing a lower-low central rounded vowel $(\mathrm{F} 1: 873 \mathrm{~Hz}$ and F2:1108Hz) instead of the phoneme / $\mathrm{s} /$ whose tongue position is completely low and also moderately more forward (Figure 31 ).

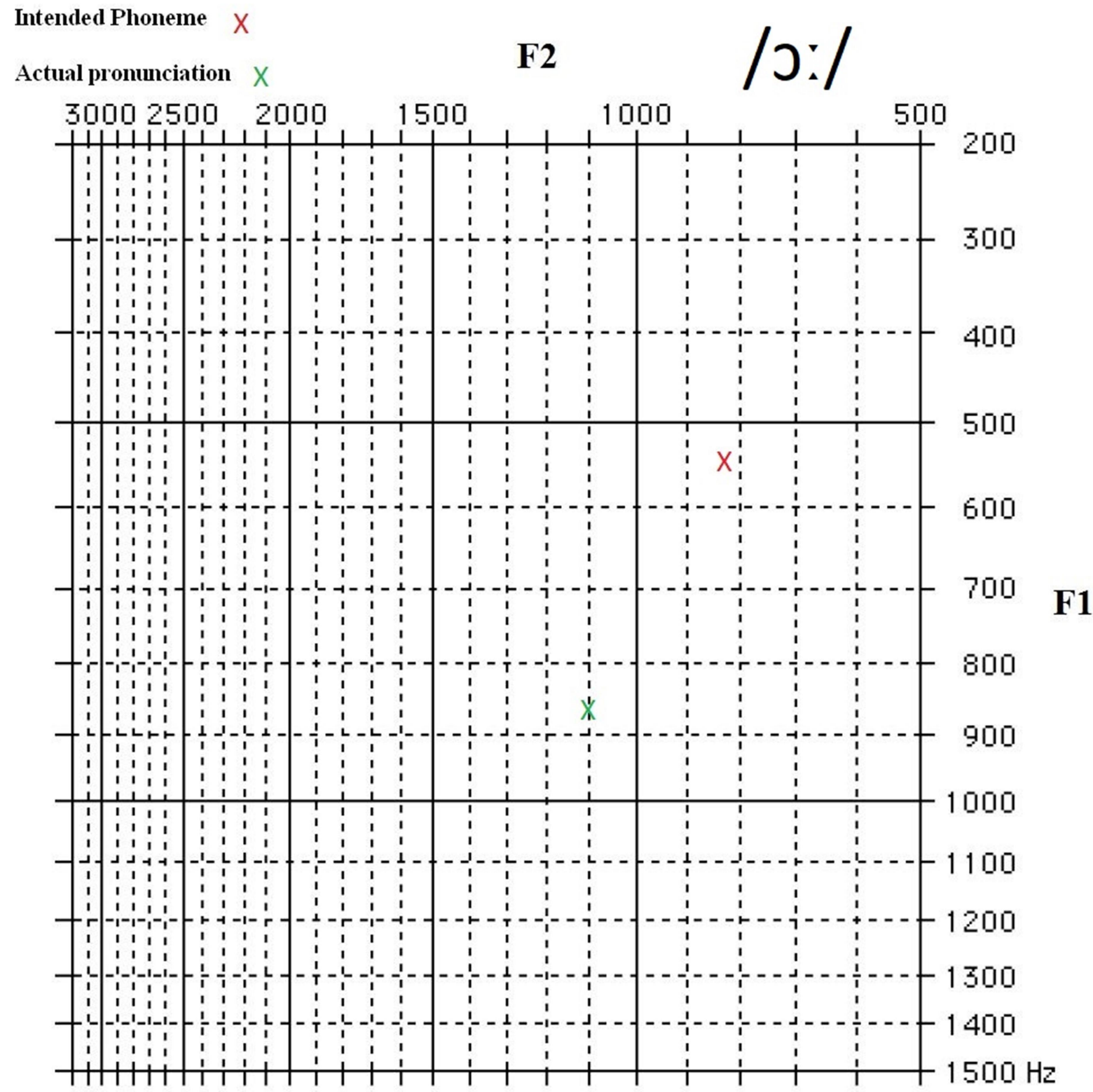

Figure 35: Misrealization of /o:/ Phoneme by Sp4 


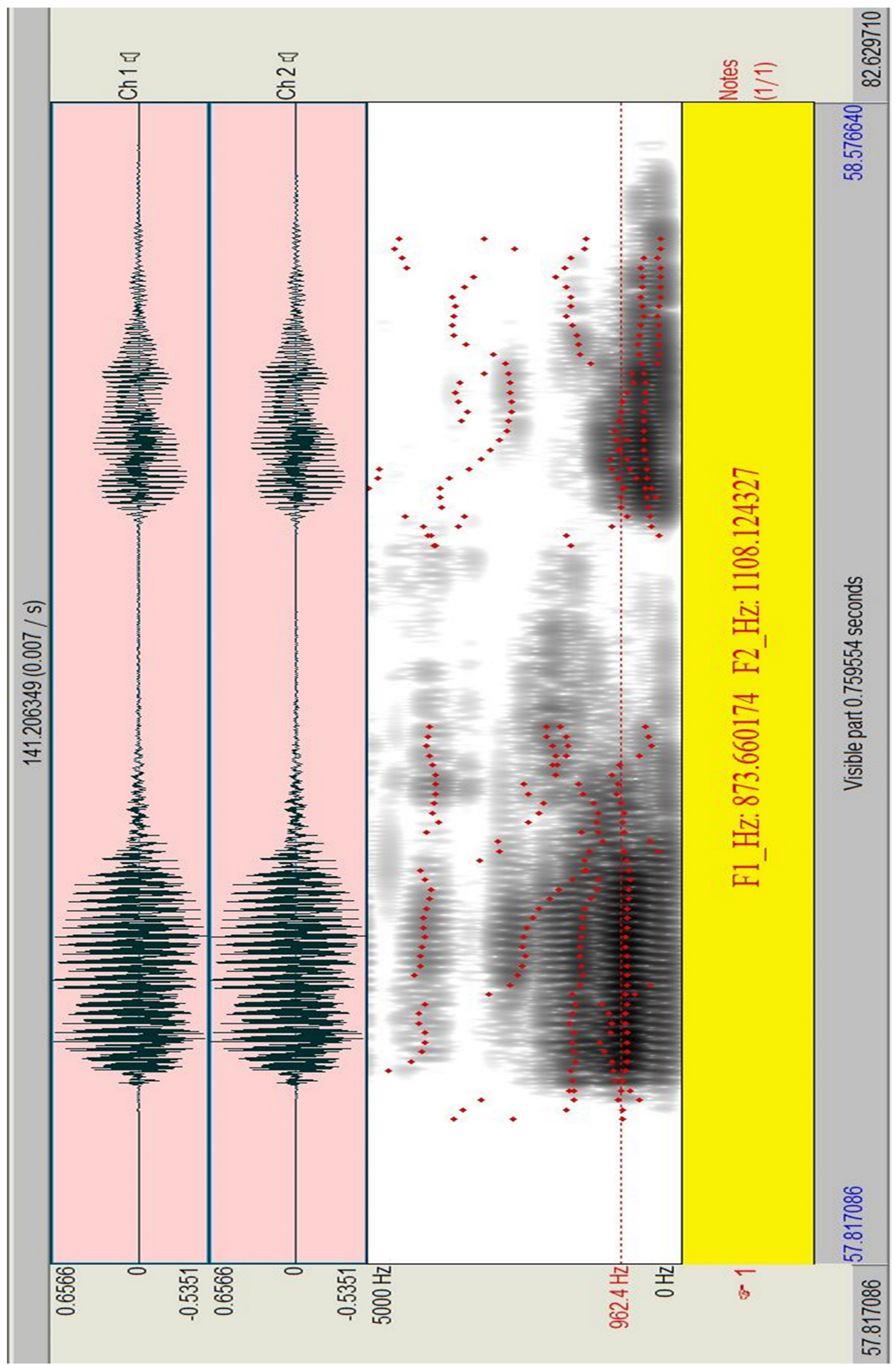


g) $/ \mathrm{p} /$

The German EFL learner mispronounced the word body (Figure 34) as a lower-low central unrounded vowel (F1: $634 \mathrm{~Hz}$ and F2: 1563Hz). The tongue height is near right; however the frontness is completely wrong. The phoneme /p/ is in the back (F1: approx. 652 and F2: 843) while he mispronounced it as a central vowel (Figure 33).

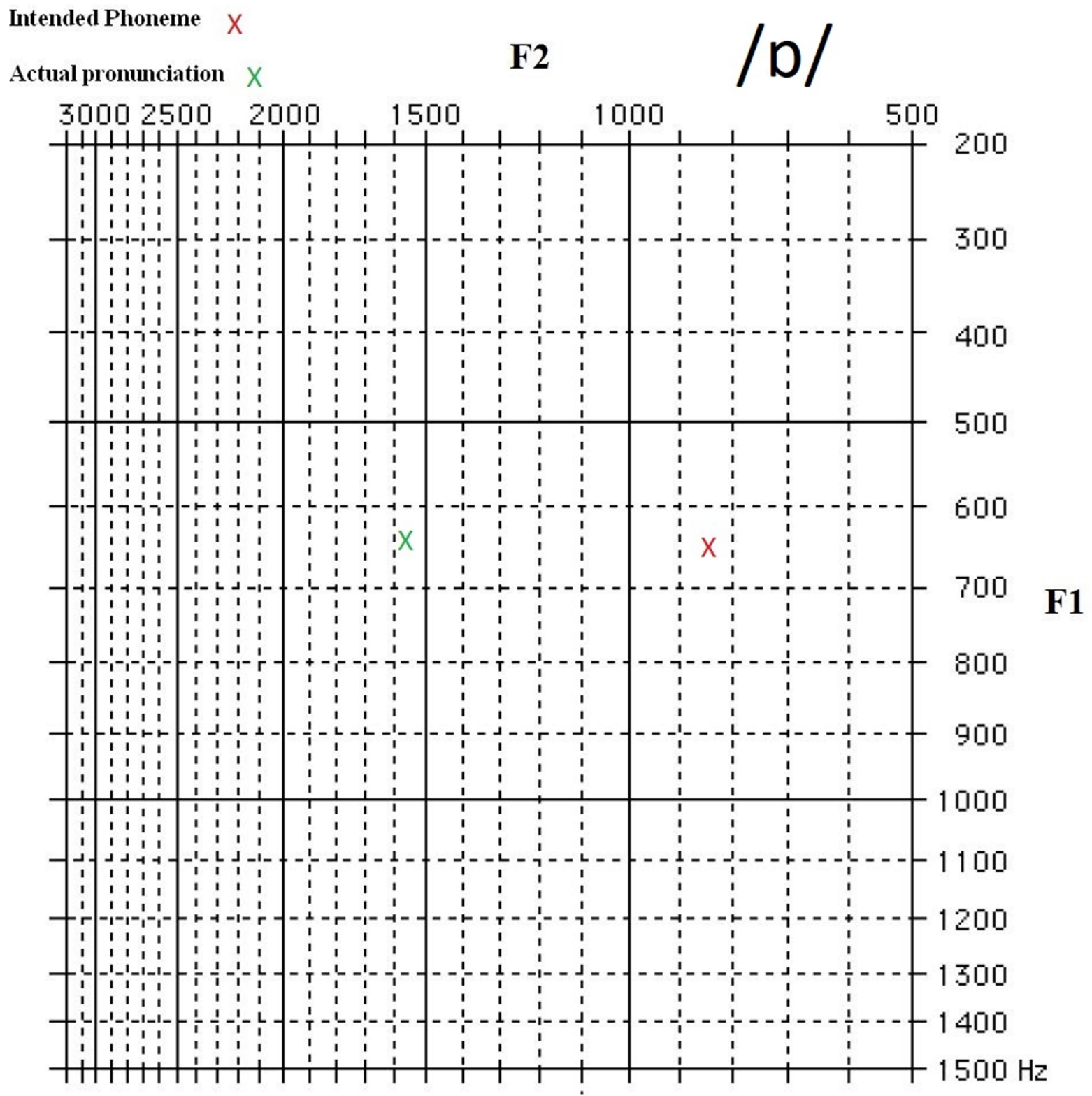

Figure 37: Misrealization of / $\mathbf{w} /$ Phoneme by Ge1 


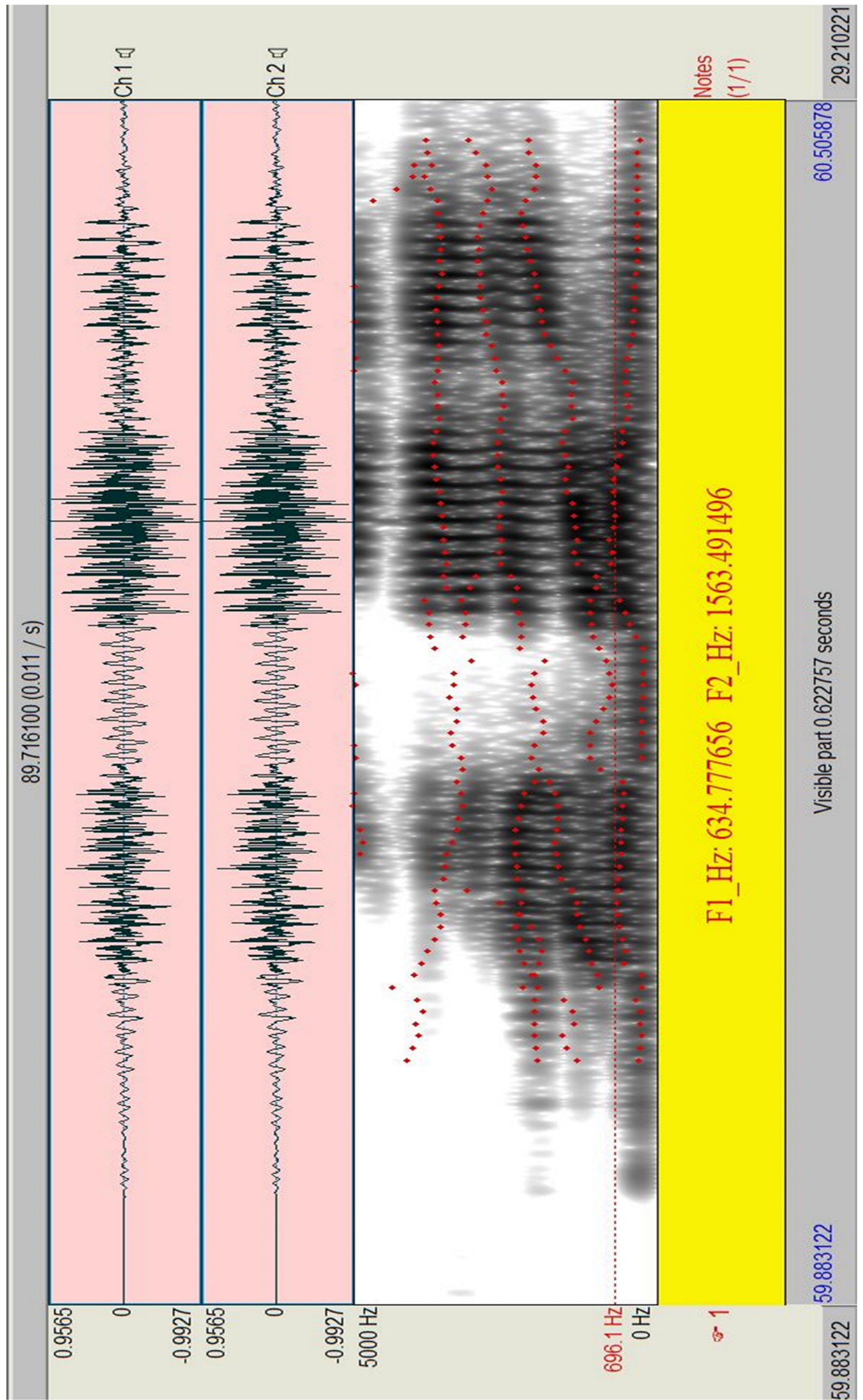

Figure 38: Spectrogram of Body by Ge1 
h) $/ \mathrm{u}: /$

The word noose has been mispronounced by a Russian EFL speaker (Figure 36).

Instead of the vowel phoneme /u:/ (F1: 295Hz and F2: $750 \mathrm{~Hz})$, the participant used a lowermid back unrounded vowel (F1: $607 \mathrm{~Hz}$ and F2: 1092Hz). Figure 35 shows that the position of the tongue should be higher and more forward, in order to fulfil a central position.

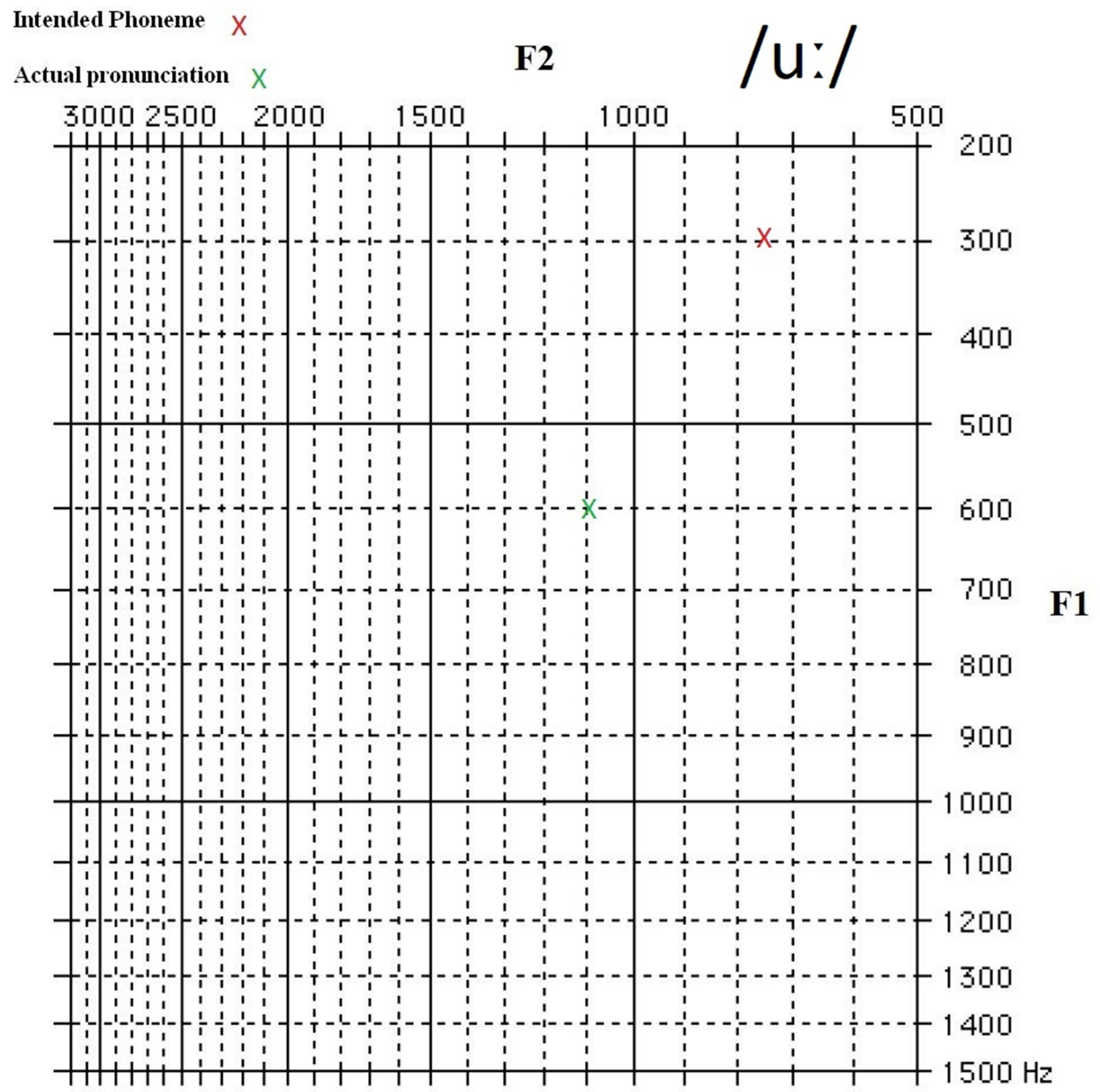

Figure 39: Misrealization of /u:/ Phoneme by Ru2 


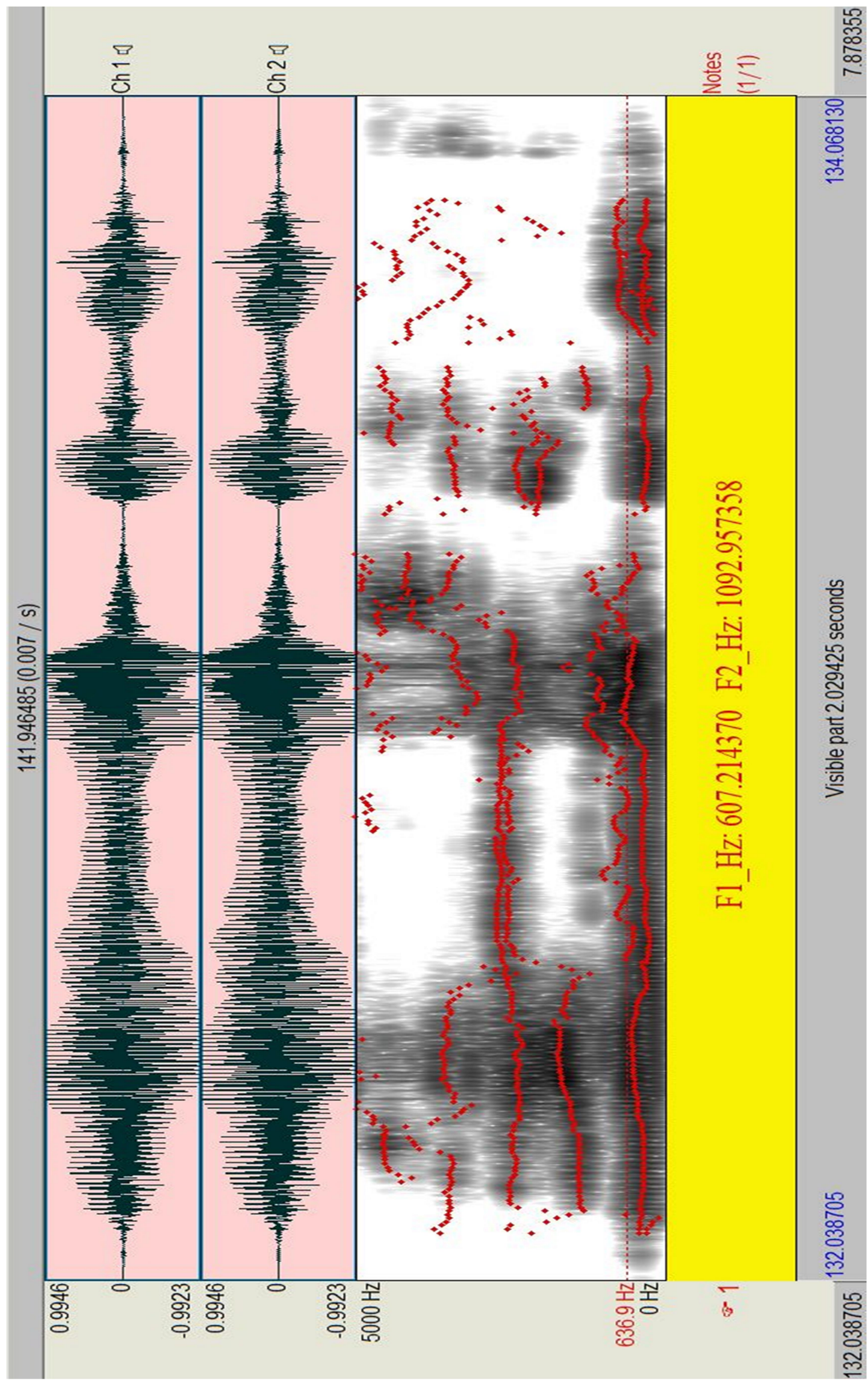

Figure 40: Spectrogram of Noose by Ru2 
i) $/ \mathrm{v} /$

A Russian EFL learner mispronounced the word could (Figure 37), because instead of realizing the phoneme / $/(\mathrm{F} 1: 334$ and F2: 910$)$, the participant did not lower the tongue position enough in order to use the right phoneme (Figure 36).

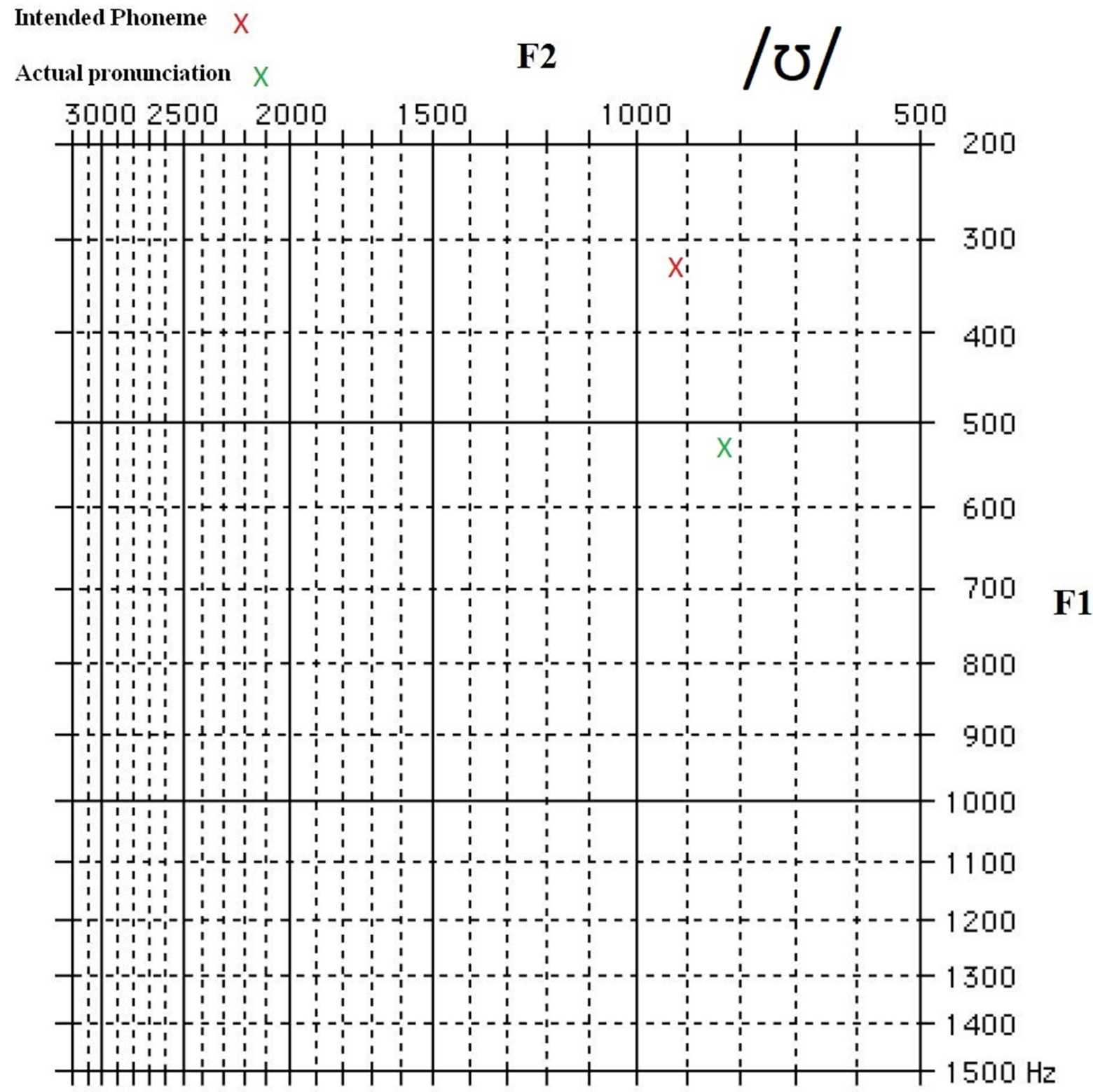

Figure 41: Misrealization of / $/$ / Phoneme by Ru6 


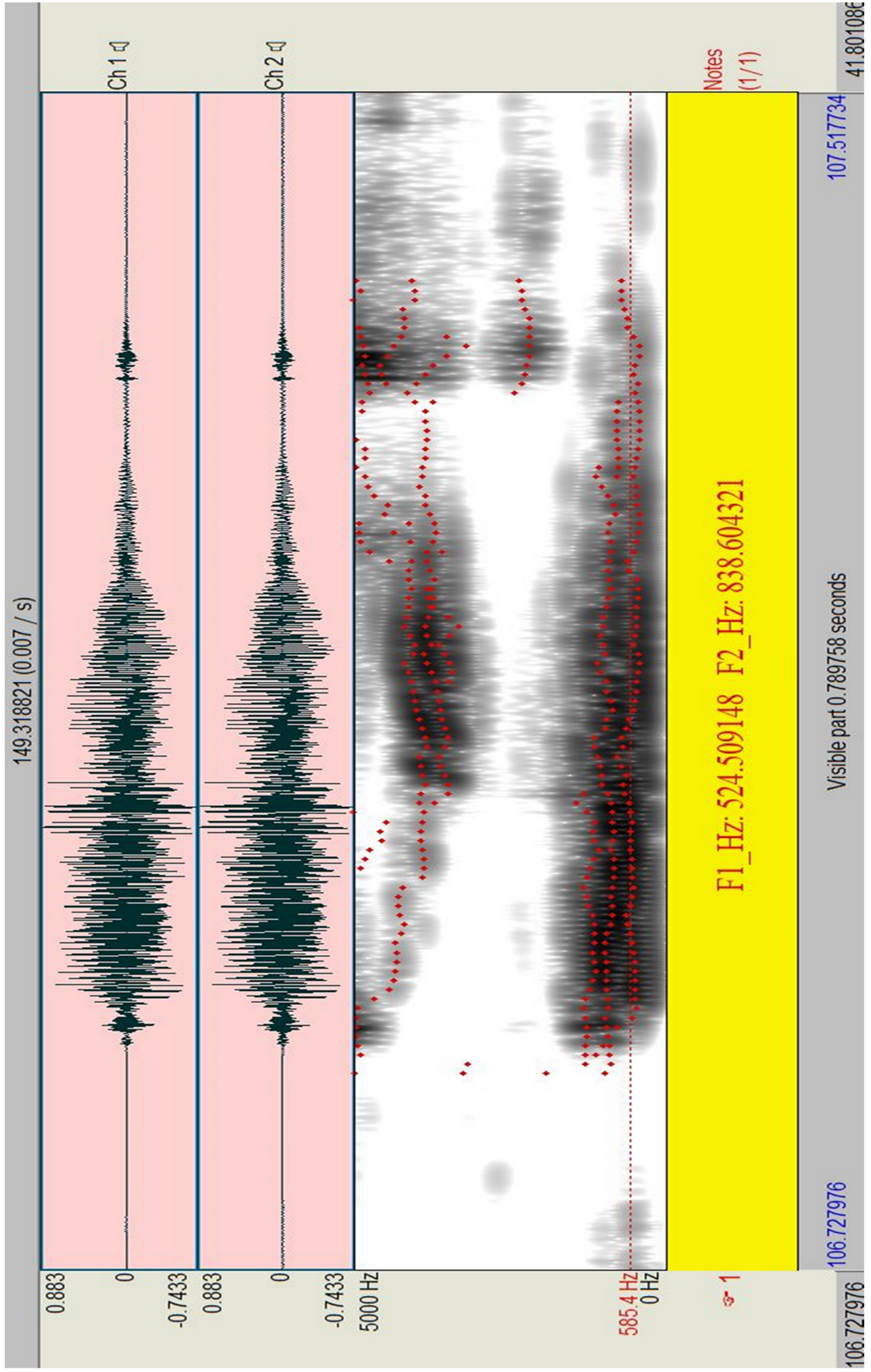

Figure 42: Spectrogram of Could by Ru6 
j) $/ 3: /$

The word her has been mispronounced (Figure 40) by this participant from France. Instead of realizing the phoneme /3:/ correctly (F1: $557 \mathrm{~Hz}$ and F2: $1696 \mathrm{~Hz})$, the speaker pronounced it as lower-low central vowel $(\mathrm{F} 1: 764 \mathrm{~Hz}$ and $\mathrm{F} 2: 1209 \mathrm{~Hz})$. The tongue position must have more frontness and less height (Figure 39).

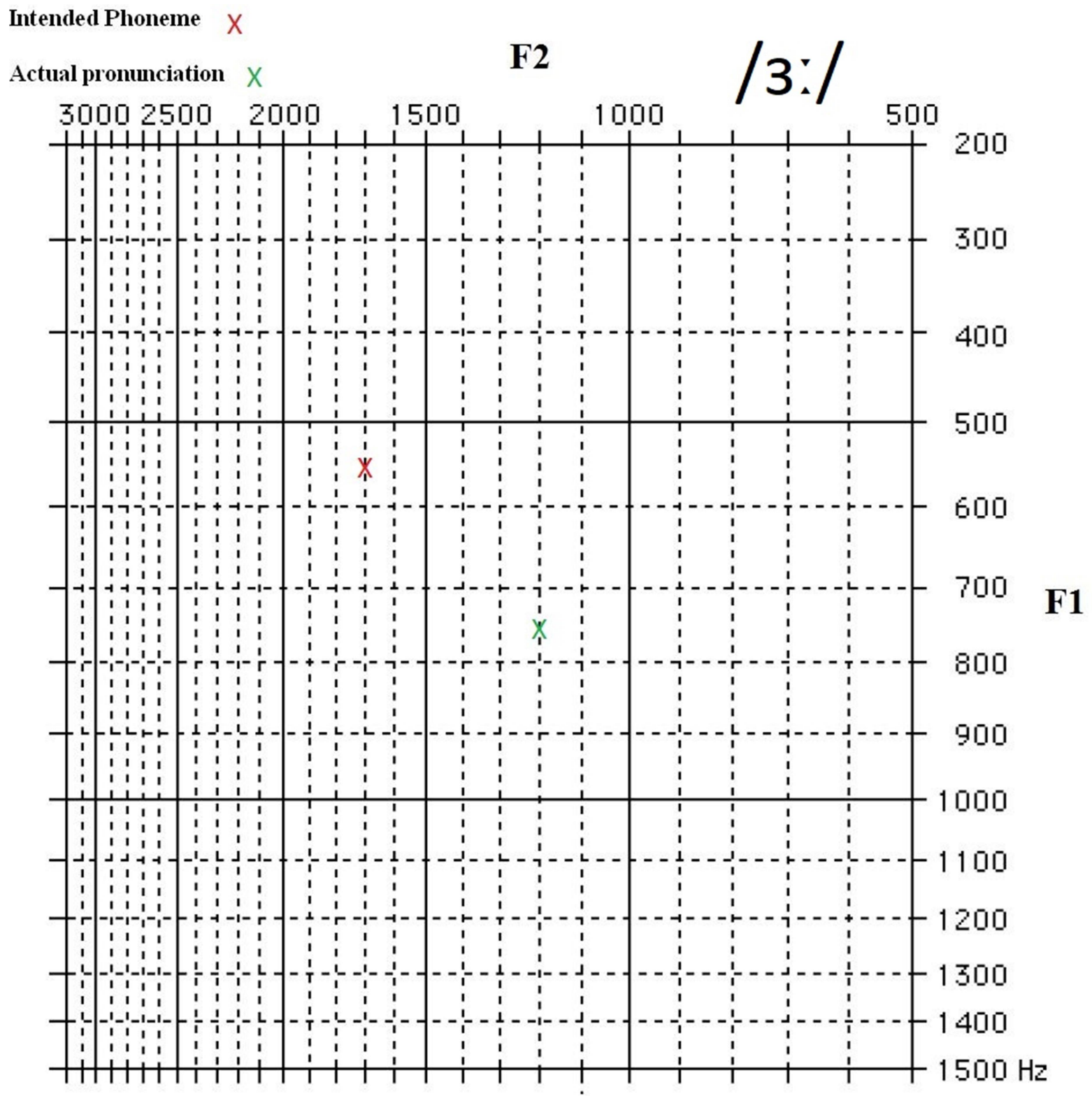

Figure 43: Misrealization of /3:/ Phoneme by Fr2 


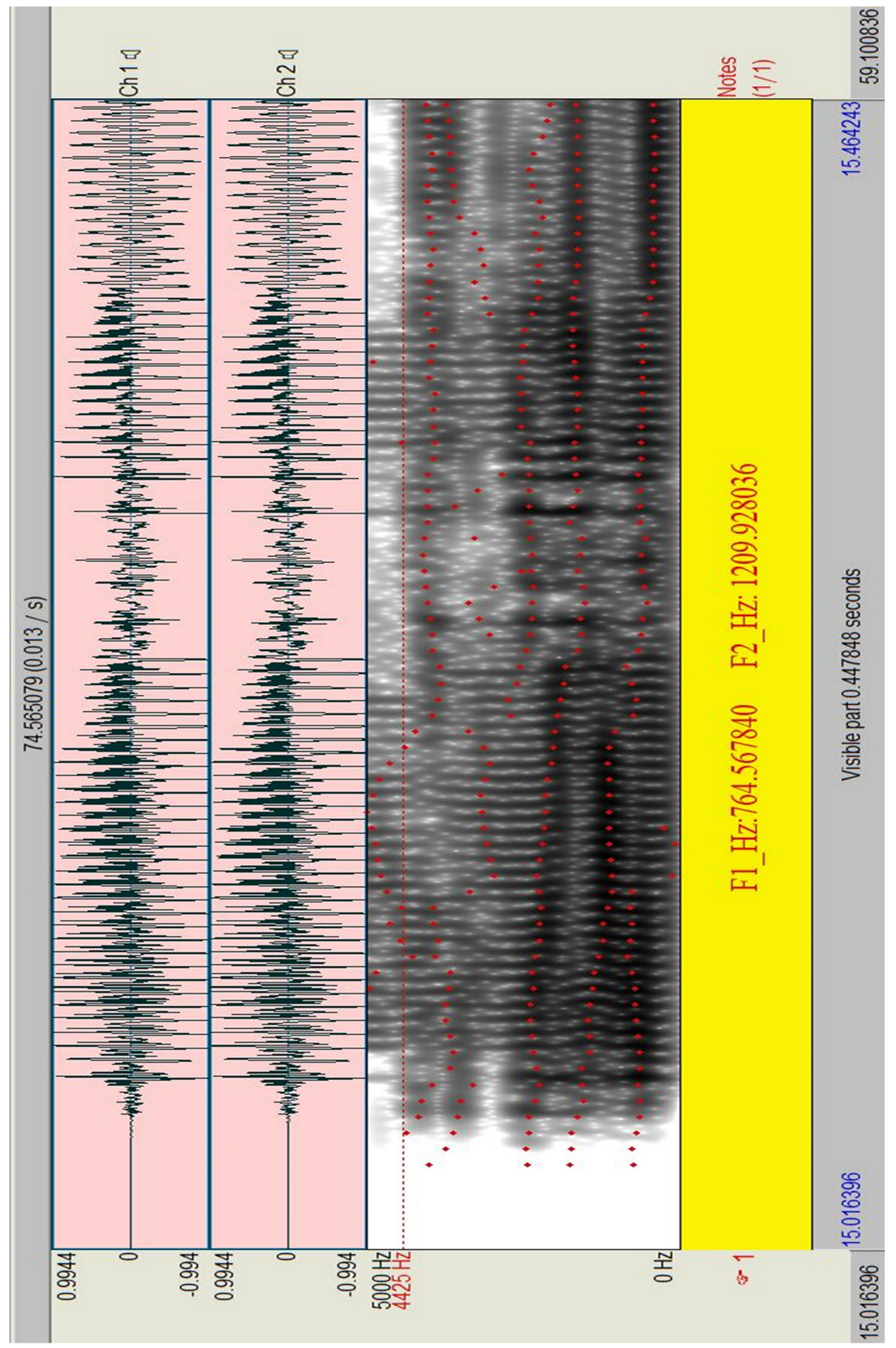


k) /e/

A Spanish EFL speaker mispronounced the word effort during the recording session (Figure 42). The correct phoneme /e/ has the tongue at a higher position (F1: 434Hz and F2: $2148 \mathrm{~Hz})$, while the pronounced vowel (F1: $241 \mathrm{~Hz}$ and F2: $2200 \mathrm{~Hz})$ had the correct frontness, but not the correct height (see Figure 40).

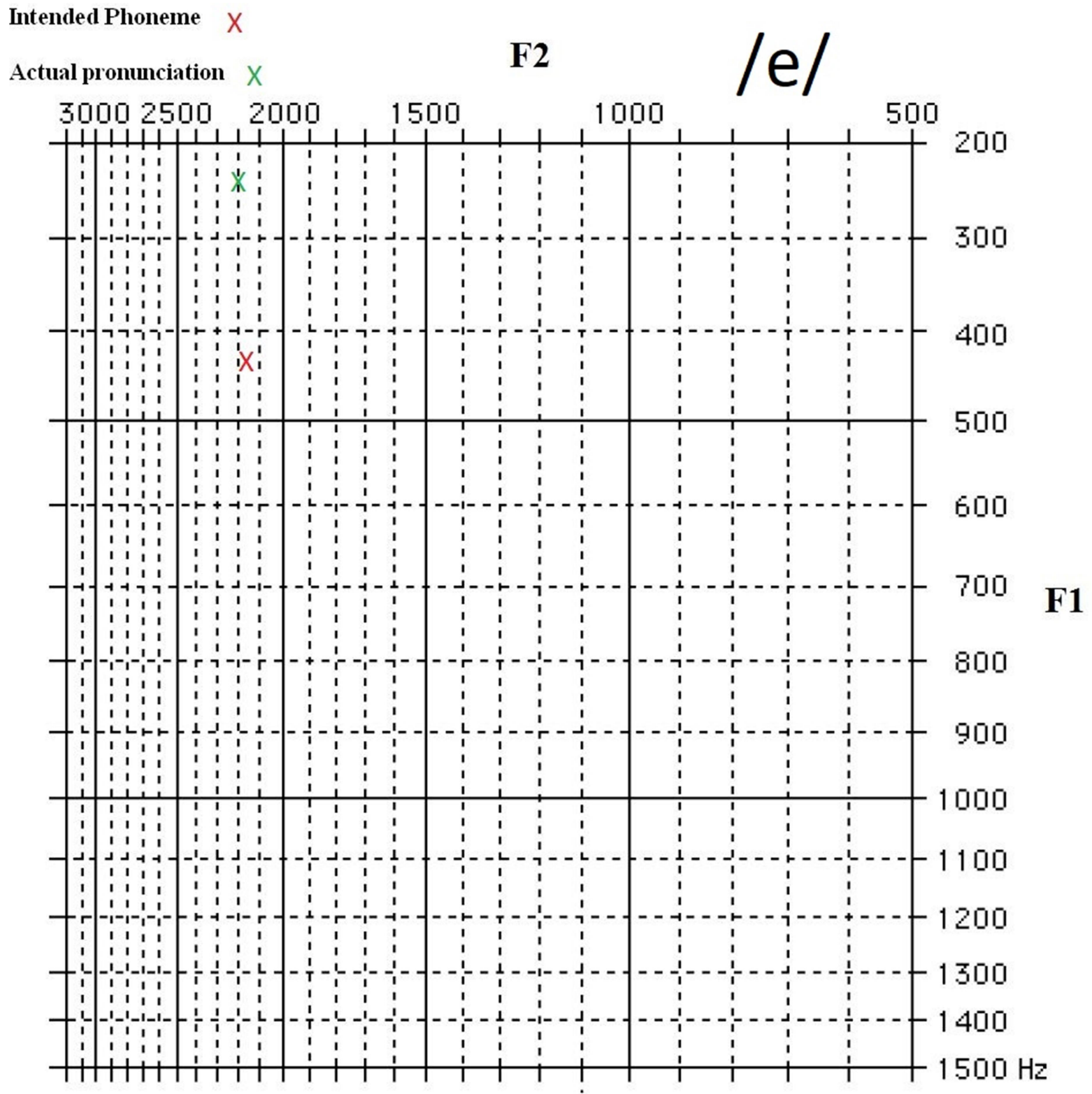

Figure 45: Misrealization of /e/ Phoneme by Sp3 


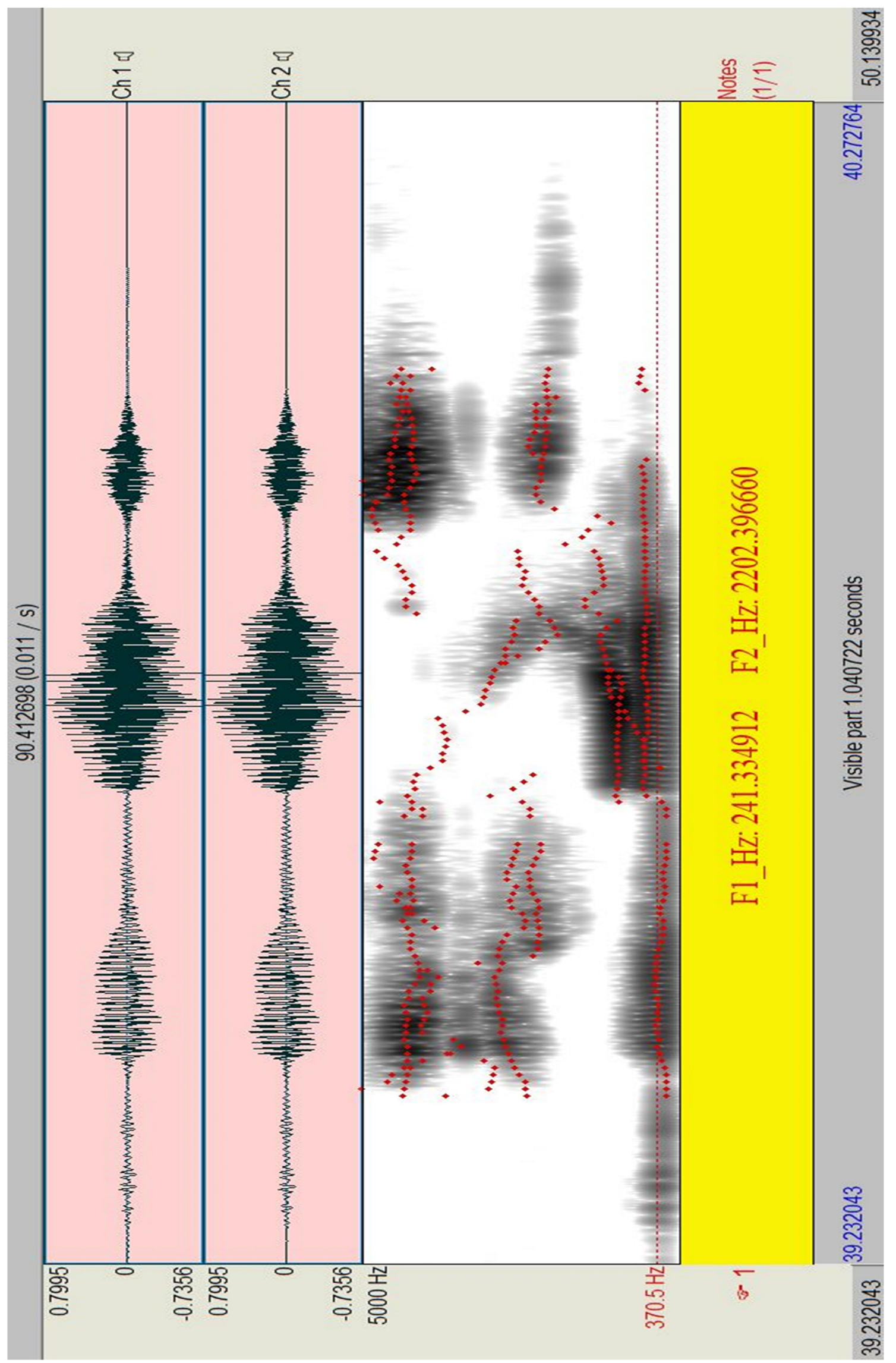

Figure 46: Spectrogram of Effort by Sp3 
1) $/ \partial /$

In Figure 44, the word alias has been mispronounced by a German EFL participant.

The correct vowel phoneme /ə/ (F1:415Hz and F2: 1955Hz) has a lower tongue position and is a little bit more fronted than the actual realization by the speaker $(\mathrm{F} 1: 576 \mathrm{~Hz}$ and $\mathrm{F} 2$ :

$1773 \mathrm{~Hz})$

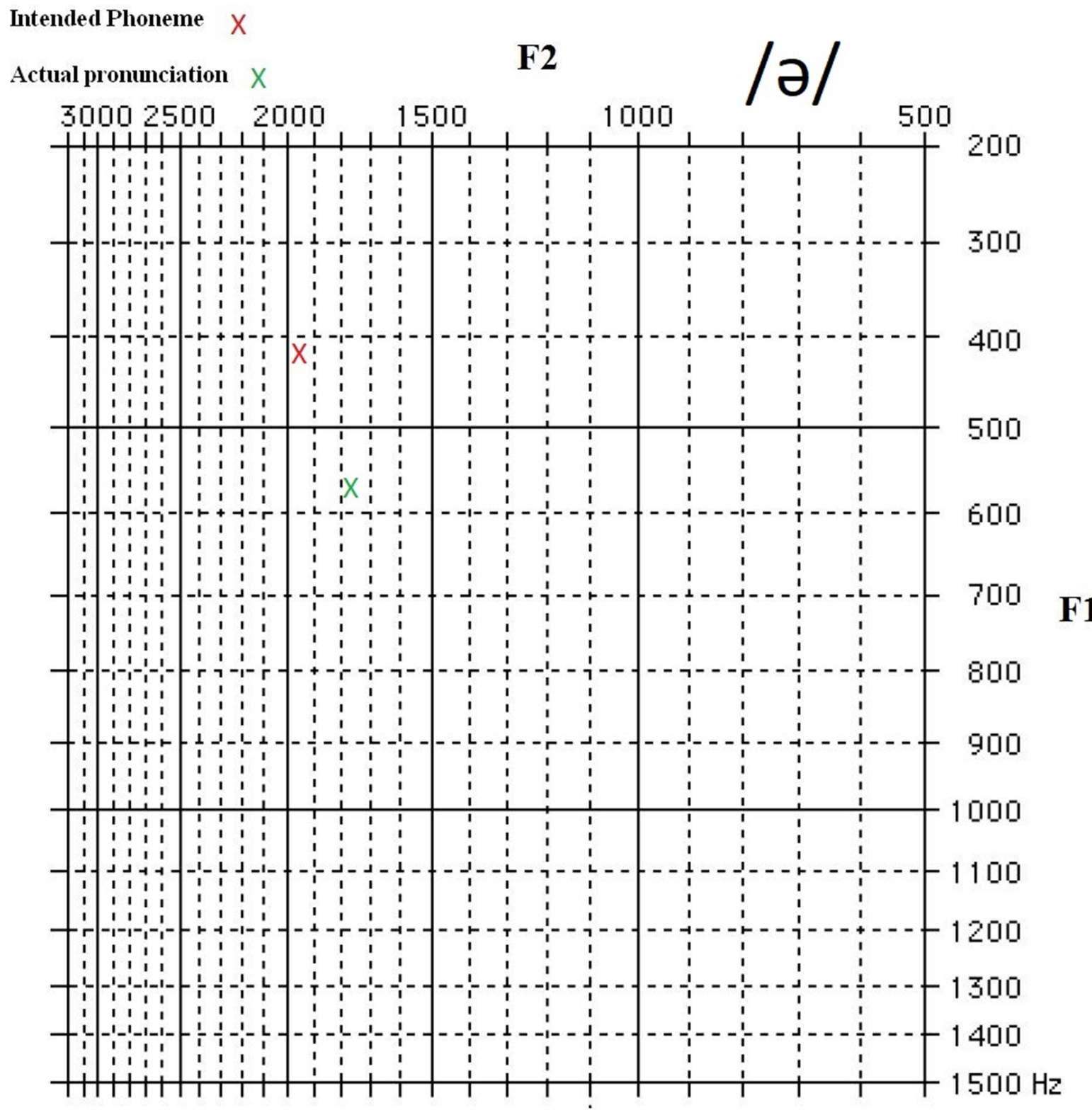

Figure 47: Misrealization of /ə/ Phoneme by Ge3 


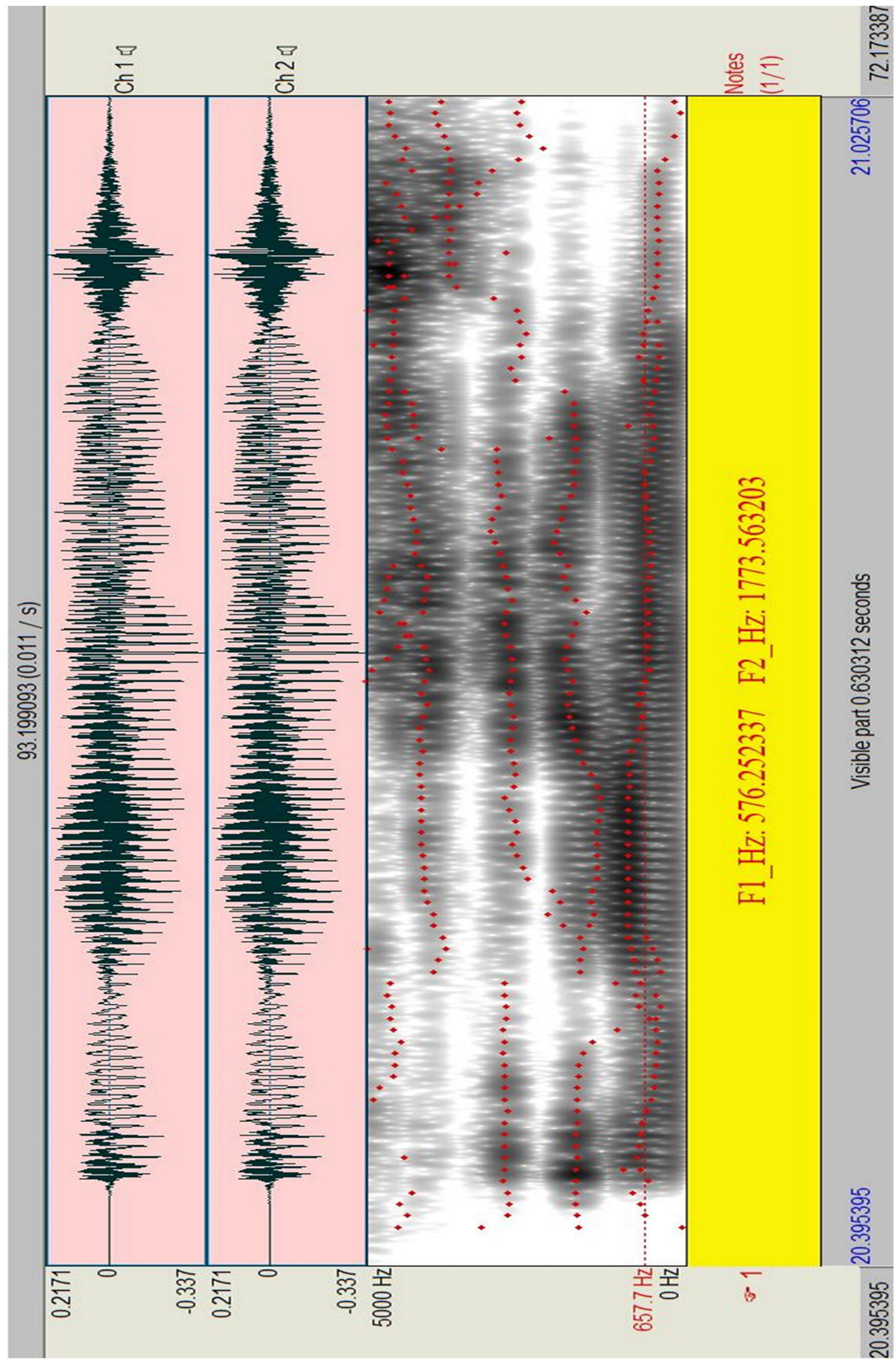

Figure 48: Spectrogram of Alias by Ge3 


\subsubsection{Clipping influence}

a) /i:/: the vast majority of mistakes (a very high $84.62 \%$ ) committed by these EFL speakers occurred when a clipping effect was involved.

b) /I/: The clipping process was less present in the mispronounced words (53.85\%), but it was still present in over half of them.

c) $/ æ /:$ The clipping process was present in $47.43 \%$ of the mispronounced words.

d) /a:/: The clipping process did not show up significantly in the mistakes made by the EFL speakers (a low 9.09\%).

e) $/ \Lambda /$ : Regarding the clipping process: $40.9 \%$ of the mispronounced words were affected by it.

f) /o:/: Clipping was significantly present (61.90\%) amongst the mispronounced words (homogenously amidst the 4 language groups).

g) $/ \mathfrak{p} /$ : The Clipping process was not prominent at all in the mistakes (a mere $11.11 \%)$.

h) /u:/: The clipping process was present but not in the majority $(45.45 \%)$.

i) $/ \mho /$ : Clipping process was inherent in two out of three of the mispronounced words.

j) /3/: Clipping in mispronounced words was only present in the Spanish EFL group (making up two thirds of all mispronounced words), while the rest of the languages had zero clipping in their mispronounced words. $\left(\mu^{\mathrm{t}}=15.38 \%\right)$.

k) /e/: The clipping process was present in $63.63 \%$ of the mispronounced words.

1) $/ \partial /$ : The clipping was present in $55 \%$ of the mispronounced words. 


\subsubsection{Simple vs. complex vowel system}

This section wants to compare languages with different vowel systems. For this comparison, the languages were divided into two groups:

1. Languages with a simple vowel system; which means languages with 5 vowel phonemes (e.g. Spanish, Russian, Japanese or Arabic)

2. Languages with a complex vowel system; which means languages with more than 5 vowel phonemes (e.g. German, French, Turkish or Portuguese)

a) /i:/: Compared against their vowel system (simple vs. complex), simple vowel systems (Russian and Spanish) showed more difficulties $(\mu=12.5 \%)$, than complex vowel systems $(\mu=3.75 \%)$.

b) /I/: The difference between simple (11.25\%) and complex vowel systems (5\%) is neglectable.

c) /æ/: Differences between simple and complex vowel systems are non-significant

d) /a:/: Since the 4 groups were very homogenous; there are no interesting differences, between different vowel systems.

e) $/ \Lambda /$ : There are also no differences between their different vowel systems. They are homogenous in both aspects.

f) / :/: Despite German and French both having complex vowel systems, and the fact that this phoneme was present in both languages but not in Spanish and French, it was expected to see some differences but in the end there were no significant differences in vowel system distributions. 
g) /p/: Like the previous phoneme, one could expect something different, since this phoneme is present in both languages that share a complex vowel system. But, there were again no significant differences with the vowel system differentiation.

h) /u:/ Once again, comparing them against their different vowel systems did not deliver evidence of some importance.

i) $/ \mho /$ : Comparing the languages through their vowel systems did not reveal anything remarkable in this layout.

j) /3:/: Vowel systems comparisons did not evince any significant differences.

k) /e/: Comparing them against their vowel systems did not deliver any significant data.

1) /ə/: Simple vs. complex vowel systems comparison did not offer any differentiating data.

\subsubsection{Stress- vs. syllable-timed languages}

This section compares languages with different isochronies. For this comparison, the languages were divided into two groups:

1. Languages with stress-timed isochrony (e.g. Portuguese, German, Arab and Russian)

2. Languages with syllable-timed isochrony (e.g. Spanish, French, Turkish or Japanese)

a) /i:/ there are no noteworthy differences or discoveries, if we compare the languages based on their isochrony. 
b) /I/: Speaker of stress-timed languages had a bit more difficulties $(\mu=14.54 \%)$ than syllable-timed languages $(\mu=4.76 \%)$.

c) /æ/: Differences between stress- and syllable timed languages are non-significant.

d) /a:/: Since the 4 groups were very homogenous, there are no interesting differences between different isochronies.

e) $/ \Lambda /$ : There are also no differences between different isochronies.

f) /o:/: No significant differences in isochrony.

g) /p/: Like the previous phoneme, one could expect something different, since this phoneme is present in both languages but, there were again no significant differences with the isochrony.

h) /u:/: Once again, comparing them against their different isochronies did not deliver evidence of some importance.

i) $/ \mho /$ : Comparing the languages through their isochronies did not reveal anything remarkable in this layout.

j) /3:/: Isochrony did not evince any significant differences.

k) /e/: Comparing them against their isochronies did not deliver any significant data.

1) /ə/: Comparing the languages through their isochrony shows that stress-timed languages had less difficulties $\left(\mu^{\text {str }}=38.18 \%\right)$ with this phoneme than syllable-timed languages $\left(\mu^{\text {syl }}=53.19 \%\right)$. 


\subsubsection{Presence vs. absence of similar phonemes in native language}

Before we look at each English vowel phoneme in detail, table 17 gives a quick overlook at the similar phonemes in the languages of the 4 groups compared to the 12 analysed phonemes in this study. A green tick marks a similar, but not exact phoneme, a yellow wave dash indicates an occurrence in a regional variety of that language and finally a red $\mathrm{x}$ means no occurrence at all in that language.

Table 17: Occurrence of English Vowel Phonemes in Other Languages

\begin{tabular}{|c|c|c|c|c|}
\hline & Spanish & French & German & Russian \\
\hline$/ \mathbf{i}: /$ & $\checkmark$ & $\checkmark$ & $\checkmark$ & $\checkmark$ \\
\hline$/ \mathbf{I} /$ & $\sim$ & $x$ & $\checkmark$ & $V$ \\
\hline$/ \mathfrak{a} /$ & $\sim$ & $\sim$ & $\sim$ & $x$ \\
\hline$/ \mathbf{a}: /$ & $x$ & $\sim$ & $\checkmark$ & $V$ \\
\hline$/ \mathbf{N} /$ & $x$ & $x$ & $\checkmark$ & $\sim$ \\
\hline$/ \mathbf{0}: /$ & $x$ & $\checkmark$ & $\checkmark$ & $x$ \\
\hline$/ \mathbf{p} /$ & $x$ & $\checkmark$ & $\checkmark$ & $\sim$ \\
\hline$/ \mathbf{u}: /$ & $x$ & $x$ & $\sim$ & $V$ \\
\hline$/ \delta /$ & $x$ & $\checkmark$ & $\sim$ & $\checkmark$ \\
\hline /3:/ & $\sim$ & $\checkmark$ & $\checkmark$ & $\checkmark$ \\
\hline$/ \mathrm{e} /$ & $\checkmark$ & $x$ & $\checkmark$ & $\checkmark$ \\
\hline$/ / 2 /$ & $x$ & $x$ & $\checkmark$ & $x$ \\
\hline
\end{tabular}


a) /i:/

This close front unrounded vowel occurs naturally in most languages, for our interests, it occurs in all 4 languages and a similar sound to this phoneme is realized by their speakers. The words used to test this vowel are tree, people, sea, week and leaf. Table 18 below shows the amount of errors the EFL participants made during the recording.

Table 18: Error Frequency of /i:/ Phoneme

\begin{tabular}{|c||c|c|c|c|c|}
\hline & $\boldsymbol{n}$ & items & $\begin{array}{c}\text { Number of } \\
\text { Mistakes }\end{array}$ & $\boldsymbol{\mu}$ & Clipping influence \\
\hline \hline Spanish & 10 & 50 & 5 & $10 \%$ & $100 \%$ \\
\hline French & 11 & 55 & 3 & $5.45 \%$ & $66 \%$ \\
\hline Russian & 6 & 30 & 5 & $16.6 \%$ & $80 \%$ \\
\hline German & 5 & 25 & 0 & $0 \%$ & $0 \%$ \\
\hline Total & 32 & 160 & 13 & $8.13 \%$ & $84.62 \%$ \\
\hline
\end{tabular}

Since this English phoneme is present in all the participants' native languages, the error frequency is subsequently very low $\left(\mu^{\mathrm{t}}=8.13 \%\right)$. Even the $16.6 \%$ by the Russian EFL speakers are far from being something noteworthy of analysis.

The word leaf proved to be the most difficult one to pronounce with $84.62 \%$ of all the mistakes. Also, no participant committed an over proportionately higher amount of mistakes compared to the rest. $65.63 \%$ of the participants made no mistakes at all, and the average mistake rate was a low 0.41 . 
b) /I/

This near-close front unrounded vowel occurs in a few languages, but in our research two similar phonemes occur only in German and Russian. French does not have this vowel, whereas Standard Spanish does not have it either, though regional varieties like Andalusian and Murcian have a similar sound. Since part of this research was conducted in Murcia, there is thus a fair chance that it will occur within the production of Spanish speakers. The words selected for this vowel were bill, business, symbol, bit and recall. Table 19 below shows the error frequency for this phoneme.

Table 19: Error Frequency of /I/ Phoneme

\begin{tabular}{|c||c|c|c|c|c|}
\hline & $\boldsymbol{n}$ & items & $\begin{array}{c}\text { Number of } \\
\text { Mistakes }\end{array}$ & $\boldsymbol{\mu}$ & Clipping influence \\
\hline \hline Spanish & 10 & 50 & 3 & $6 \%$ & $66 \%$ \\
\hline French & 11 & 55 & 2 & $3.63 \%$ & $0 \%$ \\
\hline Russian & 6 & 30 & 6 & $20 \%$ & $66 \%$ \\
\hline German & 5 & 25 & 2 & $8 \%$ & $50 \%$ \\
\hline Total & 32 & 160 & 13 & $8.13 \%$ & $53.85 \%$ \\
\hline
\end{tabular}

Despite not being present in all languages, this vowel did not have a particular high mistake rate $\left(\mu^{\mathrm{t}}=8.13 \%\right)$. The Russian EFL speakers had the most difficulties $\left(\mu^{\mathrm{r}}=20 \%\right)$, but again, it is not worrying data.

Recall was the most mispronounced word ( $46.15 \%$ of all the phoneme mistakes) and no participant produced an overproportionately higher amount of mistakes (the average mistake rate was a low 0.41$), 59,38 \%$ of them even made no mistakes at all. 
c) $/ æ /$

This open front unrounded phoneme has only some similar phonemes in our research. It occurs only in some regional varieties of Spanish (Murcian and Andalusian), German (Austrian) and French (Parisian and Quebec) while there is no equivalent in Russian at all. Again, parts of the Spanish participants were from Murcia, so this could factor into the results. The words selected for this vowel were man, fan, random, apple and compact. Table 20 below shows the error frequency for this phoneme.

Table 20: Error Frequency of /a/ Phoneme

\begin{tabular}{|c||c|c|c|c|c|}
\hline & $\boldsymbol{n}$ & items & $\begin{array}{c}\text { Number of } \\
\text { Mistakes }\end{array}$ & $\boldsymbol{\mu}$ & Clipping influence \\
\hline \hline Spanish & 10 & 50 & 36 & $72 \%$ & $41.66 \%$ \\
\hline French & 11 & 55 & 23 & $41.81 \%$ & $56.52 \%$ \\
\hline Russian & 6 & 30 & 19 & $63.33 \%$ & $47.37 \%$ \\
\hline German & 5 & 25 & 0 & $0 \%$ & $0 \%$ \\
\hline Total & 32 & 160 & 78 & $48.75 \%$ & $47.43 \%$ \\
\hline
\end{tabular}

This phoneme, absent in most of the languages of the study, proved prone to be difficult. The total error ratio was $\mu^{\mathrm{t}}=48.75 \%$ and it is not higher because the German EFL participants had a flawless pronunciation run. The other languages had difficulties with this vowel, especially Russians $\left(\mu^{\mathrm{Ru}}=63.33 \%\right)$ and Spaniards $\left(\mu^{\mathrm{Sp}}=72 \%\right)$, both had significant trouble with this phoneme.

The most mispronounced word was compact with $26.92 \%$ and the German EFL speakers stood out, because they pronounced this phoneme flawlessly, despite it not being 
present in their standard language. The average mistake rate though, even with one language group performing impeccably, was a very high 2.44 per person.

d) /a:/

This open back unrounded phoneme occurs similarly in a few languages, and in some form in all of the languages in this research. It is a comparable phoneme in the standard German and Russian language, whereas in French variants a similar phoneme can be found (Parisian and Quebec) and in Spanish it is not used at all. The words selected for this vowel are garage, far, car, market and marketing. Table 21 below shows the error frequency of this phoneme.

Table 21: Error Frequency of /a:/ Phoneme

\begin{tabular}{|c||c|c|c|c|c|}
\hline & $\boldsymbol{n}$ & items & $\begin{array}{c}\text { Number of } \\
\text { Mistakes }\end{array}$ & $\boldsymbol{\mu}$ & Clipping influence \\
\hline \hline Spanish & 10 & 50 & 11 & $22 \%$ & $0 \%$ \\
\hline French & 11 & 55 & 9 & $16.36 \%$ & $11.11 \%$ \\
\hline Russian & 6 & 30 & 8 & $26.66 \%$ & $25 \%$ \\
\hline German & 5 & 25 & 5 & $20 \%$ & $0 \%$ \\
\hline Total & 32 & 160 & 33 & $20.63 \%$ & $9.09 \%$ \\
\hline
\end{tabular}

This phoneme did not represent too many difficulties $\left(\mu^{\mathrm{t} 8}=20.63 \%\right)$ and was quite homogeneous among the 4 groups (ranging from the French $\mu^{\mathrm{fr} 9}=16.36 \%$ to the Russian $\mu^{\text {ru10 }}$ $=26.66 \%$ ).

\footnotetext{
${ }^{8} \mu^{\mathrm{t}}=$ Mean of all the groups of EFL learners that participated in the research project

$9 \mu^{\mathrm{fr}}=$ Mean of the group of French EFL learners that participated in the research project

${ }^{10} \mu^{\mathrm{ru}}=$ Mean of the group of Russian EFL learners that participated in the research project
} 
The most mispronounced word was garage, making up $60.60 \%$ of all the mistakes with this phoneme. $28.13 \%$ of the participants made no mistakes at all, and the average mistake rate per person was 1.03 .

e) $/ \Lambda /$

This near-open central English phoneme only has one analogue in the German language. Spanish and French do not use an equivalent of this phoneme, while Russian only uses one counterpart in its Moscow variant. The words selected for this phoneme are mum, other, love, up and couple. Table 22 below shows the error frequency of this phoneme by the EFL participants.

Table 22: Error Frequency of / $/ \mathbf{s}$ Phoneme

\begin{tabular}{|c||c|c|c|c|c|}
\hline & $\boldsymbol{n}$ & items & $\begin{array}{c}\text { Number of } \\
\text { Mistakes }\end{array}$ & $\boldsymbol{\mu}$ & Clipping influence \\
\hline \hline Spanish & 10 & 50 & 11 & $22 \%$ & $27.27 \%$ \\
\hline French & 11 & 55 & 18 & $32.72 \%$ & $44.44 \%$ \\
\hline Russian & 6 & 30 & 10 & $33.33 \%$ & $60 \%$ \\
\hline German & 5 & 25 & 5 & $20 \%$ & $20 \%$ \\
\hline Total & 32 & 160 & 44 & $27.5 \%$ & $40.9 \%$ \\
\hline
\end{tabular}

This phoneme was mildly troublesome for the participants $(\mu=27.5 \%)$, and the ranges were one word out of five being mispronounced by Germans up to one word out of three by Russians.

Couple and other (ach $29.55 \%$ of the mispronounced words), but also love $(27.27 \%)$ were the words EFL learners had the most difficulty with. No participant had significantly more difficulties than another and the average mistake rate was 1.38 per person. 
f) $/ 0: /$

This close mid-back rounded phoneme has a similar sound present in French and German but has no presence at all in Spanish and Russian. The words selected for this phoneme are floor, ball, board, bought and awful. Table 23 below shows the error frequency of this phoneme by EFL participants.

Table 23: Error Frequency of /o:/ Phoneme

\begin{tabular}{|c||c|c|c|c|c|}
\hline & $\boldsymbol{n}$ & items & $\begin{array}{c}\text { Number of } \\
\text { Mistakes }\end{array}$ & $\boldsymbol{\mu}$ & Clipping influence \\
\hline \hline Spanish & 10 & 50 & 15 & $30 \%$ & $60 \%$ \\
\hline French & 11 & 55 & 14 & $25.45 \%$ & $64.29 \%$ \\
\hline Russian & 6 & 30 & 11 & $36.66 \%$ & $63.63 \%$ \\
\hline German & 5 & 25 & 2 & $8 \%$ & $50 \%$ \\
\hline Total & 32 & 160 & 42 & $26.25 \%$ & $61.90 \%$ \\
\hline
\end{tabular}

This phoneme proved moderately bothersome to the participants. $\left(\mu^{\mathrm{t}}=26.25 \%\right)$.

There were differences though, Germans had significantly less problems with it ( $\mu^{\text {gel1 }}=8 \%$ ) than Russians $\left(\mu^{\mathrm{Ru}}=36.66 \%\right)$ though.

The most difficult word seemed to be awful, making up one third of all the mistakes. In the German EFL group, one participant stood slightly out by the mere fact that he made mistakes, while the rest of the group did not. But this is nothing significant though, the average mistake rate was 1.31 .

g) $/ \mathrm{p} /$

${ }^{11} \mu^{\mathrm{ge}}=$ Mean of group of German EFL participants 
This open mid-back rounded vowel is present in French and German with a similar phoneme, but it is not present at all in Spanish and Russian. The words selected for this phoneme are knowledge, body, mob, impossible and rock. Table 240 below shows the error frequency of this phoneme by EFL participants.

Table 24: Error Frequency of /w/ Phoneme

\begin{tabular}{|c||c|c|c|c|c|}
\hline & $\boldsymbol{n}$ & items & $\begin{array}{c}\text { Number of } \\
\text { Mistakes }\end{array}$ & $\boldsymbol{\mu}$ & Clipping influence \\
\hline \hline Spanish & 10 & 50 & 4 & $8 \%$ & $0 \%$ \\
\hline French & 11 & 55 & 11 & $20 \%$ & $18.18 \%$ \\
\hline Russian & 6 & 30 & 1 & $3.33 \%$ & $0 \%$ \\
\hline German & 5 & 25 & 2 & $8 \%$ & $0 \%$ \\
\hline Total & 32 & 160 & 18 & $11.25 \%$ & $11.11 \%$ \\
\hline
\end{tabular}

This phoneme did not cause too many pronunciation problems to the EFL participants $\left(\mu^{\mathrm{t}}=11.25 \%\right)$, despite the French EFL learners having overproportionately more problems than the rest of the participating languages $\left(\mu^{\mathrm{fr}}=20 \%\right)$.

Body became the most difficult word for the EFL speakers $(33.33 \%$ of all the mistakes) and all participants from all participating languages were homogenous in their mistake rate. $59.38 \%$ of the participants made zero mistakes and the average mistake rate was a low 0.56 .

h) $/ \mathrm{u}: /$

This close central rounded phoneme is only present as an allophone in Russian and as a similar vowel in a German variant (Saxon). Neither Spanish nor French have this 
phoneme. The words selected for this part are true, through, shoes, moose and noose. Table 25 below shows the error frequency of this phoneme.

Table 25: Error Frequency of /u:/ Phoneme

\begin{tabular}{|c||c|c|c|c|c|}
\hline & $\boldsymbol{n}$ & items & $\begin{array}{c}\text { Number of } \\
\text { Mistakes }\end{array}$ & $\boldsymbol{\mu}$ & Clipping influence \\
\hline \hline Spanish & 10 & 50 & 10 & $20 \%$ & $30 \%$ \\
\hline French & 11 & 55 & 9 & $16.36 \%$ & $44.44 \%$ \\
\hline Russian & 6 & 30 & 7 & $23.33 \%$ & $28.57 \%$ \\
\hline German & 5 & 25 & 7 & $28 \%$ & $87.71 \%$ \\
\hline Total & 32 & 160 & 33 & $20.63 \%$ & $45.45 \%$ \\
\hline
\end{tabular}

The mistake rate for this phoneme was moderate and homogenous throughout all four languages $\left(\mu^{\mathrm{t}}=20.63 \%\right.$ ), ranging from $16.36 \%$ mistake rate by the French, up to the $28 \%$ rate from the Germans.

Noose was the word that was mispronounced the most (36.36\% of all mistakes) with through a close second (30.3\%). No student stood out positively or negatively in the mistake production and the average mistake rate per person was 1.03).

i) $/ \mho /$

This close-mid central rounded vowel is present with a similar phoneme in Russian and French. In German, the Swabian variant includes an analogue too, while in Spanish it is completely absent. The words selected for this phoneme are pull, good, could, foot and put. Table 26 below shows the error frequency of this phoneme. 
Table 26: Error Frequency of /o/ Phoneme

\begin{tabular}{|c||c|c|c|c|c|}
\hline & $\boldsymbol{n}$ & items & $\begin{array}{c}\text { Number of } \\
\text { Mistakes }\end{array}$ & $\boldsymbol{\mu}$ & Clipping influence \\
\hline \hline Spanish & 10 & 50 & 3 & $6 \%$ & $66.66 \%$ \\
\hline French & 11 & 55 & 3 & $5.45 \%$ & $100 \%$ \\
\hline Russian & 6 & 30 & 5 & $16.66 \%$ & $40 \%$ \\
\hline German & 5 & 25 & 1 & $4 \%$ & $100 \%$ \\
\hline Total & 32 & 160 & 12 & $7.5 \%$ & $66.66 \%$ \\
\hline
\end{tabular}

The mistake rate for this phoneme is quite low $\left(\mu^{t}=7.5 \%\right)$, with the only standout being the Russian EFL speakers that more than doubled that mean (16.66\%).

Put was the most mispronounced word in this phoneme group (50\%) and there were no participants that stood out, neither positively nor negatively $(68.75 \%$ made zero mistakes and the average mistake rate was a very low 0.38 per person).

j) $/ 3: /$

This open-mid front unrounded phoneme is present with an analogue sound in French, German and Russian. Spanish has a similar phoneme only in regional variants (Andalusian and Murcian). Since part of this research was conducted in Murcia, this variant could factor into the results. The words selected are turn, word, her, first and search. Table 27 below shows the error frequency of this phoneme in this research. 
Table 27: Error Frequency of /3:/ Phoneme

\begin{tabular}{|c||c|c|c|c|c|}
\hline & $\boldsymbol{n}$ & items & $\begin{array}{c}\text { Number of } \\
\text { Mistakes }\end{array}$ & $\boldsymbol{\mu}$ & Clipping influence \\
\hline \hline Spanish & 10 & 50 & 3 & $6 \%$ & $66 \%$ \\
\hline French & 11 & 55 & 3 & $5.45 \%$ & $0 \%$ \\
\hline Russian & 6 & 30 & 5 & $16.66 \%$ & $0 \%$ \\
\hline German & 5 & 25 & 2 & $8 \%$ & $0 \%$ \\
\hline Total & 32 & 160 & 13 & $8.13 \%$ & $15.38 \%$ \\
\hline
\end{tabular}

The mistake rate for this phoneme was low $\left(\mu^{\mathrm{t}}=8.13 \%\right)$. With the exception of the Russian participants $\left(\mu^{\mathrm{Ru}}=16.66 \%\right.$ ) the mistake rates were quite low (from $5.45 \%$ to $8 \%$ the rest of the languages.

Turn and her were both the most mispronounced words (each 38.46\%). No participant in any group stood out in any positive or negative way (68.75\% made no mistakes and the average mistake rate per person was a low 0.40 ).

k) /e/

This mid front unrounded phoneme is present with a similar phoneme in Spanish, German and Russian, but not in French. The words selected for it are head, friend, bed, effort and left. Table 28 below shows the error frequency of this phoneme by EFL learners from countries participating in this research. 
Table 28: Error Frequency of /e/ Phoneme

\begin{tabular}{|c||c|c|c|c|c|}
\hline & $\boldsymbol{n}$ & items & $\begin{array}{c}\text { Number of } \\
\text { Mistakes }\end{array}$ & $\boldsymbol{\mu}$ & Clipping influence \\
\hline \hline Spanish & 10 & 50 & 2 & $4 \%$ & $100 \%$ \\
\hline French & 11 & 55 & 4 & $7.27 \%$ & $75 \%$ \\
\hline Russian & 6 & 30 & 3 & $10 \%$ & $33 \%$ \\
\hline German & 5 & 25 & 2 & $8 \%$ & $50 \%$ \\
\hline Total & 32 & 160 & 11 & $6.88 \%$ & $63.63 \%$ \\
\hline
\end{tabular}

The average mistake rate for all participants for this phoneme is very low $\left(\mu^{\mathrm{t}}=6.88\right)$.

The range starts with the error rate of $4 \%$ from the Spanish and ends already at $10 \%$, which is the mistake rate of the Russians.

The word effort was by far the most mispronounced word in this group (63.63\%), and, again, no participants stood out one way or another ( $75 \%$ of the participants made zero mistakes and the average mistake number for everyone was a very low 0.34 ).

1) $/ \partial /$

This mid central phoneme, also known as a schwa, is not present in Spanish, French and Russian; only German has a similar sounding phoneme. The words selected for this phoneme are banana, enemy, about, alias and relative. Table 29 below shows the error frequency of this phoneme by the EFL learner participating in this research. 
Table 29: Error Frequency of /ə/ Phoneme

\begin{tabular}{|c||c|c|c|c|c|}
\hline & $\boldsymbol{n}$ & items & $\begin{array}{c}\text { Number of } \\
\text { Mistakes }\end{array}$ & $\boldsymbol{\mu}$ & Clipping influence \\
\hline \hline Spanish & 10 & 50 & 29 & $58 \%$ & $48.28 \%$ \\
\hline French & 11 & 55 & 30 & $54.54 \%$ & $60 \%$ \\
\hline Russian & 6 & 30 & 13 & $43.33 \%$ & $53.85 \%$ \\
\hline German & 5 & 25 & 8 & $32 \%$ & $62.5 \%$ \\
\hline Total & 32 & 160 & 80 & $50 \%$ & $55 \%$ \\
\hline
\end{tabular}

The average mistake is very high with this phoneme, every second word was pronounced wrongly. The Germans, probably thanks to having a counterpart in their own language, reduced this rate to a still high $32 \%$, while the Spanish EFL Learners upped it even more than the average $\left(\mu^{\mathrm{sp}}=58 \%\right)$.

Three words were almost equally difficult to pronounce correctly in this phoneme group: relative and banana (both $28.75 \%$ of all mistakes) and alias $(26.25 \%)$. With the exception of one German participant, the rest of the people committed at least one mistake with this phoneme (up to 5 mistakes with an average mistake rate per participant of 2.5).

At the end of this section, it is time to review the hypotheses and research questions. The first variable was related to stress-timed languages versus syllable-timed languages. This lead to the hypothesis that the Germans participants (being a stress-timed language with a complex vowel system) would have fewer problems. On the other hand, the Spanish participants (with a syllable-timed language and a simple vowel system) would have the most problems. 
The obtained data confirm that, indeed, German participants had the least problem of all four language communities that participated during this research (12\%). However, Spanish participants $(21.83 \%)$ were not the group with the biggest amount of phonetic problems. Their mistake ratio was above the average (20.26\%) of all the participants but the Russian participants (which share the stress-timed rhythm with English) had the most difficulties in the end $(25.83 \%)$.

The second variable was related to the complexity of the vowel system, which has been traditionally considered the main source for mistakes. According to this variable simple vowel system languages like Russian and Spanish would have more difficulties than complex vowel system languages like French or German.

The results, surely, corroborated this hypothesis: Russian (25.83\%) and Spanish participants (21.83\%) did have more difficulties than French (19.54\%) and German participants (12\%). In fact, both simple vowel system language communities had an above average mistake rating in this research.

This leads us back to our research questions from Chapter 3.1:

1. Are the variables stress-timed and vocalic system complexity determining the difficulty and the error? Are these factors cumulative, so if they come together in one language, the speakers of that language will make it worse?

2. Which variable is more determining V1 (rhythm) or V2 (vowel system)? 
The first variable (rhythm) is not as determinant as the second variable (vowel system). While German participants (sharing both variables with English) did most certainly fare better than the other linguistic communities in this research, Spanish participants did not turn out to have the biggest mistake ratio. Russian participants (which share the rhythm variable with English speakers) had a higher mistake ratio and thus refuted the research question that both variables would act as a cumulative factor to the detriment of proper vowel pronunciation.

The complexity of the vowel system was definitely the more determining variable, as French participants (which share the vowel system variable) had fewer problems with the English vowel phonemes than Russian participants that share the rhythm variable with the English language.

\subsection{Final considerations}

This is the point where the results of this project must be critically reviewed. Have the proposed new methods achieved anything of value? What were the results? Can they be considered advances at all?

It was obvious from the start, that this research would have a hard time finding the solution to the inaccurate acquisition of English vowel phonemes. And unfortunately it came true; the "new" proposals did not redefine the wheel. But when other researchers during decades had the same outcome, it can hardly be considered surprising. So, it is better to focus on what we wanted to obtain, which was within the reach of this research project: modern methods combined with classic ones, delivering new data that could prove useful. 
The Johari Window is in its original use, a tool to gather information about ourselves that are hidden from us or not evident at all. For this project, the window system was used as a distribution tool to compare languages against each other. Like a distribution table in mathematics, the idea behind this inclusion was that this distribution would juxtapose different categories and that it would lead to a new angle to look at results.

Only in a few cases did a distribution according to vowel systems or isochrony deliver a different look at the results. Far too few, in order to generalize a tendency or something of value by using this approach. 3-4 cases in which it worked, against 18 speaks a clear language. Maybe it was because of the small sample size (especially Germans and Russians), that impeded better generalizations. The use of a Johari Window distribution with better variables could improve further research.

Next time, it would improve the data by a lot to add more participants from more countries. Definitely, also trying to come up with better variables. Isochrony delivered some results, but vowel system did not work out, but the Johari Window in general, helps to distribute different languages across variables, an elegant way to distribute languages into four different fields according to two variables.

Spectrography was a great success. During the review section with the native professor were instances where some pronunciation was dubious in its accuracy and yet, he as a native, confirmed it was ok. Unfortunately, it was not possible to remunerate a few more experts in order to get more than just a single voice and to check different opinions. Current free software like PRAAT can analyse the formants for each vowel. But the limit is only one at a time, for now. In the unforeseeable future the same type of software will analyse complete recordings and cold and objectively decide if the pronunciation is prototypical, acceptable or not acceptable. 
There's no arguing against human evaluation; on the contrary, this would be a perfect setting: having more data, more opinions on the research and be able to access different ways to look at things. Spectrography is like phonetic fingerprints, something traceable. Phonology has always been one of the least studied fields in linguistics for a very good reason. It relies on human ability to distinguish soft nuances in pronunciation order to discriminate phonemes, allophones and whatnot. It also relies on technical equipment just for the recording session and my guess is, with the non-stoppable rise of technological advances, phonology will be one of the beneficiaries in linguistic studies.

The reasons are evident: previously we were able to hear mispronunciations, but seeing something is better and more accurate than just hearing it. And, thanks to specific software, we can do even more now than see it: we can turn it into numbers. In this research, PRAAT was swiftly able to give the approximate frequencies of the 12 vowel phonemes needed for this research. Doing research with numbers is incredibly more helpful, because it is more objective.

At this moment, several research projects around the world in various fields (Lyakso \& al., 2020, are defining and reviewing (Shaykhislamov \& Makhmudov, 2020) this approach to linguistics: data on prototypical formant frequencies is showing up more and more. And it is my belief, that having numbers as an objective approach to error analysis will play in favour of language learning. Like GPS on cars, the formant frequencies locate the tongue within its natural habitat. With the frequencies we know at all time, why the pronunciation is not working. We will know the tongue is lower than it should be, we will know the tongue should be near the front and not centre. This really opens up an infinite amount of language learning possibilities. 


\section{Chapter 6: Conclusion}

The aim of this research was never to revolutionize language learning as we know it, and solving the century old problem of correct phonetic acquisition the accuracy in the acquisition of the English vowel system. The scope was challenging and ambitious, since combining several languages requires a lot of (human) resources.

However, the objective was to use different tools (like the Johari Window and Spectrography) to check the relationship between the complexity of the first variable (simple or complex vowel systems) and the second variable (related to stress-timed versus syllabletimed languages), in light of the errors made by the speakers of the corresponding languages.

This lead to the hypotheses that languages like German (that share both variables) would have less than problems, while languages like Spanish (that do not share both variables) would have the most problems. Are these variables decisive for the difficulties and phonetic mistakes in EFL? Would the variables act as a cumulative factor? Which variable would be more determinant for the correct pronunciation (rhythm or vowel system)?

\subsection{Main Findings}

The variables used in this research, did not reveal insightful gains into the problematic nature of vowel phone acquisition. Neither the isochrony, nor the vowel system, showed any statistically relevant information that could reveal why some languages have certain problems with certain phonemes.

Additionally, the limited numbers of participants also narrows down any small findings in that regard, since a generalization of results is not possible due to the low numbers of participants in the languages reviewed. Ten participants per language is already low, five, 
however, is the bare minimum for research but not easily extrapolatable for generalised conclusive findings.

\subsection{Limitations}

The inaccurate acquisition of EFL phonemes is a phonetic problem that has existed for a very long time. From the point of view of a researcher that means that the solution is nowhere near likely. That is why the research question involving error analysis through spectrography is less focused on solving it, and instead wants to collect data and look at it from a different lens. Again, the solution is probably out of reach because it involves many fields outside of language research (e.g. biology) but what it could do is reduce problem space. Even finding that something is not working, is one space less of problems, regarding the eventual discovery of a solution.

Another limitation is the samples themselves. Having 5-11 representatives of each language is far from ideal. Any discovery made here cannot be catalogued as representative for all speakers of that language.

The participants themselves are not representative for their whole country. They are just representatives of the conditions that were asked for, and are the ones that were available during the time this research was conducted.

Additionally, only 4 languages fitting the variables combinations in the Johari Window were analysed. It would have been ideal to have at least two languages per field (e.g. German and Portuguese, French and Turkish, Russian and Arabic or Spanish and Japanese).

Another problem is the target language itself: English. It has many variants throughout the world, and despite the fact that in the countries related to my research the 
aimed pronunciation is RP, the influence of American English in TV, music and Internet could interfere in the proper RP vowel pronunciation.

Finally, another limitation is of course human error, both on parts of the participants in the research project, and most of all the researcher's own errors and limitations.

\subsection{Directions for Future Research}

Linguists and researchers in general, always fear that question: "What is it good for?" and try to avoid the mandatory response. Though, there is no need for excuses, rationalizations or justifications, because using modern methods in addition to classic methods is exciting and interesting.

There were certainly setbacks during all these years, personally, scientifically and economically, because even if we do not want it to happen, all three things affect each other reciprocally. Have more test subjects would have been better. Better (and easier) access to foreign EFL learners would have been an immense help. The researcher's own ignorance is also at fault, complicating thus the possibility to design better research projects. Doing research (or a Ph.D. for that matter) should not mean either sacrificing research time in order to earn money to be able to do research. But complaining is useless; it is better to try to find solutions to these problems. And the recent advances in cognitive phonology are poised to solve problems.

The last decades have seen the exploding growth of the computer industry and how those advances have spilled over into other areas: medicine, communication or linguistics. This technological revolution is far from over, in fact it can be assumed that we are not even at the top of the wave right now; in fact, we are just starting to realize the possibilities.

As such this research is in many ways a starting point: 
- Spectrography as a research method for Phonology is going places. It is undeniable. The same way analysing fingerprints revolutionized Forensics, phonetic fingerprints are going to revolutionize Phonology and all its related fields.

- Future researcher can add many more languages that fit the variables. That way, the research questions can be further corroborated through additional data.

- Finally, it is also the starting point in order to continue in this field. It could be interesting to continue recording people from different countries and most importantly, it would also be a chance to continue growing as a researcher and a human being.

\subsection{Final Considerations}

It is disappointing, that due to a number of limitations (physically, economically and personally), results obtained in this research were limited. However, with the increase in technological awareness and disposition, the general direction is still interesting, which means, that comparing as many languages as possible, and according to several variables and criteria, is a stimulating field of research full of opportunities.

The way big companies analyse nowadays big data for their market research, is something that could be transferred to the language analysis and research. If big data can be analysed by these companies and even by governmental institutions, in order to predict future tendencies, it is only a question of time until big amount of linguistic data can be analysed. 
Hundreds of languages analysed according to several variables by technology, is clearly something that will happen sooner or later. In the meantime, researching in that direction, though in smaller numbers is still an engaging and thought-provoking idea.

The idea would be, in the meantime, to keep refining the research methods and criteria, until more conclusive data can be found through contrastive analysis of several different languages. Ideally, it would also be important to combine these efforts with other researchers around the world in order to have a higher number of participants available. Collaboration with similarly interested researchers could lead to higher numbers and thus a higher possibility of generalization of results.

Although this thesis stands alone in presenting my research, the research itself does not exist in isolation. After all, doing research involves adding to the discourse; adding data and/or knowledge that could move the discourse along. It is said that "research proceeds by baby steps" or that researcher have to stand on each other's shoulder". A small contribution could be considered a baby step, and that one combined with other baby steps by other researchers, could produce progress (Petre \& Rugg. 2004). 


\section{Chapter 7: Resumen Final}

La presente tesis se erige sobre 6 capítulos, los cuales se agrupan principalmente en tres partes. La primera parte consiste de los dos primeros capítulos y está dedicada a la contextualización de la tesis y al conocimiento previo, cuya función esencial es proporcionar todo el material básico necesario para entender esta investigación y ser el punto de partida para mi propia investigación. En consecuencia, los Capítulos 2 y 3 no sólo describen y definen lenguas, conceptos y métodos de investigación, sino que además proporcionan una revisión crítica sobre la teoría y literatura existentes. El capítulo 3.1 se basa en el contexto, el conocimiento relevante, la teoría y la práctica de las explicaciones anteriores para desarrollar algunas hipótesis y formula las preguntas de investigación que resultan de ellas. El objetivo de esto es que, al final del Capítulo 3, tanto el contexto previo como el motivo de mi investigación sean visibles y comprensibles.

La segunda parte empieza en el Capítulo 4 y versa sobre los datos resultantes de mi investigación. En primer lugar, describe cómo una encuesta piloto preliminar me ayudó a mejorar la encuesta definitiva utilizada en la investigación y las grabaciones reales. Luego, describe rigurosamente los procedimientos para obtener los datos de la investigación. Los datos resultantes relacionados con errores de pronunciación reciben especial atención a través del análisis espectrográfico y las similitudes y diferencias se detallan en los hallazgos.

Finalmente, la tercera parte de la tesis engloba los capítulos 5 y 6. El Capítulo 5 ofrece un análisis de los hallazgos encontrados y el Capítulo 6 concluye con los resultados obtenidos. Aquí, gracias a toda la información recabada a lo largo de la tesis, nos percatamos finalmente de las deficiencias y limitaciones. Los resultados se analizan por su importancia e implicaciones. También comprueba seriamente si arroja alguna luz nueva sobre algunos de 
los conceptos o metodologías mencionadas en la primera parte de la tesis, o qué ventajas o incluso avances puede ofrecer.

A continuación, me dispongo a explicar resumidamente los seis capítulos de mi tesis doctoral.

\subsection{Introducción}

Después de décadas de mejora en los diferentes métodos de aprendizaje de idiomas, EFL (inglés como lengua extranjera) todavía no ha encontrado la manera de evitar las dificultades que los estudiantes de todo el mundo tienen con la pronunciación correcta de las distintas vocales en inglés. Cada comunidad lingüística se centra en su propia parte de los problemas relacionados con el idioma en cuestión y, a pesar de años de investigación, el problema persiste.

Primero, contextualizo el motivo del tema de mi investigación. Durante la fase de lectura inicial leí varias áreas diferentes relacionadas con el aprendizaje de idiomas y descubrí que los lingüistas describieron exactamente los mismos problemas fonéticos durante lo largo del siglo pasado dentro de las comunidades lingüísticas. Esos problemas siguen siendo los mismos a día de hoy.

Los estudiantes de inglés como lengua extranjera siempre se enfrentan al problema de aprender el idioma inglés mientras carecen de algunos de los fonemas necesarios para el inglés en sus respectivas lenguas maternas. En algunos casos, esto puede conducir a acentos llamativos que dan a los hablantes nativos una impresión errónea sobre las capacidades lingüísticas de los estudiantes de inglés como lengua extranjera. Sucede lo mismo en los idiomas relativamente cercanos al inglés como el alemán o el español o idiomas distantes como el coreano o el japonés. Los diferentes sistemas fonéticos de, por ejemplo, español 
(Hammond, 2001), alemán (Kohler, 1999) y ruso (Timberlake, 2004) no siempre comparten los mismos fonemas o incluso a veces tampoco las mismas características fonéticas para un fonema concreto. El español, por ejemplo, no tiene vocales largas (Morrison, 2004), mientras que el ruso asimila consistentemente los fonemas vocales que faltan a sus contrapartes rusas (Gilichinskaya \& Strange, 2010). Esta es una barrera lingüística que debe superarse para adquirir una pronunciación adecuada.

El objetivo es abordar el problema desde una perspectiva diferente. Hasta ahora, la mayoría de los estudios en este campo consistían en investigadores que comparaban su lengua materna con el inglés. La idea de esta tesis es comparar varios idiomas con ciertos criterios tipológicos frente al inglés. Además, los datos serán analizados primero por un experto (hablante nativo) y luego algunos de los errores que aparezcan serán investigados más a fondo mediante análisis espectrográfico. La interdisciplinariedad y la originalidad son los dos principios clave de este enfoque.

\subsection{Contexto}

Este capítulo proporciona suficientes conocimientos previos para comprender las teorías sobre la que se basa la investigación. Delinea la posición del investigador con respecto al trabajo definiendo conceptos y dando una breve descripción que incluye descripciones históricas o geográficas.

Comienza definiendo el modelo de aprendizaje del habla, que es el marco esencial para la investigación basada en los errores de aprendizaje de idiomas. La fonología y sus diferentes métodos a lo largo de los años es lo siguiente que se revisará: la historia de la Fonología (Panini, Henry Sweet), la API, el comienzo de la Fonología moderna y las diferentes y contrastantes teorías que se desarrollaron desde entonces. La tarea relativamente 
complicada de explicar la fonología cognitiva en contraste con la fonología será la siguiente sección.

Luego, este capítulo estudia la Fonología contrastiva, un importante subcampo de la lingüística, esencial en la investigación que desea comparar diferentes idiomas.

Posteriormente, este capítulo revisa la Fonética y luego examina las características segmentarias y suprasegmentarias. Ambas categorías serán necesarias para esta investigación.

Otro apartado importante cubre el idioma; tanto sus orígenes, como más específicamente los idiomas propiamente empleados en esta investigación, esto es: español, francés, alemán y ruso. Posteriormente, este capítulo concluye con la breve explicación de la Ventana de Johari, concepto clave para la presente investigación.

\subsection{Métodos}

Después de proporcionar un contexto y un conocimiento básico esencial, el Capítulo 3 establece las preguntas de investigación, discute y justifica los métodos de investigación utilizados en los siguientes capítulos para probar hipótesis, responder preguntas o evaluar innovaciones.

El capítulo 3.1 empieza con el enunciado de las preguntas de investigación, antes de revisar los métodos que se utilizaron, discutir sus limitaciones y justificar su uso. La suma de estas partes debe posicionar esta investigación.

Esta investigación trata sobre la comparación y contraste de estos procesos de adquisición de vocales, tomando como término comparativo las respectivas lenguas maternas. El objetivo de la tesis es la descripción detallada y contrastiva de las dificultades que presenta la fonología inglesa para hablantes de diferentes idiomas. Para ello, se llevará a cabo una recogida de datos mediante metodología experimental en grupos de alumnos de diferentes 
comunidades lingüísticas. Si este objetivo se lleva a cabo con éxito, se podrán ver los patrones de aprendizaje de la fonología en la lengua extranjera. Se puede establecer una hipótesis de partida sobre las configuraciones fonológicas que podrían resultar del análisis de datos. Esta hipótesis nos lleva a establecer como punto de partida la premisa de que los sistemas fonológicos nativos proporcionan una plantilla cognitiva sobre la que se configura el aprendizaje. Se espera demostrar que las configuraciones fonológicas de los aprendices de cada comunidad lingüística marcarán diferentes caminos de aprendizaje para cada comunidad. A partir de esta hipótesis, se propone un análisis de datos basado en el método experimental.

Más específicamente, la pregunta importante aquí es si se podría deducir algún patrón en el proceso de adquisición de vocales, comparando 4 idiomas entre sí en un diseño específico. ¿Algunas características del idioma facilitan la adquisición del idioma?

Esta investigación maneja dos variables: La primera es las lenguas de isocronía acentual versus las lenguas de isocronía silábica. La segunda variable es los sistemas de vocales complejos versus los sistemas de vocales simples.

La línea de pensamiento es la siguiente: dado que el inglés es un idioma con isocronía acentual y con un sistema de vocales complejo, la hipótesis nula sugiere que el alemán, al ser también de isocronía acentual y con un sistema de vocales complejo, debería tener menos dificultades y, en consecuencia, menos errores. Siguiendo esta hipótesis, el español, al ser una lengua de isocronía silábica con un sistema de vocales simple, debería ser la que tenga más dificultades y, por tanto, más errores. Además, el ruso y el francés comparten cada uno una variable distinta con el inglés: el ruso tiene un isocronía acentual y el francés es un sistema vocálico complejo. Este proceso de pensamiento sigue el diseño de estructura de la Ventana de Johari. 
La segunda variable se ocupa de la complejidad del sistema de vocales, que tradicionalmente se ha considerado como el factor determinante del error. Por este motivo, la hipótesis nula indica que el ruso (sistema de vocales simples) presentará más dificultades y más errores que el francés (sistema de vocales complejo).

Así, las preguntas de investigación serían:

1. ¿Las variables de isocronía acentual y la complejidad del sistema vocálico determinan la dificultad y el error? ¿Son estos factores acumulativos, de modo que si se juntan en un idioma, los hablantes de ese idioma lo tienen más difícil?

2. ¿Qué variable es más determinante: V1 o V2?

\subsection{Diseño experimental \& Datos}

Este capítulo explica el diseño del experimento y el procedimiento de investigación. Con la ayuda de la información de los Capítulos 2 y 3 , se pueden identificar claramente las hipótesis de investigación y las preguntas de investigación. Así se delineará claramente la posición de este trabajo (comparar varios idiomas y estudiar la mala pronunciación) y la dimensión que es apropiada (primero un análisis por un profesor nativo de inglés, luego un análisis de errores por espectrografía) para lograr con éxito este objetivo.

Este capítulo explica la encuesta piloto preliminar. Se lleva a cabo antes del estudio final a gran escala (Ismail, 2018) para identificar las fortalezas y debilidades del proceso de investigación. Esta retroalimentación ayuda al investigador a ajustar y perfeccionar la metodología utilizada en el proyecto de investigación final.

Luego describe el proceso de reclutamiento de los participantes seleccionados para la investigación, qué aparatos técnicos y software se utilizó y cómo se llevó a cabo el registro y la recolección de datos. A continuación, se explica el cuestionario y la sesión de grabación 
y se describen los resultados: participaron 37 personas de diferentes países, pero al ser necesario un mínimo de 5 sujetos para representar cada idioma, 5 sujetos de 3 países diferentes (Portugal, Italia y Japón) tuvieron que ser descartados. Por tanto, la muestra final se reduce a $n=32$.

El cuestionario tenía dos propósitos:

- Adquirir algunos datos estadísticos sobre los grupos y sus participantes (también reconociendo la limitación y generalización debido al número limitado de participantes)

- Recopilar datos personales sobre cómo creen que se adquiere la pronunciación adecuada en inglés

Los resultados muestran que todos los grupos valoran más las formas sociales de adquirir una pronunciación adecuada del inglés que las clases de fonética. A pesar de que las clases de fonética ocupan el cuarto lugar, está claramente considerada un nivel por debajo de los primeros tres factores. También muestra que todos los grupos valoran menos comenzar a aprender inglés lo antes posible (excepto el ruso), y las cláusulas de gramática descriptiva se consideran las menos útiles para la pronunciación del inglés.

El propósito de las grabaciones es analizar la pronunciación en inglés de los estudiantes de inglés como lengua extranjera de diferentes países, más específicamente la pronunciación incorrecta de 12 fonemas vocales en inglés / I,, , e, ə, p, æ, $\Lambda, \mathrm{i}:$, u:, ๖:, 3:, a: /. Los datos obtenidos se analizaron con la ayuda de un profesor nativo. A lo largo de varias horas se examinaron todas las grabaciones válidas (al menos 5 participantes por idioma). En total, se comprobaron 1920 ítems.

\subsection{Discusión}


La idea detrás de este capítulo es ofrecer información desconocida previamente al proyecto y, posteriormente, ayudarnos a sacar algunas conclusiones. Sin embargo, los resultados teóricos necesitan una mayor validación antes de que se acepte su idoneidad en la práctica.

Los datos obtenidos deben sistematizarse en diferentes parámetros para poder comparar los 4 grupos de EFL y obtener resultados significativos.

Al final de esta sección, es el momento de revisar las hipótesis y preguntas de investigación. La primera variable estaba relacionada con los lenguajes de isocronía acentual versus los lenguajes de isocronía silábica. Esto llevó a la hipótesis de que los participantes alemanes (al ser un idioma de isocronía acentual con un sistema de vocales complejo) tendrían menos problemas. Por otro lado, los participantes españoles (con un idioma de isocronía silábica y un sistema de vocales simple) serían los que tendrían más problemas.

Los datos obtenidos confirman que, de hecho, los participantes alemanes tenían el menor problema de las cuatro comunidades lingüísticas que participaron durante esta investigación (12\%). Aunque los españoles (21,83\%) no fueron el grupo con mayor cantidad de problemas fonéticos, su tasa de errores estuvo por encima de la media $(20,26 \%)$ de todos los participantes. Los rusos (que comparten la isocronía acentual con el inglés) tuvieron las mayores dificultades $(25,83 \%)$.

La segunda variable estaba relacionada con la complejidad del sistema de vocales, que tradicionalmente se ha considerado la principal fuente de errores. Según esta variable, los idiomas con sistemas de vocales simples como el ruso y el español tendrían más dificultades que los idiomas con sistemas de vocales complejos como el francés o el alemán. 
Los resultados corroboraron esta hipótesis: los participantes rusos $(25,83 \%)$ y españoles $(21,83 \%)$ tenían más dificultades que los franceses $(19,54 \%)$ y los alemanes $(12 \%)$. De hecho, ambas comunidades lingüísticas del sistema de vocales simples tuvieron una calificación de error superior a la media en esta investigación.

Esto nos lleva de nuevo a nuestras preguntas de investigación del Capítulo 3.1:

1. ¿Son las variables de isocronía acentual y de sistema vocálico complejo determinantes para la dificultad y el error? ¿Son estos factores acumulativos, de modo que si ambas variables se juntan en un mismo idioma, los hablantes de ese idioma tendrían más dificultades en la pronunciación correcta de las vocales inglesas?

2. ¿Qué variable es más determinante: V1 (ritmo) o V2 (sistema de vocales)?

La primera variable (ritmo) no es tan determinante como la segunda variable (sistema de vocales). Si bien los participantes alemanes (que comparten ambas variables con el inglés) obtuvieron mejores resultados que las otras comunidades lingüísticas en esta investigación, los participantes españoles no resultaron tener la mayor proporción de errores. Los participantes rusos (que comparten la variable de isocronía acentual con los angloparlantes) tenían una tasa de error más alta y, por lo tanto, refutaron la pregunta de investigación de que ambas variables actuarían como un factor acumulativo en detrimento de la pronunciación adecuada de las vocales.

La complejidad del sistema de vocales fue en definitiva la variable más determinante, ya que los participantes franceses (que comparten la variable del sistema de vocales) tuvieron menos problemas con las vocales en inglés que los participantes rusos que comparten la variable de ritmo con el idioma inglés. 


\subsection{Conclusión}

Este capítulo final resume los principales hallazgos, limitaciones, direcciones para futuras investigaciones y conclusiones finales.

El objetivo de esta investigación fue utilizar diferentes herramientas (como la Ventana de Johari y la Espectrografía) para comprobar la relación entre la complejidad de la primera variable (simple o compleja) de los sistemas de vocales y la segunda variable relacionada con los lenguajes de isocronía acentual versus los de isocronía silábica.

Esto lleva a la hipótesis de que idiomas como el alemán (que comparten ambas variables) tendrían menos problemas, mientras que idiomas como el español (que no comparten ambas variables) tendrían más problemas.

¿Son estas variables decisivas para las dificultades y errores fonéticos en EFL? ¿Actuarían las variables como un factor acumulativo? ¿Qué variable sería más determinante para la pronunciación correcta (ritmo o sistema de vocales)?

Las variables utilizadas en esta investigación no revelaron avances profundos sobre la naturaleza problemática de la adquisición de vocales. Ni la isocronía, ni el sistema de vocales mostraron información estadísticamente relevante que pudiera revelar por qué algunas lenguas tienen ciertos problemas con ciertos fonemas.

Además, el número limitado de participantes también reduce los pequeños hallazgos en ese sentido, ya que no es posible generalizar los resultados debido al bajo número de participantes en los idiomas revisados. Diez participantes por idioma es ya bajo; sin embargo, cinco es el mínimo indispensable para la investigación, pero no se puede extrapolar fácilmente para obtener resultados concluyentes generalizados. 
La adquisición inexacta de fonemas EFL es un problema fonético que existe desde hace mucho tiempo. Desde el punto de vista de un investigador, eso significa que la solución no es nada probable. Es por eso que la pregunta de investigación que involucra el análisis de errores a través de la espectrografía está menos enfocada en resolverlo y, en cambio, quiere recopilar datos y mirarlos desde una lente diferente. Una vez más, la solución probablemente esté fuera de alcance porque involucra muchos campos fuera de la investigación del lenguaje (por ejemplo, biología), pero lo que podría hacer es reducir el número de problemas. Incluso encontrar que algo no funciona, es un problema menos que se puede eliminar de la ecuación, y es una ayuda de cara al eventual descubrimiento de una solución.

Sin embargo, esta investigación también es en muchos sentidos un punto de partida:

- La espectrografía como método de investigación de la fonología está avanzando. Es innegable. De la misma manera que el análisis de huellas dactilares revolucionó la ciencia forense, las huellas dactilares fonéticas van a revolucionar la fonología y todos sus campos relacionados.

- Los futuros investigadores pueden agregar muchos más lenguas que se ajusten a las variables. De esa manera, las preguntas de la investigación se pueden responder aún más gracias a datos adicionales.

- Finalmente, también es mi punto de partida para continuar en este campo. Sería interesante continuar grabando personas de diferentes países y, lo más importante, también sería una oportunidad para seguir creciendo como investigador y como ser humano. 


\section{Bibliography}

Abercrombie, D. (1966). Elements of General Phonetics. Edinburgh University Press.

Al-hindawi, F. H., \& Al-Adili, N. M. (2018). The Basic Tenets of Generative Phonology. Journal of Education and Practice, 9(1). https://doi.org/10.7176/JEP

Alter, S. (2005). William Dwight Whitney and the Science of Language. Johns Hopkins University Press.

Anderson, J., Ewen, C., \& Staun, J. (1985). Phonological Structure: Segmental, Suprasegmental and Extrasegmental. Phonology, 2(1), 203-221. https://doi.org/10.1017/S0952675700000439

Andreassen, M., Smith, B., \& Guyette, T. (1991). Pressure-Flow Measurements for Selected Oral and Nasal Sound Segments Produced by Normal Adults. The Cleft PalateCraniofacial Journal, 28(4), 398-407. https://doi.org/10.1597/1545-1569

Anthony, M., \& Biggs, N. (1992). Computational Learning Theory. Cambridge University Press.

Aoyama, K., Flege, J., Guion, S., Akahane-Yamada, R., \& Yamada, T. (2004). Perceived Phonetic Dissimilarity and L2 Speech Learning: the Case of Japanese /r/ and English /1/ and /r/. Journal of Phonetics, 32. https://doi.org/10.1016/S0095-4470(03)00036-6

Aronoff, M., \& Rees-Miller, J. (2017). The Handbook of Linguistics. John Wiley \& Sons Inc.

Ashby, P. (2011). Understanding Language. Routledge.

Bachmann, R., Kemper, G., \& Gerzer, T. (2014). Big Data - Fluch oder Segen? Unternehmen im Spiegel gesellschaftlichen Wandels. Hüthig Jehle Rehm. 
Bally, C., \& Sechehaye, A. (1916). Course in General Linguistics. Bloomsbury Academic.

Banathy, B., Trager, E. C., \& Waddle, C. D. (1966). The Use of Contrastive Data in Foreign Language Course Development. Trends in Language Teaching.

Banzina, E., Dilley, L., \& Hewitt, L. (2016). The Role of Secondary-Stressed and Unstressed-Unreduced Syllables in Word Recognition: Acoustic and Perceptual Studies with Russian Learners of English. Journal of Psycholinguistic Research, 45(4), 813-831. https://doi.org/https://doi.org/10.1007/s10936-015-9377-z

Barnes, J. (2004). Vowel Reduction in Russian: the Categorical and the Gradient. Boston.

Beard, R. (1995). Lexeme-Morpheme Base Morphology: A General Theory of Inflection and Word Formation. State University of New York Press.

Beddor, P. S. (1983). Phonological and Phonetic Effects of Nasalization on Vowel Height. Indiana University Linguistics Club.

Bergmann, C., Nota, A., Sprenger, S., \& Schmid, M. (2016). L2 Immersion Causes Nonnative-like L1 Pronunciation in German Attriters. Journal of Phonetics, 58, 71-86. https://doi.org/https://doi.org/10.1016/j.wocn.2016.07.001

Bhaskararao, P., \& Ladefoged, P. (1991). Two Types of Voiceless Nasals. Journal of the International Phonetic Association, 21(2), 80-88.

https://doi.org/10.1017/S0025100314000437

Binos, P., Thodi, C., Vogazianos, P., Psillas, G., \& Constantinidis, J. (2020). An Acoustic and Auditory Analysis of Vocants in Infants with Cochlear Implants. Logopedics Phoniatrics Vocology, February. https://doi.org/10.1080/14015439.2020.1724325

Boerma, P., Dekkers, J., \& Van de Weijer, J. (2000). Optimality Theory: Phonology, Syntax, 
and Acquisition. Oxford University Press.

Böhtlingk, O. (2018). Pânini's Grammatik. Forgotten Books.

Booij, G. (2006). Lexical Phonology and Morphology. Encyclopedia of Language and Linguistics. Elsevier.

Brunori, R. (2016). Pre-Fortis Clipping. Retrieved May 1, 2019, from http://www.englishpronunciationmadrid.com/

Burguera, M. L. (2005). Textos clásicos de teoría de la literatura. Cátedra.

Bylund, E. (2009). Effects of Age of L2 Acquisition on L1 Event Conceptualization Patterns. Bilingualism: Language and Cognition, 12(3), 305-322.

Byun, K., Hong, S.-H., \& Ahn, H. (2018). A Quantitative Analysis of the Phonemic Status of the Russian Vowel y. Russian Linguistics, 42(3), 375-390. https://doi.org/s11185-0189203-y

Cantos Gómez, P. (2013). Statistical Methods in Language and Linguistic Research. Equinox.

Carstairs-McCarthy, A. (2017). Origins of Language. In M. Aronoff \& J. Rees-Miller (Eds.), The Handbook of Linguistics (p. 712). Wiley-Blackwell. https://doi.org/10.1002/9781119072256.ch1

Catford, J. C. (1988). A Practical Introduction to Phonetics. Oxford University Press.

Chapman, S., \& Routledge, C. (2012). Key Ideas in Linguistics and the Philosophy of Language. Language in Society, 41(1). https://doi.org/10.1017/S0047404511001011

Chew, P. (2003). A Computational Phonology of Russian. Dissertation.Com.

Chomsky, N. (1988). Language and Problems of Knowledge: The Managua Lectures. The 
MIT Press.

Chomsky, N., \& Halle, M. (1968). The Sound Pattern of English. MIT Press.

Christ, H., \& Rang, H. (1985). Fremdsprachenunterricht unter staatlicher Verwaltung 17001945. Narr Francke Attempto.

Clark, A., \& Lappin, S. (2012). Computational Learning Theory and Language Acquisition. Philosophy of Linguistics, 14, 445-475. https://doi.org/10.1093/oxfordhb/9780199935314.013.002

Clark, J., \& Yallop, C. (1995). An Introduction to Phonetics \& Phonology. Wiley Blackwell. https://doi.org/B008YT3PO2

Clenell, C. (1999). Promoting Pragmatic Awareness and Spoken Discourse Skills with EAP Classes. ELT Journal, 53(2), 83-91. https://doi.org/10.1093/elt/53.2.83

Collins, B., \& Mees, I. (2003). Practical Phonetics and Phonology: A Resource Bookfor Students. Routledge.

Colombat, B., Fournier, J.-M., \& Puech, C. (2010). Histoire des idées sur le langage et les langues. KLINCKSIECK.

Comrie, B., \& Corbett, G. (1993). The Slavonic Languages. Routledge.

Cooper, W., \& Eady, S. (1986). Metrical Phonology in Speech Prodcution. Journal of Memory and Language, 25, 369-384. https://doi.org/0749-596X

Crystal, D. (1981). Segmental Phonology. Clinical Linguistics, 3, $23-57$. https://doi.org/10.1007/978-3-7091-4001-7_2

Cyran, E. (1997). Voice Elements in Phonology. A Study in Munster Irish. In Resonance 
Elements in Phonology (p. 232). Folium.

De la Cierva, R. (1978). Historia del franquismo. Aislamiento, transformación, agonía. Planeta.

Derbyshire, D. C., \& Pullum, G. K. (1986). Handbook of Amazonian Languages: 1. Mouton De Gruyter.

Dressler, W. (1989). Morphonology, the Dynamics of Derivation. Karoma.

Elbert, S., \& Pukui, M. (2001). Hawaiian Grammar. University of Hawaii Press.

Elsami-Rasekh, Z. (2005). Raising the Pragmatic Awareness of Language Learners. ELT Journal, 59(3), 199-208. https://doi.org/10.1093/elt/cci039

England, J., \& Caramés, J. (1978). El uso y abuso de anglicismos en la prensa española de hoy. Arbor.

Ertel, W. (2016). Grundkurs Künstliche Intelligenz: Eine praxisorientierte Einführung. Springer Vieweg.

Escudero, P. (2006). The Phonological and Phonetic Development of New Vowel Contrasts in Spanish Learners of English. In English with a Latin Beat: Studies in Portuguese/Spanish-English Interphonology (p. 214). John Benjamins Publishing Company.

Escudero, P., \& Wanrooij, K. (2010). The Effect of L1 Orthography on Non-native Vowel Perception. Language and Speech, 53(3), 343-365.

Evans, V., \& Green, M. (2006). Cognitive Linguistics - An introduction (1st ed.). Routledge.

Eysenck, M. W., \& Keane, M. T. (2005). Cognitive Psychology: A Student's Handbook. 
Cognitive Psychology (Vol. 5).

Fernández-García, A. (1972). Anglicismos en el español (1890-1936). Lux.

Filippi, P. (1998). Acoustics: Basic Physics, Theory and Methods. Academic Press.

Finch, D., \& Ortiz Lira, H. (1982). A Course in English Phonetics for Spanish Speakers. London: Heinemann Educational Books Ltd.

Flege, J. E. (1995). Second Language Speech Learning: Theory, Findings and Problems. Speech Perception and Linguistic Experience: Issues in Crosslanguage Research, 92, $233-277$.

Flege, J. E., \& Wayland, R. (2019). The Role of Input in Native Spanish Late learners' Production and Perception of English Phonetic Segments. Journal of Second Language Studies, 2(1), 1-44. https://doi.org/https://doi.org/10.1075/jsls.00004.fle

Galarnyk, M. (2018). Explaining the 68-95-99.7 Rule for a Normal Distribution. Retrieved May 1, 2018, from https://towardsdatascience.com/understanding-the-68-95-99-7-rulefor-a-normal-distribution-b7b7cbf760c2

Gast, V. (2012). Contrastive Analysis: Theories and Methods. Dictionaries of Linguistics and Communication Science: Linguistic Theory and Methodology.

Gilichinskaya, Y., \& Strange, W. (2010). Perceptual assimilation of American English vowels by inexperienced Russian listeners. The Journal of the Acoustical Society of America, 128(2). https://doi.org/10.1121/1.3462988

Glück, H. (2005). Metzler Lexikon Sprache. J.B. Metzler.

Goldsmith, J. (1976). An Overview of Autosegmental Phonology. Linguistic Analysis, 2(1), 23-68. https://doi.org/10.1515/9783110222517 
Goldsmith, J. (1993). Cognitive Phonology. In The Last Phonological Rule: Reflections on Constraints and Derivations (p. 246). University of Chicago Press.

Goldsmith, J., \& Pierrehumbert, J. (1993). Autosegmental and Metrical Phonology. Journal of Phonetics, 21, 357-362. https://doi.org/10.1016/S0095-4470(03)00039-1

Gómez-Capuz, J. (1997). Anglicismos en español actual: su estudio en el registro coloquial. University of Valencia.

Guisán, M.-C. (2014). El español se atasca como lengua científica. Retrieved from https://www.agenciasinc.es/Noticias/El-espanol-se-atasca-como-lengua-cientifica

Halpern, H. (2009). Supervision and the Johari Window: A Framework for Asking Questions. Education for Primary Care, 20(1). https://doi.org/10.1080/14739879.2009.11493757

Hammond, R. (2011). The Sounds of Spanish: Analysis and Application. Cascadilla Press.

Hansen, A. (1998). Les voyelles nasales du français parisien moderne. Aspects linguistiques, sociolinguistiques et perceptuels des changements en cours. Museum Tusculanum Press.

Hao, Y.-C. (2014). The Application of the Speech Learning Model to the L2 Acquisition of Mandarin Tones (No. TAL-2014). https://doi.org/10.1016/j.wocn

Hartgerink, C., Voelkel, J., Wicherts, J., \& Van assen, M. (2013). Detection of Data Fabrication Using Statistical Tools. https://doi.org/osf.io/b24pq/

Haselton, M., Nettle, D., \& Andrews, P. (2005). The Evolution of Cognitive Bias. In The Handbook of Evolutionary Psychology (pp. 724-746). John Wiley \& Sons Inc.

Hobler, D., Pfahl, S., \& Horvath, S. (2016). Studienanfänger/innen nach Hochschulart 19952015. Düsseldorf. Retrieved from https://www.boeckler.de/52369.htm\# 
Hockett, C. (1950). Learning Pronunciation. The Modern Language Journal, 34(4), 261-269. https://doi.org/10.1111/j.1540-4781.1950.tb06009.x

Hohenhaus, P. (2007). How to Do (even more) Things with Nonce Words (Other than Naming). In J. Munat (Ed.), Studies in Functional and Structural Linguistics (58th ed., p. 294). Amsterdam: John Benjamins Publishing Company.

Honeybone, P. (1999). I Blame the Government. Language Sciences, 21, 177-221. https://doi.org/10.3389/fpsyg.2020.556667

Howatt, A. P. R., \& Widdowson, H. G. (2004). A History of English Language Teaching. Oxford University Press.

Huber, D. (2017). Föck! Die Deutschen können besser Englisch als wir?! Aber nur wegen der Welschen. Aargauer Zeitung. Retrieved from https://www.aargauerzeitung.ch/schweiz/foeck-die-deutschen-koennen-besser-englischals-wir-aber-nur-wegen-der-welschen-131896455

Hyett, N., Kenny, A., \& Dickson-Swift, V. (2014). Methodology or method? A critical review of qualitative case study reports. International Journal of Qualitative Studies on Health and Well-Being, 9(1). https://doi.org/10.3402/qhw.v9.23606

Ingham, H., \& Luft, J. (1955). The Johari Window: a Graphic Model for Interpersonal Relations. Los Angeles: Proceedings of the western training laboratory in group development. University of California Western Training Lab.

Ioup, G. (1984). Is There A Structural Foreign Accent? A Comparison of Syntactic and Phonological Errors in Second Language Acquisition. Language Learning, 34(2), 1-15. https://doi.org/10.1111/j.1467-1770.1984.tb01001.x 
IPA. (1999). Handbook of the International Phonetic Association. Cambridge University Press.

Ismail, N. (2018). Pilot Study, Does It Really Matter? Learning Lessons from Conducting a Pilot Study for a Qualitative PhD Thesis. International Journal of Social Science Research, 6(1). https://doi.org/2327-5510

Jakobson, R., Fant, G., \& Morris, H. (1952). Preliminaries to Speech Analysis: The Distinctive Features and their Correlates. MIT Press.

Jones, D. (1917). English Pronouncing Dictionary. Cambridge: Cambridge University Press.

Jones, D., \& Trofimov, M. (1923). The Pronunciation of Russian. Cambridge University Press.

Jopson, N. B. (1934). Postanovka Angliyskogo Proiznosheniya (The Pronunciation of English: For Russian Students). The Slavonic and East European Review, 13(37), 222226. https://doi.org/4202981

Kager, R. (2011). Optimality Theory. Cambridge University Press.

Kartushina, N., Hervais-Adelman, A., Frauenfelder, U. H., \& Golestany, N. (2016). Mutual Influences Between Native and Non-native Vowels in Production: Evidence from Shortterm Visual Articulatory Feedback Training. Journal of Phonetics, 57, 21-39. https://doi.org/https://doi.org/10.1016/j.wocn.2016.05.001

Kauffmann, E., Peral, J., Gil, D., Ferrández, A., Sellers, R., \& Mora, H. (2019). Managing Marketing Decision-Making with Sentiment Analysis: An Evaluation of the Main Product Features Using Text Data Mining. Sustainability, 11(15). https://doi.org/10.3390/su11154235 
Kawahara, S. (2016). Japanese has Syllables: a Reply to Labrune. Phonology, 33(1), 169-194. https://doi.org/10.1017/S0952675716000063

Kaye, J. (1989). Phonology: A Cognitive View. Routledge.

Kenworthy, J. (1987). Teaching English Pronunciation. Pearson.

King, M. (2018). 3 Common Pronunciation Difficulties for Spanish Speakers... .... and How to Overcome them. Retrieved May 1, 2018, from http://www.tesoltraining.co.uk/blog/professional-development/3-commonpronunciation-difficulties-for-spanish-speakers/

Kleiner, S., \& Knöbl, R. (2015). Das Aussprachewörterbuch. Dudenverlag.

Klippel, F. (1994). Englischlernen im 18. und 19. Jahrhundert: Die Geschichte der Lehrbücher und Unterrichtsmethoden. Nodus.

Klippel, F. (2007). Fremdsprachenunterricht (19./20. Jahrhundert). Retrieved May 1, 2018, from https://www.historisches-lexikonbayerns.de/Lexikon/Fremdsprachenunterricht_(19./20._Jahrhundert)\#19._Jahrhundert

Koerner, E. F. K. K., \& Szwedek, A. (2001). Jan Baudouin de Courtenay’s contribution to linguistic theory. In Towards a History of Linguistics in Poland: From the early beginnings to the end of the 20th century (p. 355). John Benjamins Publishing Company.

Kohler, K. (1999). Handbook of the International Phonetic Association Paperback: A Guide to the Use of the International Phonetic Alphabet. Cambridge University Press. https://doi.org/10.1017/S0025100300004874

Kristiansen, G. (2006). Towards a Usage-based Cognitive Phonology. International Journal of English Studies, 6(2), 107-140. 
Kruppa, U. (1985). Kontrastive Analyse von Interferenzerscheinungen im deutsch-englischen Bereich. Neusprachliche Mitteilungen, 28(2), 92-99. https://doi.org/0028-3983

Kubota, R. (1998). An Investigation of L1-L2 Transfer in Writing Among Japanese University Students: Implications for Contrastive Rhetoric. Journal of Second Language Writing, 7(1), 69-100.

Labrune, L. (2012). The Phonology of Japanese. Oxford University Press.

Ladefoged, P. (1972). Preliminaries to Linguistic Phonetics. University of Chicago Press.

Ladefoged, P., \& Disner, S. F. (2012). Vowels and Consonants. Wiley-Blackwell.

Ladefoged, P., \& Johnson, K. (2011). A Course in Phonetics. Wadsworth.

Lado, R. (1957). Linguistics across cultures: Applied Lingusitics for Language Teachers. University of Michigan Press.

Lakoff, G. (1989). Cognitive Phonology. In The Berkeley Conference on Nonderivational Phonology (p. 35). Retrieved from https://georgelakoff.files.wordpress.com/2011/04/cognitive-phonology-lakoff-1989.pdf

Lakoff, G. (1993). Cognitive Phonology. In In The Last Phonological Rule. UC Berkeley.

Langacker, R. (2008). Cognitive Grammar A Basic Introduction. Oxford University Press.

Lauerman, J. (2011). Mandarin Chinese Most Useful Business Language After English. Retrieved May 1, 2018, from https://www.bloomberg.com/news/articles/2011-0830/mandarin-chinese-most-useful-business-language-after-english-1-

Leitch, R. (2018). Teaching English in Russia: Demand Far Exceeds Supply. Retrieved May 1,2018 , from 
https://www.transitionsabroad.com/publications/magazine/0505/teaching_english_in_ru ssia.shtml

Lenneberg, E. (1967). Biological Foundations of Language. John Wiley \& Sons Inc.

Lodge, A. (2004). A Sociolinguistic History of Parisian French. Cambridge University Press. https://doi.org/10.1017/CBO9780511486685

Luft, J., \& Ingham, H. (1961). The Johari window, a graphic model of interpersonal awareness. Human Relations Training News, 5.9.

Lyakso, E., Frolova, O., Grigorev, A., Gorodnyi, V., Nikolaev, A., \& Kurazhova, A. (2020). Speech Features of 13-15 Year-Old Children with Autism Spectrum Disorders. International Conference on Speech and Computer, 12335. https://doi.org/978-3-03060276-5_29

Mahood Macey, N. (2019). S Morpheme Durations in English: An Experimental Approach. Yale University. Retrieved from https://ling.yale.edu/sites/default/files/files/Noah Macey.pdf

Martín-Gamero, S. (1961). La enseñanza del inglés en España (Desde la Edad Media hasta el siglo XIX). Gredos.

Martínez-Celdrán, E., Fernández-Planas, A. M., \& Carrera-Sabaté, J. (2003). Castilian Spanish. Journal of the International Phonetic Association2, 33(2), 255-259.

McAarthur, T., \& McArthur, R. (1992). The Concise Oxford Companion to the English Language. Oxford University Press.

McCawley, J. (1968). The Phonological Component of a Grammar of Japanese. Mouton. McKinney, J. (2005). Diagnosis and Correction of Vocal Faults: A Manual for Teachers of 
Singing and for Choir Directors. McGraw-Hill.

Meyer, A., \& Schiller, N. (2003). Phonetics and Phonology in Language Comprehension and Production: Differences and Similarities. Mouton De Gruyter. https://doi.org/9783110178722

Michalewicz, Z., \& Fogel, D. (2000). How To Solve It: Modern Heuristics. Springer Verlag.

Mishima, A., Yamashita, T., \& Takahashi, M. (2018). Gender bias in Japanese society adds up to fewer women in college. The Asahi Shimbun. Retrieved from http://www.asahi.com/ajw/articles/AJ201810230001.html

Mohanan, K. (1987). The Theory of Lexical Phonology. Springer Verlag.

Molina, A. (2018). Mujeres en la universidad: un 60\% de tituladas y solo el 14\% de las rectoras. Retrieved March 4, 2018, from https://cadenaser.com/ser/2018/03/02/sociedad/1520005123_473823.html

Mompeán, J. A. (2006). Introduction: Cognitive Phonology. International Journal of English Studies, 6(2), VII-XII. https://doi.org/1989-6131

Mompeán, J. A. (2014). Cognitive Linguistics and Phonology. In The Bloomsbury Companion to Cognitive Linguistics (pp. 253-276). London: Bloomsbury Publishing. https://doi.org/978-1441195098

Morello, C., \& Englund, W. (2019). Jon Huntsman, Ambassador to Russia, Submits Resignation. The Washington Post. Retrieved from https://www.washingtonpost.com/national-security/us-ambassador-to-russia-jonhuntsman-submits-resignation/2019/08/06/8018730c-b85d-11e9-b3b42bb69e8c4e39_story.html? noredirect $=$ on 
Morrison, G. S. (2004). Perception of English /i/ and /I/ by Japanese and Spanish Listeners: Longitudinal Results. In Proceedings of the Northwest Linguistic Conference 2002.

Nathan, G. S. (2008). Phonology: A cognitive grammar introduction. America. Retrieved from http://books.google.com/books?hl=en\&amp;lr=\&amp;id=gTVGb9pv2mAC\&amp;oi=fn d\&amp;pg=PR9\&amp;dq=Phonology: + A + cognitive+grammar+introduction\&amp;ots= TjCDbMzvL8\&amp;sig=hqIH9Cgne6ric4TxgJRIGLIL13A

Nehal, M., \& Afzal, M. (2012). Origin and Evolution of Human Language-A Brief Survey of Some Theories and Approaches. Language in India, 12.

Newmark, L., \& Reibel, D. (1968). Necessity and Sufficiency in Language Learning. International Review of Applied Linguistics in Language Teaching, 9/3.

Oaks, D. (2015). The Tower of Babel Account: A Linguistic Consideration. Science, Religion and Culture, 2(2), 42-60.

Ocklenburg, S., Friedrich, P., Fraenz, C., Schlüter, C., Beste, C., Güntürkün, O., \& Genç, E. (2018). Neurite architecture of the planum temporale predicts neurophysiological processing of auditory speech. Science Advances, 4(7). https://doi.org/10.1126/sciadv.aar6830

Odden, D. (2005). Introducing Phonology. Journal of African Languages and Linguistics (Vol. 69). https://doi.org/10.1017/CBO9780511808869

Ohala, J. (1990). The Phonetics and Phonology of Aspects of Assimilation. In Papers in Laboratory Phonology (Vol. 1, p. 506). Cambridge University Press. https://doi.org/9780521368087 
Oller, J., \& Ziahosseiny, S. (1970). The Contrastive Analysis Hypothesis and Spelling Errors. Language Learning, 20(2), 183-189. https://doi.org/10.1111

Palacios-Martínez, I. M. (1994). La Enseñanza del Inglés en España a Debate. Perspectivas de Profesores y Alumnos. Universidad de Santiago de Compostela.

Penfield, W. (1959). Speech and Brain Mechanisms. Princeton University Press.

Pennington, J., Ruth, B., Miller, J., Peterson, J., Xu, B., Masino, A., ... Crenshaw, B. (2019). Perspective on the Development of a Large-Scale Clinical Data Repository for Pediatric Hearing Research. Ear and Hearing, (August). https://doi.org/10.1097/AUD.0000000000000779

Petre, M., \& Rugg, G. (2004). The Unwritten Rules of PhD Research. McGraw-Hill.

Pierrehumbert, J. (1980). The Phonology and Phonetics of English Intonation. Massachusetts Institute of Technology.

Piske, T., MacKay, I., \& Flege, J. E. (2001). Factors Affecting Degree of Foreign Accent in an L2: a Review. Journal of Phonetics, 29(2), 191-215. https://doi.org/https://doi.org/10.1006/jpho.2001.0134

Prince, A., \& Smolensky, P. (1993). Optimality Theory: Constraint Interaction in Generative Grammar. John Wiley \& Sons Inc.

Proshina, Z. (2006). Russia English: Status, Attitudes, Problems. The Journal of Asia TEFL, 3(2), 79-101. https://doi.org/10.18823/asiatefl.2017.14.4.1.587

Pulleyblank, D. (2011). Vowel Height. In The Blackwell Companion to Phonology (pp. 1-28). https://doi.org/10.1002/9781444335262.wbctp0021

Rallo Fabra, L., \& Jacob, K. (2014). Does CLIL Enhance Oral Skills? Fluency and 
Pronunciation Errors by Spanish-Catalan Learners of English. Content-Based Language Learning in Multilingual Educational Environments, 23, 163-177.

https://doi.org/https://doi.org/10.1007/978-3-319-11496-5_10

Rasskazova, T. (2017). English Language Teacher Development in a Russian University: Context, Problems and Implications. Ampersand, 4, 1-9. https://doi.org/10.1016/j.amper.2017.01.001

Rich, E., \& Knight, K. (1983). Artificial Intelligence. Mc Graw Hill.

Richter, K. (2018). Factors Affecting the Pronunciation Abilities of Adult Learners of English. A Longitudinal Group Study. Exploring Language Aptitude: Views from Psychology, the Language Sciences, and Cognitive Neuroscience, 16, 339-361. https://doi.org/https://doi.org/10.1007/978-3-319-91917-1_18

Riegert, B. (2013). In Brief: What is Actually in the Elysee Treaty? Retrieved from https://www.dw.com/en/in-brief-what-is-actually-in-the-elysee-treaty/a-16520266

Roberts, J. (2016). Thinking Machines: The Search for Artificial Intelligence. Distillations, 2(2), 14-23. Retrieved from https://www.sciencehistory.org/distillations/magazine/thinking-machines-the-search-forartificial-intelligence

Robins, R. H. (2014). General Linguistics. Routledge.

Rodríguez Medina, M. J. (2003). La Presencia Del Inglés En España. Analecta Malacitana Electrónica, 13(Junio).

Rousseau, J.-J., \& Herder, J. G. (1781). On the Origin of Language. University of Chicago Press. 
Ruisz, D. (2014). Umerziehung durch Englischunterricht?: US-amerikanische ReeducationPolitik, neuphilologische Orientierungsdebatte und bildungspolitische Umsetzung im nachkriegszeitlichen Bayern (1945-1955). Waxmann Verlag.

Saito, H., \& Ashby, M. (2013). Edward Gauntlett's Phonetics (1905). Proceedings of the Phonetics Teaching and Learning Conference 2013, 104.

Sajavaara, K. (1981). The Nature of First Language Transfer: English as L2 in a Foreign Language Setting. In First European-North American Workshop on Cross-Linguistics Second Language Acquisition Research. Lake Arrowhead.

Sapir, E. (1933). La réalité psychologique des phonèmes. Journal de Psychologie Normale et Pathologique, 30(1), 247-265.

Sato, H., Hirabayashi, Y., Tsubokura, H., Kanai, M., Ashida, T., Konishi, I., ... Maki, A. (2012). Cerebral hemodynamics in newborn infants exposed to speech sounds: A wholehead optical topography study. Human Brain Mapping, 33(9), 2092-2103. https://doi.org/10.1002/hbm.21350

Sato, S. (2014). Constructing and Constructed Japanese: The History of Standard Japanese and Practice at a Japanese Preschool. In Rethinking Language and Culture in Japanese Education: Beyond the Standard (p. 269). Multilingual Matters.

Satow, E. M., \& Masakata, I. (1876). An English-Japanese Dictionary of the Spoken Language. Ulan Press. https://doi.org/B009RFH2VY

Selinker, L. (1972). Interlanguage. IRAL-International Review of Applied Linguistics in Language Teaching, 10(1-4), 209-232. https://doi.org/10.1515/iral.1966.4.1-4.U

Shaykhislamov, N., \& Makhmudov, K. (2020). Linguistics and Its Modern Types. Academic 
Research in Educational Sciences, 1(1). https://doi.org/2181-1385

Sievers, E. (1901). Grundzüge der Phonetik: zur Einführung in das Studium der Lautlehre der indogermanischen Sprachen. Breitkopf \& Härtel.

Simons, G., \& Fennig, C. (2018). Ethnologue: Languages of the World. SIL International.

Simons, S. (2015). Au revoir, Goethe? Retrieved from https://www.spiegel.de/lebenundlernen/schule/deutsche-sprache-in-frankreichschulreform-gefaehrdet-bilinguales-lernen-a-1029814.html

Spiewak, M. (2016). Do You Speak English? Hell yeah! Die Zeit-Online. Retrieved from https://www.zeit.de/2016/45/sprachen-englisch-schueler-faehigkeit-laendervergleich

St. Clair, R. (2006). Cycles in Metrical Phonology. Intercultural Communication Studies, 15(3), 128-148. https://doi.org/10.1080/22041451

Stampe, D., \& Donegan, P. J. (1979). The Study of Natural Phonology. Current Approaches to Phonological Theory. https://doi.org/9780253051127

Stockwell, R., \& Bowen, D. (1967). The Sounds of English and Spanish. The University of Chicago Press. https://doi.org/B000XXZHIE

Timberlake, A. (2004). A Reference Grammar of Russian. Cambridge University Press.

Tomaschek, F., Truckenbrodt, H., \& Hertrich, I. (2011). Categorical Processing of German Vowel Quantity. The Journal of the Acoustical Society of America, 129(4). https://doi.org/10.1121/1.3587924

Trentmann, N. (2013). Deutsche sprechen nur mittelmäßig Englisch. Die Welt. Retrieved from https://www.welt.de/print/die_welt/wirtschaft/article121540310/Deutschesprechen-nur-mittelmaessig-Englisch.html 
Trubetzkoy, N. (1939). Grundzüge der Phonologie. Vandenhoeck + Ruprecht Gm.

Van de Weijer, J. (2006). Autosegmental Phonology. Encyclopedia of Language \& Linguistics. https://doi.org/10.1016/B0-08-044854-2/04223-1

Van den Berg, J. (1958). Myoelastic-Aerodynamic Theory of Voice Production. Journal of Speech and Hearing Research, 1(3), 227-244. https://doi.org/10.1044/jshr.0103.227

Veenendaal, N., Groen, M., \& Verhoeven, L. (2016). The Contribution of Segmental and Suprasegmental Phonology to Reading Comprehension. Read Res Q, 51(1), 55-66.

Verklan, T. (2007). Johari Window: A Model for Communicating to Each Other. The Journal of Perinatal \& Neonatal Nursing, 21(2).

https://doi.org/10.1097/01.JPN.0000270636.34982.c8

Virginia Reid, C. (2016). Study of Locus Equations as Features for Speech Classification and Recognition. University of Georgia.

Wählisch, M. (2019). Big Data, New Technologies, and Sustainable Peace: Challenges and Opportunities for the UN. Journal of Peacebuilding \& Development, 1(5). https://doi.org/10.1177/1542316619868984

Wells, J. (1990). Longman Pronunciation Dictionary. Longman.

White, T., Asfaw, B., Beyene, Y., Haile-Selassie, Y., Lovejoy, O., Suwa, G., \& Woldegab, G. (2009). Ardipithecus Ramidus and the Paleobiology of Early Hominids. Science, 326(5949), 75-86. https://doi.org/10.1126/science.1175802

Wiese, R. (1996). The Phonology of German. Oxford University Press.

Zemsky, A., Svetlayev, M., \& Kriuchkov, S. (1971). Russian. I. Lexicography, Phonetics, and Morphology. Textbook for Teachers' Colleges. Mockba Academa. 
Zikopoulos, P., \& Eaton, C. (2011). Understanding Big Data: Analytics for Enterprise Class Hadoop and Streaming Data. Mc Graw Hill. 


\section{Appendix}

\section{Appendix A: Glossary}

Allophone: one of a set of multiple possible spoken sounds used to pronounce a single phoneme in a particular language.

Artificial Intelligence: used to describe machines (or computers) that mimic "cognitive" functions that humans associate with the human mind, such as "learning" and "problem solving.

Big Data: a phrase used to mean a massive volume of both structured and unstructured data that is so large it is difficult to process using traditional database and software techniques.

Computational Learning Theory: a subfield of A.I., devoted to studying the design and analysis of machine learning algorithms.

Contrastive Analysis Hypothesis: the systematic study of a pair of languages with a view to identifying their structural differences and similarities.

English as a Foreign Language (EFL): the use of English by speakers with different native languages.

Formant: in speech science and phonetics, a formant is the spectral shaping that results from an acoustic resonance of the human vocal tract.

International Phonetic Alphabet: an alphabetic system of phonetic notation based primarily on the Latin alphabet. It was devised by the International Phonetic Association in the late 19 th century as a standardized representation of the sounds of spoken language. 
Isochrony: Isochrony is the postulated rhythmic division of time into equal portions by a language. Rhythm is an aspect of prosody, others being intonation, stress and tempo of speech. Three alternative ways in which a language can divide time are postulated:

1. The duration of every syllable is equal (syllable-timed);

2. The duration of every mora is equal (mora-timed).

3. The interval between two stressed syllables is equal (stress-timed).

L1: a language that a person has been exposed to from birth [1] or within the critical period. L2: a language that is not the native language (first language or L1) of the speaker, but is learned later (usually as a foreign language, but it can be another language used in the speaker's home country).

Processing: The way in which we process (and therefore understand) written and spoken texts is often described as either top-down or bottom-up.

1. Top-down processing is the idea that to process and understand a text we start with "higher-level" features - background knowledge, context, overall meaning - and proceed through a series of steps "down" to "lower-level" semantic, syntactical and phonological features.

This contextual information at the top can come from knowledge about the world or the speaker/writer, from a mental image or expectation set up before or during listening or reading (often called a schema), or from predictions based on the probability of one word following another.

2. To process and understand a text with bottom-up processing, we start by recognising phonemes, combining these into syllables, syllables into words, words into clauses, and so on "up" to contextual and background information. 
Received Pronunciation: an accent of Standard English in the United Kingdom.

Syllable: a unit of organization for a sequence of speech sounds. It is typically made up of a syllable nucleus (most often a vowel) with optional initial and final margins (typically, consonants). Syllables are often considered the phonological "building blocks" of words. They can influence the rhythm of a language, its prosody, its poetic metre and its stress patterns. 


\section{Appendix B: Preliminary Survey}

\section{Phonetic Difficulties}

This participation is voluntary and your data is anonymous and confidential.

First we'd like to ask a few general questions.

How old are you?

What is your gender?

Male

Female

Are you monolingual?

Yes

No

How long (in years) have you been learning English?

For the next several statements, please choose a number from 1-5 and write it next to each statement to indicate how much you agree with it.

\begin{tabular}{|c|c|c|c|c|}
\hline 1 & 2 & 3 & 4 & 5 \\
\hline Not at all & & Neutral & & $\begin{array}{c}\text { Total } \\
\text { agreement }\end{array}$ \\
\hline
\end{tabular}

1. It is important for me to have good English pronunciation.

2. English learner should aim for native English pronunciation.

3. I try to speak with native English pronunciation.

4. The people in my country speak English very well. 
How important are the following factors in order to improve the English pronunciation?

5. Listening to authentic English.

6. Practical Phonetic classes.

7. Contacts with native speakers.

8. Imitating authentic speech.

9. Self-study on pronunciation.

10. Stay in an English speaking country.

11. Primary/Secondary school.

12. Descriptive grammar classes. 


\section{Appendix C: Preliminary Recording Exercises}

\section{Exercise 1:}

The cat climbs the tree near the garage.

My other business belongs to my woman

The awful crew saw the rock.

My friend's foot could not turn.

The floor creaked until the next day.

https://www.phon.ucl.ac.uk/resource/sfs/wasp.php

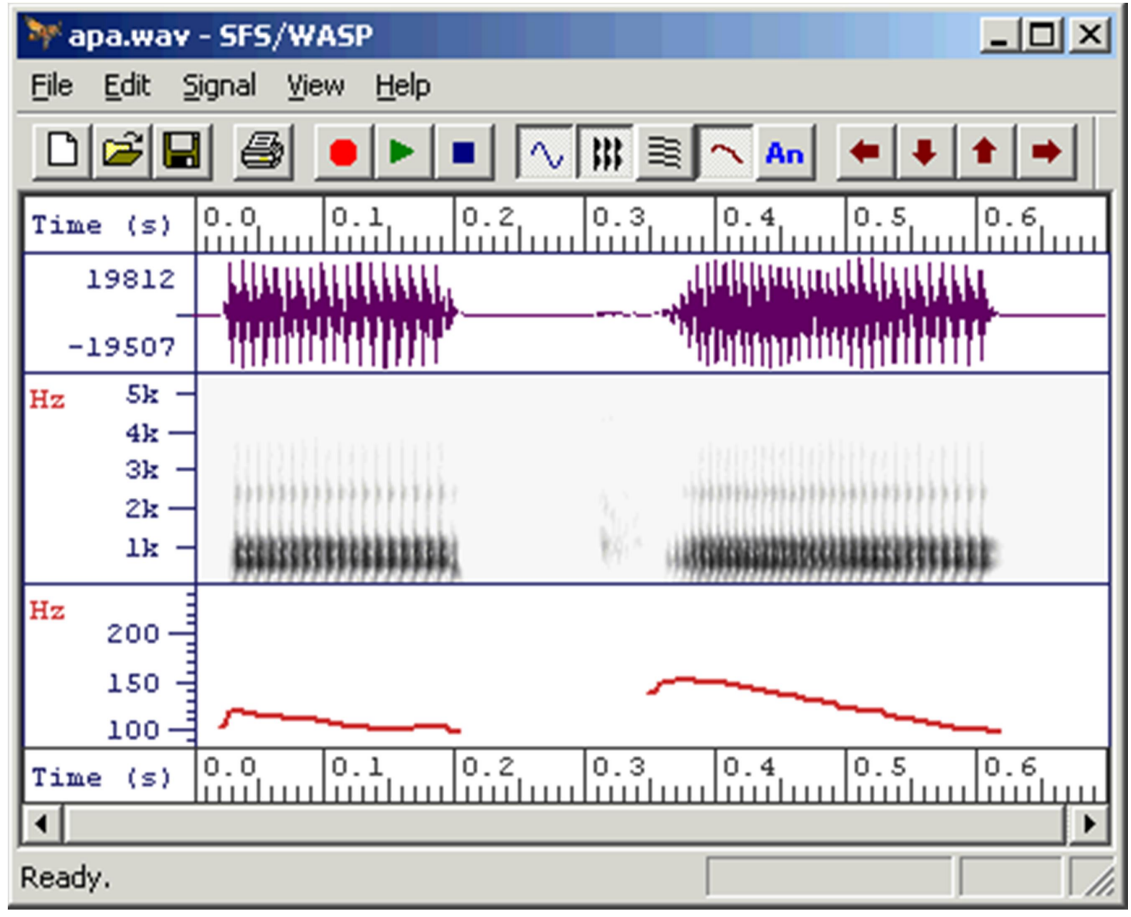


https://audio-class.ru/english-phonetics.php

English vowels (RP)

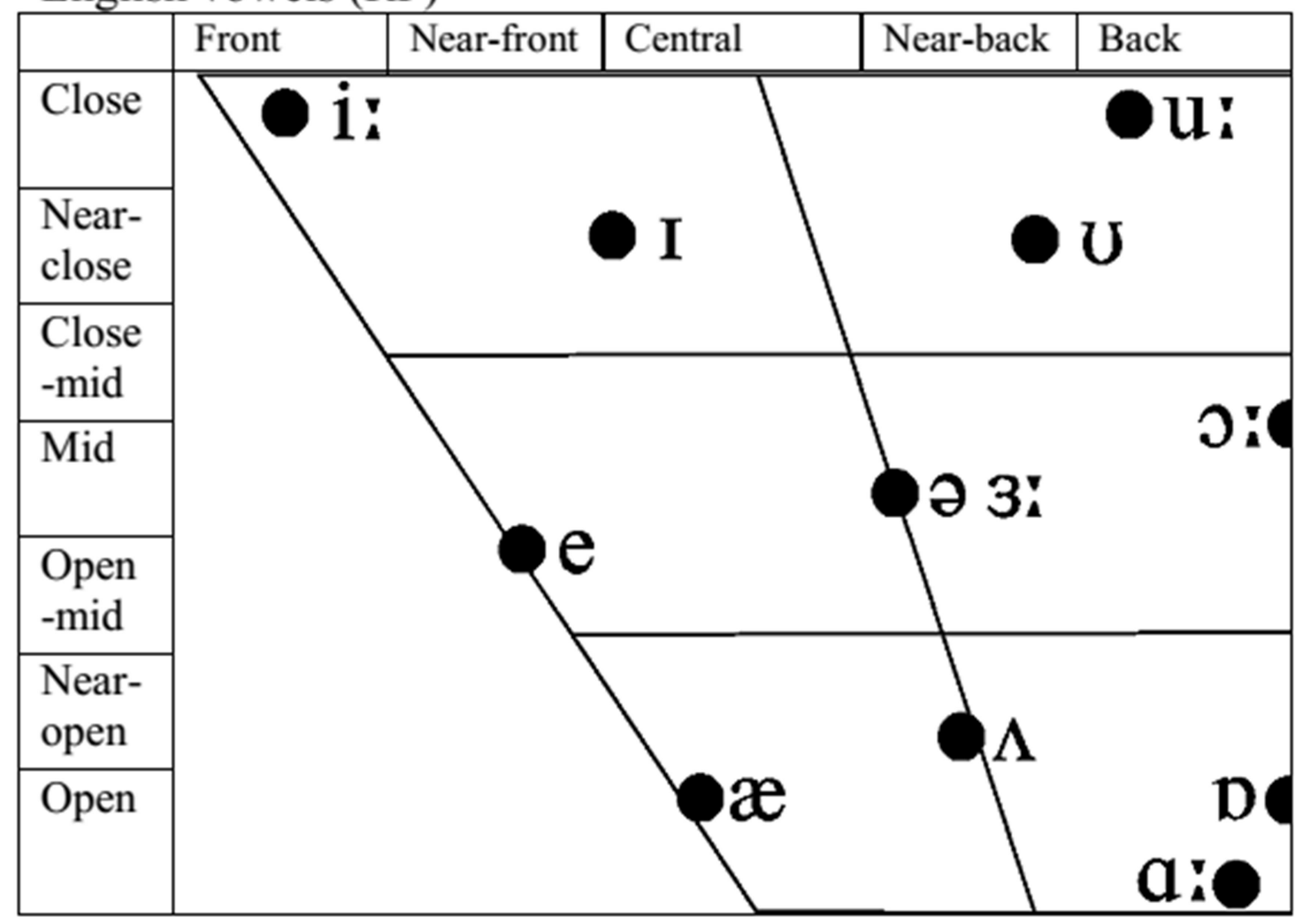


Exercise 2:

The butcher bit the apple.

Her alias was impossible to recall.

The cat climbs the tree near the garage.

My first bed broke the floor.

Women's hearts are full of love.

My other business belongs to my woman.

The ball went through the windows and broke the keyboard.

Compact shoes go far.

The awful crew saw the rock.

People search knowledge but avoid the effort.

The car costs about $10,000 \$$.

My friend's foot could not turn.

We could as a couple to the sea.

The true symbol made my head spin.

The floor creaked until the next day.

My body could not put up much longer.

Japan has of course many rivers. 


\section{Appendix D: Participant's Background Information Survey}

\section{Phonetic Difficulties}

This participation is voluntary and your data is anonymous and confidential.

First we'd like to ask a few general questions.

How old are you?

What is your gender?

Male

Female

Are you monolingual?

Yes

No

How long (in years) have you been learning English?

What's your highest English Certificate?

Cambridge: $\quad$ IELTS: TOEFL: Other: None

How long have you stayed in an English speaking country?

Less than 1 month 1-3 months 3-6 months 6-9 months More than 9 months

For the next several statements, please choose a number from 1-5 and write it next to each statement to indicate how much you agree with it.

\begin{tabular}{|c|c|c|c|c|}
\hline 1 & 2 & 3 & 4 & 5 \\
\hline Not at all & & Neutral & & $\begin{array}{c}\text { Total } \\
\text { agreement }\end{array}$ \\
\hline
\end{tabular}

1. It is important for me to have good English pronunciation.

2. English learner should aim for native English pronunciation.

3. I try to speak with native English pronunciation.

4. The people in my country speak English very well. 
How important are the following factors in order to improve the English pronunciation?

5. Listening to authentic English.

6. Practical Phonetic classes.

7. Contacts with native speakers.

8. Imitating authentic speech.

9. Self-study on pronunciation.

10. Stay in an English speaking country.

11. Primary/Secondary school.

12. Descriptive grammar classes. 


\section{Appendix E: Research Reading Exercise}

To cheat and mock are a waste.

The church was wet and had no map.

The red women were reaching for the cat.

I look at the map and see a lack of blue.

In his heart he knew the muse.

The butcher bit the apple.

Her alias was impossible to recall.

The man climbs the tree near the garage.

My first bed broke the floor.

Bill's heart is full of love.

My other business belongs to my woman.

The ball went through the window

Compact shoes go far.

The awful crew saw the rock.

People search knowledge but avoid the effort.

The car costs about $10000 \$$.

My friend's foot cannot turn.

Next week, they would go as a couple to the sea. 
The true symbol made my head spin.

The leaf creaked even the next day.

My body could not put up much longer.

Japan has of course many rivers.

A fan bought the board

The mob left the enemy.

The relative eats at random a banana.

My mum and her moose love the market.

To pull the noose is good.

The marketing of love has a red word. 


\section{Appendix F: Scanned Questionnaires from Participants (1 Example of each Country)}

\section{$\leq P 1$}

\section{Phonetic Difficulties}

This participation is voluntary and your data is anonymous and confidential.

First we'd like to ask a few general questions.

How old are you? 25

What is your gender?

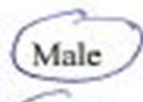

Female

Are you monolingual?

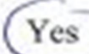

No

How long (in years) have you been learning English?

6

What's your highest English Certificate?

Cambridge: $\$ P E T$ IELTS: TOEFL: Other: None

How long have you stayed in an English speaking country?

Less than 1 month 1-3 months 3-6 months 6-9 months More than 9 months

For the next several statements, please choose a number from 1-5 and write it next to each statement to indicate how much you agree with it.

\begin{tabular}{|c|c|c|c|c|}
\hline 1 & 2 & 3 & 4 & 5 \\
\hline Not at all & & Neutral & & $\begin{array}{c}\text { Total } \\
\text { agreement }\end{array}$ \\
\hline
\end{tabular}

1. It is important for me to have good English pronunciation.

2. English learner should aim for native English pronunciation.

3. I try to speak with native English pronunciation.

4. The people in my country speak English very well.

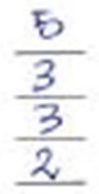

How important are the following factors in order to improve the English pronunciation?

5. Listening to authentic English.

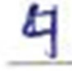

6. Practical Phonetic classes.

7. Contacts with native speakers.

8. Imitating authentic speech.

9. Self-study on pronunciation.

10. Stay in an English speaking country.

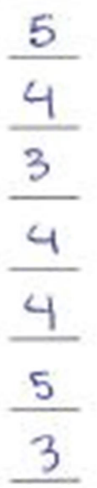

11. Primary/Secondary school.

12. Descriptive grammar classes. 


\section{F2}

\section{Phonetic Difficulties}

This participation is voluntary and your data is anonymous and confidential.

First we'd like to ask a few general questions.

How old are you? 22

What is your gender?

Male

Are you monolingual?

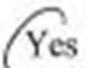

Female

No

How long (in years) have you been learning English? 12

What's your highest English Certificate?

Cambridge: B2 IELTS: TOEFL: Other: None

How long have you stayed in an English speaking country?

Less than 1 month $1-3$ months 3-6 months 6-9 months More than 9 months

For the next several statements, please choose a number from 1-5 and write it next to each statement to indicate how much you agree with it.

\begin{tabular}{|c|c|c|c|c|}
\hline 1 & 2 & 3 & 4 & 5 \\
\hline Not at all & & Neutral & & $\begin{array}{c}\text { Total } \\
\text { agreement }\end{array}$ \\
\hline
\end{tabular}

1. It is important for me to have good English pronunciation.

2. English learner should aim for native English pronunciation.

3. I try to speak with native English pronunciation.

4. The people in my country speak English very well.

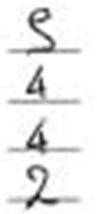

How important are the following factors in order to improve the English pronunciation?

5. Listening to authentic English.

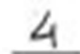

6. Practical Phonetic classes.

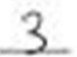

7. Contacts with native speakers.

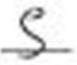

8. Imitating authentic speech.

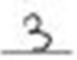

9. Self-study on pronunciation.

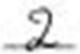

10. Stay in an English speaking country.

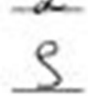

11. Primary/Secondary school.

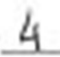

12. Descriptive grammar classes. 


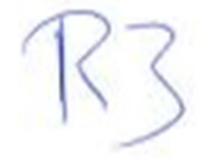

Phonetic Difficulties

This participation is voluntary and your data is anonymous and confidential.

First we'd like to ask a few general questions.

How old are you?

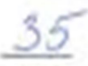

What is your gender?

Male

Female

Are you monolingual?

Yes

No

How long (in years) have you been learning English?

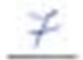

What's your highest English Certificate?

Cambridge: IELTS: TOEFL: Other: None

How long have you stayed in an English speaking country?

Less than 1 month $\quad 1.3$ months $\quad 3.6$ months $\quad 6.9$ months More than 9 months

For the next several statements, please choose a number from 1.5 and write it next to each statement to indicate how much you agree with it.

\begin{tabular}{|c|c|c|c|c|}
\hline 1 & 2 & 3 & 4 & 5 \\
\hline Not at all & & Neutral & & $\begin{array}{c}\text { Total } \\
\text { agreement }\end{array}$ \\
\hline
\end{tabular}

1. It is important for me to have good English pronunciation.

2. English learner should aim for native English pronunciation.

3. I try to speak with native English pronunciation.

4. The people in my country speak English very well.

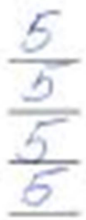

How important are the following factors in order to improve the English pronunciation?

5. Listening to authentic English.

6. Practical Phonetic classes.

7. Contacts with native speakers.

8. Imitating authentic speech.

9. Self-study on pronunciation.

10. Stay in an English speaking country.

11. Primary/Secondary school.

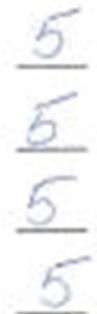

12. Descriptive grammar classes. 


\section{4}

\section{Phonetic Difficulties}

This participation is voluntary and your data is anonymous and confidential.

First we'd like to ask a few general questions.

How old are you? 22

What is your gender?

Male

$\times$ Female

Are you monolingual?<smiles></smiles>

No

How long (in years) have you been learning English?

12

What's your highest English Certificate?
Cambridge:
IELTS:
TOEFL:
Other:
XNone

How long have you stayed in an English speaking country?

Xess than 1 month $\quad 1-3$ months $\quad 3-6$ months $\quad 6-9$ months More than 9 months

For the next several statements, please choose a number from 1-5 and write it next to each statement to indicate how much you agree with it.

\begin{tabular}{|c|c|c|c|c|}
\hline 1 & 2 & 3 & 4 & 5 \\
\hline Not at all & & Neutral & & $\begin{array}{c}\text { Total } \\
\text { agreement }\end{array}$ \\
\hline
\end{tabular}

1. It is important for me to have good English pronunciation.

2. English learner should aim for native English pronunciation.

3. I try to speak with native English pronunciation.

4. The people in my country speak English very well.

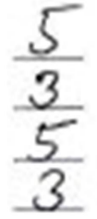

How important are the following factors in order to improve the English pronunciation?

5. Listening to authentic English.

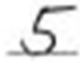

6. Practical Phonetic classes.

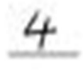

7. Contacts with native speakers.

8. Imitating authentic speech.

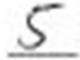

9. Self-study on pronunciation.

10. Stay in an English speaking country.

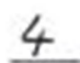

11. Primary/Secondary school.

12. Descriptive grammar classes. 


\section{Appendix G: Scanned unused questionnaires by other nationalities ( 2 examples)}

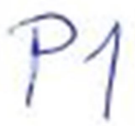

\section{Phonetic Difficulties}

This participation is voluntary and your data is anonymous and confidential.

First we'd like to ask a few general questions.

How old are you?

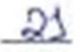

What is your gender?

Male

Female $X$

Are you monolingual?

Yes

Nox

How long (in years) have you been learning English?

34

What's your highest English Certificate?

Cambridge:

IELTS:

TOEFL:

Other:

Nonex

How long bave you stayed in an English speaking country?

XLess than 1 month 1-3 months 3-6 months 6-9 months More than 9 months

For the next several statements, please choose a number from 1-5 and write it next to each statement to indicate how much you agree with it.

\begin{tabular}{|c|c|c|c|c|}
\hline 1 & 2 & 3 & 4 & 5 \\
\hline Not at all & & Neutral & & $\begin{array}{c}\text { Total } \\
\text { agreement }\end{array}$ \\
\hline
\end{tabular}

1. It is important for me to have good English pronunciation.

2. English learner should aim for native English pronunciation.

3. I try to speak with native English pronunciation.

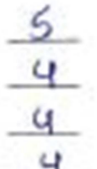

4. The people in my country speak English very well.

4

How important are the following factors in order to improve the English pronunciation?

5. Listening to authentic English.

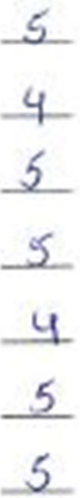

11. Primary/Secondary school.

12. Descriptive grammar classes. 


\section{$\operatorname{Iap} 2$}

Phonetic Difficulties

This participation is voluntary and your data is anonymous and confidential.

First we'd like to ask a few general questions.

I $\mid 1$ How old are you? $\underline{20}$

II 2 'hat is your gender?

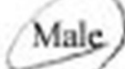

Female

III 3 Are you monolingual?

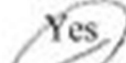

No

IV 4 How long (in years) have you been learning English?

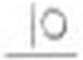

For the next several statements, please choose a number from 1-5 and write it next to each statement to indicate how much you agree with it.

\begin{tabular}{|c|c|c|c|c|}
\hline 1 & 2 & 3 & 4 & 5 \\
\hline Not at all & & Neutral & & $\begin{array}{c}\text { Total } \\
\text { agreement }\end{array}$ \\
\hline
\end{tabular}

1. It is important for me to have good English pronunciation.

2. English learner should aim for native English pronunciation.

3. I try to speak with native English pronunciation.

4. The people in my country speak English very well.

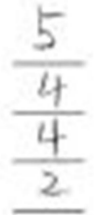

How important are the following factors in order to improve the English pronunciation?

5. Listening to authentic English.

6. Practical Phonetic classes.

7. Contacts with native speakers.

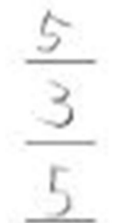

8. Imitating authentic speech.

9. Self-study on pronunciation.

10. Stay in an English speaking country.

11. Primary/Secondary school.

12. Descriptive grammar classes.

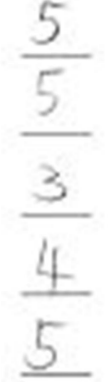

